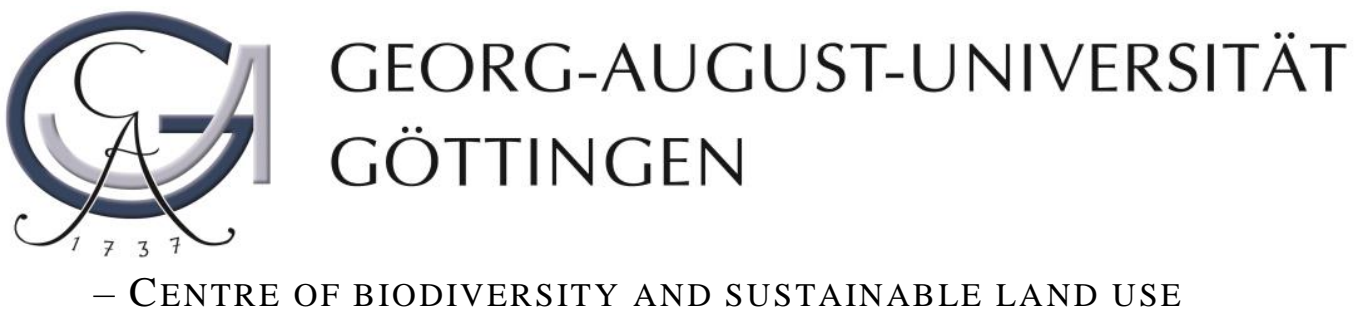

SECTION: BIODIVERSITY, ECOLOGY, AND NATURE CONSERVATION -

\title{
Ecological impacts of biodiversity enrichment in oil palm plantations
}

\author{
Dissertation zur Erlangung des Doktorgrades \\ der Mathematisch-Naturwissenschaftlichen Fakultäten \\ der Georg-August-Universität Göttingen
}

Vorgelegt von M.Sc.

\section{Miriam Teuscher}

Geboren in

Bad Kreuznach 

Referent: Prof. Dr. Ulrich Brose

Koreferent: PD Dr. Yann Clough

Tag der mündlichen Prüfung: 27.11.2015 

„,Wer Bäume pflanzt, wird den Himmel gewinnen “

- Konfuzius - 



\section{Table of contents}

Table of contents............................................................................................... vii

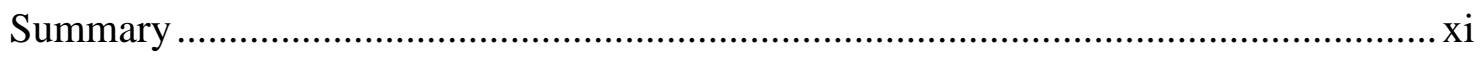

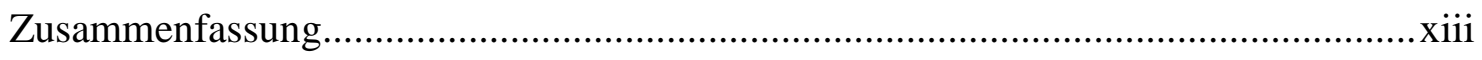

Contributions to the chapters of this thesis ...........................................................

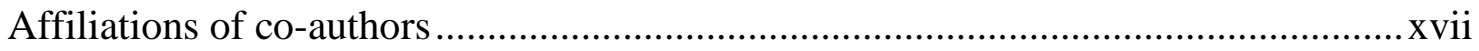

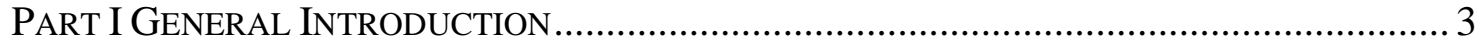

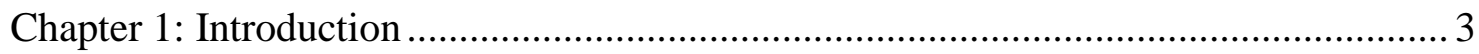

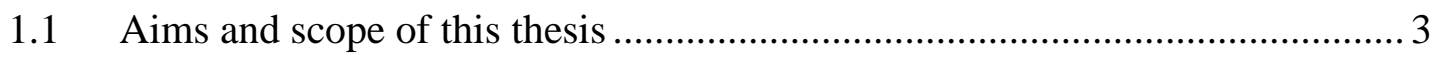

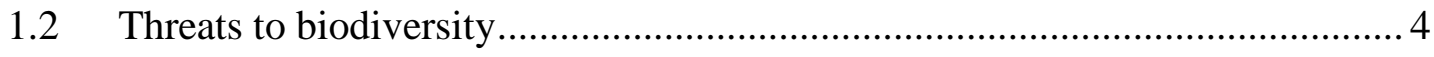

1.3 Biodiversity and its importance for humanity ......................................... 5

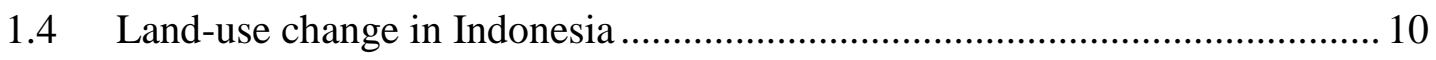

1.5 Conservation strategies for biodiversity in agricultural landscapes ............... 12

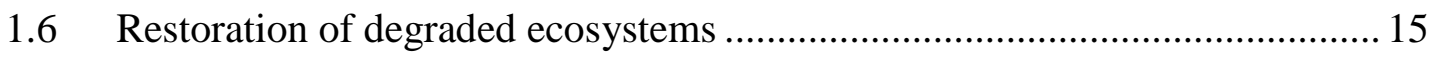

1.7 Towards a better understanding of restoration effects on biodiversity and ecosystem functioning in oil palm landscapes ..................................................... 19

1.8 Overarching project framework and study area ........................................ 20

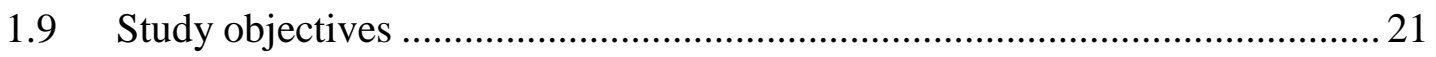

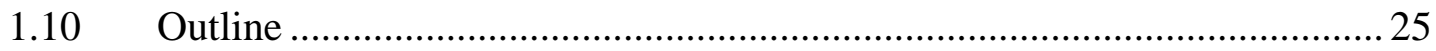

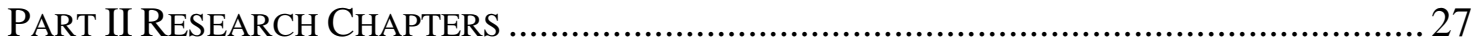

Chapter 2: Trade-offs between bird diversity and abundance, yields and revenue in

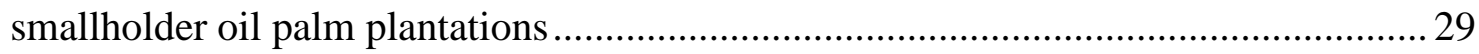

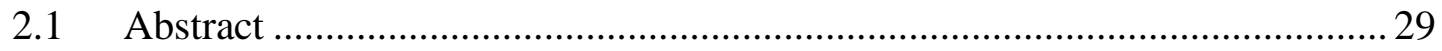

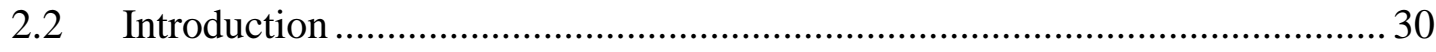

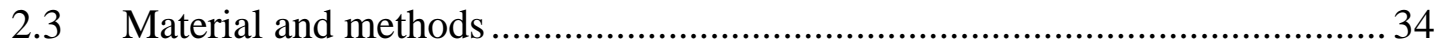




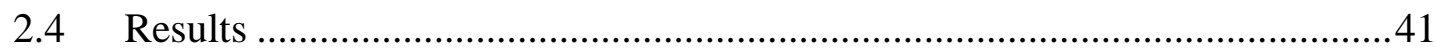

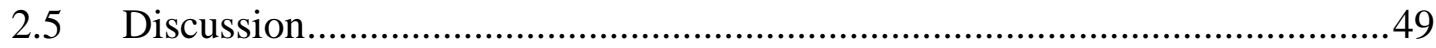

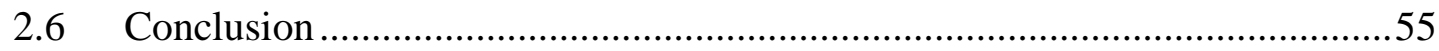

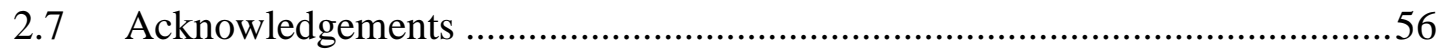

Chapter 3: Biodiversity enrichment in oil palm landscapes: A tree planting experiment

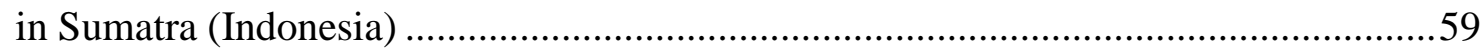

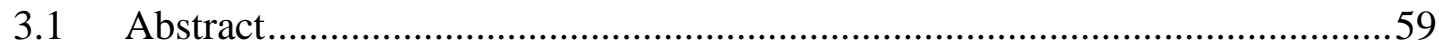

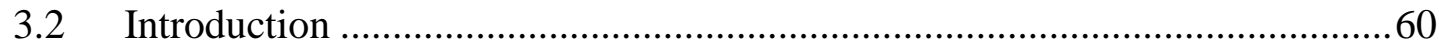

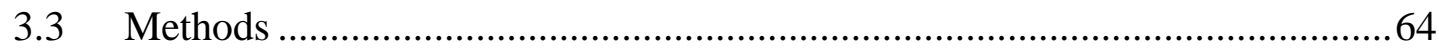

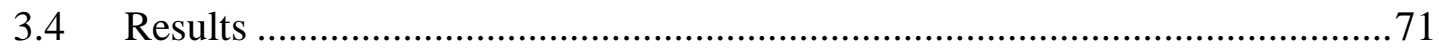

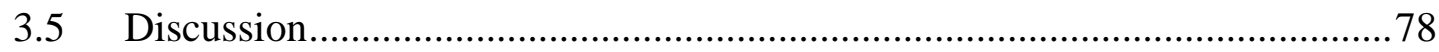

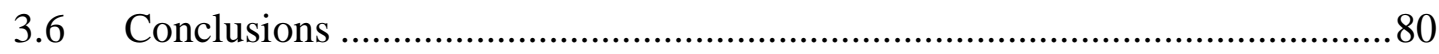

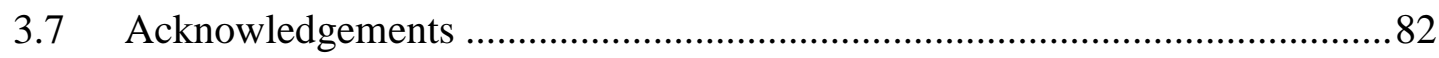

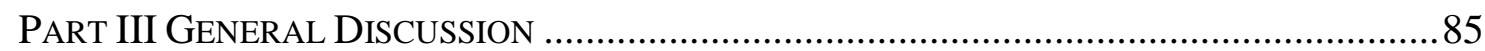

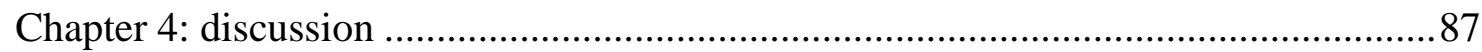

4.1 Trade-off between ecology and economics in oil palm plantations ................88

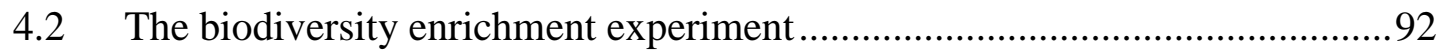

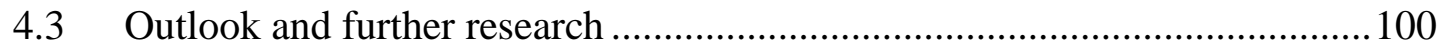

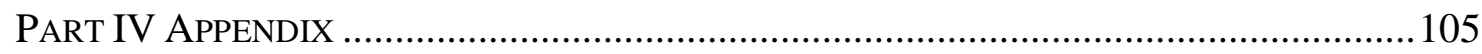

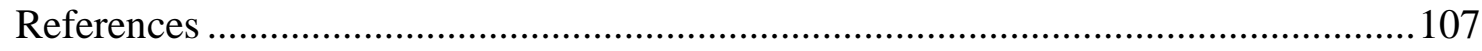

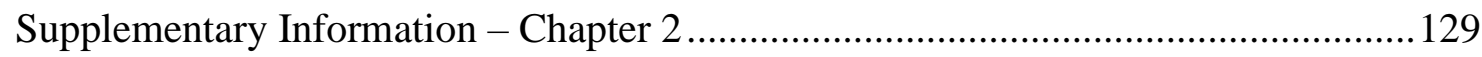

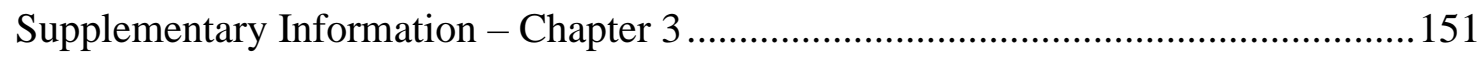

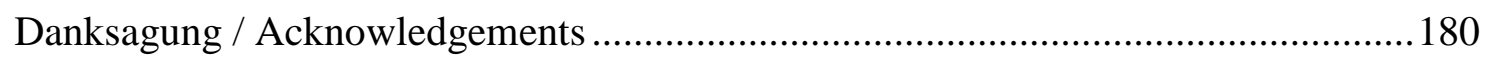

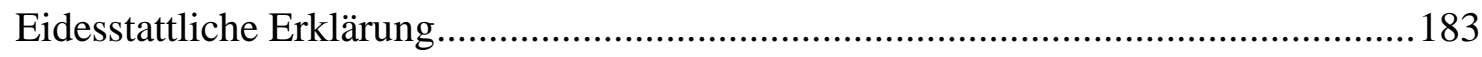






\section{Summary}

Land-use change is one of the major drivers of biodiversity loss. To satisfy the demand for palm oil in food and biofuel, complex, species-rich rainforests are converted into large, simply-structured mono-culture oil palm plantations. This has dramatic consequences for biodiversity and ecosystem functioning, thereby also putting human well-being at risk. Facing the severe decline in biodiversity, the re-establishment of diverse habitats and their multi-functionality through restoration measures could help biodiversity and ecosystem functioning recover faster. However, knowledge about the underlying ecological and socio-economic mechanisms of restoration in oil palm plantations and clear instructions towards a wildlife-friendly management of oil palm are lacking.

In this thesis, I provide initial insights into the relationship between ecology and economics when a wildlife-friendly farming strategy is applied in oil palm systems. Focusing on birds of smallholder oil palm-dominated landscapes in the Jambi province, Sumatra, Indonesia, I uncovered the ecological-economic relationship when having remnant or planted trees within oil palm plantations and estimated the costs for the conservation of bird diversity and abundance. The results suggest that bird diversity and abundance depends on the number of trees on the plot and that an increase in bird diversity and abundance results in revenue penalties, indicating that there is a win-lose relationship between ecological and economic outcomes. However, since the relationship was non-linear, an increase in bird diversity could be achieved at lower costs in highly intensified oil palm plantations as compared to extensively managed oil palm plantations. Furthermore, the costs for increased bird abundance were lower than for increased bird diversity. Overall, these findings illustrate that there is room for treebased enrichment in intensively managed oil palm plantations as a measure to maintain a baseline level of biodiversity at relatively little costs.

In order to address various open questions and to effectively be able to shed light on additional ecological and socio-economic mechanisms linked to enrichment plantings, I established a long-term, large-scale biodiversity enrichment in a monoculture oil palm plantation in the Jambi province, Sumatra, Indonesia. The 
establishment of the experiment comprised planting tree islands of different sizes and with varying tree diversity and composition within gaps of an oil palm plantation. I assessed initial environmental and biotic characteristics of the plantation prior to the tree planting against which the longitudinal data from the tree islands will be compared to throughout the years following the establishment. The design allows for disentangling the effects of tree diversity and island size on the diversity and composition of different organism groups such as plants, birds and invertebrates. Herewith, conclusions can be drawn on changes in ecosystem functioning. I investigated early effects of the tree plantings on the bird and invertebrate communities. Interestingly, birds and invertebrates responded positively to the enrichment plantings already one year after the establishment of the tree islands. Overall bird species richness and abundance of herb-layer invertebrates was increased on plots with trees. Invertebrates were not only positively affected by enrichment plantings on a landscape scale but also on plot level. In summary, these findings illustrate the great potential of restoration plantings to benefit biodiversity and associated ecosystem functioning as birds and invertebrates play a key role in initiating succession processes, thereby enhancing biodiversity. Both, birds and invertebrates fulfil many tasks that are essential for the functioning and resilience of ecosystems. The biodiversity enrichment experiment provides lucrative ground for further research in various disciplines in order to develop ecologically improved and socio-economically viable management strategies for oil palm plantations.

Overall, this thesis contributes substantially to make advances in BEF and restoration research in tropical agricultural landscapes. Scientific evidence on the costs and benefits of enrichment plantings provides the ground for future political decisionmaking towards increased ecological and socio-economic sustainability in oil palm management. Ultimately, the biodiversity enrichment experiment may contribute to increasing and conserving biodiversity in tropical agricultural landscapes without jeopardizing the food security of a growing human population. 


\section{Zusammenfassung}

Landnutzungsänderung gilt als eine der wichtigsten Ursachen für den Verlust an biologischer Artenvielfalt. Um der Nachfrage nach Palmöl in Lebensmitteln und Biokraftstoffen nachzukommen, werden komplexe, artenreiche Regenwälder in große, einfach strukturierte Monokulturplantagen umgewandelt. Das hat dramatische Folgen für die biologische Vielfalt und die ökologische Funktionsfähigkeit dieser Systeme, was wiederum das menschliche Wohl gefährdet, da wir von Produkten (z.B. Holz, Früchte) und Funktionen (z.B. Bestäubung, Regulierung des Klimas und der Wasserqualität) unserer Ökosysteme abhängig sind. Breite Landstriche Indonesiens, die vorher aus tropischem Regenwald bestanden, wurden bereits komplett in Plantagen konvertiert, wodurch eine Reinitialisierung von natürlichen Gemeinschaften auf Kosten der Plantagenfläche zum Erhalt der ökologischen Funktionsfähigkeit notwendig wird. Die ökologischen und sozio-ökonomischen Prozesse im Zusammenhang mit dem Wiederaufbau natürlicher Ökotope in Ölpalmplantagen sind jedoch weitgehend unbekannt.

In dieser Arbeit beleuchte ich den Zusammenhang zwischen Ökologie und Ökonomie in von Kleinbauern bewirtschafteten Ölpalmplantagen. Der Fokus lag dabei auf Vögeln in einer Ölpalmlandschaft in der Provinz Jambi, Sumatra, Indonesien. Ich untersuchte, inwiefern die Artenvielfalt und Abundanz (Anzahl der Individuen) der Vögel von der Anzahl anderer übrig gebliebener oder gepflanzter Bäume auf der Plantage abhängt und wie das wiederum die Ökonomie der Plantage beeinflusst. Weiterhin errechnete ich die geschätzten Kosten für den Erhalt der Artenvielfalt und Abundanz von Vögeln. Die Ergebnisse legen nahe, dass die Vogelartenvielfalt und Abundanz der Vögel positiv mit der Anzahl von Bäumen zusammenhängt, dass allerdings eine Erhöhung der Artenvielfalt und Abundanz zu Gewinneinbußen führt. Aufgrund der Nichtlinearität der Beziehung zwischen diesen ökologischen und ökonomischen Funktionen ist eine Erhöhung der Vogelartenvielfalt auf einer intensiv bewirtschafteten Plantage mit geringeren Kosten verbunden, als dies auf bereits extensiv bewirtschafteten Ölpalmplantagen der Fall ist. Außerdem ist eine Erhöhung der Abundanz an Vögeln kostengünstiger als die Erhöhung ihrer Artenvielfalt. 
Zusammenfassend zeigen die Ergebnisse, dass eine Baum-basierte Anreicherung in intensiv bewirtschafteten Ölpalmplantagen eine relativ kostengünstige Maßnahme darstellt, um ein Grundniveau an Biodiversität zu erhalten.

Um verschiedene offene Fragen bezüglich der ökologischen und sozioökonomischen Mechanismen im Zusammenhang mit Anreicherungsmaßnahmen in Ölpalmplantagen effektiv zu beleuchten, wurde ein Langzeit-Anreicherungsexperiment in einer Ölpalm-Monokulturplantage in der Provinz Jambi, Sumatra, Indonesien etabliert. $\mathrm{Zu}$ diesem Zweck wurden Bauminseln angepflanzt, wobei die Vielfalt und Identität der Bäume sowie die Größe der Inseln systematisch variiert. Das Design des Experiments ermöglicht eine Entflechtung der Auswirkungen der Baumartenvielfalt und -inselgröße auf die Vielfalt und Zusammensetzung verschiedener Organismengruppen, wie beispielsweise Pflanzen, Vögel und wirbelloser Tiere. Vor der Pflanzung wurden die biotischen und abiotischen Parameter der Plantage erhoben, um spätere Daten mit den Anfangsdaten zu vergleichen und Rückschlüsse auf Veränderungen in der Vielfalt und Zusammensetzung von Flora und Fauna oder den assoziierten Ökosystemfunktionen feststellen zu können. Weiterhin habe ich frühe Auswirkungen der Anreicherungspflanzungen auf Vögel und Wirbellose untersucht. Interessanterweise reagierten Vögel und wirbellose Tiere bereits ein Jahr nach Anpflanzung der Bauminseln positiv auf diese Veränderungen der Baumartenvielfalt und -anzahl innerhalb der Plantage. Insgesamt waren die Vogelartenvielfalt und die Abundanz der Wirbellosen in der Krautschicht auf den Versuchsflächen mit Bäumen erhöht. Außerdem wurde ein positiver Zusammenhang zwischen Anzahl und Vielfalt von Wirbellosen und der Größe der Versuchsflächen festgestellt. Zusammenfassend verdeutlichen diese ersten positiven Ergebnisse das große Potenzial der Bauminseln für die Wiederherstellung biologischer Vielfalt und der damit verbundenen Ökosystemfunktionen. Vögel und wirbellose Tiere spielen eine Schlüsselrolle bei der Initiierung wichtiger Sukzessionsprozesse innerhalb von Ökosystemen, was sich positiv auf die allgemeine Vielfalt im System auswirkt. Vögel und Wirbellose erfüllen zahlreiche Aufgaben, die für das Funktionieren und die Widerstandsfähigkeit der Ökosysteme essentiell sind. Das Anreicherungsexperiment bietet eine lukrative Basis für weitere Forschungsprojekte in verschiedenen Disziplinen, um ökologisch 
verbesserte und sozio-ökonomisch nachhaltige Strategien zur Bewirtschaftung von Ölpalmplantagen zu entwickeln.

Insgesamt trägt diese Arbeit wesentlich zu Fortschritten in der Biodiversitäts- und Ökosystemforschung sowie im Bereich der Forschung zur Wiederherstellung von vielfältigen Systemen in tropischen Agrarlandschaften bei. Wissenschaftliche Erkenntnisse über die Kosten und Nutzen der Anreicherungspflanzungen sind die Basis für künftige politische Entscheidungen hin zu erhöhter ökologischer und sozioökonomischer Nachhaltigkeit im Palmölmanagement. Nicht zuletzt kann das Anreicherungsexperiment zur Steigerung und Erhaltung der biologischen Vielfalt in tropischen Agrarlandschaften beitragen, ohne die Ernährungs- und Versorgungssicherheit einer wachsenden Weltbevölkerung zu gefährden. 


\title{
Contributions to the chapters of this thesis
}

\author{
Chapter 2: Trade-offs between bird diversity and abundance, yields and revenue \\ in smallholder oil palm plantations in Sumatra, Indonesia
}

Miriam Teuscher, Miriam Vorlaufer, Meike Wollni, Ulrich Brose, Yeni Mulyani, Yann Clough

All authors designed the study. The questionnaire for the household study was developed by MV, MW and MT. The vegetation and bird survey was carried out by MT, the household survey by MT and MV. MT and MV analysed the data with support form YC, UB and MW; MT and MV wrote the first draft of the manuscript and all authors contributed to revisions.

Published in Biological Conservation, 2015, 186, 306-318, doi: 10.1016/j.biocon.2015.03.022

(C) Elsevier Ltd.

\section{Chapter 3: Biodiversity enrichment in oil palm landscapes: A tree planting experiment in Sumatra (Indonesia)}

Miriam Teuscher, Anne Gérard, Ulrich Brose, Damayanti Buchori, Yann Clough, Martin Ehbrecht, Hendrayanto, Dirk Hölscher, Bambang Irawan, Yeni Mulyani, Prijanto Pamungkas, Leti Sundawati, Meike Wollni, Holger Kreft

The experiment was designed by UB, YC, DH, HK and MW. BI, LS, PP, DH, HK, YC, ME, MT and AG searched for possible oil palm plantations to set up the experiment and were involved in negotiations with plantation owners on-site. MT and AG planned and carried out the establishment of the experimental plots. DB, LS, PP, BI, H and YM provided scientific and logistical support in Indonesia during the establishment phase of the experiment. Soil data were collected by AG; all other environmental data by MT and AG. Hemisperical photographs were taken by AG. The plant survey was designed by AG and HK and carried out by AG. Faunal surveys were designed by MT, YC and UB and carried out by MT. MT and AG analyzed the data. The text was written by MT and AG with comments from UB, HK, YC, DH, MW and ME. 


\section{Affiliations of co-authors}

Ulrich Brose

Damayanti Buchori

Yann Clough

Martin Ehbrecht

Anne Gérard

Hendrayanto

Dirk Hölscher

Bambang Irawan

Holger Kreft

Yeni Mulyani

Prijanto Pamungkas

Leti Sundawati

Miriam Vorlaufer

Meike Wollni
German Centre for Integrative Biodiversity Research Halle-JenaLeipzig, Leipzig, Germany Institute of Ecology, Friedrich Schiller University Jena, Dornburger-Str. 159, Jena, Germany

Department of Plant Protection, Bogor Agricultural University, Bogor, Indonesia

Centre for Environmental and Climate Research, Lund University, Lund, Sweden

Department of Tropical Silviculture and Forest Ecology, GeorgAugust-University Göttingen, Göttingen, Germany

Free Floater Research Group, Biodiversity, Macroecology and Conservation Biogeography, Georg-August-University Göttingen, Göttingen, Germany

Department of Forest Management, Faculty of Forestry, Bogor Agricultural University, Bogor, Indonesia

Department of Tropical Silviculture and Forest Ecology, GeorgAugust-University Göttingen, Göttingen, Germany

Faculty of Forestry, University of Jambi, Jambi, Indonesia

Free Floater Research Group, Biodiversity, Macroecology and Conservation Biogeography, Georg-August-University Göttingen, Göttingen, Germany

Department of Forest Resource conservation and ecotourism, Faculty of Forestry, Bogor Agricultural University, Bogor, Indonesia

Department of Silviculture, Faculty of Forestry, Bogor Agricultural University, Bogor, Indonesia

Department of Forest Management, Faculty of Forestry, Bogor Agricultural University, Bogor, Indonesia

Department of Agricultural Economics and Rural Development, Georg-August-University Göttingen, Göttingen, Germany

Department of Agricultural Economics and Rural Development, Georg-August-University Göttingen, Göttingen, Germany 



\section{PART I}

\section{GENERAL INTRODUCTION}





\section{Chapter 1: Introduction}

\subsection{Aims and scope of this thesis}

Tropical ecosystems, especially rainforests, are known as the most species-rich habitats in the world (Whitmore 1998). However, rainforests are subject to extensive land-use transformation which results in loss of species (Newbold et al. 2015). One of the most common cultivation systems in the tropics are oil palm (Elaeis guineensis) plantations, which harbour very low biodiversity compared to natural tropical forest (Koh \& Wilcove 2008; Fitzherbert et al. 2008; Fayle et al. 2010; Edwards et al. 2014), but are of utmost importance to Southeast Asian economies (Basiron 2007). Consequently, oil palm agriculture will most likely expand further in the future to satisfy a globally increasing demand for food and biofuel. This will put even more pressure on tropical biodiversity (Laurance, Sayer \& Cassman 2014). In this context, conservation of natural habitat, alone, might not be sufficient to stop the severe decline in biodiversity. Restoration efforts are needed to help biodiversity recover faster and to maintain ecosystem functioning linked to biodiversity. Developing management strategies that jointly benefit biodiversity and economic returns are the key to balance these conflicting interests of ecology and economy. The main questions to be investigated in this context are: 1) "how do ecology and economics respond when having trees within or at the border of oil palm plantations?"; 2) "how much does is cost to conserve a diversity of species in oil palm habitats?"; 3) "can we enhance biodiversity and ecosystem functions through tree-based restoration in oil palm landscapes and at the same time keep economic losses low?" and 4) "what is the best planting strategy?".

In this thesis, I shed light on how remnant or planted trees affect the ecology and economics in oil palm plantations in a combined field and household study on 120 smallholder oil palm plantations. Furthermore, I sat the scene for long-term research on restoration in oil palm landscapes to gain fundamental knowledge of the ecological and socio-economic impacts of such enrichment plantings in oil palm plantations. Together with researchers from Germany and Indonesia, I established a biodiversity enrichment experiment by planting tree islands in gaps in a mono-culture oil palm plantation in the 


\section{Chapter 1: Introduction}

province of Jambi on Sumatra, Indonesia. This biodiversity enrichment experiment provides a lucrative foundation for interdisciplinary research to investigate the effects of restoration in tropical landscapes on biodiversity, ecosystem functioning and socioeconomics. The experiment aims at contributing to the development of ecologically improved and socio-economically viable management strategies. In the framework of this biodiversity enrichment project, my focus is on the taxonomic and functional diversity response of birds and invertebrates to such tree plantings.

Before I present my research objectives in detail and lead you through the chapters of my thesis, I will introduce some general topics. To begin with, I will talk about the main threats to biodiversity. Then, I elaborate on the complexity of biodiversity and ecosystem functioning, as well as on problems induced by biodiversity loss. Further, I illustrate proposed conservation strategies to retain biodiversity or even enhance it. To conclude my introduction, I elucidate opportunities and challenges of restoration in degraded ecosystems.

\subsection{Threats to biodiversity}

Biodiversity is lost and ecosystem functioning is being impaired by a vast array of human activities (Millenium Ecosystem Assessment 2005). Increasing human population and consumption pressures push ecosystems to the brink of their capacities and create conditions that greatly harm our environment. This leads to extinctions of species and populations, degradation of ecosystems, erosion of genetic diversity and evolutionary potential, loss of ecosystem services as well as to the erosion of support systems for human society (Millenium Ecosystem Assessment 2005). Five main drivers for biodiversity loss have been identified: land-use change, overexploitation, spread of invasive species, pollution, and climate change (Millenium Ecosystem Assessment 2005). An increased food demand has initiated an increase in food production, which was made possible by the expansion and intensification of agriculture (Matson et al. 1997; Laurance, Sayer \& Cassman 2014), thereby imposing a huge impact on ecosystems. Forty percent of the Earth's land surface is, for instance, currently occupied by cropland and pastures (Foley et al. 2005). Such anthropogenic impacts have 
contributed to an unprecedented increase in the rate of global species extinctions (Barnosky et al. 2011; Monastersky 2014).

Obviously, these practices are unsustainable as we are erasing essential resources and natural capital, thereby endangering our own future. However, to better understand why we should be concerned with biodiversity loss and why this also puts our future well-being at risk, I provide some background on biodiversity and its importance for the functioning of ecosystems and humanity in the following section.

\subsection{Biodiversity and its importance for humanity}

\subsubsection{Definition of biodiversity}

Biodiversity (or biological diversity) describes the immense richness and variation of all living things in the world. It can be considered on many different levels of biological variation, ranging from genes - the ultimate source of biodiversity at all levels - to populations, species, ecosystems and entire biomes (Groom, Meffe \& Carroll 2006). In the convention for biological diversity in Rio de Janeiro in 1992, biodiversity was defined as "[...] the variability among living organisms from all sources including, inter alia, terrestrial, marine and other aquatic ecosystems and the ecological complexes of which they are part; this includes diversity within species, between species and of ecosystems" (Box 1.1). This definition draws the attention to the many dimensions of biodiversity. It recognizes that all biota can be described by taxonomic or genetic diversity and that variation across space and time is a key feature of this diversity (Millenium Ecosystem Assessment 2005). When people hear or talk about biodiversity, however, they most often refer to it as species diversity, which indeed is one of the fundamental levels of biodiversity. Landscape heterogeneity is an important driver of biodiversity and it varies with spatial scales (Stein, Gerstner \& Kreft 2014). Therefore, to understand the full picture of biodiversity, it is important to take account of it at different scales. In 1960, Rob Whittaker considered three diversity levels of natural communities across space. Alpha diversity describes local diversity, i.e. the species richness found in a habitat in which species are influenced by inherent biotic and abiotic characteristics. Beta diversity describes the spatial differentiation 
between communities in an area of interest and is high when two communities have very different species compositions, meaning they have very few species in common. The third level of diversity categorized by Whittaker (1960) is gamma diversity, which describes diversity on a regional scale. It is the sum of all alpha diversities in a region.

In my thesis I mainly focus on alpha diversity (species richness) and how it differs a) between oil palm plantations along a management intensity gradient and b) between planted tree islands of different plot size, tree diversity level and tree species compositions.

\section{Box 1.1: Glossary}

Biodiversity: variety of life. It is a measure of the variety of different organisms present in different ecosystems. This can refer to genetic variation, species variation or ecosystem variation within an area or entire biome.

Ecosystem functions: ecological processes that control the fluxes of energy, nutrients and organic matter through an environment. Examples include: primary production, which is the process by which plants use sunlight to convert in organic matter into new biological tissue; nutrient cycling, which is the process by which biologically essential nutrients are captured, released and then recaptured; and decomposition, which is the process by which organic waste, such as dead plants and animals, is broken down and recycled.

Ecosystem functioning: reflects the collective life activities of plants, animals, and microbes and the effects these activities - feeding, growing, moving, excreting waste, etc. - have on the physical and chemical conditions of their environment.

Ecosystem service: a property or process in an ecosystem that confers either direct or indirect benefits to humans. We focus on the goods that are directly used by humans (e.g., food, fuel, and fiber) and the ecological processes that influence the provision of these goods (e.g., pollination, soil nutrient cycling, etc.).

\subsubsection{Where do we find biodiversity?}

Interestingly, biodiversity is not distributed evenly on our planet. There are places where astonishingly high biological diversity can be found: tropical rainforests - the ecosystems that blanket the Earth along the equator (Morley 2009). The stable climate in the tropics enables the establishment of heterogenic, multi-strata forests which harbour a tremendous, yet poorly understood, diversity of species and ecological processes (Whitmore 1998). The intrinsic value of tropical rainforests is much greater than, e.g. that of forests in temperate regions, as they harbour a much greater gene pool, 
necessary for securing a long future of plant and animal life (Morley 2009). Moreover, they are a major source of wood, plant and animal products, and form the economic base of many households (Grimes et al. 1994). Tropical rainforests also provide numerous services that make up crucial parts of the Earth's water, carbon and nutrient cycles (Bawa et al. 2004). These forests, above all, play an important role in regulating the global climate as they are a major absorber of atmospheric $\mathrm{CO}_{2}$ (Morley 2009).

\subsubsection{Why is biodiversity important?}

The ecological value of species diversity is often characterized by the sum of functions that are fulfilled by the species present in an ecosystem. Biodiversity has been identified as being critical for maintaining ecosystem functions (Box 1.1) (Hooper, Chapin III \& Ewel 2005). The biodiversity hypothesis states that a reduction in species diversity will ultimately lead to a reduction in ecosystem function (Srivastava \& Vellend 2005). But how many species do we need to keep the system working? And, are all species equally important in their contributions to the functioning of the ecosystem? To address these questions, four major hypotheses have been developed regarding the relationship between biodiversity and ecosystem functioning (BEF):

- The equally important species hypothesis (Vitousek \& Hooper 1997) posits that all species are equally important and thus contribute equally to ecosystem functioning. The relationship between species number and their function is linear and positive (Figure $1.1 \mathrm{a}$ ).

- The species redundancy hypothesis (Walker 1992) postulates that many species have similar functions. First, functioning will increase with increasing species number until it reaches a saturation point. After this point, a further increase in species richness does not result in an increase in function (Figure $1.1 \mathrm{~b}$ ).

- The rivet popper hypothesis (Ehrlich \& Ehrlich 1981) is similar to the species redundancy hypothesis, with the addition that many species can get lost unnoticed, but if a keystone species disappears, the function of the whole species community collapses (Figure $1.1 \mathrm{c}$ ). 
- The idiosyncratic hypothesis (Lawton 1994) proposes no systematic relationship between the species number and the function that the species fulfils (Figure $1.1 \mathrm{~d}$ ).

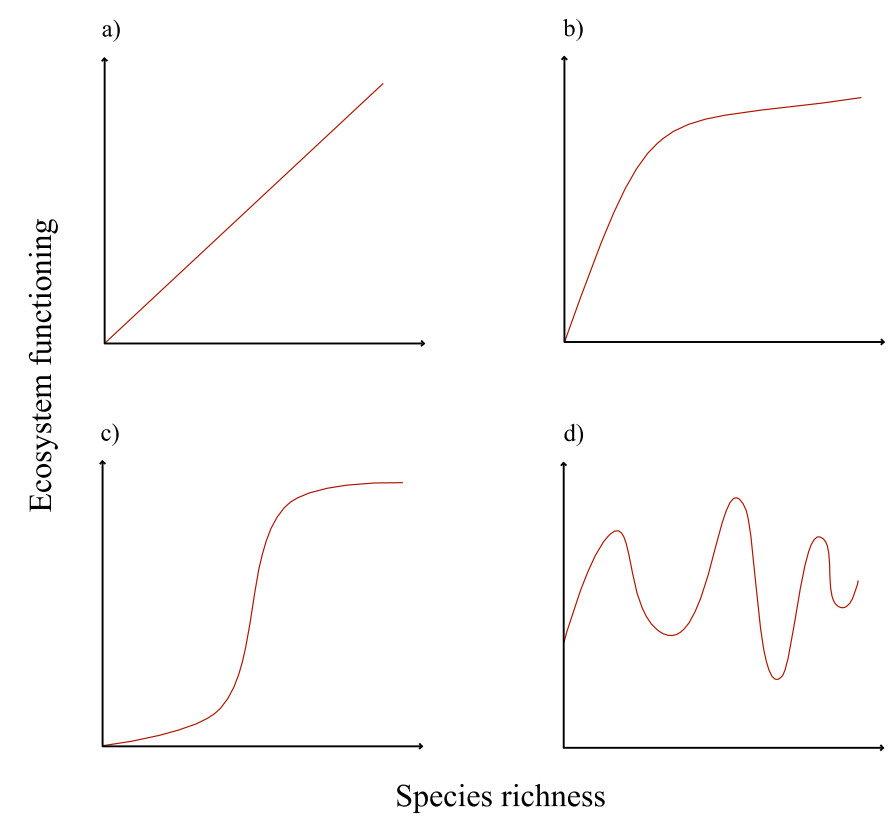

Figure 1.1: Graphic representation of four potential types of relationships between species richness and ecosystem functioning: a) linear (Vitousek \& Hooper 1997); b) redundant (Walker 1992); c) rivet popper (Ehrlich \& Ehrlich 1981); and d) idiosyncratic (Lawton 1994).

In the last few decades, the results of numerous studies and experiments that tested extinction scenarios in different spatial and temporal settings caused controversy over the influence of biodiversity on ecosystem functioning, stability and resource efficiency (Cardinale et al. 2006, 2012; Balvanera et al. 2006). However, considering the different dimensions of BEF in space and time allowed a more holistic understanding of the BEF relationship and provided strong support for the conclusion that species diversity tends to be positively related with ecosystem functioning in the shape of a saturating curve (Cardinale et al. 2012). This suggests that the species redundancy hypothesis is well supported (Figure 1.1 b). A low number of species should already provide a certain level of ecosystem function in a constant environment. However, if these species are negatively affected by a perturbation, this level of functioning will only be maintained, when other species with a similar effect on functioning are not affected or respond positively to the same perturbation (Naeem et 
al. 2009). Therefore, redundancy of species can be seen as a buffer, making an ecosystem more resilient and stable against unpredictable disturbances, as other species with similar functions can replace the lost species (Isbell et al. 2011). This highlights that the effects of species loss in already species-poor systems can be relatively more disadvantageous due to lacking redundancy of species for sustaining processes in an ecosystem compared to species-rich ecosystems (Hooper, Chapin III \& Ewel 2005; Srivastava \& Vellend 2005; Cardinale et al. 2012).

People often seek mainly economic justifications for the conservation of biodiversity and ecosystem functions. In the next paragraph I describe the essentiality of ecosystem functions for human well-being and why we therefore should be motivated to act in an environmentally friendlier way.

\subsubsection{Ecosystem services}

Humans have evolved as part of the world's ecosystems and depend to a large degree on goods and services provided by them. These goods and other benefits are used, or required by humans and are referred to as 'ecosystem services' (Box 1.1). This term has often been used synonymously with the term ecosystem function. More precisely, however, ecosystem services can be described as a selection of ecosystem functions and components, that are related to human well-being (Costanza et al. 1997; Daily et al. 1997; Cardinale et al. 2012). For example, food production is an ecosystem service and the associated ecosystem function would be the part of gross primary production that can be extracted as food. Biological control - the reduction of herbivores by toppredators - is another example of an ecosystem service, provided via the trophicdynamic regulation of populations which is also an ecosystem function (Costanza et al. 1997). In the Millenium Ecosystem Assessment (2005), ecosystem services were distinguished into four categories: 1) provisioning (e.g. food, timber, or genetic resources), 2) regulating (e.g. water purification or disease control), 3) supporting (e.g. nutrient cycling or pollination), and 4) cultural (e.g. recreational or spiritual benefits). The demand for ecosystem services has significantly increased in the last 50 years as the world population has doubled (Millenium Ecosystem Assessment 2005) and will 
increase further, as the human population is expected to approach 11 billion people this century (Laurance, Sayer \& Cassman 2014).

Anthropogenic activities impact the biodiversity, and with it, the functions and services that ecosystems provide. As a result, there has been increasing interest in quantifying the value of ecosystem services as this is important for developing arguments and strategies for protecting these services (e.g. Storkey et al. 2013; Ojea \& Martin-Ortega 2015; Zhang et al. 2015). Some services can be quantified easily, such as the production of food, fiber, pharmaceuticals, and fuel. For other services, like prevention of soil erosion, regulation of climate or services of cultural value, however, it is difficult to assign a monetary value, particularly because such values vary among countries and continents. Nevertheless, there are estimates that number the value of ecosystem services to be in the order of trillions $\left(10^{12}\right)$ of US dollars annually, which is most likely an underestimation (Costanza et al. 1997, 2014). Nonetheless, if clean air and water or the production of food depends upon the maintenance of biodiversity, this definitely should be a powerful motivation for conserving it.

\subsection{Land-use change in Indonesia}

One of the key drivers of biodiversity loss worldwide is land-use change (Immerzeel et al. 2014; McGill 2015; Newbold et al. 2015). In the tropics, land-use change often implies the transformation of complex tropical rainforests into depauperate agricultural production systems (Gibbs et al. 2010). Although tropical forests cover less than $10 \%$ of the Earth's land surface (FAO \& JRC 2012), they harbor a huge amount of irreplaceable biodiversity (Gibson et al. 2011). Therefore, the transformation of tropical forest into other land-use systems is especially detrimental for biodiversity.

Indonesia is a distinct example of this transformation. It is known as one of the 'hottest' hotspots of biodiversity in the world (Myers et al. 2000), yet the ongoing proliferation of oil palm plantations in Indonesia is placing tremendous pressure on forest cover and, hence, on biodiversity. Between 2000 and 2012, a forest cover loss of 15.79 Mha (8.4\% of total land area) was reported for Indonesia (Hansen et al. 2013), where 6.02 Mha or 38\% occurred within primary forest (Margono et al. 2014). In 2012, 
Indonesia underwent the largest increase in annual forest loss globally, even more than Brazil that had been the leader in deforestation of tropical forest before (Margono et al. 2014). The establishment of oil palm plantations has been identified as one of the key drivers for the loss of forest (but see Gatto, Wollni \& Qaim 2015), thus heavily contributing to decline in biodiversity, ecosystem functioning of species communities, land degradation and rising greenhouse gas emissions (see Box 1.2) (Koh \& Wilcove 2008; Fitzherbert et al. 2008; Wilcove \& Koh 2010; Margono et al. 2014; Allen et al. 2015; Guillaume, Damris \& Kuzyakov 2015). On Sumatra, where our biodiversity enrichment experiment is located, forest has traditionally been replaced by rubber (Hevea brasiliensis) and - in line with the trend in Indonesia in general - more currently predominantly by oil palm (Villamor, Pontius \& van Noordwijk 2014), leaving behind only $28.3 \%$ of the original extent of primary forest on the island (Margono et al. 2014). Looking forward, one of the greatest challenges that we are facing in the $21^{\text {st }}$ century is thus to meet the growing demand of food while simultaneously reducing agriculture's environmental impact. There are biodiversity conservation strategies that are proposed to protect or enhance biodiversity in agricultural landscapes. I will discuss them in the following paragraph and give some examples from oil palm plantations in particular.

\section{Box 1.2: Facts about oil palms}

The oil palm (Elaeis guineensis) originates from West and Central Africa and it was introduced to SE Asia in 1848. It is a perennial crop that starts yielding palm fruits for oil about three years after planting and has a continual productive lifespan of 25-30 years (Corley \& Tinker 2003). With a total yield of about $4 \mathrm{t}$ per ha, the oil palm is the most productive oil crop in the world, using proportionally less land compared to other oil crops (soybean, sunflower or rapeseed less produce less than $0.8 \mathrm{t}$ per ha) (Sheil et al. 2009; UNCTAD 2015). Palm oil has therefore become the most important vegetable oil in the world (Phalan et al. 2013) and Indonesia is ranked second after Malaysia among the top five producers of palm oil globally (FAO 2015). As the secret in our shopping basket (Paddison 2014), palm oil is an ingredient in about one out of ten products available in the supermarket. Apart from that, oil palm is also the most relevant crop for biodiesel production (Koh et al. 2009). The Indonesian government used oil palm cultivation to improve the livelihood of rural households. But the high demand for palm oil did not only offer a potential pathway out of poverty but also created environmental and social problems (McCarthy, Gillespie \& Zen 2012). 


\subsection{Conservation strategies for biodiversity in agricultural landscapes}

Detrimental impacts of agricultural practices on the environment and the associated loss in ecosystem functions stress the need to develop strategies that conserve biodiversity and at the same time are economically viable (see also Box 1.3). Two models have been proposed to increase agricultural production whilst mitigating the negative consequences for biodiversity: 'land sparing' and 'land sharing'. Land sparing relates to farming for high yield, potentially enabling the protection of non-farmland habitat, whereas the land sharing strategy is lower yielding farming with more biodiversity within the farmland (Green et al. 2005). The latter is also known as wildlife-friendly farming. The two models have often been controversially discussed (Edwards et al. 2010; Ghazoul, Koh \& Butler 2010; Clough et al. 2011; Phalan et al. 2011b; Foster et al. 2011; Hulme et al. 2013). However, both strategies represent realistic solutions, depending on the local circumstances (Baudron \& Giller 2014). A holistic view on the situation supported with results from field experiments is needed (Fischer et al. 2011).

\section{Box 1.3: Incentives for nature conservation}

The primary goal of landowners is to maximize profit to make up their livelihood. If there are differences in management strategies that favor conservation of biodiversity and those that favor economic output, returns must be reconciled (Banks 2004). Conservation efforts must be pragmatic and strategies have to be developed that are jointly beneficial for landowners and biodiversity. In order to increase the farmer's motivation to adopt alternative management practices that are less harmful to biodiversity, incentives, such as 'Payments for Ecological Services' (PES) (Tscharntke et al. 2011), could be offered in exchange for managing their land sustainably (i.e. decreased use of pesticides and herbicides, enrichment of plantation with other trees, retaining forest fragments within their plantation). Certification schemes such as the 'Roundtable for Sustainable Oil Palms' (RSPO) are another motivation for farmers to manage their land in a wildlife-friendly way (RSPO 2013). However, the performance of the RSPO still needs to be improved for nature conservation, as their main focus is on the conservation of large areas of high conservation value and on already endangered species only. This scheme neglects that smaller habitat fragments with a lower habitat value as well as more common species are also contributing to biodiversity and thus are worth being protected (Laurance et al. 2010; Edwards, Fisher \& Wilcove 2011; Edwards \& Laurance 2012). 


\subsubsection{Land-sparing}

Set-aside areas for conservation might indeed enhance habitat availability for wildlife and may thus benefit biodiversity. Land areas spared for nature, however, vary considerably in size and habitat quality, from contiguous forest to small forest fragments, and with or without buffer zones around intensively managed areas. Consequently, the magnitude of benefits of such forest patches on wildlife varies accordingly. Nevertheless, forest fragments can be important stepping stones between forest areas, increase the connectivity in the landscape and can have a 'spillover effect' on adjacent agricultural land (Lucey \& Hill 2012; Gilroy et al. 2015). In oil palm plantations, positive effects of forest fragments on biodiversity were reported for butterflies, birds (Koh 2008a; Edwards et al. 2010; Gilroy et al. 2015) and ants (Lucey \& Hill 2012; Lucey et al. 2014). The potential of spared land to house a high level of biodiversity, however, might be negatively impacted by edge effects around forest fragments (Groom, Meffe \& Carroll 2006). These edge effects increase with decreasing size of the fragments. To alleviate such negative consequences of hard borders between natural and intensively managed habitats, buffer zones are proposed (Koh et al. 2009; Barnes et al. 2014a). Furthermore, the survival of species largely depends on their dispersal ability - i.e., whether or not they are capable to move between the habitat patches (Lucey et al. 2014). Isolation of forest habitat within a hostile and simplestructured landscape matrix with large distances between the spared natural areas, can negatively affect a species' survival due to lacking connectivity between protected sites and limited dispersal abilities of species (Lucey et al. 2014).

Despite many positive effects of forest fragments on biodiversity, land-sparing by increasing yields has not been very efficient in preventing further expansion of oil palm plantations and encroachment of forest (Ewers et al. 2009). It is an insufficient solution and not a panacea for all conservation problems, although forest fragments surely are essential for habitat conservation as they are still important source habitats of wildlife. Therefore, land-sharing wildlife-friendly approaches should in addition to land-sparing strategies be considered for protection of biodiversity in agricultural landscapes. 


\subsubsection{Land-sharing}

There is increasing recognition that areas of conservation alone are not sufficient to slow down current declines in biodiversity and that, therefore, conservation outside protected areas is necessary (Bhagwat et al. 2008). Agroecosystems can contribute considerably to the diversity of landscapes (Perfecto \& Vandermeer 2002; Tscharntke et al. 2011; Perfecto, Vandermeer \& Philpott 2014). Sustainable management of agriculture with a reduced application of pesticides or active improvement of habitat promotes functional agrobiodiversity (Pywell et al. 2012). This in turn facilitates the increase of ecosystem services such as enhanced biological pest control or improved crop pollination; services that directly increase the farmers' income (Tscharntke et al. 2011). Benefits from biological pest-control services can be high for farmers, as they can greatly reduce damage by harmful insects on yield. Birds, for example, have been shown to reduce infestations by $50 \%$ in wildlife-friendly managed coffee plantations, thereby preventing US\$75-US\$310 $\mathrm{ha}^{-1} \mathrm{yr}^{-1}$ in damage (Karp et al. 2013). Several other studies have also shown that birds can reduce herbivore density, underlining their importance for pest control (Van Bael et al. 2008; Koh 2008b; Maas, Clough \& Tscharntke 2013). Pest control not only delivers direct benefits to human-welfare but also provides economic incentives for crop producers to make plantations more hospitable for biodiversity (Koh 2008b).

Especially promising examples of wildlife-friendly farming methods that enhance biodiversity in combination with maintaining high yields are agroforests (Bhagwat et al. 2008; Clough et al. 2011; Maas, Clough \& Tscharntke 2013). Agroforestry is defined as a "natural resource management practice, that, via the integration of trees and other tall woody plants on farms and in the agricultural landscape, diversifies production for increased social, economic, and environmental benefits" (Schroth et al. 2004). Agroforests have the potential to provide habitat outside protected habitats, connect nature reserves and alleviate resource-use pressure on conservation areas. Therefore, they play an important role in maintaining species diversity in humandominated landscapes (Bhagwat et al. 2008). Furthermore, agroforests diversify the farmer's income due to mixed crop production, thereby reducing the negative impact of crop failure. Agroforestry with oil palms is rather uncommon in Southeast Asia; e.g. in Sumatra, large mono-cultural oil palm estates dominate the landscape. However, few 
examples exist, where oil palms were intercropped with trees, i.e. with rubber (Corley \& Tinker 2003), teak (Chia 2011), or cacao (Lee \& Kasbi 1980; Egbe \& Adenikinju 1990; Amoah et al. 1995).

So far, I have discussed various methods for sustainable management of crops in order to protect or enhance biodiversity and simultaneously keep yields high. One strategy is sparing contiguous forest or forest fragments with buffer zones around them whilst increasing yield on agricultural land (Koh et al. 2009). The alternative strategy is wildlife-friendly farming where crops are produced in extensive management, i.e. agroforests, which can also result in a win-win for both, biodiversity and farmers (Waldron et al. 2012). Especially in Indonesia, where most of the forests have already been cleared to make way for large, biodiversity-impoverished oil palm landscapes, the attention should be on these wildlife-friendly strategies for biodiversity conservation. This will not only increase biodiversity value of anthropogenic landscapes but also decrease the pressure on conservation areas. In light of the ever-increasing decline of biodiversity, it might not be enough to just conserve what is remaining. Active restoration of degraded habitats through tree planting has been identified as a tool to help biodiversity recover and restore ecosystem functions and should additionaly be consiered. The following section therefore elucidates opportunities and challenges of tree-based restoration in degraded, agricultural systems.

\subsection{Restoration of degraded ecosystems}

As many parts of the world are facing severe biodiversity loss due to anthropogenic land transformation (Rockström et al. 2009), the restoration of biodiversity - and with it ecosystem functioning - has become equally important as biodiversity conservation. The saturating relationship between biodiversity and ecosystem functioning that has been discovered from extinction scenario experiments (i.e. analysis of the relationship in the direction of biodiversity loss) (Cardinale et al. 2012) indicates that if we simply turn the tables and add species to a system that is already extremely depauperate, we can expect a relatively rapid positive effect on biodiversity and ecosystem functioning. The added species in restoration plantings can directly contribute to increased biodiversity and ecosystem functioning and increase the structural heterogeneity that 


\section{Chapter 1: Introduction}

could attract other organisms (Tews et al. 2004; Stein, Gerstner \& Kreft 2014). In the restoration context, collaboration of different disciplines is necessary to simultaneously tackle and ameliorate the consequences of environmental change on biodiversity and human well-being (Perring et al. 2015).

Restoration ecology is a sub-discipline of ecology that informs the "intentional activity that initiates or accelerates the recovery of an ecosystem with respect to its health, integrity and sustainability" (Wright et al. 2009). Restoration activities can also serve as powerful tools for exploring some of the central biodiversity-ecosystem functioning (BEF) questions. However, for BEF research to be useful for ecological restoration, ecosystem functions must be related to the ecosystem services desired as the outcome of restoration. In the following paragraphs I will discuss some factors related to restoration.

\subsubsection{Tree plantings as nuclei for natural succession}

Tree planting is considered an important measure to accelerate natural succession (Chazdon 2008a). Planted trees are likely to attract seed dispersing animals by e.g. providing habitat for foraging, nesting, or roosting (Thiollay 1995) and thus increasing seed rain. Even within small stands, trees may facilitate seedling establishment by creating a more favorable microclimate and enhancing the soil. One strategy that has been used in forest restoration is applied nucleation, which involves planting of tree islands as focal areas of recovery (sensu Yarranton \& Morrison 1974; reviewed in Corbin \& Holl 2012). Once these patches or nuclei are established, they attract seed dispersing animals and thereby facilitate recruitment of other woody plants (Corbin \& Holl 2012). An example for this restoration method can be found in a pasture landscape of Honduras where small tree islands $\left(64,16\right.$, and $\left.4 \mathrm{~m}^{2}\right)$ were planted as recruitment foci (Zahawi \& Augspurger 2006). Within two years after planting, bird activity, seed rain, seedling establishment, and seedling species richness were elevated in the tree islands. In another study in southern Costa Rica, tree islands of $16-250 \mathrm{~m}^{2}$ were planted and compared with an unplanted control in an agricultural landscape (Cole, Holl \& Zahawi 2010). Two years after planting, seed rain was highest in the large plots, intermediate in the smaller tree islands, and lowest on the control plots. Planting design 
was more important than surrounding forest cover within a $500 \mathrm{~m}$ radius area. The advantage of applied nucleation over restoration of entire landscapes is that it a promising restoration strategy to accelerate forest recovery to a similar extent as plantation-style restoration but is more economical (Zahawi et al. 2013).

\subsubsection{Size of restoration plantings}

In highly productive agricultural landscapes, such as oil palm-dominated landscapes, space for conservation is sparse and opportunity costs for the establishment of newly created conservation areas are very high. In this context, the question about the optimal size of tree islands to be planted arises: small enough to be reasonable in cost, but large enough to achieve reasonable positive effects on biodiversity and ecosystem functioning. In a macro-scale study within a human-dominated landscape, bats showed positive and negative responses to increasing size of fragments, suggesting that there is no clear pattern on how species richness responds to island size (Mendenhall et al. 2014). Hence, the most effective minimum tree island size as recruitment foci in the oil palm system to enhance biodiversity has yet to be identified.

\subsubsection{Diversity of restoration plantings}

Conventional tree planting in the tropics has mainly been based on exotic species from a few genera grown in single-species stands in the past. This practice has been criticized for contributing little to ecosystem functioning and biodiversity (Lamb, Erskine \& Parrotta 2005). More recent approaches, however, propose the use of native species in mixed stands (Erskine, Lamb \& Bristow 2005; Petit \& Montagnini 2006; Hall et al. 2011; Bruelheide et al. 2014). Many positive effects of tree planting on biodiversity have been reported (Balvanera et al. 2006; Quijas, Schmid \& Balvanera 2010) but most such studies took place in grasslands and outside the tropics. However, in a tropical tree biodiversity experiment in Panama, primary productivity was significantly higher in three-species mixtures than in monocultures (Potvin \& Gotelli 2008a); tree species composition, however, did not affect productivity (Salisbury \& Potvin 2015). Similar results regarding the diversity of plantings were found in a tree diversity experiment in Costa Rica, were mixed tree plantations had a higher 


\section{Chapter 1: Introduction}

productivity compared to mono-culture tree plantations (Petit \& Montagnini 2006). In a large-scale forest biodiversity experiment in subtropical China, where 40 tree species were planted with varying tree diversity on plots of the same size (Bruelheide et al. 2014), the proportion of trophobioses, symbiotic associations between organisms where food is obtained or provided, increased with increasing tree diversity. This finding suggests that tree diversity could increase the robustness of insect associations against changing environmental conditions through bottom-up processes (Staab, Blüthgen \& Klein 2015).

A limitation of many restoration projects has been the unknown effects of tree diversity because of missing experimental manipulations of the number of species. However, there is evidence that not only structure, which is essentially a function of age rather than diversity, is likely to be important for associated animal biota (Kanowski et al. 2003), but that birds and lizards benefit more from diverse rainforest restoration plantings than from species-poor timber plantations (Erskine, Lamb \& Bristow 2006). This shows that diverse restoration plantings have a higher potential to increase animal diversity, which is not only important for animal biodiversity per se, but also for associated ecosystem functions, such as seed dispersal, which may affect successional trajectories and/or speed.

Overall, these examples illustrate the great benefits of tree islands for biodiversity and associated ecosystem functions. So far, however, no tree-based restoration experiment exists that a) simultaneously manipulates the size and the diversity of the tree plantings, b) considers socio-economic impacts of such plantings and c) is conducted in a plantation that is further maintained whilst restoaration effects are studied. In order to develop clear guidelines that can improve the management of agricultural systems such as oil palm plantations and benefit both, biodiversity and humanity, it is, however, essential to study the impacts of such tree plantings on both, ecology and socio-economics and find the most effective planting strategy. In the following section, I will introduce the concept of a biodiversity enrichment experiment that is designed to simultaneously address ecological and socio-economic aspects of tree enrichment in a mono-culture oil palm plantation. 


\subsection{Towards a better understanding of restoration effects on biodiversity and ecosystem functioning in oil palm landscapes}

Ecological restoration has recently adopted insights from the biodiversity-ecosystem function perspective (Aerts \& Honnay 2011). Currently, there are 19 tree diversity restoration experiments in 16 countries worldwide that also focus on BEF ('TreeDivNet' 2015). These experiments are connected via the informal research network of tree diversity experiments 'TreeDivNet' (www.TreeDivNet.ugent). Four experiments are located in the tropics: the UADY tree diversity experiment on pasture land in Mexico (Moreira et al. 2014), the Gazi Bay experiment in Kenyan mangrove forests (Kirui et al. 2008), the Sabah biodiversity experiment in Bornean tropical forests (Hector et al. 2011) and the Sardinilla experiment in Panama on pasture land (Scherer-Lorenzen, Bonilla \& Potvin 2007). Furthermore, there is another tree diversity experiment which addresses BEF-questions in Costa Rica (Petit \& Montagnini 2006) but it is not part of the TreeDivNet forum. To date, there is no such project in an oil palm plantation, which is already established and further maintained. While there is broad consensus that the re-establishment of diverse habitats and the restoration of ecological multi-functionality in oil-palm-dominated landscapes is an urgent need, there is little knowledge on how this can be implemented in a way that is both ecologically and economically effective.

To bridge this gap and in order to investigate the general underlying mechanisms and specific management strategies of biodiversity enrichment with trees, I established a combined biodiversity enrichment and biodiversity-ecosystem functioning experiment in collaboration with colleagues from Germany and Indonesia. Tree islands were planted as 'recruitment foci' within a large-scale, mono-culture oil palm plantation in the province of Jambi (Sumatra, Indonesia) in December 2013 within the framework of my $\mathrm{PhD}$ project. Plot size as well as species diversity and composition of six multi-purpose tree species native to Sumatra that deliver a variety of products (fruits, latex, timber) to local people were systematically varied (plot sizes: $5 \times 5 \mathrm{~m}$, 10x10 m, 20x20 m, 40x40 m); tree diversity levels of six, three, two and one). A random partitions design was followed (as described by Bell et al., 2009) with four partition series plus four plots without planting, subjected to natural succession. This 


\section{Chapter 1: Introduction}

experiment is planned to run for at least nine years. Monitoring of ecological processes focuses on seed rain, growth rates and survival of trees, and taxonomic and functional diversity responses of birds and arthropods. Parallel to the ecological studies, socioeconomic surveys are planned to assess opportunities and constraints of enrichment plantings for local communities. With the results of this interdisciplinary biodiversity enrichment experiment, it is aimed to significantly contribute to the development of ecologically improved and socio-economically viable management strategies.

The three main hypotheses addressed with the experiment are:

- Gap enrichment plantings have a beneficial effect on biodiversity and ecosystem functioning in oil palm landscapes

- Tree islands act as recruitment foci and thereby have a positive effect on the colonization of flora and fauna

- Trade-offs between socio-economic and ecological functions are minimized a) due to the economic value of the planted trees and b) by increased provisioning of ecosystem services, which directly benefit farmers' income (e.g. ecological pest control, increased pollination)

\subsection{Overarching project framework and study area}

The study for my $\mathrm{PhD}$ thesis was carried out on the island of Sumatra, one of the 17,508 islands of Indonesia, and the second largest in the Malay Archipelago after Borneo. My project sits within the overarching framework of the collaborative research centre entitled 'Ecological and socio-economic functions of tropical lowland rainforest transformation systems on Sumatra, Indonesia' (EFForTS), which is a research initiative of the University of Göttingen in Germany and three universities in Indonesia (University of Jambi on Sumatra; University of Bogor on Java; and University of Tadulako on Sulawesi). The main goal of this international, interdisciplinary research program is to investigate the impacts and forces responsible for deforestation in the Province of Jambi, one of the most severely converted regions in Indonesia (Miettinen, Shi \& Liew 2011), and to evaluate the ecological, economic and social consequences linked to the transformation of rainforest into other land-use systems. 


\subsubsection{Study area}

Jambi province is located in the eastern part of central Sumatra. The climate is humid tropical with a mean annual rainfall of $26.7 \pm 1.0^{\circ} \mathrm{C}$ and a mean annual rainfall of 2235 $\pm 385 \mathrm{~mm}$ (1991-2011; climate station at the Jambi Sultan Thaha airport of the Meteorological, Climatological and Geophysical Agency). There is a dry season from June to August, where rainfall can reach measures below $100 \mathrm{~mm}$. The natural vegetation in the Jambi Province is dipterocarp dominated lowland rainforest in the centre and peat-swamp forest along the east coast (Laumonier 1997; Whitten 2000). Dominant soil types are loam and clay Acrisols, of which we find the first in the Bungku region (Allen et al. 2015).

\subsection{Study objectives}

The main focus of most of the projects within the EFForTS- project is on the consequences of lower diversity in e.g. oil palm plantations compared to tropical lowland rainforest. In my subproject, however, the focus is to investigate how ecological and socio-economic functions respond if habitat is restored within a monocultural oil palm plantation. The title of my subproject is 'Biodiversity enrichment in oil palm plantations - ecological and socio-economic impacts'. My focus in this subproject is on the ecological impacts of enrichment plantings, in particular on bird and invertebrate communities. In my thesis I therefore a) studied the ecological and economic effects of remnant or planted trees in smallholder oil palm plantations to uncover the economic and ecological trade-offs and b) established a biodiversity enrichment experiment to study the effect of biodiversity enrichment plantings on bird and invertebrate communities in oil palm systems.

In a first step, I assessed the shape of the relationship between ecological (bird diversity, bird abundance) and economic outcomes (oil palm yield and revenue) of remnant or planted trees in smallholder oil palm plantations along a management intensity gradient (Figure 1.3). This interdisciplinary approach allowed me to study not only the ecological impacts of "natural" enrichment plantings on biodiversity but also to gain a deeper understanding of the potential economic constraints and opportunities 
to encourage increased use of enrichment plantings in the area. Furthermore, I aimed at estimating the costs for increased bird diversity/bird abundance in oil palm plantations. The analysis to answer these research questions is based on economic and ecological data from 120 smallholder oil palm plantations.
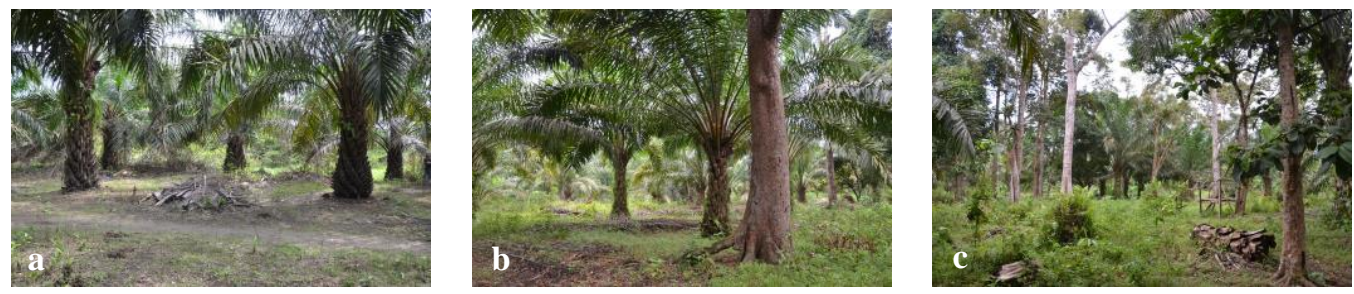

Figure 1.3: Smallholder oil palm plantations of different management intensity: a) high intensity, no trees b) intermediate management intensity, few trees c) extensive management, many trees within the oil palm plantation.

In a second step, I sat the scene for long-term research on ecological and socioeconomic processes of enrichment plantings in oil palm plantations by establishing a biodiversity enrichment experiment in an oil palm plantation in the Province of Jambi, Sumatra, Indonesia (Figures 1.4-1.7). This long-term experiment is aimed at contributing to the development of management guidelines for an ecologically improved and socio-economically viable management of oil palm plantations. The establishment of the experiment comprised the planting of tree islands in gaps of an oil palm plantation. The design allows for disentangling effects attributed to island size and those to the diversity of plantings in order to find the best planting strategy for increased diversity and associated ecosystem functions, while simultaneously minimizing opportunity costs. My focus for the early phase of the experiment and within the timeframe of my $\mathrm{PhD}$ project was on the establishment of the tree islands, the assessment of the initial abiotic and biotic conditions prior to the tree planting on the plantation, as well as on monitoring the effects of enrichment plantings on bird and invertebrate communities one year after establishment.

The first part of my research project took place on smallholder oil palm plantations surrounding four villages in the Batanghari region in the province of Jambi, Sumatra, Indonesia. The second part of the study was conducted on the plantation of PT Humusindo near Bungku, also in the Jambi province. 

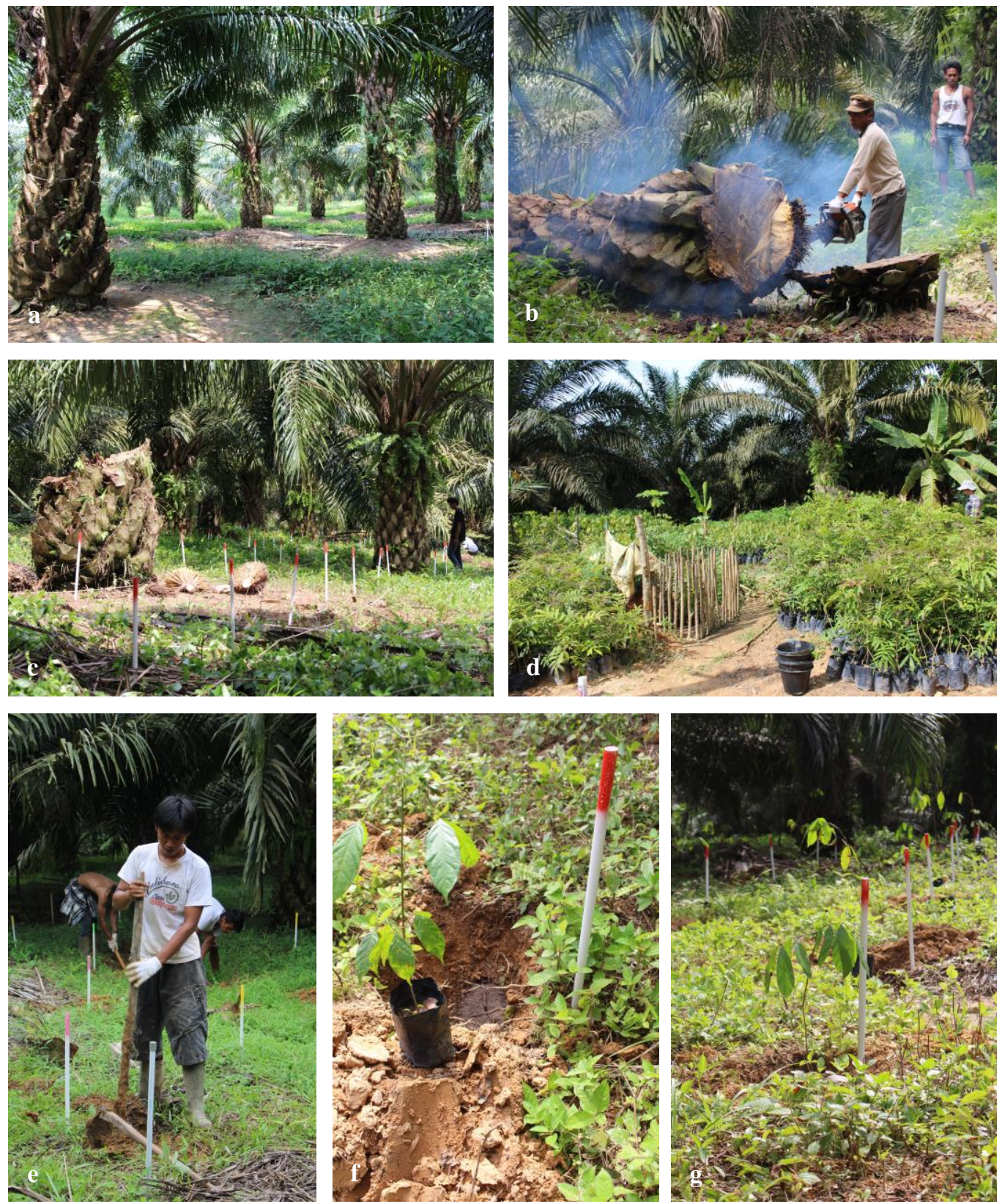

Figure 1.5: Establishment process of the biodiversity enrichment experiment: a) plots were measured in a mono-cultural oil palm plantation; b) roughly $40 \%$ of the oil palms were cut to increase light conditions for better growth of freshly planted trees; c) marked plastic poles were set to assisted the adherence to the strict planting scheme; d) tree seedlings waiting to enrich the oil palm plantation; e) digging of holes; f) application of organic and an-organic fertilizer to enhance establishment of the planted trees; g) planted trees on the experimental plots. 

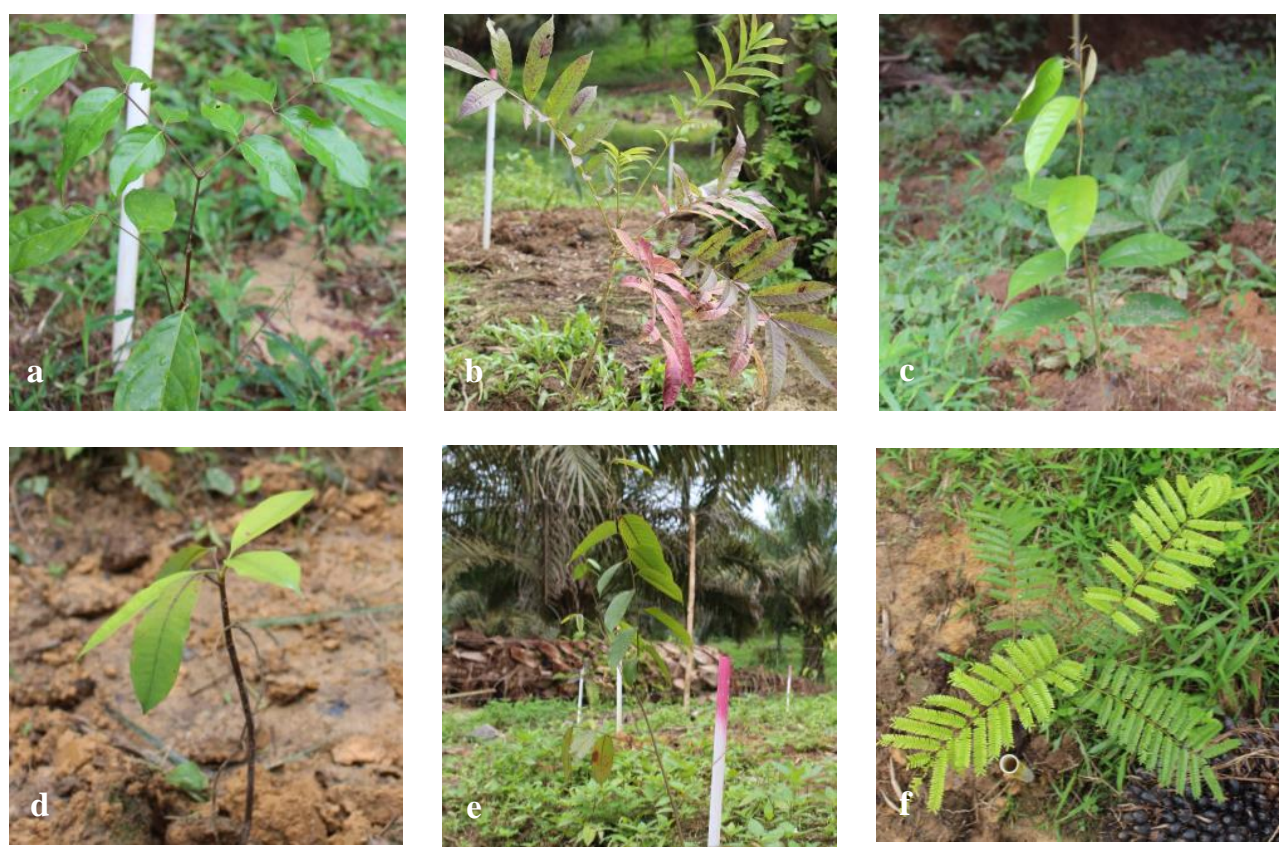

Figure 1.4: Seedlings of the six multi-purpose tree species selected for the biodiversity enrichment experiment a) Archidendron pauciflorum, b) Peronema canescens, c) Durio zibethinus, d) Dyera polyphylla, e) Shorea leprosula and f) Parkia speciosa.
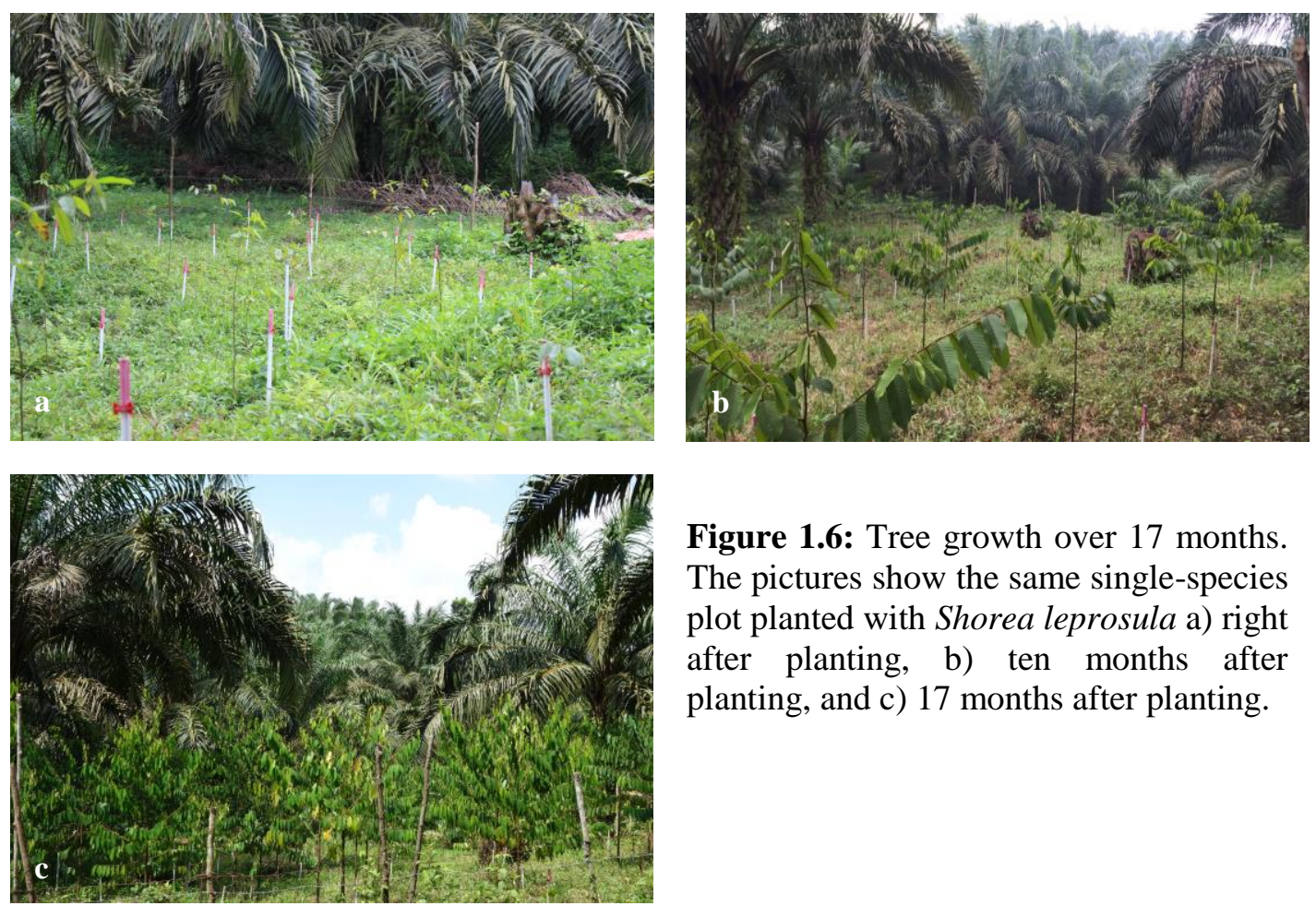

Figure 1.6: Tree growth over 17 months. The pictures show the same single-species plot planted with Shorea leprosula a) right after planting, b) ten months after planting, and c) 17 months after planting. 

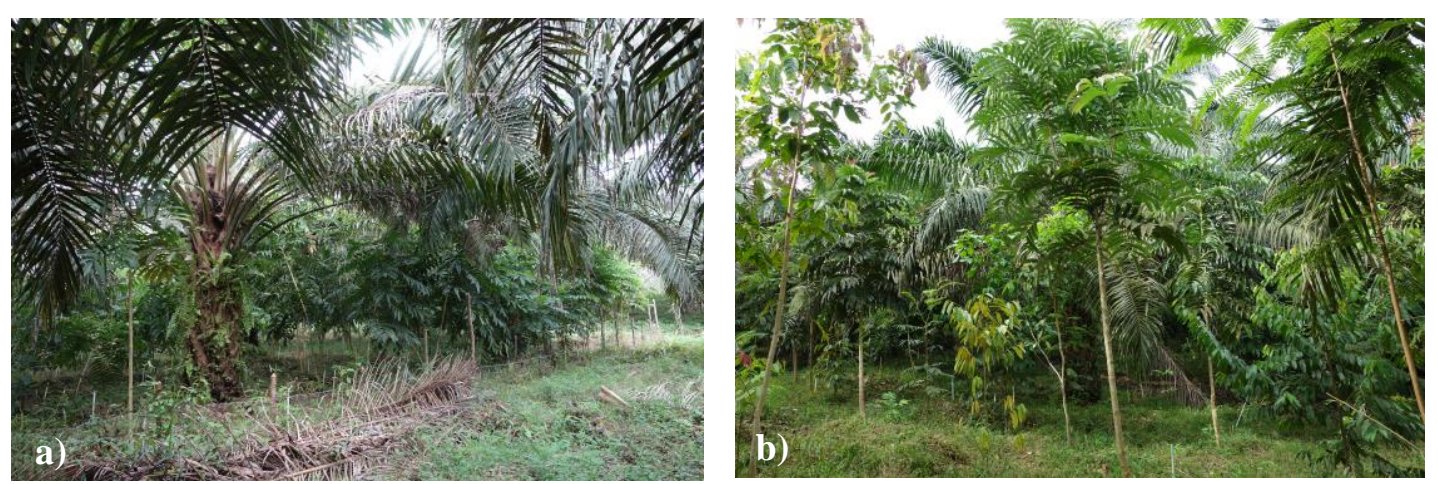

Figure 1.7: Tree islands 17 months after planting. a) A single-species plot planted with Peronema canescens; b) A mixed-species plot.

\subsection{Outline}

In the research chapters of this thesis, I investigate the effects of enrichment plantings in oil palm plantations on ecology and economics.

In Chapter 2 "Trade-off between bird diversity and abundance, yield and revenue in smallholder oil palm plantations in Sumatra, Indonesia", I present a study on the economic-ecological relationship of remnant or planted trees in smallholder oil palm plantations along a management intensity gradient. In addition, I investigated different possibilities to estimate the price for increased bird species richness and abundance in oil palm plantations.

In Chapter 3 "Biodiversity enrichment in oil palm landscapes: A tree planting experiment in Sumatra (Indonesia)", I give an introduction to the biodiversity enrichment experiment. The initial abiotic and biotic characteristics of the experimental plots prior to the tree plantings are presented and I also give first insights on early effects of the planted tree islands on the bird and invertebrate fauna one year after establishment.

Finally, Chapter 4 summarizes the main findings and concludes with suggestions for further research. 



\section{PART II}

\section{RESEARCH CHAPTERS}





\section{Chapter 2: Trade-offs between bird diversity and abundance, yields and revenue in smallholder oil palm plantations}

\subsection{Abstract}

Global land-use change has drastic consequences for biodiversity leading to losses of ecological functioning, ecosystem services and human well-being. While species dependent on undisturbed natural habitat are most affected by conversion to agriculture, even populations of disturbance-tolerant species can be endangered in landscapes dominated by high-input mono-cultural cropping systems. This has raised the question of how, and at what cost, a diversity of species can be conserved in such habitats. Focusing on birds of smallholder oil palm-dominated landscapes, we investigated the relationship between the ecological and economic outcomes of remnant or planted trees in smallholder oil palm plantations. The study comprised a household and a field component. We gathered plot specific data on yields, revenue and inputs from 120 households owning productive oil palm plantations in the Jambi Province, Sumatra, Indonesia. Bird diversity and abundance as well as vegetation structure was assessed on the same oil palm plots. We tested the effects of a set of economic and ecological variables on measures of bird diversity, bird abundance, oil palm yield, and total revenue. Our results show that a gain in bird diversity and bird abundance conditional on increases in number of trees comes along with a loss in revenue for farmers indicating that there is a win-lose relationship between ecological and economic functions. However, since the relationship is non-linear, costs for bird species gain or gain in bird abundance change depending on the number of trees within an oil palm plantation: in a relatively extensively managed oil palm plantation (high number of trees, low oil palm yields), a further increase in the number of bird species or individuals leads to a relatively high loss in total revenue, whereas in an intensively managed oil palm plantation the same increase in number of bird species results in a smaller loss in revenue. An increase in bird abundance can be fostered at smaller costs when compared to the costs for increasing biodiversity. This suggests that thereis room 
for tree-based enrichment of intensively managed oil palm plantations, where a relatively high increase in bird species richness or bird abundance could be achieved at relatively low cost.

Keywords: ecological-economic trade-off, bird diversity, agro-ecosystems, oil palm, Southeast Asia

\subsection{Introduction}

Land-use change is globally the most important cause for biodiversity loss (Sala et al. 2000; Immerzeel et al. 2014). Both the transformation of natural or semi-natural habitats into mono-cultural annual or perennial cropping as well as agricultural intensification at local and landscape-scale lead to losses in biodiversity and ecosystem functioning of species communities (Sala et al. 2000; Sodhi et al. 2004; SteffanDewenter et al. 2007; Koh \& Wilcove 2008; Wilcove et al. 2013; Edwards et al. 2014), with a risk of negative effects on human well-being (Cardinale et al. 2012; but see Raudsepp-Hearne et al. 2010). In the next few decades, the pressure on biodiversity will proceed or even amplify due to an increasing demand for food (Tilman et al. 2002) and biofuels (Koh \& Wilcove 2007; Field, Campbell \& Lobell 2008; Corley 2009; Koh $\&$ Ghazoul 2010). The mitigation of the loss of biodiversity and of land degradation is therefore one of the major challenges in the current decade (UN's 'decade of biodiversity') (Tscharntke et al. 2012a).

Almost two-third of the cropland expansion in tropical countries in the last decade can be attributed to the expansion of annual crops, such as soybean and maize. Oil palm (Elaeis guineensis), ranking the fifth of the most rapidly expanding crops in harvested area, is the most rapidly expanding perennial crop in the tropics (Phalan et al. 2013). Within 25 years, the total plantation area of oil palm has tripled, with current global estimates of over 15 million ha (Gilbert 2012). In Indonesia, the area under oil palm cultivation almost doubled from 4.2 million ha in 2000 to around 8 million ha in 2010, which account for $46 \%$ of the world's crude oil production (Obidzinski et al. 2012). In 2009, the Indonesian government claimed that the oil palm area can be nearly 
doubled to 18 million ha "without disturbing [...] forest preservation efforts" (The Jakarta Post 2009).

On the one hand, oil palm cultivation is an attractive pathway out of poverty for many rural households (The World Bank 2011) even though smallholder productivity (in 2010, 38\% of the total oil palm area was managed by smallholders (Rianto, Mochtar \& Sasmito 2012)) is approximately 35-40\% lower than yields in the private and government sectors (Lee et al. 2013) and varies considerably conditional on institutional, agronomic and biophysical factors (McCarthy 2010; Rist, Feintrenie \& Levang 2010; Koh \& Ghazoul 2010; Budidarsono 2012; Lee et al. 2013). On the other hand, oil palm cultivation is also a pervasive threat to biodiversity (Belcher \& Schreckenberg 2007; Fitzherbert et al. 2008). Large areas of Southeast Asia, where around $80 \%$ of palm oil are produced, belong to the most biologically diverse terrestrial ecosystems on earth, characterized by a high degree of endemicity (Fitzherbert et al. 2008). It is estimated that between 1990 and 2005 around $57 \%$ of the oil palm expansion occurred at the expense of tropical rainforest (Koh \& Wilcove 2008; Wilcove \& Koh 2010). Between 1990 and 2005, Indonesia reported an absolute decline in forested area of $280,000 \mathrm{~km} 2$, ranking second among the countries which face a significant decline in forested area (World Trade Organization 2010). Oil palm plantations are also often established on extensive complex smallholder production systems, such as "jungle rubber" (hutan karet), which is characterized by rubber trees mixed with other tree species forming a stand structure similar to secondary forest (Gouyon, Foresta \& Levang 1993; Ekadinata \& Vincent 2011). Both, forest and jungle rubber, are valuable habitats for conservation. Jambi Province in Indonesia is one of the provinces with the fastest and most complete transformation of tropical lowland rainforest and extensive traditional production systems into rubber or oil palm plantations worldwide (Laumonier et al. 2010). Compared to jungle rubber as a complex agroforestry system, oil palm production is characterized by a high degree of intensification at the landscape and habitat scale, including landscape simplification (Foster et al. 2011) and rather low structural habitat complexity (uniform stand age; low canopy; low ground layer vegetation cover; low-stability micro-climate). 
Oil palm landscapes are among the poorest habitats for biodiversity in tropical regions (Fitzherbert et al. 2008) and the conversion of natural or logged forest to oil palm plantations leads to dramatic losses in biodiversity in the majority of taxonomic groups (Foster et al. 2011). Fayle et al. (2010), for example, report a decline of forest ant species of $81 \%$ as forest is converted to oil palm. This loss of species is mainly caused by a loss in habitat heterogeneity. Moreover, conversion of tropical forests into oil palm can lead to a loss in ecosystem functions that disproportionately exceeds the decline in species diversity (Barnes et al. 2014b). Edwards et al. (2013) showed that functional diversity of birds experiences severe declines along a gradient from unlogged forest to logged forest to oil palm. Similar results were found by Azhar et al. (2013) who found reduced bird functional diversity in oil palm compared to peat swamp forest. Species that dominantly colonized oil palm landscapes after conversion are mainly generalist disturbance-tolerant species with large geographical ranges and low conservation status (Peh et al. 2006; Edwards et al. 2013).

However, it has been highlighted that even in such impoverished landscapes, there can be significant variation in abundance and diversity of species, dependent on the management of the vegetation and the presence of nearby forests (Koh 2008a; Azhar et al. 2011), suggesting that the - from many species' perspective - inhospitable monoculture landscape can be softened up to some degree. Achieving this is valuable, not only in order to maintain populations of disturbance-tolerant species, which have been shown to keep declining elsewhere long after major changes in land use (e.g. farmland birds in Europe), but also to ensure ecosystem functions such as pest control. Birds, for instance, play an important role in an ecosystem as they maintain a wide range of ecosystem functions such as pest control, seed dispersal and pollination (Sekercioglu et al. 2002; Sekercioğlu, Daily \& Ehrlich 2004; Van Bael et al. 2008; Karp et al. 2013). Birds were shown to contribute to the control of leaf-eating oil palm pests (Koh 2008a) and have a beneficial impact on agroforestry crops as they effectively suppressed arthropod densities leading to an increase of yield by about a third (Maas, Clough \& Tscharntke 2013).

One wildlife-friendly option are designer plantation landscapes in which monocultural plantations are enriched with trees planted in gaps within the plantation or with 
agroforestry buffer zones to surrounding natural vegetation. They are proposed as a means to maintain livelihood needs while increasing biodiversity and ecological functions and thus to alleviate the negative environmental impacts of intensively managed transformation systems such as oil palm (Bhagwat et al. 2008; Bhagwat \& Willis 2008; Koh et al. 2009; Clough et al. 2011). In particular, tree planting is considered an important measure. Planted trees are likely to attract seed dispersing animals by providing habitat for foraging, nesting, or roosting and thus increase seed rain and allow natural succession (Chazdon 2008b). Even within small stands, trees may alleviate stressful conditions and thus facilitate seedling establishment by creating a more favourable microclimate and amelioration of the soil (Zahawi \& Augspurger 2006; Manning, Fischer \& Lindenmayer 2006; Herrera \& García 2009; Fischer, Stott \& Law 2010; Cole, Holl \& Zahawi 2010).

The evaluation of management options that aim to conserve biodiversity, both at the landscape and habitat scale, depends on the shape of relationship between ecological and economic outcomes (Perfecto et al. 2005; Steffan-Dewenter et al. 2007; Tscharntke et al. 2012a). The effect of mixed trees in oil palm plantations, controlling for management regimes (e.g. fertilizer and herbicides application) and habitat complexity (ground vegetation, shrubs) on yields and revenue has rarely been studied. On the one hand, oil palm yields most probably decrease with increasing number of other trees within the plantation because of competition for light and nutrients (Corley $\&$ Tinker 2003), and depending on the method of establishment, on space forgone for planting oil palm. On the other hand, Miccolis et al. (2014) show, based on a study of oil palm grown in trial plots of ecologically diverse agroforestry systems in northern Brazil, that after five years oil palm yields in agroforestry systems were on average higher than those in mono-cultural systems. Thus, agro forests managed to be more "wildlife-friendly" do not necessarily result in a decrease in agricultural output.

Here, we investigate the relationship between the ecological and economic outcomes of remnant or planted trees in smallholder oil palm plantations, as a contribution towards the scientific basis for designing incentives for structurally complex oil palm plantations for enhanced species diversity. This study comprises a field and a household survey component. We conducted a bird and vegetation 
assessment and a socio-economic household survey from the same 120 smallholder oil palm plantations in four villages in the province of Jambi, Sumatra, Indonesia, along a gradient of habitat complexity and management intensity. This study aims to answer the following research questions: (1) Do remnant or planted trees within oil palm plantations affect bird diversity and bird abundance? (2) Do remnant or planted trees within oil palm plantations affect economic outcome variables, such as yield and revenue? (3) Is there a trade-off between ecological and economic functions? (4) What is the shape of the relationship between ecological and economic functions?

\subsection{Material and methods}

\subsubsection{Study site}

The survey was conducted in four villages (Bukit Harapan $1^{\circ} 31^{\prime} 25.9746 " \mathrm{~S}, 102^{\circ} 56^{\prime}$ 3.3864" E; Bukit Sari 1 31' 59.7606" S, 103 10' 16.8882" E; Karmeo 1 47' 39.7242" S, $103^{\circ} 2^{\prime} 38.1402^{\prime \prime}$ P Pulau Betung $1^{\circ} 33^{\prime} 41.4216^{\prime \prime}$ S, $103^{\circ} 25^{\prime} 41.6958^{\prime \prime} E$ ) in the Batanghari region in the Province of Jambi, Sumatra, Indonesia, between February and April 2013. A map of the study area is provided in Figure 2.1. Total area of all 101 plots used in the analyses (excluding missing data points) was 164 ha (70 ha in Bukit Harapan; 53 ha in Bukit Sari; 27 ha in Karmeo; 14 ha in Pulau Betung). The climate is humid tropical, with a mean temperature range from $25.9-26.8^{\circ} \mathrm{C}$ and an annual rainfall of $2268.3 \mathrm{~mm}$ year-1 (1960-1990 average). To establish mono-cultural oil palm and rubber cultivation area, natural lowland rainforest was cut massively in the 1970's and 1980's by concession logging. Hence, large areas of lowland rainforest do no longer exist in the Batanghari region but only small patches of jungle rubber or secondary forest. This transformation of lowland rainforest into mono-cultural rubber and oil palm plantations was fostered by the transmigration program, which was launched by the Indonesian government in the 1980's (Fearnside 1997; Elmhirst 1999). Within the framework of this program, households were resettled from the over-populated islands of Java or Bali to the less-populated islands of Kalimantan and Sumatra. These settlements were established in Nucleus Estates and smallholder plantations (NES), where a company-owned refinery and estate is surrounded by smallholder-owned 
plantations. Besides access to credit and oil palm technology, early transmigrant households obtained certified land entitlements, which include 2 ha of already established oil palm plantation within the NES plantation (McCarthy, Gillespie \& Zen 2012). Transmigrant smallholder oil palm plantations intend to be intensively used agricultural systems characterized by high input use and contribute to landscape homogenization. Oil palm plantations within one NES plantation are similar in terms of oil palm age, oil palm density, and management practices and form a large monocultural oil palm plantation by bordering each other.

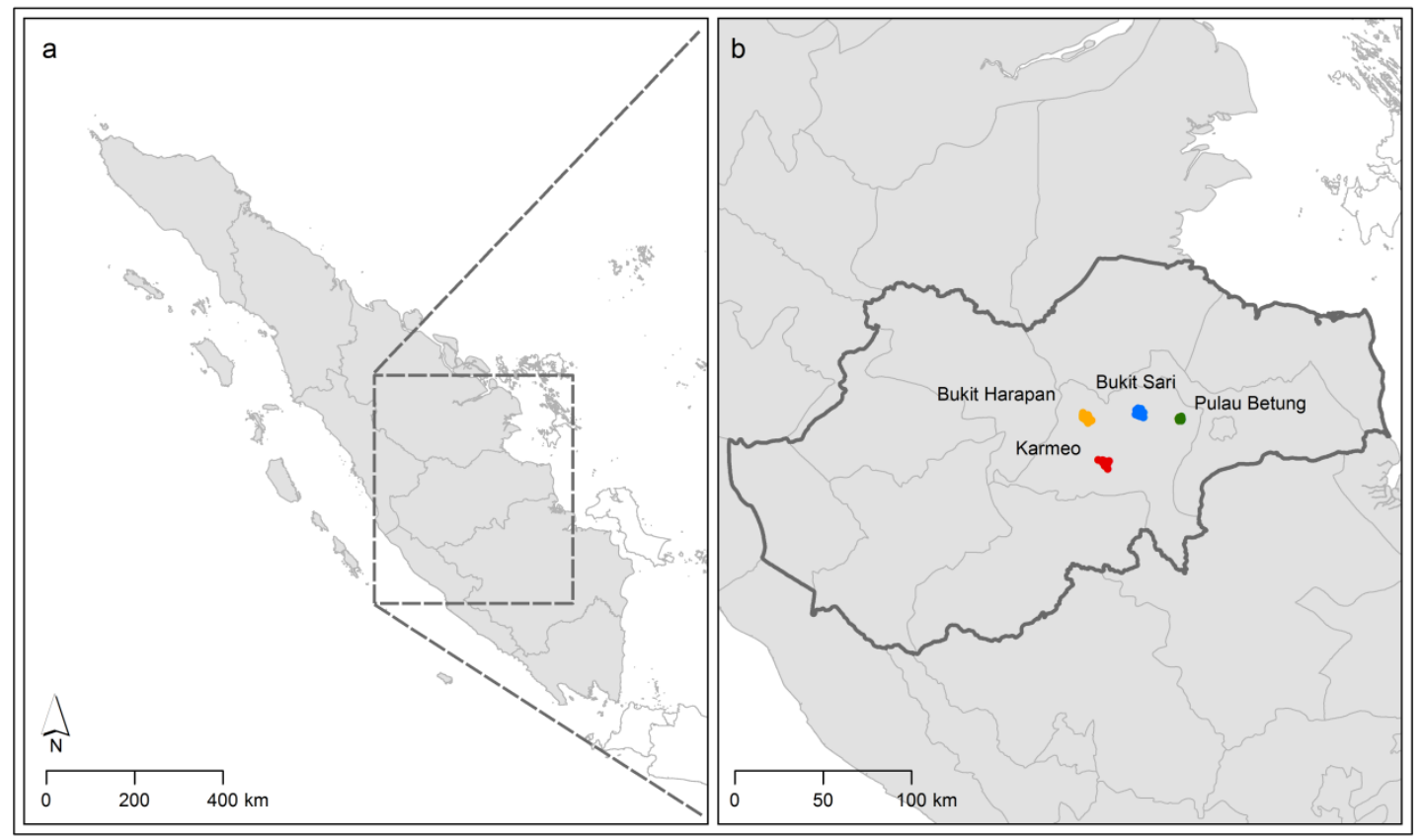

Figure 2.1: Map of the study area: (a) Sumatra (b) Location of the study plots in the four study villages Bukit Harapan (yellow), Bukit Sari (blue), Pulau Betung (green) and Karmeo (red) in the Jambi province.

In the last 10 years, however, the expansion of smallholder oil palm area has been mainly driven by independent smallholders, who are located in autochthonous, rather than transmigrant villages (Ekadinata \& Vincent 2011). These independent smallholders are either locals or spontaneous migrants (e.g. from other parts of the Jambi province). Autochthonous oil palm plots are considerably different compared to the transmigrant ones in terms of oil palm age, oil palm density and management practices. The landscape of autochthonous villages is characterized by oil palm plantations that incorporate a management intensity gradient and small patches with 
different land use types (e.g. rubber mono-culture, jungle rubber, bush fallow land, home garden etc.).

To capture a wide range of variability in structural complexity on the habitat and landscape scale among oil palm plantations and accounting for the gradient in agricultural intensity in that region, the survey was carried out in two autochthonous villages (Pulau Betung, Karmeo) and two transmigrant villages (Bukit Sari, Bukit Harapan).

\subsubsection{Household survey}

Based on a village census, a total of 120 households that individually manage productive oil palm plots were randomly selected. In the case that a household owned more than one productive oil palm plot, the largest oil palm plot was selected for further consideration. In the transmigrant villages, 70 oil palm cultivating households were interviewed. Due to the lower number of households owning productive oil palms, only 50 plots were selected in the autochthonous villages. Information on farm and household characteristics including plot specific data was obtained from the household heads. The standardized questionnaire contains information on plot characteristics (plot size, oil palm age, oil palm density, location etc.), abundance and use of trees within or along the border of the specific plot, costs and benefits of oil palm cultivation and cultivation of trees, respectively. All plot characteristics and management related information refer to the calendar year 2012. Afterwards, we accompanied the farmer to the plot that he/she was interviewed about to take GPS coordinates and tracked the borders of each plot by surrounding it with a GPS device. Plots sizes ranged from 0.19 ha to 9.26 ha (mean plot size: $1.62 \pm 0.98$ ).

\subsubsection{Bird sampling}

Birds were recorded visually and acoustically, and by systematic tape recordings in accordance with a standardized observation method using 15 minutes point counts at the centre of each plot. We did only one point count per plot, independent of the plot size, as we only wanted to assess the local bird diversity and the sum of observations at the centre of each plot. Each plot was visited twice from 6 am to 10.30 am and there 
was a minimum of six days between the first and the second sampling period on plots within each of the villages. Point counts were only done when weather conditions were appropriate (no rain). For every species, we recorded the maximum number of individuals present simultaneously on the plot. Individuals flying only above the canopy were excluded from analyses. Migratory species were not recorded. For taxonomy we followed MacKinnon et al. (1993). To get a standardized measure for all plots for the analyses, we used bird observations within a $25 \mathrm{~m}$ radius only, as this was the maximum area that could fit into every plot. For vulnerability status, we used the species' IUCN (International Union for Conservation of Nature) classification (IUCN 2014).

\subsubsection{Vegetation assessment}

Vegetation structure was assessed on $100 \mathrm{~m} \times 6 \mathrm{~m}$ transects on each plot starting from the centre of the plot proceeding into northerly, southerly, westerly and easterly direction. We distinguished between trees and shrubs and noted the distance of each vegetation structure from the centre. The height and percentage cover of ground vegetation was assessed within circles (radius $=3 \mathrm{~m}$ ) at the centre point and along each of the four transects at $50 \mathrm{~m}$ and $100 \mathrm{~m}$ distance from the centre. Density measures for vegetation variables were calculated only from data that was collected within each plot. Vegetation data collected outside the plot were not considered.

\subsubsection{Data analysis}

Using mixed effects models, we tested the effect of a set of economic and ecological variables on bird diversity, bird abundance (sum of bird observations in two sampling periods), yields (ton year -1 ha-1) and revenue (US\$ year-1 ha-1), with village as a random effect to control for unobserved heterogeneity between the four study villages. Table 2.1 depicts the set of variables used, as well as their range.

For the bird models, we pooled the observations from the two sampling periods and ran a glmm with a Poisson distribution and a log-link function using the "glmer" function (R Core Team 2014). There was no over-dispersion in the bird diversity model 
whereas the bird abundance model was highly over-dispersed. To deal with the overdispersion in the abundance model, we included an observation level random effect.

Table 2.1: Explanatory variables considered in the full models to explain bird abundance (number of bird individuals within a $25 \mathrm{~m}$ radius around the centre point), bird diversity (number of bird species within a $25 \mathrm{~m}$ radius around the centre point), yields (ton fresh bunches of oil palm ha-1y-1) and revenue (IDR ha-1y-1); transformed values in parentheses. Offsets used for log transformation of variables including zeros in parentheses.

\begin{tabular}{|c|c|c|c|c|}
\hline Variable name & Description & Min & Mean & Max \\
\hline Village & $\begin{array}{l}\text { Factor with four levels, Bukit Harapan, Bukit } \\
\text { Sari, Karmeo and Pulau Betung, entered the } \\
\text { model as random effect }\end{array}$ & - & - & - \\
\hline $\begin{array}{l}\text { Number of trees } \\
\text { (ecology models) }\end{array}$ & $\begin{array}{l}\text { Number of all trees }>2 \mathrm{~m} \text { per ha, log transformed } \\
\text { (offset: } 2.51 \text { ) }\end{array}$ & 0 & 27.93 & 314.72 \\
\hline $\begin{array}{l}\text { Number of trees } \\
\text { (economic models, } \\
\text { negative input) }\end{array}$ & $\begin{array}{l}\text { Number of trees per ha, log transformed (offset: } \\
0.22 \text { ) }\end{array}$ & 0 & 12.26 & 125.67 \\
\hline Number of oil palms & Number of oil palms per ha, log transformed & 86.98 & 159.26 & 349.99 \\
\hline Forest border & $\begin{array}{l}\text { Factor with two levels, forest patch bordering the } \\
\text { oil palm plot (1) and no forest patch at the border } \\
\text { of the plot }(0)\end{array}$ & 0 & - & 1 \\
\hline Shrubs & Number of shrubs $>1.5 \mathrm{~m}$ per ha, untransformed & 0 & 30.63 & 193.72 \\
\hline $\begin{array}{l}\text { Height ground } \\
\text { vegetation }\end{array}$ & $\begin{array}{l}\text { Factor with five levels: (1) } 0-15 \mathrm{~cm} \text {, (2) } 16- \\
30 \mathrm{~cm} \text {, (3) } 31-50 \mathrm{~cm} \text {, (4) } 51-100 \mathrm{~cm} \text {, (5) } 101- \\
150 \mathrm{~cm}\end{array}$ & 0 & - & 5 \\
\hline Age & Age of oil palms & 1 & 12.39 & 21 \\
\hline Age, squared & Age of oil palms, squared transformed & 1 & 189.41 & 441 \\
\hline Quantity of fertilizer & $\begin{array}{l}\text { Total amount of applied fertilizer }(\mathrm{kg}) \text { per ha and } \\
\text { year, log transformed (offset: } 1.14)\end{array}$ & 0 & 771.10 & 2493.22 \\
\hline Value of herbicides & $\begin{array}{l}\text { Total value of applied herbicides (IDR) per ha } \\
\text { and year, log transformed (offset: 14127.2) }\end{array}$ & 0 & 184094.6 & 3461947 \\
\hline Labour hours & $\begin{array}{l}\text { Total working hours of family and non-family } \\
\text { labourers per ha and year, log transformed }\end{array}$ & 32.43 & 286.31 & 2190.72 \\
\hline Marehat & $\begin{array}{l}\text { Factor with two levels, marehat clones plantes (1) } \\
\text { and no marehat clones planted }(0)\end{array}$ & 0 & - & 1 \\
\hline
\end{tabular}

For the economic models, we estimated a Cobb-Douglas production function, which was specified as a linear relationship between the log-transformed outcome variables and a range of log-transformed input variables. The "lme" function was used 
assuming a normal distribution and fitting the models by maximum likelihood estimation (R Core Team 2014).

Oil palm yields were calculated as the total output of oil palm bunches divided by oil palm area. The total revenue comprises the revenue generated both from marketed oil palm bunches and from fruit and timber products of the remnant or planted trees within or at the border of the oil palm plantation. In addition, the opportunity costs of fruits and timber products generated from remnant or planted trees and consumed by the household were valued using the respective market prices. For the oil palm revenue, for each individual farmer the average fresh oil palm bunch price was calculated based on the average fresh oil palm bunch price received in the dry and in the rainy season weighted by the length of each season.

The choice of explanatory variables considered in the economic models was guided by the production technologies and practices hypothesized to influence oil palm output and output generated from remnant or planted tree stands. Oil palm smallholders use three main discretionary inputs: herbicides, fertilizer and labour. Since herbicides are partly used as concentrates, we considered the total value of the applied herbicides in the analyses, assuming a positive correlation between the concentration of active substances and price. For fertilizers, it was feasible to use the total amount of applied fertilizer. Labour reflects the total working hours of family and hired labourers spent on weeding of ground layer vegetation and epiphytes, herbicide, fertilizer and soil amendment applications and harvesting. All management-related explanatory variables are given per hectare and year. Previous studies have shown that the yield potential is determined by the quality of the seedlings (Phalan et al., 2009) and that transmigrant smallholders tended to receive better quality seedlings (McCarthy et al., 2012). While most of the transmigrant oil palm plantations in our sample were planted with Marehat clones, the variety can be found on a significantly lower share of the autochthonous plots. To control for differences in yields and revenues conditional on the seedling quality, we considered a dummy for Marehat clones.

As for the ecological predictors, besides height and percentage cover of ground vegetation as well as number of trees, a forest factor describing whether or not a forest patch (> 1 ha) was bordering the plot was included because we assumed that forest 
patches at the border should function as source habitats and influence bird diversity and abundance on the plot (Anand, Krishnaswamy \& Das 2008; Clough et al. 2009). Nearest fragment distance or nearest forest fragment size could not be adequately assessed as there were neither suitable maps with a detailed enough land-use classification, nor recent enough aerial pictures available from which size and distance of forest fragments could have been derived. Collecting this information in the field was not possible due to time and labour constraints.

We used two different tree variables - one for the economic models and one for the bird models - because in the economic survey all the information (e.g. number of oil palms, amount of fertilizer) relates to an entire plot, whereas the ecological variables were derived from only part of a plot (100 x $6 \mathrm{~m}$ transects for vegetation, $25 \mathrm{~m}$ radius for birds). As the tree variable is our determining factor and links the economic and ecological parts of the study, we decided to maintain the same scales for the tree variable as for the corresponding response variables (data on bird diversity and abundance for only part of the plot; data on yield and revenue for the whole plot). Hence, for the bird models we used the tree densities that were derived from data collected on transects. In the economic models we included a tree variable, which was based on household survey data and related to the area of the whole plot; it is the number of trees which the farmer recalled having within his plot. The field and household based data on number of trees is significantly correlated $(\mathrm{p}=0.008)$. In the economic models we included the tree variable as a negative input given that this better described the data (lower AIC). Additionally, we multiplied the tree variable with a constant term (1.05), as this better approximated the correct shape of the function. In the case of the bird models, the tree variable was entered as a positive input.

Due to incomplete data we only considered 101 of the originally 120 observations in the analysis ( 37 plots in autochthonous villages, 64 plots in transmigrant villages).

We checked for correlations between the explanatory variables. Not surprisingly, correlation between percentage cover and height of ground vegetation was relatively high (Pearson's $r=0.59$ ). Both variables are known to be important structural parameters for birds (Atkinson et al. 2005; Clough, Kruess \& Tscharntke 2006; Azhar 
et al. 2013), but due to the correlation we only included height of ground vegetation. All of the other variable pairs were not strongly correlated (Pearson's $r<0.5$ ).

Number of oil palms, number of trees (both variables), labour hours, amount of fertilizer, and value of herbicides were log-transformed. As those variables - except for number of oil palms - contained zeros, we added the smallest value of each variable divided by two to each value of the variable in order to be able to do the logtransformation. Age of oil palms entered the model untransformed and with an additional squared term, as we expected optimal yields at intermediate palm age. All other terms entered the models without transformation. To avoid a leverage effect of some explanatory variables as compared to others, we normalized all predictors by subtracting the mean and dividing by the standard deviation (Schielzeth 2010).

We checked for spatial autocorrelation by calculating Moran's I values for each of the model's residuals. Using the Moran's I standard deviate in the 'spdep' package in R (R Core Team 2014), we tested for spatial autocorrelation but found no support for spatial autocorrelation of variation in any of the response variables (Moran's I test results yielded $\mathrm{p}>0.1$ ).

Model adequacy of full and best models, including normality, homoscedasticity of the residuals, and whether a linear relationship was likely to be appropriate, was checked graphically using diagnostic plots. A forward and backward selection was done with each full model. The best models were chosen on the basis of the Akaike Information Criterion (AIC). All analyses were conducted in R (R Core Team 2014), with additional functions provided by the packages lme4 and nlme.

\subsection{Results}

\subsubsection{Household survey: trees}

For almost half of the sampled oil palm plantations (47.9\%) trees were reported by the respondents. 1843 trees were recorded on all plots in total. The five most common tree species in the oil palm plantations were rubber Hevea brasiliensis $(\mathrm{N}=1495)$, banana Musa spec. $(\mathrm{N}=120)$, durian Durio zibethinus $(\mathrm{N}=46)$, langsat Lansium domesticum 
$(\mathrm{N}=42)$ and alstonia Alstonia scholaris $(\mathrm{N}=30)$, which account for $94 \%$ of the total number of trees. Some other species occurred infrequently; overall 35 species of trees were found. Of those, 19 tree species could be classified as fruit trees and 15 tree species as timber trees (and rubber). When considering only the plantations with trees, on average $1.9286(\mathrm{SD}=0.1817)$ different tree species were cultivated, indicating a rather low level of tree species diversity. Even though the number of trees and the number of tree species are significantly correlated, the strength of the relationship is relatively weak (Pearson's $r=0.31$ ). Respondents indicated that $85.8 \%$ of the trees were planted, while the remaining $14.2 \%$ are remnants from former cultivation systems. Unfortunately, the data does not contain information on the age of the trees to assess whether the trees were planted before or after the establishment of the oil palm plantation. With respect to the management of the trees, results revealed that $40 \%$ of the trees were pruned, herbicides were applied to $27.9 \%$ of the trees and only $2.7 \%$ of the trees received fertilizer application. Manure and pesticides were not used.

\subsubsection{Bird species composition and abundance}

727 birds of 33 species were detected across all plots within a $25 \mathrm{~m}$ radius around the centre point of each plot. The Yellow-Vented Bulbul Pycnonotus goiavier was the most common species $(\mathrm{N}=197)$, followed by the Olive-Winged Bulbul Pycnonotus plumosus $(\mathrm{N}=156)$ and the Bar-Winged Prinia Prinia familiaris $(\mathrm{N}=127)$. There was one observation of the Green Iora Aegitina viridissima, which was the only recorded species listed as "nearly threatened" according to the IUCN. All other recorded species are listed as "least concern" (IUCN 2014) (Table S 2.1).

The three most important parameters for explaining variation in bird diversity were number of trees, height of ground vegetation and whether or not high quality oil palm seedlings (Marehat) were planted on the plot, as depicted in Table 2.2. The number of trees and height of ground vegetation had a positive effect on species richness, whereas the presence of high quality seedlings had a negative effect on species diversity. Similar results were found for bird abundance, which was also positively affected by number of trees and height of ground vegetation. However, the 
Marehat variable did not enter the model. Instead, the number of oil palms was included and had a negative effect on the number of bird observations.

Table 2.2: Coefficients of variables $( \pm \mathrm{SE})$ included in the bird and economic models.

\begin{tabular}{|c|c|c|c|c|}
\hline & Bird species & Bird abundance & Yield & Revenue \\
\hline Village & random effect & random effect & random effect & random effect \\
\hline \multicolumn{5}{|l|}{ Number of trees } \\
\hline $\begin{array}{l}\text { (ecology models, } \\
\text { positive input) }\end{array}$ & $0.243 \pm 0.059$ & $0.277 \pm 0.093$ & - & - \\
\hline \multicolumn{5}{|l|}{ Number of trees } \\
\hline $\begin{array}{l}\text { (economic models, } \\
\text { negative input) }\end{array}$ & - & - & $0.404 \pm 0.053$ & $0.256 \pm 0.143$ \\
\hline Number of oil palms & - & $-0.205 \pm 0.099$ & - & - \\
\hline Forest border & - & - & - & - \\
\hline Shrubs & - & - & $-0.068 \pm 0.049$ & - \\
\hline $\begin{array}{l}\text { Height ground } \\
\text { vegetation }\end{array}$ & $0.144 \pm 0.056$ & $0.194 \pm 0.097$ & $-0.123 \pm 0.051$ & $-0.131 \pm 0.052$ \\
\hline Age of oil palm & & & $1.247 \pm 0.272$ & $1.655 \pm 0.299$ \\
\hline $\begin{array}{l}\text { (Age productive oil } \\
\text { palm) } 2\end{array}$ & - & - & $-1.016 \pm 0.271$ & $-1.226 \pm 0.297$ \\
\hline Quantity of fertilizer & - & - & & - \\
\hline Value of herbicides & - & - & - & - \\
\hline Labour hours & - & - & $0.309 \pm 0.053$ & $0.344 \pm 0.056$ \\
\hline Marehat & $-0.227 \pm 0.141$ & - & $0.212 \pm 0.127$ & - \\
\hline
\end{tabular}

The predicted bird diversity conditional on the number of trees ranged from 2.58 species $(\mathrm{N}$ tree ha-1 $=0)$ to 5.15 species $(\mathrm{N}$ tree ha-1 $=125)$ (Figure 2.2 a). Predicted sums of bird observations ranged from 3.66 individuals $(\mathrm{N}$ tree ha-1 $=0)$ to 8.05 individuals ( $\mathrm{N}$ tree ha-1 $=125$ ) (Figure $2.2 \mathrm{c}$ ). Bird diversity and the sum of bird observations showed a positive nonlinear response to an increase in the number of trees (Figure 2.2 a and Figure $2.2 \mathrm{c}$ ), with a decrease in the marginal effect of trees on bird diversity and abundance, respectively, with increasing number of trees (Figure $2.2 \mathrm{~b}$ and Figure $2.2 \mathrm{~d}$ ). This implies that a further increase in the number of trees in a plantation with low numbers of remnant or planted trees has a larger effect on bird 
diversity and abundance than the same increase in the number of trees on an oil palm plot with high numbers of remnant or planted trees.
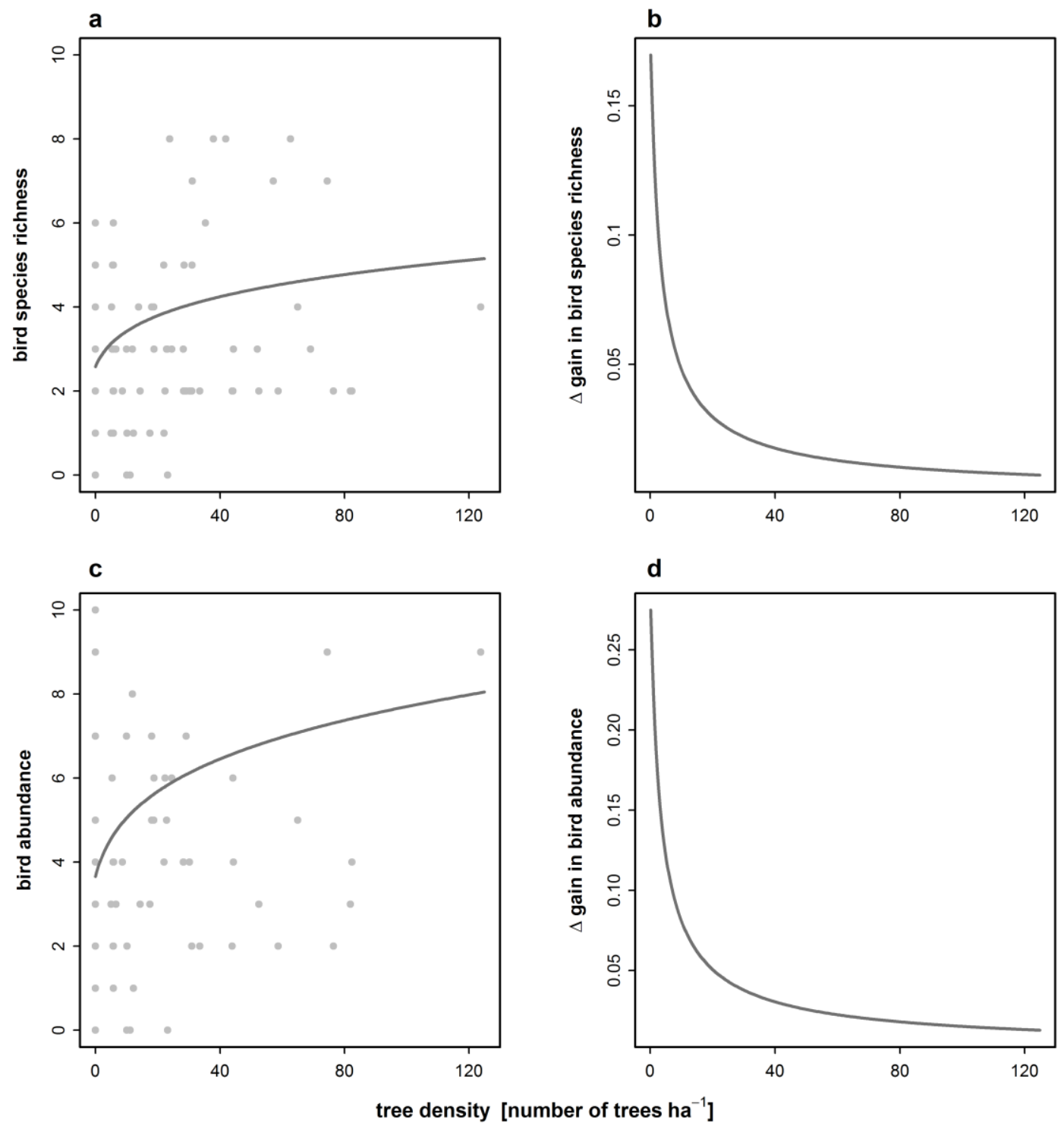

Figure 2.2: Effects of trees within oil palm plantations on bird species richness (a), as well as bird abundance (c). The marginal gain in bird species (b) and bird abundance conditional on the number of trees are given. Grey dots indicate original observations.

\subsubsection{Determinants of yields}

As expected, yields were highest at intermediate oil palm age, as both the age of the oil palm plantation and its squared value were significant in the best model, as depicted in Table 2.2. Oil palm yields were positively affected by the amount of labour hours 
(family and hired labour hours) spent on weeding of ground layer vegetation and epiphytes, herbicide, fertilizer and soil amendment applications and harvesting. The cultivation of Marehat clones (improved oil palm seedlings) positively affected oil palm yields. Further management parameters such as the amount of applied fertilizers and the value of applied herbicides did not enter the best model. Yields were not affected by landscape variables, such as the dummy for neighbouring forest patches, which was not considered in the best model. In contrast, both variables capturing the habitat complexity determined the yields of the oil palm plantation; the height of the ground vegetation layer and the number of shrubs $>1.5 \mathrm{~m}$ negatively affected the yields. We found the number of trees within or at the border of the oil palm plantation to negatively affect yields, too. The predicted oil palm yields conditional on the number of trees ranged from 11.15 ton ha-1y-1 ( $\mathrm{N}$ tree ha-1 = 0$)$ to 1.80 ton ha-1y-1 ( $\mathrm{N}$ tree ha$1=125$ ) (Figure $2.3 \mathrm{a}$ ). Testing for the functional form of the relation between yields and number of trees, results indicated that the predicted yields conditional on the number of trees follow a non-linear pattern, with an increase of the marginal effect of trees on yields with increasing numbers of trees.

\subsubsection{Trees and revenue}

To test whether or not the benefits generated from trees compensated for the loss in oil palm yield, we tested the effect of the set of predictors on total revenue (US\$ ha-1y-1) (Phalan et al. 2011b). Again, results outlined in Table 2.2 revealed that the total revenue was highest at intermediate age of the oil palm as both, the age and the squared term of age, entered the model. Similar to yields, revenue was not affected by neighbouring forest patches, the amount of applied fertilizer or the value of applied herbicides. Revenue was positively affected by the amount of labour hours (considering family and hired labour hours) and negatively by height of ground vegetation, being one of the proxies for habitat complexity As opposed to the yield model, the cultivation of Marehat clones and shrubs were not important parameters to explain variation in revenue. Again, we found that the number of trees within or at the border of the oil palm plantation negatively affected the total revenue. The predicted revenue conditional on the number of trees ranged from 1010.83 US\$ ha-1y-1 (N tree ha-1 = 0) to 222.87 US\$ ha-1y-1 ( $\mathrm{N}$ tree ha-1 = 125). Similar to the functional form of the 
production function for yield, the relation between predicted revenue and number of trees is non-linear, with an increase in the marginal effect of trees on predicted revenue with increasing tree stands (Figure $2.3 \mathrm{~b}$ ).

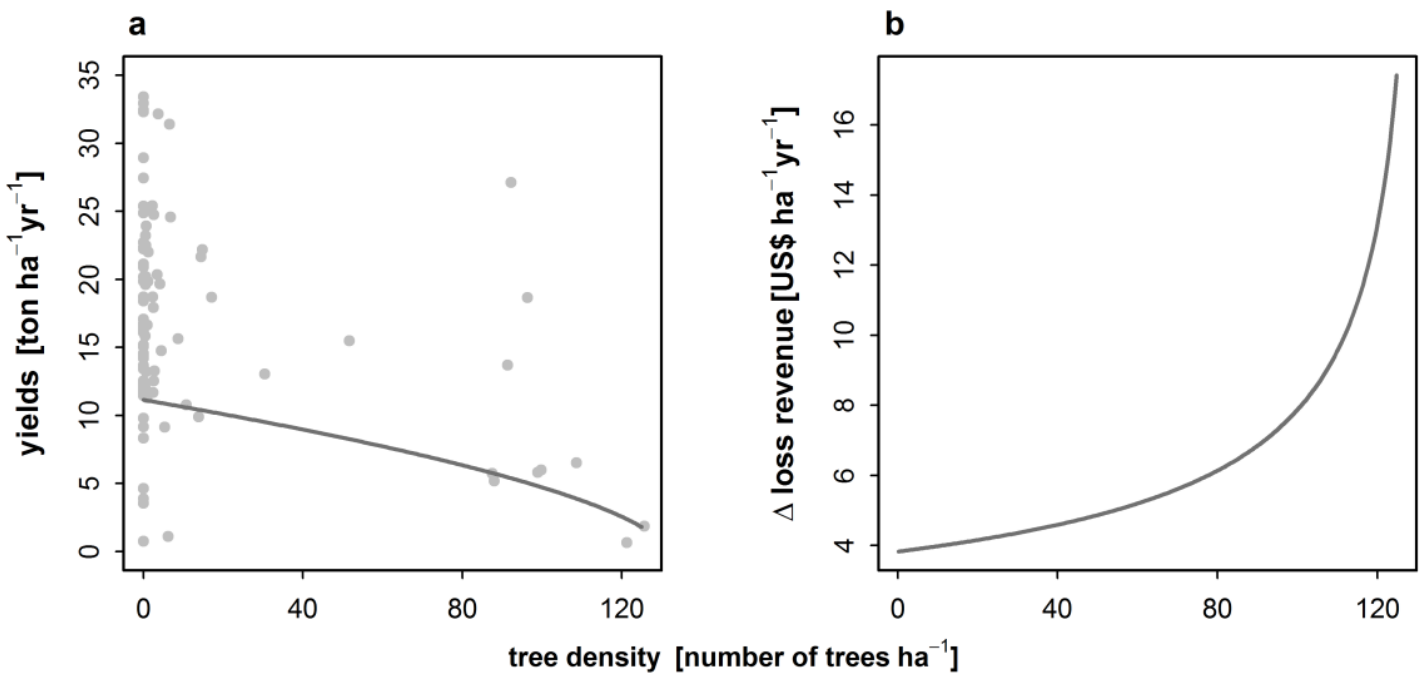

Figure 2.3: Effects of trees within oil palm plantations on oil palm yields (a). The marginal loss in revenue (b) conditional on the number of trees are given. Grey dots indicate original observations.

\subsubsection{Bird diversity and abundance - revenue relationship}

The predicted bird diversity and the predicted revenue can be defined as a "yield set", since both outcome variables can be parameterized with respect to trees (Perfecto et al. 2005). The functional form of the "yield set" revealed a trade-off between the revenue and the bird diversity (Figure 2.4 a). Thus, the bird diversity loss can only be mitigated at the cost of revenue. It implies that external incentives have to be provided to encourage profit-maximizing farmers to conserve (Kragt \& Robertson 2014). The slope, also called marginal rate of transformation (MRT), measures how much of revenue is given up for one more unit of bird diversity or vice versa. It also reflects the (marginal) shadow prices of bird diversity (the shadow prices of bird diversity in terms of revenue at the margin). The "yield set" curve is convex, indicating that the MRT increases with increasing revenue (agricultural intensification). Given a relatively extensively managed oil palm plantation (high number of trees, low revenue), a further increase in number of bird species leads to a distinct loss in revenue. In contrast, given a relatively intensively managed oil palm plantation (relatively low number of tree 
stands and high revenue), the same increase in number of bird species results in a smaller revenue loss. Thus, up to a certain level of intensification, bird diversity shows a relatively low sensitivity to an increase in intensification.

Similar results were found for the bird abundance - revenue relationship. There was also a trade-off between bird abundance and revenue (Figure $2.4 \mathrm{c}$ ) with distinct losses in revenue when bird abundance is increased on relatively extensively managed oil palm plantations and only small losses in revenue with increases in bird abundances on intensively managed plantations. However, in general, the revenue loss for additional bird individuals is smaller than for additional bird species, meaning that for the same amount of funds more individuals could be locally conserved compared to species.

\subsubsection{Marginal shadow price of bird species richness and abundance - tree relationship}

To evaluate potential target groups of conservation programs that aim to foster bird diversity and abundance by giving external incentives to establish or expand the number of trees within oil palm plantations, we illustrate the marginal loss in revenue with every unit increase in bird diversity (Figure $2.4 \mathrm{~b}$ ) and bird abundance (Figure $2.4 \mathrm{~d}$ ) conditional on the trees within or at the border of the oil palm plantation. Results revealed that the marginal loss in revenue induced by a one unit increase in bird diversity, and hence the shadow price of bird diversity expansion, increases with increasing numbers of trees (extensification of oil palm cultivation). We calculated the percentage of revenue that has to be given up for an additional bird species exemplified for a plantation with 10 and 50 trees per ha, respectively. A farmer that has ten trees within his/her plantation experiences a $20 \%$ loss of total revenue for an additional bird species, whereas on a plantation with 50 remnant or planted trees the same increase in bird species results in a $67 \%$ loss of total revenue. Similarly, for every unit increase in bird abundance, the marginal loss in revenue increased with increasing number of trees. However, a farmer that has ten trees within his/her plantation experiences a $12 \%$ loss of total revenue for an additional bird individual, whereas on a plantation with 50 remnant or planted trees the same increase in bird individuals results in a $39 \%$ loss of total 
revenue. This shows, that an increase in bird abundance can be enhanced at smaller costs when compared to the costs for increasing bird diversity.
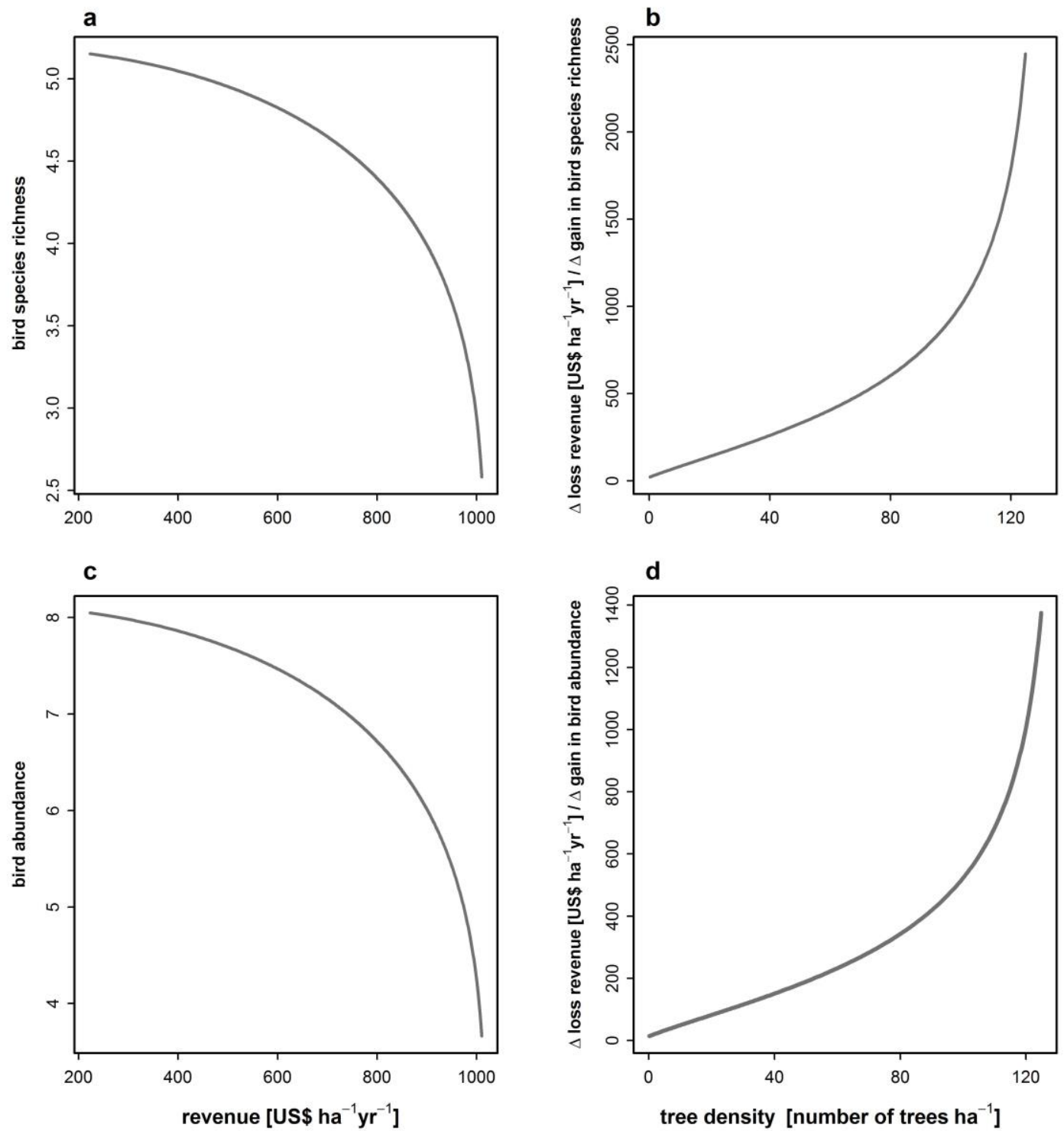

Figure 2.4: Relationship between predicted revenue and predicted bird diversity (a) and predicted bird abundance, respectively (c). Marginal loss in revenue with every one-unit change in bird diversity (b) and bird abundance (d), respectively, conditional on the tree stands within or at the border of the oil palm plantation. 


\subsection{Discussion}

Forests and traditional cultivation systems with a high degree of habitat complexity in Southeast Asia are being converted to oil palm plantations at high rate and there is growing interest in oil palm agriculture in other tropical regions, such as South America and Western Africa. Besides the obvious need to conserve large expanses of natural habitats, this raises the question on how to maintain a baseline level of biodiversity in oil palm-dominated landscapes. Focusing thus on a "wildlife-friendly" strategy of having remnant or planted trees within or at the border of oil palm plantations, we investigated the relationship of bird diversity and bird abundance with oil palm yields and total revenue along a gradient from low-intensity oil palm plantations enriched with trees to intensively managed mono-cultural oil palm plantations. Consistent with our expectations, we found a win-lose relationship between these ecological and economic functions indicating that a gain in bird diversity and bird abundance conditional on an increase in the number of trees comes along with a loss in revenue for farmers. It implies that profit-maximizing farmers do not have a private incentive to conserve. However, incremental increases in bird diversity and bird abundance come at different costs depending on the initial number of trees (and therefore the initial level of bird species diversity or bird abundance).

Overall, our study confirmed that bird communities supported by oil palm plantations are extremely impoverished in comparison to natural forests (Peh et al., 2006). Only a few common and widespread species are found in this type of habitat and there is a loss of species with high conservation status and restricted ranges. We observed one forest species and five edge-tolerant species besides mostly edge-tolerant, open habitat and generalist species (for definitions see Rotenberg and Stouffer, 2007) (see Table S 2.1). With one exception, all sampled bird species had low conservation status. Oil palm sites, however, differed significantly in their bird diversity and abundance depending on the vegetation in the plantation.

Even though oil palm plantations are often pure monocultures, especially in large estates (Foster et al., 2011), almost half of the sampled smallholder oil palm plantations had remnant or planted trees on them, and varying levels of ground vegetation. We found that the number of trees and the height of ground vegetation were important 
parameters in explaining variation in bird abundance and species richness. Structural complexity is in general known to positively affect avian community structure (Tews et al. 2004; Gordon et al. 2007; Van Bael et al. 2007; Stein, Gerstner \& Kreft 2014). Azhar et al. (2011) showed that oil palm plantation estates and smallholdings supported similar bird assemblages, but the latter supported slightly more species due to higher complexity of vegetation structure compared to a typical mono-cultural plantation estate. However, our findings suggest that large-scale plantations could also create similar situations like in smallholdings by planting trees for conservation outcomes. A positive effect of trees on bird diversity was also found in the studies by Abrahamczyk et al. (2008) and Clough et al. (2009), where cacao plantations in Sulawesi, Indonesia, with interspersed trees harboured more bird species than plantations without trees. On oil palm plantations in Thailand, Peninsular Malaysia and Guatemala bird species richness was enhanced by a well-developed understory vegetation (Aratrakorn et al., 2006; Azhar et al., 2011; Nájera and Simonetti, 2010). While we observed a considerable range in density of different fruit and timber trees (0-314.7 trees ha-1 (trees $>2 \mathrm{~m})$ ), the average number of tree species per hectare was low compared to traditional agroforestry crop plantations, such as coffee and cacao, where tree abundance and diversity can be much higher (8-128 trees h-1 (trees >10m); 12-104 tree species ha-1) (e.g., Clough et al., 2009). In our study, bird diversity and abundance showed a positive non-linear response to increasing numbers of remnant or planted trees. With increasing numbers of trees, however, there was a decreasing marginal effect of trees on predicted bird diversity and abundance.

In line with findings by Azhar et al. (2011), landscape-level attributes such as small secondary forest patches bordering the oil palm plantation, which we included as a landscape parameter, did not explain any variation in bird diversity and abundance in our study. This may be attributed to the low dependency of the majority of bird species (non-forest species) in oil palm plantations on forest habitats and resources as they find food within the plantations (Azhar et al. 2013), and the limited value of neighbouring small secondary forest patches as a source habitat for birds. The study region is characterized by highly isolated forest fragments in wide areas of homogenous oil palm monocultures. Harapan rainforest and the National Park Bukit Duabelas are the only two significant forest areas left in the study area and are not bordering the study sites. 
While the number of trees benefited bird diversity and bird abundance, they negatively affected oil palm yields. Assuming that trees within or at the border of the oil palm plantation compete with oil palm for nutrients and light, we included the tree variable in the economic models as a negative input. Indeed, controlling for management practices, landscape, and habitat complexity, the results of the analyses showed that the oil palm yield (ton ha-1 y-1) decreased with increasing number of remnant or planted trees within or at the border of the oil palm plantation. Results indicated that the predicted yield conditional on the number of trees follow a non-linear pattern, with an increase of the marginal effect of trees on predicted yields with increasing numbers of trees. This is in accordance with findings by Corley and Tinker (2003) who stated that oil palm productivity is low when they are shaded by trees (also see Phalan et al., 2009). Oil palm, as a water-demanding plant with high light requirements would likely face intensive competition with intercropped trees for water, nutrients and light (Koh et al., 2009).

The use of a proxy measure for yields such as management intensity indices (e.g. number of trees) would not give the quantitative information on yields necessary to assess the trade-off between economic outcome and bird diversity (Phalan et al., 2011a; Steffan-Dewenter et al., 2007).

Since the economic outcome generated from the remnant or planted trees may compensate for the oil palm yield penalties, we considered the total revenue including the opportunity costs of fruit and timber products consumed by the household, even though this measure is affected by market fluctuations (Phalan et al., 2011a). The predicted total revenue also decreases with increasing number of trees within or at the border of the oil palm plantation (with increasing marginal loss in revenue).

\subsubsection{Implications for conservation}

The win-lose trade-off between the bird diversity and total revenue conditional on the number of remnant or planted trees within or at the border of the oil palm plantation implies that profit-maximizing farmers do not have, at least in economic terms, a private incentive to mitigate bird diversity loss by extensifying the oil palm cultivation. As in Europe, where land-sharing is encouraged by agri-environment payments for 
farmers (Kleijn et al. 2006), one could imagine that economic incentives could be implemented to foster the extensification of oil palm cultivation in terms of increasing the number of trees. The marginal loss in revenue with every unit increase in bird diversity conditional on the number of trees within or at the border of the oil palm plantation follows a positive non-linear pattern. Thus, with increasing extensification of the oil palm plantation in terms of the number of trees, the loss in revenue per additional bird species increases suggesting that conservation measures are relatively cheap at low abundances of trees within a plantation. While farmers of a rather intensively managed oil palm plantation (e.g. 10 trees per ha) lose $20 \%$ of their total revenue per additional bird species, farmers, who already harbour many trees (e.g. 50 trees per ha) on their oil palm plantation lose $67 \%$ of the total revenue per additional bird species. Similar results were found for bird abundance, but the loss in revenue per additional bird individual is in general lower than for an additional bird species. On an intensively managed oil palm plantation with 10 trees per ha the farmer experiences a loss in revenue of $11 \%$; farmers of extensively managed oil palm plantations with 50 trees per ha lose $39 \%$ of their revenue. Given a fixed conservation payment, farmers of highly intensified oil palm plantations with no or few trees therefore have a relatively strong incentive to expand the number of trees within the oil palm plot compared to farmers of already extensively managed oil palm plantations with many trees on the plot. In fact, the absolute number of bird individuals and bird species would still be lower in relatively intensive plantations with only a few trees compared to a more extensive plantation with more trees to start with. But even a slight increase in bird abundance on intensively managed plantations might already contribute to the system being more stable and resilient towards disturbance or pests due to increased ecosystem functioning and provision of ecosystem services such as pest control and soil fertility. Interestingly, such a gain in ecosystem functioning may exceed the associated increase in diversity (Barnes et al. 2014b). Future studies need to address whether or not an increase in bird diversity also results in higher ecosystem functioning.

To compensate for a revenue loss associated with the increased abundance of trees within the oil palm plantation, both, the implementation of a premium price for eco-friendly certified palm oil products and relevant extension services financed through national or international environmental funds, are potential solutions. The 
rising public debate about the social and environmental impacts of oil palm cultivation prompted the establishment of the Round Table on Sustainable Palm Oil Production (RSPO, 2014). The RSPO certification requirements cover a range of sustainability criteria, such as controlling of soil erosion, groundwater and chemical pollution. However, specific certification schemes requiring foliage cover, tree height and diversity, like in the SMBC (Smithsonian Migratory Bird Centre) bird friendly coffee certification scheme, do not exist for palm oil. In Europe, palm oil, as the "secret in the shopping basket" has often been hidden as generic vegetable oil in processed food (Paddison 2014). In 2014, the EU launched the law on food information to consumers (FIC), determining that hiding ingredients under generic titles is no longer permitted. Whether the labelling of palm oil translates into a change in consumer preferences towards more eco-friendly produced palm oil products still remains to be seen (Smedley, 2014).

Critics of wildlife-friendly interventions argue that they tend to reduce actual or potential farmland yields compared to conventional farming and thereby increase encroachment on natural habitat (Donald 2004; Green et al. 2005; Clough et al. 2011; Phalan et al. 2011b; Tscharntke et al. 2012b). Indeed, in the majority of management intensity gradients ranging from no or minor management to high management intensity, biodiversity declines steeply in response to a slight increase in intensification (with a decreasing marginal rate of substitution), indicated by a concave function. It implies that the target species would benefit more from land-sparing associated with maximum attainable yield agriculture than from land-sharing (Phalan et al. 2011a; b; Baudron \& Giller 2014). This shape holds for multiple taxa in Europe and the tropics (Gabriel et al., 2013; Hulme et al., 2013; Phalan et al., 2011b; Kleijn et al., 2009). Of course, also in our study region, large differences in bird diversity and abundance between forests and oil palm plantations suggest that when having to choose between diversification of oil palm and forest conservation (and assuming both are effective), the latter would be a more efficient way to maximise crop production and species conservation. The degree to which both the causal linkages (lower yields encroachment on natural habitat) implicit in the models as well as the model assumptions hold, and whether the focus on two desired outcomes rather than a breadth of ecosystem services is relevant for resource management and policy, are issues 
severely debated elsewhere (Baudron and Giller, 2014; Tscharntke et al., 2012b; Phalan et al., 2011a; Koh et al., 2009). The debate suggests that oil palm diversification, such as the maintenance of trees in oil palm plantations, while not an alternative to conserving forests, should not be rejected a priori.

Interestingly, our results show that farmer choices are not governed purely by economic considerations: although yield and revenue were negatively affected by density of trees on the plantation, a significant part of the smallholders have either implicitly or explicitly chosen to keep and/or plant trees on their plantation, despite the likely perceived standard of oil palm management as a pure monoculture, which can be easily observed on nearby estate plantations. In this study, long-term resilience, as opposed to short-term yield maximization, was not considered as an economic objective, even though it might be pursued by risk-averse decision-makers. In our rather simplistic approach, other factors, such as cultural services (spiritual enrichment, recreation and aesthetic experiences), are also neglected (Kragt \& Robertson 2014). Further progress on understanding farmer choices and value systems is critical to inform possible conservation actions.

Further research is needed to provide more specific recommendations on how to design potential oil palm plantations with high habitat complexity provided through the presence of trees and a well-developed ground layer vegetation. While this study investigated the effect of the presence of remnant or planted trees on bird diversity and abundance as well as on yields and revenue, we did not distinguish between remnant and planted trees, fruit trees and other trees nor was the size structure of trees considered. Other studies suggest that factors such as tree age, tree diversity, presence of specific functional groups of trees or tall trees, are decisive when it comes to associated animal diversity (Kanowski et al. 2003; Erskine, Lamb \& Bristow 2005; Clough et al. 2011). To test the effect of tree species diversity, size structure and composition on biodiversity and oil palm yields, a long term biodiversity enrichment experiment which systematically alters tree species richness and composition and the size of tree islands was established in the same region (Jambi Province, Sumatra, Indonesia). Monitoring the growth of trees, oil palm yield, bird and invertebrate diversity and abundance, this will allow us in the near future to address questions 
regarding the planting strategy under which biodiversity and ecosystem functions can be restored - which includes choosing the appropriate tree species for habitat enrichment - and how the economic functions of an oil palm plantation are affected by different types of enrichment plantings.

\subsection{Conclusion}

Our study confirmed that bird communities supported by oil palm plantations are extremely impoverished in comparison to natural forests. Nevertheless, the restoration of wildlife-friendly oil palm plantations associated with higher structural complexity can mitigate the loss of bird diversity with respect to edge-tolerant, open habitat and generalist species. Furthermore, we found a positive relationship between bird abundance and tree density. Thus, a slight increase in bird abundance on intensively managed plantations might already increase ecosystem functioning and provision of ecosystem services such as pest control and soil fertility. Studies, which investigate the ecological role of birds in oil palm plantations by identifying and analysing functional groups separately, are hence needed. The negative revenue - bird diversity and revenue - bird abundance relationship, respectively, suggests that profit-maximizing farmers do not have an incentive to establish or restore wildlife-friendly oil palm systems. However, since the relationship is non-linear, in a relatively extensively managed oil palm plantation (high number of trees, low oil palm yields), a further increase in the number of bird species and bird individuals leads to a relatively high loss in revenue, whereas in an intensively managed oil palm plantation the same increase in number of bird species and individuals results in a smaller loss in revenue. This indicates that there is room for tree-based enrichment of intensively managed oil palm plantations, where a relatively high increase in bird species richness and bird abundance could be achieved at relatively low cost. 
Chapter 2: Trade-offs between ecology and economics in oil palm landscapes

\subsection{Acknowledgements}

We thank all the farmers who gave permission to conduct fieldwork on their land. We also thank Lena Rohde, Dadang Dwi Putra, Viverani Desmera and Zulfi for helping with the fieldwork. Ana Meijede provided climate data for the study region. Logistical support was provided by the EFForTS staff and coordination. This study was financed by the Deutsche Forschungsgemeinschaft (DFG) in the framework of the collaborative German-Indonesian research project CRC990. 




\section{Chapter 3: Biodiversity enrichment in oil palm landscapes: A tree planting experiment in Sumatra (Indonesia)}

\subsection{Abstract}

Tropical biodiversity is threatened by the expansion of oil palm plantations. Buffer zones around plantations such as agroforestry systems, have been proposed to increase biodiversity and ecosystem functioning. In regions where plantations already dominate the landscape, this can only be achieved through systematic restoration. However, our knowledge about underlying ecological and socio-economic processes, constraints and trade-offs is very limited and clear instructions for restoration towards a wildlifefriendly management are lacking. Here we present a large-scale, long-term biodiversity enrichment planting experiment. We planted tree islands in an oil palm plantation and systematically varied tree island size, tree species richness, and tree species composition. We describe the environmental (soil, climate, topography, light availability) and biotic (associated vegetation, invertebrates, birds) characteristics of the experimental site prior to the establishment of the experiment and first effects on the faunistic diversity. Already one year after the establishment of the experiment, tree plantings had an overall positive effect on the bird and invertebrate communities on the landscape scale. Moreover and on a local scale, we found the size of tree islands to be positively related to the diversity and abundance of invertebrates. The biodiversity enrichment experiment provides the basis for further research projects to uncover the ecological and economic long-term mechanisms associated to enrichment plantings. With the results of the experiment we aim on evaluating the effectiveness of the enrichment plantings as part of the proposed designer plantation landscapes and develop clear restoration instructions to realize a more sustainable management of oil palm. 


\subsection{Introduction}

A major driver of the current biodiversity crisis in tropical South-East (SE) Asia is the large-scale transformation of natural rainforest into simplified production systems such as oil palm (Fitzherbert et al. 2008; Immerzeel et al. 2014). In consequence of the resulting dramatic losses of biodiversity, losses in ecosystem functioning of species communities are expected (Sodhi et al. 2004; Wilcove et al. 2013; Edwards et al. 2014) that can even disproportionally exceed the decline in species diversity (Barnes et al. 2014b). This puts also a risk on human well-being as ecosystems are being degraded, leading to e.g. decreased pollination success, insufficient provision of goods, or impairment of soil and water quality (Cardinale et al. 2012).

Besides the importance of protecting primary and secondary tropical forests for biodiversity conservation, integrating biodiversity conservation and ecosystem restoration into management of existing large scale oil palm plantations seems reasonable (Koh et al. 2009; Luskin \& Potts 2011; Foster et al. 2011; Teuscher et al. 2015). Designer plantation landscapes in which agroforestry zones buffer the natural vegetation from mono-culture plantations have been proposed as a means to maintain livelihood needs while increasing biodiversity and ecological functions (Koh et al. 2009). By adopting this strategy for enhanced habitat complexity, the negative environmental impacts of intensively managed cash-crop production systems such as oil palm could be mitigated. However, in a region where forest is nearly eradicated (Margono et al. 2014) and where the diversity of the species communities in the agrarian landscape is declining (Fitzherbert et al. 2008) with an increase of area under oil palm monocultures (Euler et al. 2015; Gatto, Wollni \& Qaim 2015), it is too late for reasonable landscape planning right from the beginning. Restoring habitat heterogeneity at the local and landscape levels is highly recommended in oil palm landscapes to maintain or even enhance biodiversity (Azhar et al. 2011) but currently institutions like the 'Roundtable for Sustainable Oil Palm' (RSPO) rather focus on nondeforestation policy, conservation of large expanses of high valuable habitat, and threatened species (RSPO 2013). 
From a restoration point of view, planting native trees has been considered an important measure to accelerate natural succession towards forests or agroforests (Chazdon 2008b). Tree island plantings as nuclei for natural succession have been proposed to initiate a cascading process in the surroundings (Corbin and Holl, 2012; sensu Yarranton and Morrison, 1974). Such nuclei were found to have similar effects on biodiversity compared to plantation-style restoration plantings but are more economic (Zahawi et al. 2013). Even small tree islands can act as „recruitment focie as they increase the bird activity, which contributes to elevated seed rain (Cole, Holl \& Zahawi 2010). Furthermore, seedling species richness was found to be increased within a short period and seedling establishment was facilitated due to a more favorable microclimate and amelioration of the soil (Zahawi \& Augspurger 2006). Most restoration plantings took place in abandoned agricultural land, pastures or logged forests (Zahawi \& Augspurger 2006; Cole, Holl \& Zahawi 2010; Hector et al. 2011), but tree islands were also suggested to enrich agricultural landscapes (Rey-Benayas et al. 2009). Regarding the size of restoration plantings there is no consensus yet on which is ecologically and economically the most effective. Further research is needed as the approved biogeographic assumptions for marine islands cannot simply be transferred to tree islands (Mendenhall et al. 2014). To our knowledge, restoration efforts have rarely been made while maintaining an existing plantation and, in particular, there is no experience in oil palm landscapes. Furthermore, there is not much experience of oil palm in polyculture (see Box 3.1).

Numerous experiments investigating the relationship between biodiversity and ecosystem functioning (BEF) showed that already few species can have a disproportionaly high impact on ecosystem functioning (Cardinale et al. 2006; Balvanera et al. 2006; Quijas, Schmid \& Balvanera 2010). The saturating relationship between biodiversity and ecological functioning that resulted from BEF experiments in the direction of biodiversity loss (Cardinale et al. 2012) indicates that, if we simply turn the tables and add species to a system that is already extremely depauperate, we can expect a relatively high positive effect on ecosystem functioning, both as the added species directly contribute to enhanced ecosystem functioning and increase the heterogeneity in resources and structure that could attract other organisms (Tews et al. 2004). 


\section{Box 3.1: Oil palm in polyculture}

In West Africa and Brazil, smallholders traditionally practice extensive oil palm-based agroforestry, but this system could economically not compete with the high-productive monocultures in SE Asia. To bridge the income gap until the oil palms start fruiting, oil palm seedlings are intercropped with food crops, e.g. maize, manioc, yam, cocoyam, soy bean and cassava, until the oil palm canopy closes (Okpala 1995; Salako, Lal \& Swift 1995; Erhabor \& Filson 1999; Corley \& Tinker 2003). However, this contributes little to a more heterogeneous structure which would benefit biodiversity (Phalan et al. 2009; Foster et al. 2011). Several experiments investigated services and disservices in permanent polycultures: Enhanced pest attraction harming the oil palms could not be confirmed (Dhileepan 1991). Negative effects due to light competition were reported from oil palm-rubber mixtures (Corley \& Tinker 2003) and oil palm-teak mixtures resulted in oil palm yield depression, whereas an enhanced teak performance could compensate the losses (Chia 2011). No yield depression from oil palms was noticed when intercropped with cacao (Lee \& Kasbi, 1980 (Malaysia), Amoah et al., 1995 (Ghana)). In Nigeria, cacao yields were even higher when planted under oil palms (Egbe \& Adenikinju 1990). In conclusion, negative and positive experiences were made with intercropping oil palms, suggesting that there might be suitable crops to plant with oil palms. More research is needed to identify the right best intercropping scheme, also with regard to possible differences on a regional scale.

Recently, BEF research-insights found their way into restoration ecology (Aerts \& Honnay 2011). Most of the findings related to BEF have been obtained in grasslands outside the tropics and mainly in small-scale studies, but recently, a number of largescale tree planting experiments have emerged (Scherer-Lorenzen et al., 2005; "TreeDivNet", 2015); four tree diversity experiments are located in the tropics (Petit \& Montagnini 2006; Kirui et al. 2008; Potvin \& Gotelli 2008b; Moreira et al. 2014). Results from such experiments suggest that diverse plantings are more beneficial for BEF than monocultures (e.g. Potvin and Gotelli, 2008).

The knowledge gap of the ecological consequences of restoration via enrichment plantings in oil palm landscapes goes along with a lack of experience of the impacts on the local socio-economy. The area under oil palm hold by small-scale farmers is more rapidly increasing than the area under estate (Euler et al. 2015; Gatto, Wollni \& Qaim 2015) meaning that there is a growing number of households depending on palm-oil production. Therefore, it is essential to develop a management strategy that, at least, compensates potential income losses due to restoration plantings and, in the best case, even increase the farmers' income. Crop diversification can act as an insurance for the future, e.g. as a buffer for world-market price-fluctuation, climate change impacts or possible pest attacks (Lin 2011). Additionally, it can have benefits in the short-term, 
e.g. by the provision of raw material or food for self-consumption, or also financially through more efficient use of the available arable land. Further, enhanced biodiversity can improve the provision of ecosystem services that are beneficial to oil palm management. Biological control of pests, pollination as well as litter decomposition (and thus soil fertility) are among the most important ecosystem services for productive oil palm management (Foster et al. 2011) and can directly benefit the farmers' income (Tscharntke et al. 2011). This might raise the willingness to accept and adopt novel management forms and at the same time contribute to a more heterogeneous landscape.

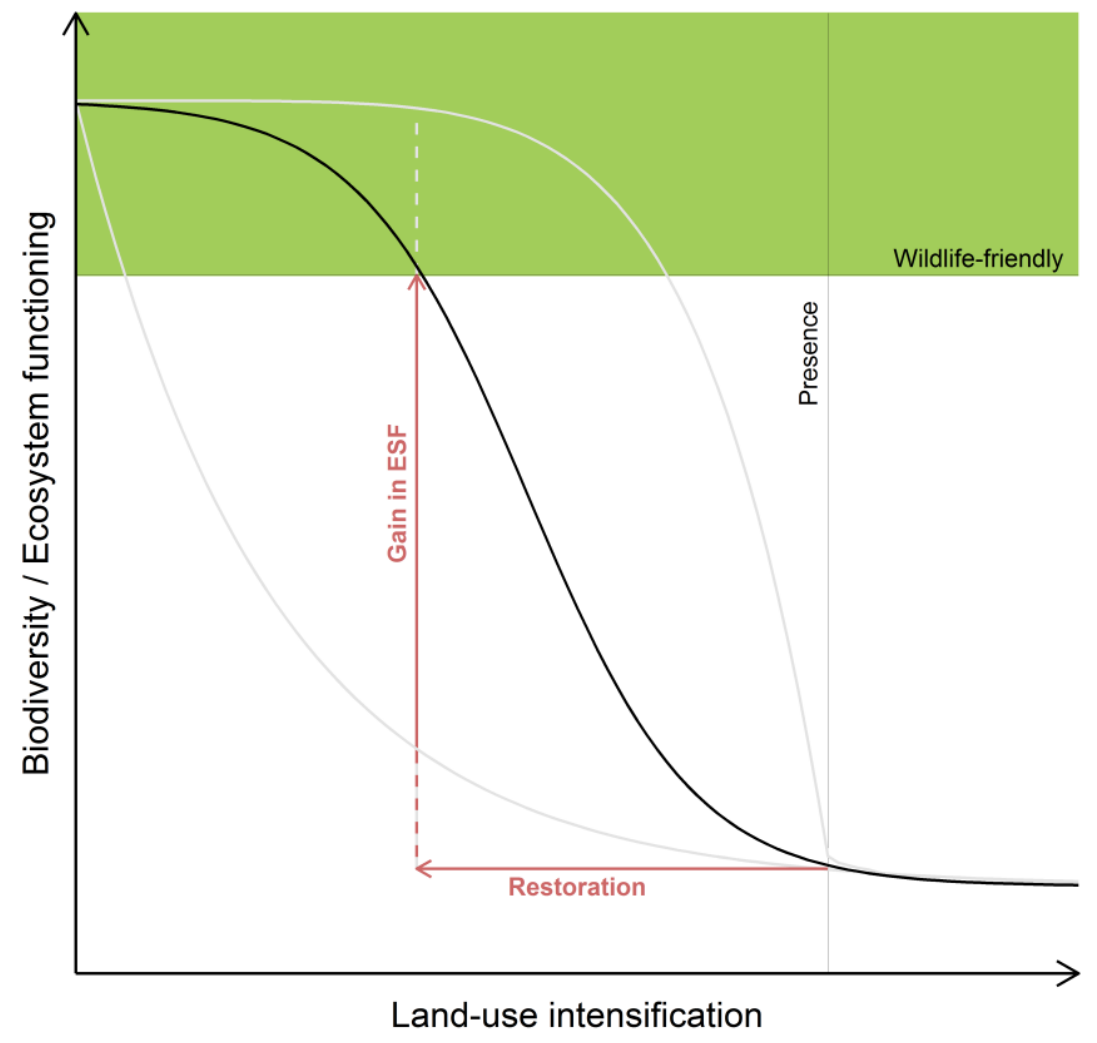

Figure 3.1: A conceptual diagram with possible scenarios of changes in ecosystem functions (ESF) as a consequence of land-use intensification. We assume a negative and non-linear relationship between ecosystem functioning and land-use intensification in the shape of the black line. Consequently, there is space for restoration measures in order to enhance ESF while still allowing for profitable land use. The loss in ESF is supposed to be relatively slow with extensive land use (shaded area) but reaches a critical point once the buffer ability of the ecosystem is exhausted. Further land-use intensification will then result in a severe decline in ESF. The optimal trade-off situation between nature conservation and land use would be when intensification is stopped before the critical point is reached. In the oil-palm-dominated landscapes, however, this optimal point might already be exceeded as biodiversity and ESF are severely degraded in oil palm systems (Barnes et al. 2014b; Dislich et al. 2015; Kotowska et al. 2015). To move back to the optimal point, diverse habitats have to be restored. 
We assume that there is room for restoration plantings that have the potential to help restore biodiversity and ecosystem functions in impoverished landscapes whilst minimizing negative impacts on the local socio-economy (Figure 3.1). Clear implications for restoration of highly intensively managed oil palm systems towards wildlife-friendly and at the same time economically attractive systems, however, are yet to be developed. Several questions have to be considered in this context: How many species need to be planted to significantly gain ecosystem functions? Assuming nonlinear effects due to facilitation or competition among species, which species composition and island size is the most effective? Which strategy results in the best relationship between BEF and socio-economics?

Here, we 1) present the design of a biodiversity enrichment experiment in a mono-culture oil palm plantation 2) measure heterogeneity in the oil palm plantation as a baseline for the experiment 3) describe abiotic and biotic characteristics of the plantation and 4) present first results of the effects of the enrichment plantings on birds and invertebrates one year after the establishment of the experiment.

\subsection{Methods}

\subsubsection{Study site}

The experiment (ca. 140 ha in size) was established on an oil palm plantation owned by PT Humusindo $\left(01.95^{\circ} \mathrm{S}\right.$ and $103.25^{\circ} \mathrm{E}, 46.9 \pm 10.46$ a.s.1. $)$ near the village Bungku in the lowlands of the Jambi province, Sumatra, Indonesia (Figure 3.2). The climate is humid tropical, with a mean temperature of $26.7 \pm 1.0^{\circ} \mathrm{C}$ and an annual rainfall of 2235 $\pm 385 \mathrm{~mm}$ (1991-2011; climate station at the Jambi Sultan Thaha airport of the Meteorological, Climatological and Geophysical Agency). The natural vegetation is dipterocarp dominated lowland rainforest in the centre and peat-swamp forest along the east coast (Laumonier, 1997; Whitten, 2000). Dominant soil types in the Bungku region are loam Acrisols (Allen et al. 2015).

The oil palms on the plantation were planted in the year 2002. The management of the plantation comprises the application of fertilizer and herbicides, regular manual 
weeding of the understory herb layer and removal of the epiphytes. In the center of the experimental area Rambutan trees (Nephelium lappaceum, Sapindaceae) are cultivated as a second source of income. Buffalo and cattle farming are practiced on the plantation, too

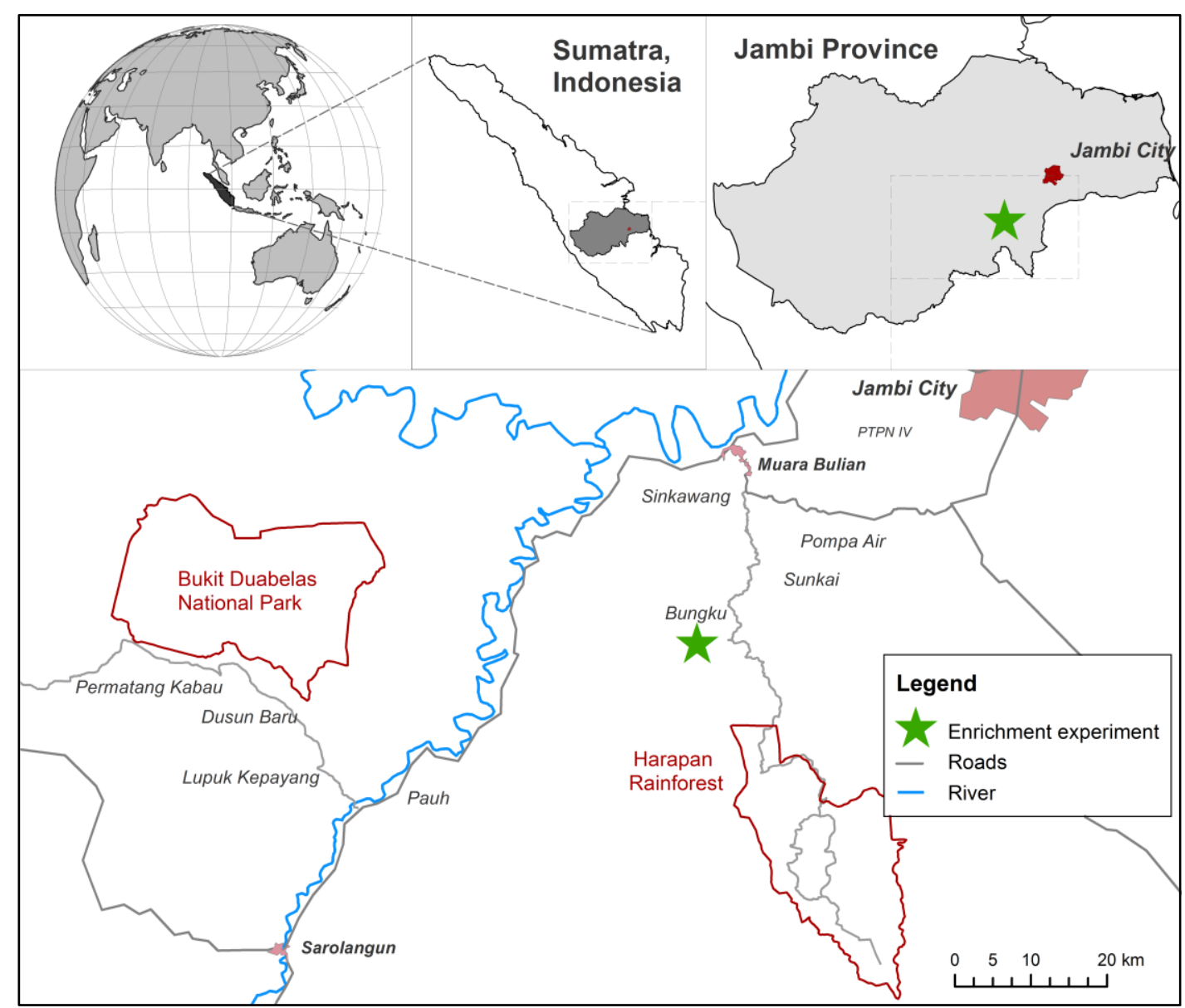

Figure 3.2: Location map of the study area. The green star indicates the location of the study site where the biodiversity enrichment experiment was established.

\subsubsection{The biodiversity enrichment experiment (BEE)}

We established a large-scale, long-term biodiversity enrichment experiment (BEE) within a mono-culture oil palm plantation. Tree islands of varying species diversities and compositions were established. Across experimental plots, we varied the diversity and identity of the tree species planted adopting a random partitions design (Bell et al. 2009) (Figure 3.3 A). The experiment comprises four partitions that differ in their plot size $(5 \times 5 \mathrm{~m}, 10 \times 10 \mathrm{~m}, 20 \times 20 \mathrm{~m}, 40 \times 40 \mathrm{~m})$. Each partition is subdivided into five 
blocks, one per tree diversity level (six, three, two, one, and zero). Within each of these blocks, every species is drawn at random from the species pool without replacement. This means that each species is selected exactly once at each diversity level and species compositions are random, with the restriction that no repetition across all plots was allowed (Table S 3.1). Additionally, there are four control plots without any experimental treatment and management-as-usual. This results in a total of 56 plots (Table S 3.2).

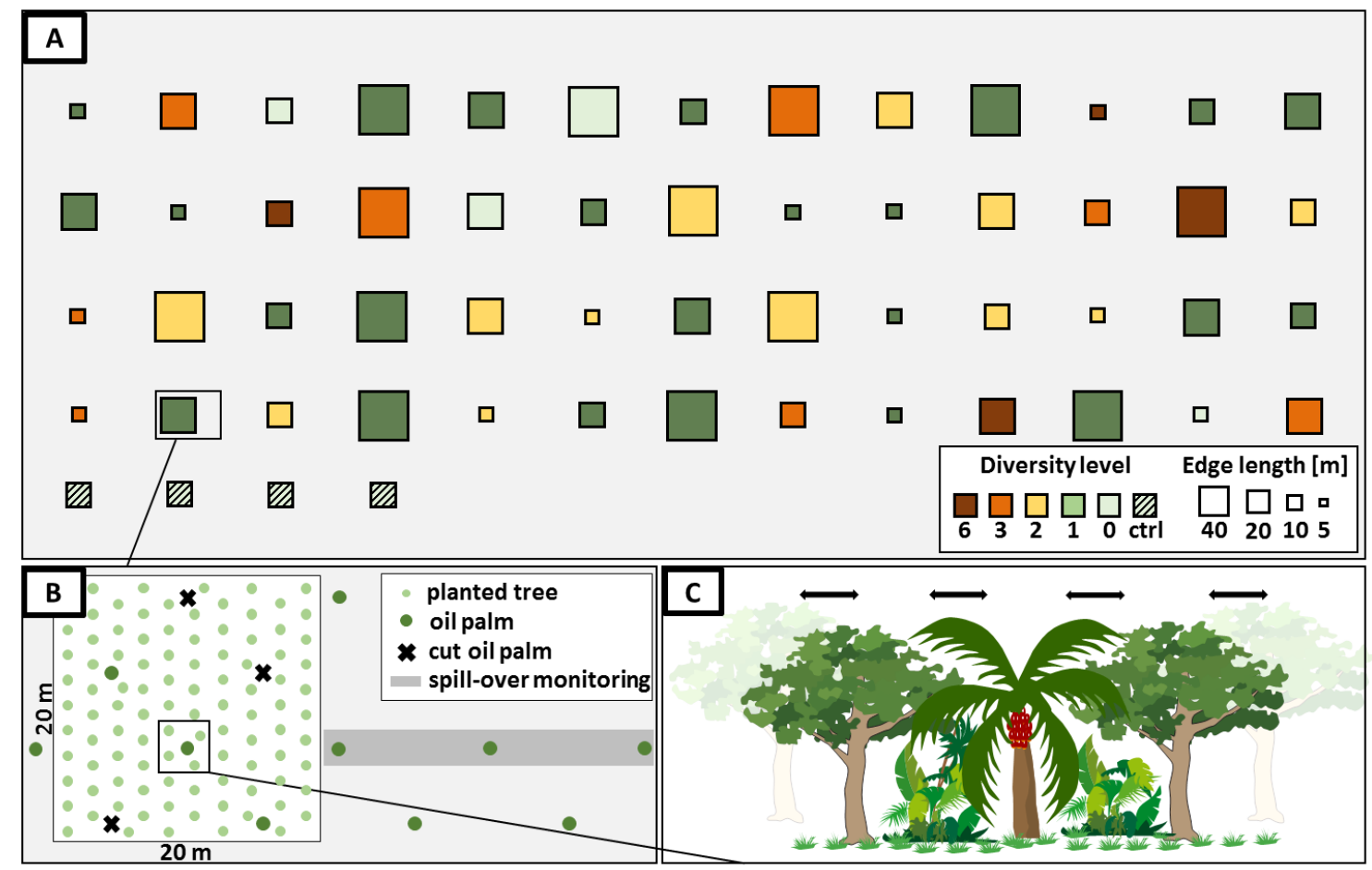

Figure 3.3: A) Design of the biodiversity enrichment experiment (BEE). Tree islands with systematically varying tree species richness (diversity level of 0,1,2,3 and 6), identity and composition as well as plot size (5x5 m, 10x10 m, 20x20 m, 40x40 m) and species composition were established adopting a random partitions design (Bell et al., 2009). Partitions differ in their plot size and are subdivided into blocks of varying tree diversity levels. At each level of diversity, each tree species is represented exactly once. The experiment includes four control plots without treatment and with management-as-usual. In total, the experiment comprises 56 plots. B) Oil palms were cut on the plot with treatments in order to enhance light conditions. Trees were planted in a $2 \times 2 \mathrm{~m}$ grid. Perpendicular to each plot, three oil palms were selected to monitor services and disservices ('spill-over effects') of the tree islands on surrounding oil palms. C) Planted trees interact/compete with each other as well as with the oil palms.

We selected six multi-purpose tree species including three fruit trees (Parkia speciosa, Fabaceae; Archidendron pauciflorum, Fabaceae; Durio zibethinus, Malvaceae), two timber species (Peronema canescens, Lamiaceae; Shorea leprosula, 
Dipterocarpaceae) and one rubber species (Dyera polyphylla, Apocynaceae). The trees are all native to Sumatra and used by local people. The two nitrogen-fixing Fabaceaespecies may further enhance nitrogen availability. To enhance the light availability in the plots with experimental treatment, $40 \%$ of the initial oil-palm-crown cover was reduced by cutting oil palms prior to tree planting (not on the control plots).

Trees were planted in a $2 \mathrm{~m}$ grid in alternating rows in north-south direction. On plots with mixed species, the trees of the same species were planted as far away as possible from one another to avoid clustering of species. We planted six trees on the $5 \times 5 \mathrm{~m}$ plots, 25 trees on the 10x10 m plots, 100 trees on the 20x20 m plots and 400 on the $40 \times 40 \mathrm{~m}$ plots. The total number of planted trees is 6354 . To enhance the establishment success of the trees, we applied organic $(250 \mathrm{~g}$; BIOST: $\mathrm{N}=1.4 \%, \mathrm{C}=$ $\left.12 \%, \mathrm{P}_{2} \mathrm{O}_{5}=1.82 \%, \mathrm{~K}_{2} \mathrm{O}=1.57 \%\right)$ and inorganic $\left(50 \mathrm{~g} ; \mathrm{NPK}\right.$ Mutiara: $\mathrm{N}=15 \%, \mathrm{P}_{2} \mathrm{O}_{5}$ $=5 \%, \mathrm{~K}_{2} \mathrm{O}=6 \%, \mathrm{MgO}=4 \%$ ) fertilizer once when we planted the trees. The management of the experimental plots comprises manual weeding to control weeds that may overgrow the planted saplings, but will be stopped after two years to allow natural succession (Figure 3.3 C). The application of fertilizer, herbicide and pesticides stopped. Fences around all plots protect the trees from feeding damage by mammals. Dead trees were replaced during the first year after establishment.

In order to quantify potential ecological services or disservices from enrichment plantings on the surrounding oil palms, three oil palm individuals in perpendicular direction from the plot are used as indicators (Figure $3.3 \mathrm{~B}$ ). For each oil palm individual yield is monitored. Additionally, the yield of each oil palm individual inside the plot is measured, too.

The monitoring within the framework of the BEE includes monitoring of a) the environment (soil, canopy cover, surrounding matrix), b) plants (tree mortality and growth, understory vegetation, seed rain, herbivory), c) animals (bird and invertebrate community), and d) socio-economics (oil palm yields, benefits from the planted trees, incentive for enrichment planting). 


\subsubsection{Sampling}

The baseline survey of the environment, vegetation, birds and invertebrates was done in October 2013 prior to the establishment of the BEE. One year after the establishment, in October 2014, bird and invertebrate surveys were repeated.

Per plot, soil composites of two depths $(0-10 \mathrm{~cm}$ and 10-30 cm) were taken. Samples were air dried $\left(40^{\circ} \mathrm{C}, 2\right.$ days $)$, grounded and sieved $(2 \mathrm{~mm})$. Soil texture $(20 \mathrm{~g}$ soil) was analyzed using the Pipette Method. Ten grams of dry soil were diluted in 25 $\mathrm{ml} \mathrm{H} 2 \mathrm{O}$ to analyze the $\mathrm{pH}$-value. For bulk density (dry weight $[\mathrm{g}]$ / cylinder volume $\left.\left[\mathrm{cm}^{3}\right]\right)$ analysis, a standardized soil volume $\left(250 \mathrm{~cm}^{3}\right)$ was taken, oven dried $\left(105^{\circ} \mathrm{C}, 48\right.$ hours) and immediately weighed. Hemispherical photographs were taken in the center of randomly placed $2 \times 2 \mathrm{~m}$ subplot per plot using a Canon 700D camera and a fisheye lens (SIGMA) (see Beckschäfer et al., 2013). The gap fraction was calculated in the best picture per subplot (maximum exposure time without being over-exposed) using 'ImageJ' (version 1.48v).

In the same subplots $(2 \times 2 \mathrm{~m})$, individual-based vegetation surveys of plants $\geq 5 \mathrm{~cm}$ were done. Herbarium specimens were collected for plant identification.

Bird sampling took place from 6 am to 10.30 am when weather conditions were appropriate. Birds within a $75 \mathrm{~m}$ radius around each plot center were recorded visually and acoustically using 15 minutes point counts. Each sampling point was visited twice. For every species, we recorded the maximum number of individuals present simultaneously on the plot. For taxonomy we followed MacKinnon et al., (1993) and for vulnerability status, we used the species' International Union for Conservation of Nature (IUCN) classification (IUCN 2015). Body masses were obtained from the literature (Wilman et al. 2014) to calculate bird biomass per species.

We extracted invertebrates from the leaf-litter (LL) by sieving the LL from $1 \mathrm{~m}^{2}$ subplot per plot through a coarse sieve (mesh width $=2 \mathrm{~cm}$ ) (see Digel et al., 2014; Ott et al., 2014). Invertebrates in the herb layer (HL) were sucked in from $1 \mathrm{~m}^{2}$ subplot using a modified vacuum cleaner. Animals were stored in $70 \%$ ethanol. Specimens were identified to family level and assigned to trophic groups (predators, omnivores, herbivores, and detritivores). Individual body length (accuracy of $0.1 \mathrm{~mm}$ ) was 
converted to fresh body mass using length-mass-regressions (Table S 3.3) and, where necessary, dry mass-fresh mass relationships from the literature (Table S 3.4). We summed together the fresh masses of the individuals to calculate the total biomass per plot.

\subsubsection{Statistical analysis}

Correlating all environmental variables (Table 3.1) showed strong relations between the two soil depths (soil texture, soil pH, C and N; Table S 3.5).

Table 3.1: Environmental variables

\begin{tabular}{lllrrr}
\hline Variable name & Description & Scale & Min & Mean \pm SD & Max \\
\hline Altitude & Height a.s.1. [m] & plot & 20 & $46.9 \pm 10.46$ & 71 \\
Slope & Slope (SW to NE) & plot & -20.80 & $-0.37 \pm 7.38$ & 20.90 \\
Bare soil & Soil without any vegetation & subplot & 0 & $10.98 \pm 10.56$ & 50 \\
& {$[\%]$} & & & & \\
Gap fraction & Relative gap fraction in the & subbplot & 0.03 & $0.14 \pm 0.14$ & 0.59 \\
& canopy [\%] & & & & \\
Bulk Density & $250 \mathrm{~cm}^{3}$ soil sample [g/cm $]$ & plot & 0.79 & $1.09 \pm 0.13$ & 1.43 \\
& & & & & \\
Soil texture sand (1) & {$[\%]$} & plot & 4.62 & $29.93 \pm 12.59$ & 59.95 \\
Soil texture sand (2) & {$[\%]$} & plot & 3.60 & $29.07 \pm 13.28$ & 63.18 \\
Soil texture silt (1) & {$[\%]$} & plot & 18.14 & $40.54 \pm 8.28$ & 57.91 \\
Soil texture silt (2) & {$[\%]$} & plot & 15.06 & $39.21 \pm 8.61$ & 62.88 \\
Soil texture clay (1) & {$[\%]$} & plot & 13.69 & $29.54 \pm 8.26$ & 53.12 \\
Soil texture clay (2) & {$[\%]$} & plot & 15.39 & $31.72 \pm 8.84$ & 56.06 \\
Soil pH (1) & $(1$ (soil) : 2.5 (1M KCl)) & plot & 3.970 & $4.11 \pm 0.23$ & 5.28 \\
Soil pH (2) & $(1$ (soil) : 2.5 (1M KCl)) & plot & 4.10 & $4.42 \pm 0.16$ & 4.96 \\
C (1) & {$[\%]$} & plot & 1.04 & $2.18 \pm 0.60$ & 3.94 \\
C (2) & {$[\%]$} & plot & 0.41 & $1.37 \pm 0.41$ & 2.31 \\
N (1) & {$[\%]$} & plot & 0.33 & $0.44 \pm 0.08$ & 0.63 \\
N (2) & {$[\%]$} & plot & 0.34 & $0.41 \pm 0.06$ & 0.55 \\
CN (1) & plot & 2.93 & $5.01 \pm 1.14$ & 7.84 \\
CN (2) & plot & 1.18 & $3.36 \pm 0.95$ & 6.1 \\
\hline
\end{tabular}

To reduce their predominance to general trends, we conducted a PCA with the soil variables and used the scores of the first three PCA axes in all further analyses. In case plots are spatially dependent, we would have to control for that in further statistical analyses. Spatial autocorrelation of the environmental parameters was tested 
by calculating Moran's I values (standard deviate with 100 permutations, distance classes of $0.15 \mathrm{~km}$ ). To check for unintended systematic correlations between the environmental variables and the experimental factors, we ran linear models with the environmental variables as responses and 'tree diversity' and 'plot size' as predictors.

Alpha-diversity was calculated with the Simpson-index; beta-diversity was calculated with the Sørensen-index based on true abundance-data (Legendre \& De Cáceres 2013). We estimated species richness for each organism group using 'Jackknife 2' due to high mean evenness-values (vegetation: 0.67, birds: 0.84, LL invertebrates: 0.72 HL invertebrates: 0.82) (Brose, Martinez \& Williams 2003). We tested for the overall effect of tree planting by comparing the means of the baseline survey and year one of the richness, abundance and biomass of birds as well as LL and HL invertebrates with generalized least square models and applying a Tukey post-hoc test.

Further, we tested for the effect of tree diversity (levels of 1, 2, 3 and 6) and plot size $\left(25,100,400\right.$ and $1600 \mathrm{~m}^{2}$; ln-transformed) on the difference in richness, abundance and biomass of birds and LL/HL invertebrates in year one compared to the baseline survey, following the stepwise linear regression approach by Bell et al., (2009). Tree diversity and plot size were taken into the models separately whilst controlling for the other variable in each model. We tested for linear, non-linear and ID-effects of plot size and tree diversity.

Shifts of invertebrate biomass and abundance within trophic compartments in year one compared to the baseline survey and how these shifts are affected by 'plot size' and 'tree diversity' were investigated based on the community weighted mean (CWM) of the biomass and abundance of HL and LL invertebrates per plot. For the calculation, scores were assigned for trophic levels (herbivores, detritivores ' 0 '; omnivores ' 0.5 '; predators ' 1 '), multiplied with the biomasses of the individuals, summed together per plot and divided by the total biomass per plot. A linear mixed model was run with the CWMs as responses; 'tree diversity', 'plot size' and its second order polynomial term (to test for non-linear effects of plot size) as well as 'year' entered the full model as predictors in a three-fold interaction. 'Plot ID' was included as a random effect. A backward selection of the full model was done. 
All analyses were conducted in $\mathrm{R}$ using the following packages: vegan, FD, spdep, nlme (R Core Team 2015).

\subsection{Results}

\subsubsection{Oil palm yields}

In 2014, the average oil palm yield on the plantation was 22.74 tons of fresh fruit bunches ha- ${ }^{-1}$.

\subsubsection{Environmental characteristics of the plantation}

Some of the environmental characteristics varied a lot between the plots (topography, light availability, proportion of bare soil, soil texture and soil carbon content, while others were rather stable (bulk density, soil $\mathrm{pH}$, nitrogen content) (Table 3.1; Figure S 3.1, Table S 3.6). The first three PCA axes explained $69.6 \%$ (from $1^{\text {st }}$ to $3^{\text {rd }}$ axis: $36 \%, 20 \%, 13.5 \%$ ) of the overall variation of the measured soil characteristics (Figure S 3.2). Soil texture (silt, sand) and carbon content contributed most to the first PCA axis; soil texture (clay), carbon content, and bulk density to the second and; nitrogen content to the third. Soil $\mathrm{pH}$ was not very important on any of the three PCA axes. (Table S 3.6). We found no support for spatial autocorrelation of the variation in any of the variables (Figure S 3.3). We detected systematic relationships between the two experimental factors 'tree diversity' and 'plot size' with some environmental and some biotic variables. However, the strengths of the effects were in all cases negligible $\left(\mathrm{R}^{2}\right.$ values <0.17) (Table S 3.7).

Table 3.2 shows diversity indices for the different organism groups. Plants and birds were identified on species level, invertebrates on family level. We found 99 plant species, 21 bird species, 87 LL (litter layer) and 148 HL (herb layer) invertebrate families. The estimated numbers of total species richness were substantially larger for plant species (168 species estimated; 58.9\% sample representativeness) and invertebrate families (LL/HL: 137/148 families estimated; 63.5\% sample representative in both groups), but not for birds (26 species estimated; 80.8\% sample 
representativeness). These findings are congruent with the results from the species accumulation curve (Figure 3.4). The Simpson index was similar for all organism groups $(0.62$ to 0.76$)$. The abundance based $\beta$-diversity ranged from 0.14 to 0.2 .

Table 3.2: Species/family numbers of the four organisms groups monitored at the experimental plots. $\mathrm{LL}=$ leaf litter, $\mathrm{HL}=$ herb layer.

\begin{tabular}{lrrrr}
\hline & Plants & Birds & $\begin{array}{r}\text { LL } \\
\text { invertebrates }\end{array}$ & $\begin{array}{c}\text { HL } \\
\text { invertebrates }\end{array}$ \\
\hline Total species/family richness & 99 (species) & 21 (species) & 87 (families) & 94 (families) \\
Estimated species/family richness & 168 & 26 & 137 & 148 \\
Mean species/family number & & & & \\
per plot $( \pm$ SD) & $16.87 \pm 4.59$ & $4.42 \pm 2.11$ & $9.4 \pm 5.76$ & $11.6 \pm 6.34$ \\
$\beta$-diversity & & & & 0.19 \\
Mean Simpson Index mean & 0.14 & 0.18 & & 0.2 \\
per plot $( \pm$ SD) & $0.77 \pm 0.11$ & $0.63 \pm 0.19$ & $0.62 \pm 0.23$ & $0.76 \pm 0.13$ \\
\end{tabular}
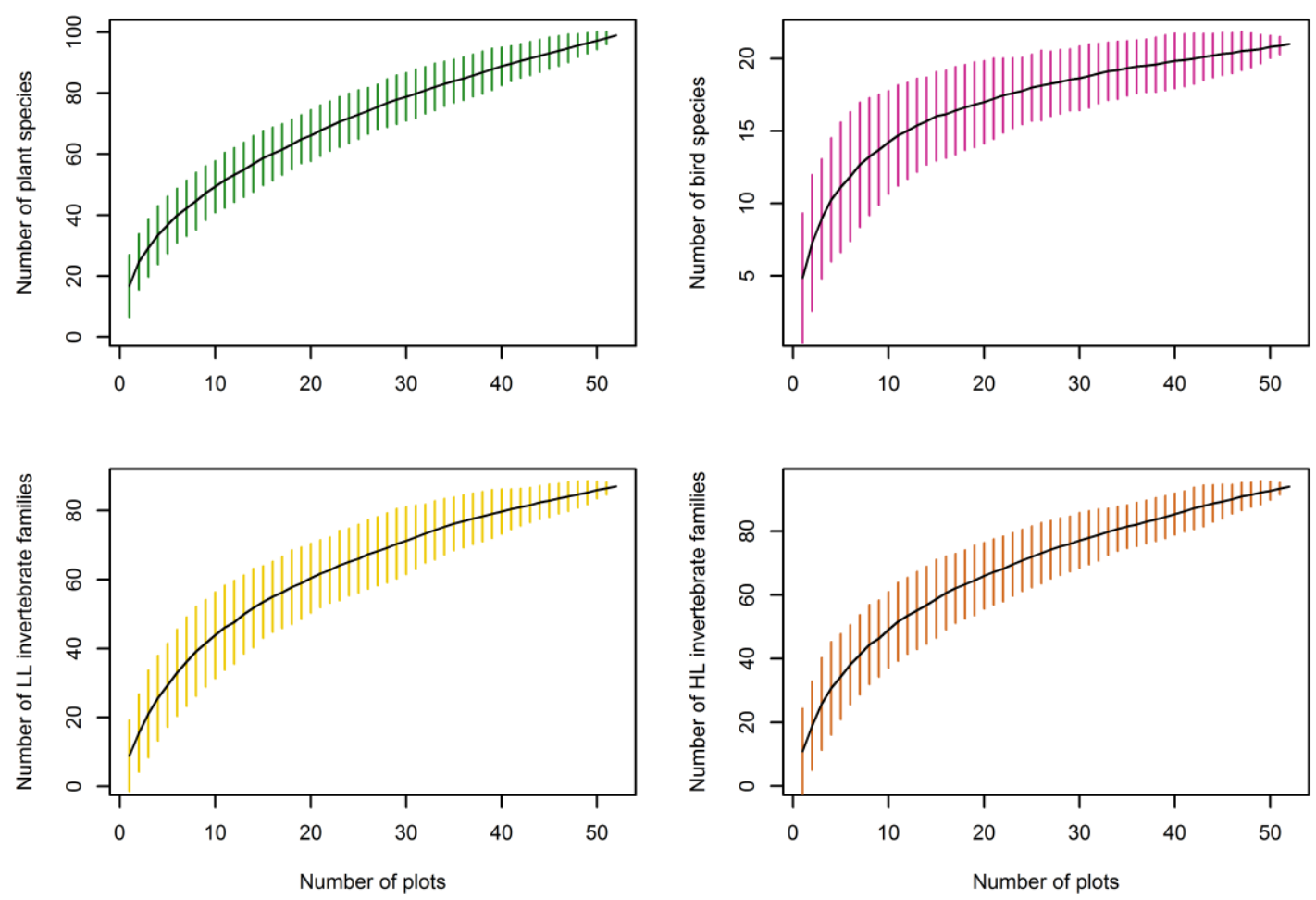

Figure 3.4: Species accumulation curve for plant and bird species as well as for families of leaf-litter (LL) and herb-layer (HL) invertebrates. 


\subsubsection{Biotic characteristics of the plantation}

\section{Vegetation}

Overall, 99 plant species were recorded in the understory herb layer (Table S 3.8 and S 3.9). The three most frequent species were Clidemia hirta (Melastomataceae), followed by Asystasia gangetica (Acanthaceae) and Paspalum cf. conjugatum (Poaceae). The three most abundant species are also among the most frequent species: A. gangetica was the most abundant species with 5253 individuals in the plots, followed by $C$. hirta (3233 individuals) and Nephrolepis cf. acutifolia (Nephrolepidaceae) (2299 individuals). A. gangetica und C. hirta were both introduced to Sumatra.

\section{Birds}

A total of 590 bird individuals of 21 species were detected (Table S 3.8 and S 3.10). Three species that were the three most frequent species were also the three most abundant ones: The Bar-Winged Prinia Prinia familiaris $(\mathrm{N}=187)$, followed by the Yellow-Vented Bulbul Pycnonotus goiavier $(\mathrm{N}=169)$, and the Ashy Tailorbird Orthotomus rufices (N=53). All species are listed as least concern (IUCN 2015).

\section{Leaf-litter invertebrates}

We hand-collected 2173 individuals from 87 families (Table S 3.8 and S 3.11) out of the sieving samples of the LL. Individuals from the family Formicidae (Hymenoptera) were most abundant $(\mathrm{N}=1291)$. The second most abundant family was Staphilinidae ( $\mathrm{N}=113)$ (Coleoptera), followed by Pyrgodesmidae $(\mathrm{N}=70)$ (Polydesmida). The sampled individuals consisted of $24.8 \%$ predators, $61.2 \%$ omnivores, $1.8 \%$ herbivores and $9.7 \%$ detritivores.

\section{Herb layer invertebrates}

1407 individuals from 94 families were collected in the HL (Table S 3.8 and S 3.12). Individuals from the family Gryllidae (Orthoptera) $(\mathrm{N}=499)$ were the most abundant ones, followed by Cicadellidae (Hemiptera) ( $\mathrm{N}=96)$ and Formicidae (Hymenoptera) $(\mathrm{N}=91)$. The invertebrates sampled consisted of $18.7 \%$ predators, $46 \%$ omnivores, $18.3 \%$ herbivores, $11.6 \%$ detritivores. 


\subsubsection{Overall effect of tree planting on bird and invertebrate community one year after establishment}

\section{Birds}

We recorded 531 birds of 20 species (Table S 3.13 and S 3.14), whereof 15 species where the same as in 2013. Six species that where present in 2013 where not recorded in 2014 anymore. $P$. familiaris $(\mathrm{N}=149)$ was the most abundant species, followed by $P$. goiavier $(\mathrm{N}=146)$, and Todiramphus chloris $(\mathrm{N}=51)$. All species in 2014 are listed as "least concern" (IUCN 2015).
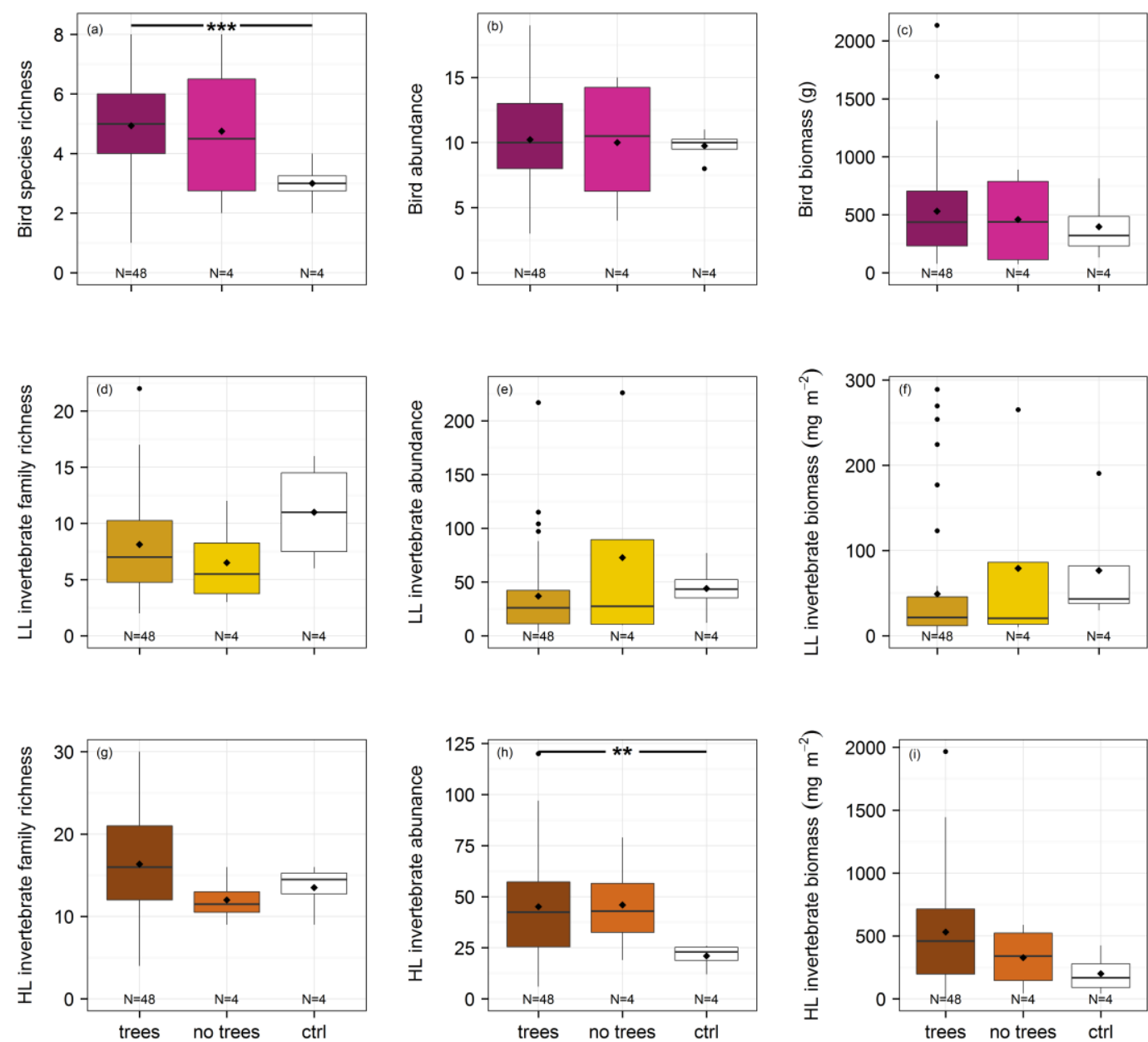

Figure 3.5: Comparison of the richness, abundance and biomass of birds, leaf-litter (LL) invertebrates and herb-layer (HL) invertebrates between plots with trees $(\mathrm{N}=48)$, plots without trees $(\mathrm{N}=4)$ and control plots $(\mathrm{N}=4)$. For birds we considered species richness, for invertebrates richness is accounted for on family level only. We found a significantly higher species richness of birds on the plots with trees as compared to the control plots (a). Furthermore, the abundance of HL invertebrates was significantly higher on plots with trees compared to the control. 
In year one of the experiment, bird species richness was significantly higher on plots with trees (diversity levels one to six) as compared to the control plots (management-as-usual) but not different to plots with diversity level zero (oil palms cut; no trees planted; manual weeding; no application of fertilizer, herbicides and pesticides) (Figure 3.5 a). There was no significant effect of tree planting on the abundance and biomass of birds (Figure $3.5 \mathrm{~b}$ and $\mathrm{c}$ ).

\section{Leaf-litter invertebrates}

A total of 2062 individuals from 74 families were collected in the LL (Table S 3.13 and S 3.15) of which 48 were the same as in the baseline survey in 2013, 26 were new and 39 families that were found in 2013 were not represented in 2014 anymore. Most abundant were individuals from the family Formicidae (Hymenoptera) ( $\mathrm{N}=1437)$. Animals from the family Lyniphiidae (Aranea) were second most abundant ( $\mathrm{N}=63$ ), followed by Pyrgodesmidae (Polydesmida) $(\mathrm{N}=62)$. The sample comprised $17.1 \%$ predators, $70.7 \%$ omnivores, $3 \%$ herbivores and $7.3 \%$ detritivores.

We found no difference in overall family richness, abundance and biomass of the LL invertebrates in year one between plots with trees (diversity level one to six), plots with diversity level zero and control plots (Figure $3.5 \mathrm{~d}$, e and f).

\section{Herb-layer invertebrates}

2349 individuals from 105 families were collected in the HL (Table S 3.13 and S 3.16). 58 families were the same as in the year before, 47 were new and 36 families that were present in 2013 were not present in 2014. Animals of the families Gryllidae (Orthoptera) (N=749), Formicidae (Hymenoptera) $\quad(\mathrm{N}=250)$ and Cicadellidae (Hemiptera) $(\mathrm{N}=139)$ were most abundant. The invertebrates consisted of $17.2 \%$ predators, $48 \%$ omnivores, $15.3 \%$ herbivores and $11.5 \%$ detritivores.

We found a significantly higher abundance of HL invertebrates on plots with trees (diversity level one to six) as compared to the control plots in year one (Figure 3.5 h). Family richness and biomass were not affected by tree planting (Figure $3.5 \mathrm{~g}$ and i). 


\subsubsection{Effect of tree diversity and plot size on the bird and invertebrate community after one year}

We found a significantly positive effect of plot size on the difference in diversity of LL family richness and the difference in abundance of HL invertebrates in year one compared to the baseline (Figure 3.6); Tree diversity, however, did not have any effect on the difference in richness, abundance and biomass of birds and invertebrates (Figure 3.7).
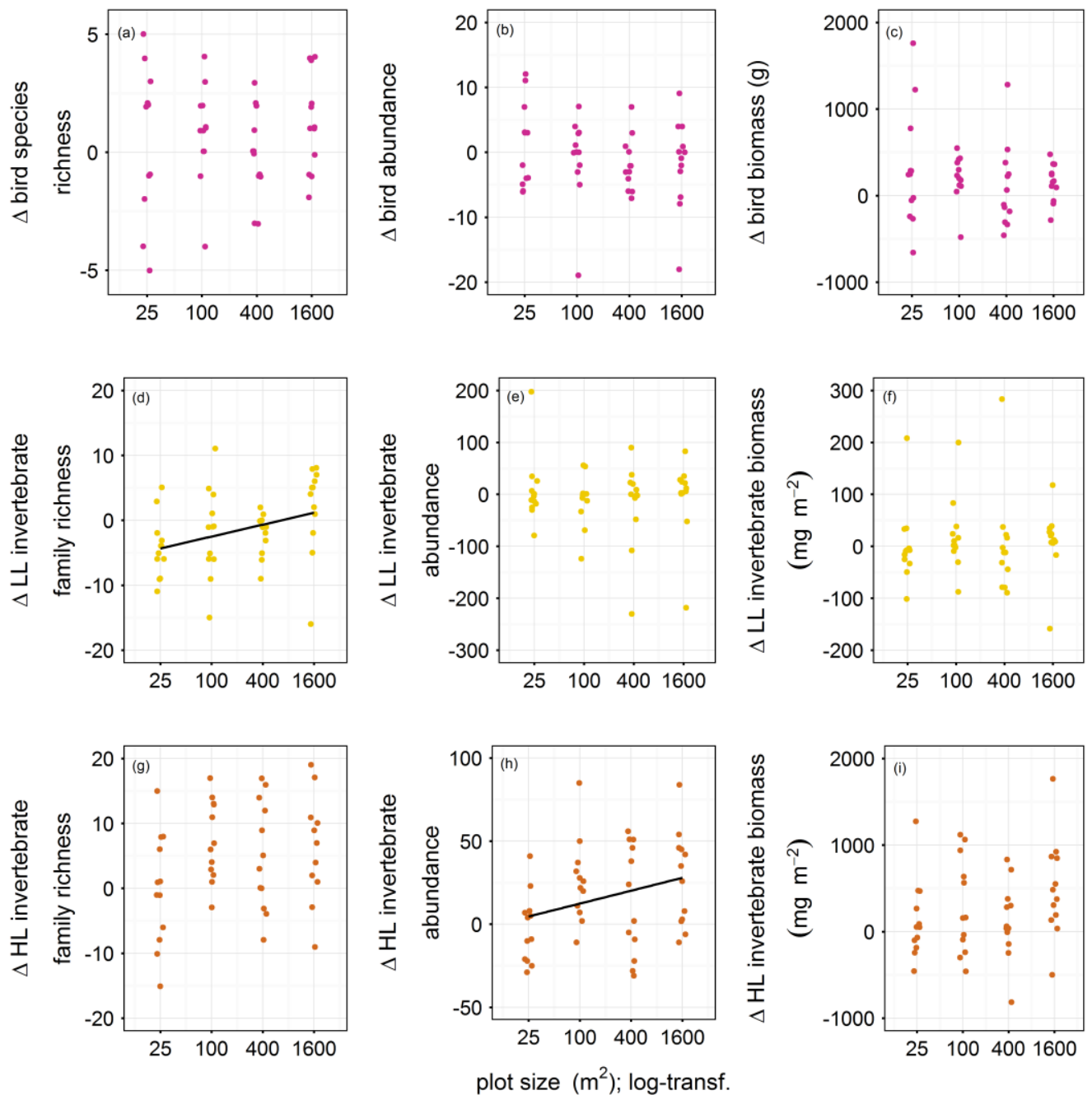

Figure 3.6: Effect of plot size on the difference in richness, abundance and biomass of birds as well as leaf-litter (LL) and herb-layer (HL) invertebrates between year one and the baseline. Birds were considered on species level, invertebrates on family level. LL invertebrate family richness (d) and HL invertebrate abundance (h) was significantly positively related to plot size (indicated by a black line). 

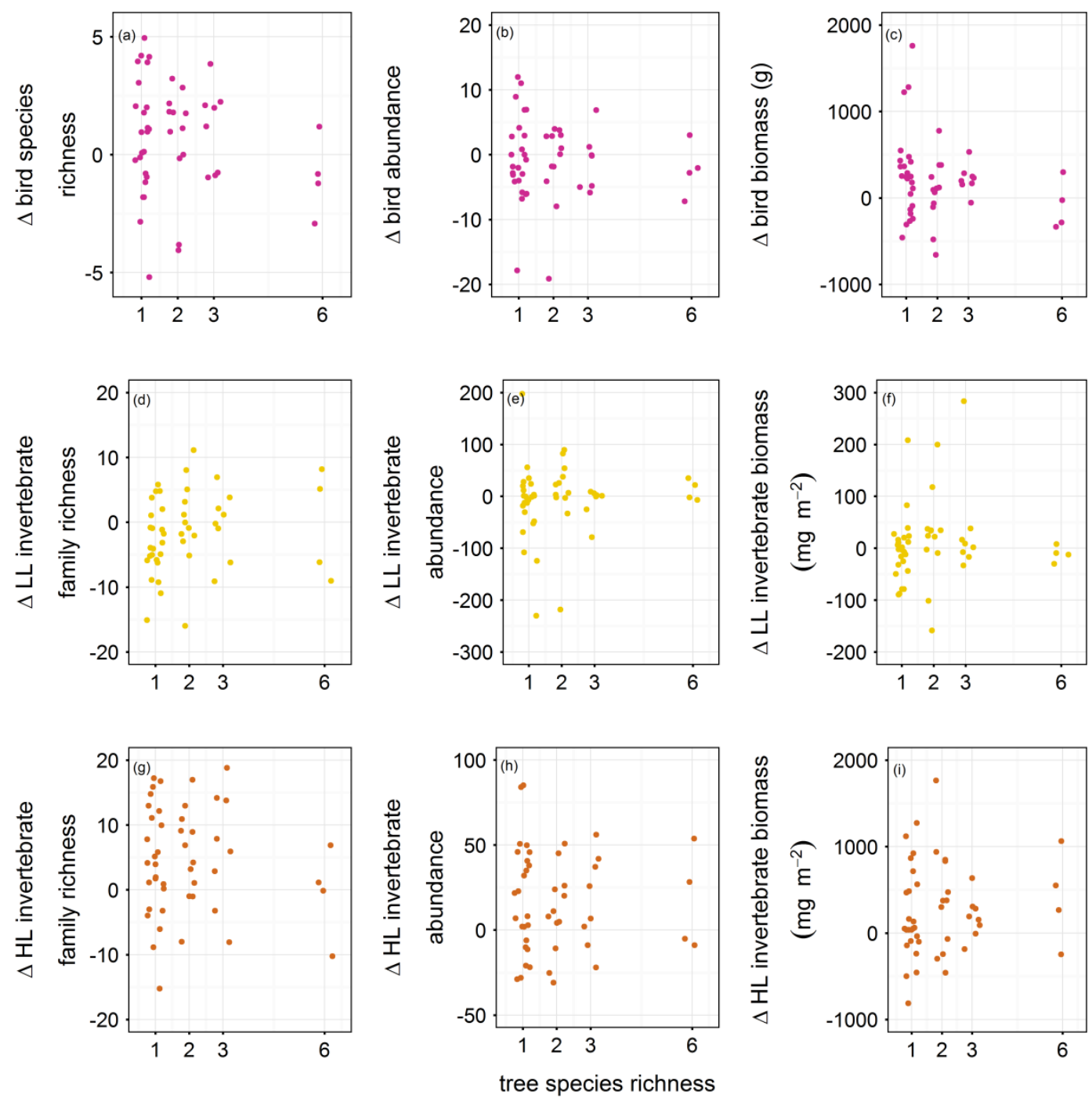

Fig. 3.7: Effect of tree diversity on the difference in richness, abundance and biomass of birds as well as leaf-litter (LL) and herb-layer (HL) invertebrates between year one and the baseline. Birds were considered on species level, invertebrates on family level. There was no effect of tree diversity on any of the responses.

\subsubsection{Shifts of invertebrate biomass and abundance within trophic compartments}

Variation in the community weighted mean (CWM) trophic index and CWM abundance of LL and HL invertebrates, respectively, between the baseline and year one of the experiment could neither be explained by tree planting in general (factor 'year') nor by plot size (plot size : year) or tree diversity (tree diversity : year). This suggests that the changes within the trophic compartments of the invertebrate communities are likely to be driven by other than the experimental factors. 


\subsection{Discussion}

By addressing the effects of two important factors in a restoration context - tree island size and tree diversity - in an experimental approach, we aim at shedding light on the ecological and socio-economic processes associated with a wildlife-friendly, oil-palmbased agroforestry. A controlled experimental design, rather than an observational design, gives also more power to learn about the underlying mechanisms of enrichment plantings.

Our study site in Jambi province, Sumatra, is an ideal place to study the long-term effects of enrichments plantings. Sumatra has experienced huge losses in biodiversity due to the transformation of lowland rainforest into rubber and oil palm plantations in the past decades (Fitzherbert et al. 2008; Margono et al. 2014), and in Jambi province, the already large proportion of area under oil palm cultivation is still increasing (Euler et al. 2015; Gatto, Wollni \& Qaim 2015). We have chosen a medium-scale oil palm plantation for the experiment that is representative for the area. Oil palm yields, management and fertilizer application are comparable to other oil palm plantations (Hassler et al. 2015; Kotowska et al. 2015). Furthermore, the diversity of plants, birds and invertebrates at the study site is comparable to and thus representative of the diversity in other oil palm plantations in the region (Table S 3.17). The results of our baseline survey showed that all plots are independent from each other as we did not find support for spatial autocorrelation, despite detecting variation in the environmental characteristics. Further, the relationship between the biotic and abiotic baseline variables and the two experimental treatments 'plot size' and 'tree diversity' is negligible. Overall, we can conclude that the site conditions are appropriate for future statistical analyses to clearly distinguish experimental impacts and that our site is representative for other oil palm plantations so that results from the BEE are transferable to other plantations.

Interestingly, we already see positive effects of the enrichment plantings on the bird and invertebrate fauna one year after the establishment of the experiment. The overall increase in bird species richness across the plantation could be attributed to an overall increase in heterogeneity within the plantation due to some of the planted trees (i.e. Archidendron pauciflorum and Parkia speciosa) having already reached 
considerable heights $(>4 \mathrm{~m}$ ) within the first year, which might provide habitat for nesting, roosting and foraging (Thiollay 1995). This result supports findings that habitat heterogeneity is a very important factor determining bird diversity and composition (Sekercioglu 2002; Walther 2002; Stein, Gerstner \& Kreft 2014; Teuscher et al. 2015). At plot level, responses of birds were non-significant indicating that overall habitat complexity at the landscape scale is more important than at a local scale at this early stage of the experiment. Most likely, more birds, especially frugivorous species that were found to be absent in oil palm plantations (Prabowo et al. 2015), will be attracted by the tree islands when trees grow bigger and carry fruits. Birds serve as seed dispersers (Sekercioğlu 2006; Whelan, Wenny \& Marquise 2008) and this might in turn positively affect succession and spontaneous colonization of the plants in the tree islands (see Cole et al., 2010). Due to an expected increase in the number of herbivorous insects feeding on the foliage of the planted trees (Schuldt et al. 2010), an increase in the proportion of insectivorous birds in a bottom-up effect is also expected as birds function as pest control agents (Sekercioğlu 2006; Koh 2008b).

Invertebrates responded to the enrichment plantings on a much smaller scale. We do not only see an overall increase in the abundance of HL invertebrates on plots with trees across the whole plantation in year one compared to the control, but also see a positive relationship between the tree island size and the difference in family richness of LL invertebrates and the difference in abundance of HL invertebrates, respectively, in year one compared to the baseline. The stop of fertilizer and pesticide application in combination with the creation of new small-scale habitat structures through the planting of trees might be the reason for these positive responses of the invertebrate communities (see Pywell et al., 2012; Tscharntke et al., 2011). The increase in leaflitter invertebrate family richness could additionally be correlated to increased litter input (Gillison et al. 2003) and increased stoichiometric diversity in the leaves (Ott et al. 2014). The significant positive relationship between invertebrate family richness as well as abundance and plot size suggests, however, that structural effects might be more important than qualitative factors such as tree diversity. Lacking shifts in the relative proportion of invertebrate biomass and abundance within trophic compartments between year one and the baseline indicate that there may be a time-lag in the response of important ecosystem processes to differences in plant diversity, which was also 
reported from other studies (Cardinale et al., 2012; Eisenhauer et al., 2012; but see Schuldt et al., 2015). Invertebrates fulfill many tasks that are essential for ecosystem functioning. They are among the most important organism for litter decomposition and, moreover, prey, pollinators, herbivores and seed predators (Ewers et al. 2015).

We chose birds and invertebrates as study organisms, as they are used as bioindicators to monitor changes in habitat quality. Ecosystem functioning was found to be negatively correlated with diversity loss of birds (Sekercioğlu 2006; Tscharntke et al. 2008) and invertebrates (Barnes et al. 2014b; Ewers et al. 2015), highlighting their key role in ecosystems and, hence, the need for their conservation or rather restoration. The early positive effects of the BEE on birds and invertebrates, two organism groups which are essential for the initiation of natural succession, are promising for further biodiversity enrichment in the future. The design allows to disentangle the effects of plot size and tree diversity on the diversity and structure of different organism communities such as plants, birds and invertebrates and herewith to draw conclusions on changes in ecosystem functioning.

\subsection{Conclusions}

Being aware of the limited contribution that some planted trees may have compared to high-value nature conservation, already some left-over trees can enhance the ecological value of a plantation by maintaining at least a baseline level of biodiversity (Teuscher et al. 2015). Tree islands are a promising restoration measure for impoverished landscapes (Rey-Benayas et al. 2009). Balancing ecosystem functioning (ESF) and the local socio-economy, one outcome of the experiment might be a combination of island size, tree diversity level and composition that is above-average cost-effective and productive to achieve high gains in ESF. This implies identifying the most wellperforming tree species in their most productive composition under the conditions of an oil palm plantation, which do not negatively affect oil palm yields.

The concept of biodiversity enrichment might be similarly relevant for companies managing large scale mono-culture plantations as well as for small-scale farmers seeking to diversify their production to reduce risks and their dependence on palm oil. 
In this context, 'Payment for Environmental Service' (PES)-schemes or a certificate for wildlife-friendly palm oil not exclusively focusing on non-deforestation policy and 'High Conservation Value' (HCV) habitats could make the biodiversity enrichment method more appealing. Depending on the goals of involved stakeholders, tree plantings could be adjusted to management forms such as agroforests, secondary forests for production of timber or for conservation. One realistic application is considered in the close-by Harapan rainforest, where an illegal oil palm plantation within the national park is supposed to be re-transformed to forest. In this case, tree islands could act as a smooth transition from plantation to forest: the plantings could make the plantation more hospitable for wildlife by reducing the land-use intensity and at the same time give farmers enough time to consider alternative means of income.

Our experiment is designed to directly address questions about the potential of enriched oil palm landscapes to maintain or enhance biodiversity and ecosystem functions and services whilst minimizing economic losses. However, this does not satisfy the need for areas of HCV which are an integral part of the aimed designed plantation landscapes. In their function as source habitats, HCV habitats are essential to recruit wildlife from and initiate successful natural succession in the BEE or other wildlife-friendly farming systems. Our long-term objectives are to improve landscape connectivity, to provide habitat for migrating biota and to buffer the inhospitality of oil palm plantations, thereby contributing to biodiversity conservation on a landscape scale. With the results of the experiment we aim on evaluating the effectiveness of the enrichment plantings as part of the proposed designer plantation landscapes and develop clear restoration instructions for oil palm farmers towards a more sustainable management of oil palm. 


\subsection{Acknowledgements}

We thank PT Humusindo to give permission to set up the experiment on their oil palm plantation. Many thanks to Pak Hasbi and his family and all the people who helped us during the establishment phase of the experiment. Special thanks to Andi, Anshori, Zeri, Pak Lele, Ahzan, Dadang Dwi Putra, Walesa Edho Prabowo, Azka, Bayu, Dery, Eka, Fahmi, Huda, Juwita, Kevin, Happy and Judith for their commitment, endurance and good work in the field and/or lab. We thank the people in the lab in Palu, in the Indonesian Institute of Science (LIPI), and at Biotrop for assisting with analyses of samples. We are grateful to the following people who kindly provided data for this article: Ana Meijede, Andrew Barnes, Malte Jochum, Kevin Darras, Walesa Edho Prabowo, Katja Rembold and Robin Naumann. Thanks to Arne Erpenbach for creating the location map and to Philip Beckschäfer who helped us processing the hemispherical photographs. Logistical support was provided by the EFForTS staff and coordination. Samples were collected based on collection permit no. 648/KKH-2/2014 and 15/KKH2/2013, recommended by LIPI and issued by the Ministry of Forestry (PHKA). This study was financed by the Deutsche Forschungsgemeinschaft (DFG) in the framework of the collaborative German-Indonesian research project CRC990. 




\section{PART III}

\section{GENERAL DisCuSSION}





\section{Chapter 4: discussion}

Land-use change is widely recognized as one of the key drivers of global biodiversity loss (Sala et al. 2000; Rockström et al. 2009; Newbold et al. 2015). In Indonesia, landuse change is fueled by an increasing demand for food and biodiesel, leading to a proliferation of oil palm plantations (Turner et al. 2008; Fitzherbert et al. 2008). Oil palm has become one of the most rapidly expanding crops in the humid tropics and over $85 \%$ of the world's palm oil production originates from Indonesia and Malaysia (UNCTAD, 2015). Potentially, palm oil production can foster development of the rural poor but often is accompanied by environmental and social problems (Gilbert, 2012; McCarthy, Gillespie, \& Zen, 2012). New establishment of oil palm plantations is often linked to deforestation (Koh \& Wilcove 2008; Gibbs et al. 2010; Abood et al. 2015) and this conversion of highly diverse tropical rainforest ecosystems into simplified agricultural production systems has devastating impacts on biodiversity and ecosystem functioning (Wilcove \& Koh 2010; Foster et al. 2011; Dislich et al. 2015). This puts a risk on human well-being, too, because ecosystem service degradation leads to e.g. insufficient provision of goods or impairment of water quality (Naeem et al. 1999; Cardinale et al. 2006, 2012).

Designer plantation landscapes where highly intensified oil palm plantations are surrounded by agroforestry buffer zones have been proposed as a measure to increase biodiversity and ecosystem functioning and simultaneously decrease negative effects on rural livelihood (Koh et al. 2009). This approach can be especially interesting in areas where new plantations are planned. However, in an already heavily deforested region it might already be too late for this kind of preventive landscape planning and re-establishing diverse habitats should be considered. Sumatra is an example of such a region, since very little forest is remaining (Margono et al. 2014) and the area under oil palm is increasing, leading to dramatic declines in biodiversity (Fitzherbert et al. 2008). To date, there are four experiments in the tropics that do research on the relationship between restoration via tree planting and associated effects on biodiversity and ecosystem functioning (Petit \& Montagnini 2006; Kirui et al. 2008; Potvin \& Gotelli 2008b; Moreira et al. 2014). These experiments were established in pastures, 
abandoned land and logged forest. However, there is no such project in an established oil palm plantation, where production/cultivation of oil palms is maintained while restoration effects are studied. Consequently, there is little knowledge on how the reestablishment of diverse habitats and the restoration of multi-functionality in oil-palmdominated landscapes can be implemented in a way that is ecologically and economically sustainable at the same time.

The aim of this thesis was to contribute to a better understanding of the ecological and economic impacts of restoration via biodiversity enrichment plantings in oil palm plantations and to set the scene for long-term research in the field of restoration of oilpalm-dominated landscapes. First, I investigated the ecological and economic trade-offs when having remnant or freshly planted non-oil-palm trees within smallholder oil palm plantations in the province of Jambi, Sumatra, Indonesia. The costs to conserve bird species diversity and abundance in oil palm plantations were estimated (Chapter II). Second, I established a long-term, large-scale biodiversity enrichment and ecosystem functioning experiment by planting tree islands in an oil palm plantation. The complexity of this experiment creates a platform for interdisciplinary research on the effects of tree-based restoration in oil palm plantations on biodiversity, ecosystem functioning and human livelihood. It aims at contributing to the development of ecologically improved and socio-economically viable management strategies for oil palm systems. My particular research focus within the framework of the experiment was on the establishment of the tree islands, the assessment of the initial abiotic and biotic conditions prior to the tree planting on the plantation, the bird and invertebrate communities in the plantation and their taxonomical and functional diversity responses to tree islands one year after establishment (Chapter III).

\subsection{Trade-off between ecology and economics in oil palm plantations}

In Chapter II, I studied the ecological-economic trade-off of oil palm plantations with remnant or retroactively planted trees (non-oil-palm trees are always referred to as 'trees'; oil palm trees are referred to as 'oil palms'). I combined economic and 
ecological data from 120 smallholder oil palm plots in the Jambi province, Sumatra, Indonesia in a preliminary study to the biodiversity enrichment experiment. I assessed the monetary costs for the conservation of bird species richness and bird abundance when a wildlife-friendly farming system is applied in oil palm landscapes. The focus was on single remnant or planted trees within or at the border of oil palm plantations. These trees varied in number along an oil palm management gradient from high intensity management (low number of trees) to low intensity management (high number of trees). My results confirm that oil palm plantations are very poor in bird species richness compared to natural forest. However, retaining trees in oil palm plantations mitigated the loss of bird species richness and abundance of common and widespread species of low conservation status. This suggests that enhanced habitat complexity in oil palm plantations can at least maintain a baseline level of biodiversity. Besides tree presence, the height of ground vegetation was an important factor that explained variation in bird species richness and abundance. The increase in bird species richness and abundance was dependent on the number of trees and linked to a decrease in revenue, implying a win-lose relationship between ecological and economic outcomes.

Both, the marginal gain in bird species and bird abundance with increasing tree density as well as the marginal loss in revenue, were non-linear. Therefore, the marginal shadow price of bird species richness and bird abundance expansion changes depending on the initial number of trees present on the oil palm plantation, hence on the initial management intensity. In relatively extensively managed oil palm plantations ( $\mathrm{N}$ trees $=50)$, an increase in bird species richness can only be achieved at the expense of relatively high revenue penalties (67\% decline in total revenue), whereas in relatively intensively managed oil palm plantations $(\mathrm{N}$ trees $=10)$, the same increase in bird species richness can be achieved with a considerably smaller loss in revenue $(20 \%$ loss of total revenue). Similarly, this was found for bird abundance as well, but where an increase in individual numbers implied lower costs compared to the costs for increased bird species richness. Furthermore, the study resolved that farmers' choices are not solely governed by economic reasons. Although remnant or planted trees negatively affected oil palm yield and revenue, farmers decided to maintain the trees within their plantations because of recreational, spiritual or aesthetic reasons. In 
summary, increasing bird diversity and abundance in highly intensified oil palm plantations is cheaper than in extensively managed oil palm plantations.

\subsubsection{Limitations of the study}

In chapter II, I obtained initial insights into the effects on ecology and economics when enrichment plantings such as remnant trees or planted trees are retained within oil palm plantations. Nevertheless, the limitations of my study have to be critically assessed.

The majority of oil palm plantations I considered for my study where highly intensively managed, containing only few remnant or planted trees; only few plantations had very large numbers of trees. This led to a high imbalance of plots with few trees compared to plots with many trees and consequently a high variability in the data. To better explain a larger proportion of variation in the data, further studies should therefore aim to cover the whole gradient from high to intermediate and low numbers of trees in the plantation. Furthermore, I did not distinguish between remnant and planted trees, fruit trees and other trees, nor was the size structure of trees considered. The study was limited to the analysis of quantitative changes in tree numbers. Qualitative factors such as tree diversity, their size structure and composition, and their economic value, however, are likely to have impacts on biodiversity and ecosystem functioning as well as on oil palm yields and revenue (see i.e. Clough et al., 2011; Erskine et al., 2006; Kanowski et al., 2003; Petit and Montagnini, 2006).

The study revealed that bird diversity increased with increasing number of trees in the oil palm plantation. It is important to remember that throughout all oil palm plantations, predominantly generalist, open-habitat and edge-tolerant bird species of low conservation status were found. Doubtless, these species also contribute to maintaining a baseline level of biodiversity. However, this also suggests that oil palm plantations enriched with single trees fail to retain forest bird species and a generally high level of biodiversity (also see Edwards et al., 2010). The overall conservation value of keeping single remnant or planted trees within oil palm plantations is therefore rather low. Nevertheless, although the absolute number of bird individuals and bird species would be lower in intensive plantations with few trees compared to a more extensive plantation with more trees to start with, even this slight increase in bird 
species richness and abundance might already lead to increased ecosystem functioning (Srivastava \& Vellend 2005) and, thereby, to increased provision of ecosystem services such as pollination, seed dispersal and pest control (Foster et al. 2011). However, the benefits in ecosystem service provision due to marginal changes in bird species richness or abundance might depend on the initial number of bird species or individuals. Further studies should, therefore, address the form of the relationship between bird diversity and abundance and the associated provision of ecosystem services.

My study revealed that some farmers retained trees within the plantation for recreational, spiritual or aesthetic reasons. A 'choice experiment' to assess farmers' willingness to plant or retain trees within their oil palm plots could be a useful extension to the household study to specify their motivation for a wildlife-friendly farming strategy. The design of the choice experiment could include different levels of compensation to elicit farmers' willingness to accept such farming strategies. These results would be valuable for informing the design of 'Payment for Ecosystem Service' (PES) programs (see Vorlaufer 2015). Considering the negative relationship between biodiversity and economics, profit-maximizing farmers factually have no motivation to retain trees within their plantations. However, given a fixed conservation payment, farmers of highly intensive oil palm plantations would have a comparatively higher incentive to increase the number of trees on their plantation than farmers of already extensively managed oil palm plantations. Studies to investigate whether or not economic losses could entirely or to a relatively high extent be lessened by planting trees of high economic value would elucidate if PES are even necessary.

Thus, my study is a starting point and provides the basis for further research on enrichment plantings in oil palm plantations. In order to address various open questions and to effectively be able to shed light on additional ecological and socio-economic mechanisms linked to enrichment plantings, a long-term, large-scale experiment with a controlled design is needed, which will be more effective to gain a deeper understanding than further short-term, observational studies. Therefore, I established a biodiversity enrichment planting experiment with colleagues from Germany and Indonesia in a second step. 


\subsection{The biodiversity enrichment experiment}

In Chapter III, I introduced the biodiversity enrichment planting experiment and presented some initial results. The experiment was established in a mono-culture oil palm plantation in the province of Jambi, Sumatra, Indonesia.

In total, colleagues and I planted 56 experimental tree islands in December 2013. Plot size as well as tree species diversity, identity, and composition were systematically manipulated. For the experiment, a random partitions design was adopted (Bell et al. 2009), with four partition series that differ in their plot size $(5 \times 5 \mathrm{~m}, 10 \times 10 \mathrm{~m}, 20 \times 20 \mathrm{~m}$, 40x40 m). Each partition was subdivided into five blocks, one per tree diversity level (levels of six, three, two, one, and zero). Additionally, four control plots without any experimental treatment were set up. This resulted in a total of 56 pots. The set of trees chosen for the experiment comprised six multi-purpose tree species native to Sumatra that deliver products (fruits, timber latex) to local people. Prior to planting the trees, selected oil palms were cut on the experimental plots in order to reduce canopy cover to ensure that there was enough light for the planted trees to establish and grow. On the control plots no palms were cut. The management of the plots with treatments included manual weeding, but the application of fertilizer, pesticides and herbicides completely stopped. On the control plots, management-as-usual was applied. A fence was built around all plots to avoid large mammals to damage the tree islands. To assess services or disservices of the tree islands on the surrounding oil palms, three consecutive oil palms were marked outside each plot in perpendicular direction, for which yield and spillover of biota is monitored. Within the framework of the experiment, long-term monitoring includes the environment (soil, canopy cover, surrounding matrix), plants (growth performance and survival of trees, seed rain, understory vegetation), animals (functional and taxonomic changes in the composition of bird and invertebrate communities), and socio-economics (oil palm yields, benefits from planted trees, willingness to accept enrichment plantings by local people).

In a baseline survey, the initial abiotic and biotic characteristics of the experimental plots prior to the plantings were assessed. The focus was on environmental parameters as well as on canopy cover, floristic composition of 
understory vegetation, invertebrate community composition in the leaf litter and the herb layer, and on the bird community.

Results from the baseline survey showed that the experimental site very well exemplifies other oil palm plantations in the region in terms of their abiotic and biotic characteristics. There was no support for spatial autocorrelation and the relationships between measured abiotic and biotic variables and the two experimental factors 'plot size' and 'tree diversity' was negligible. This suggests a high reliability of the experimental effects on various parameters measured in the future. Interestingly, one year after the establishment of the experiment, positive effects of the tree plantings on the fauna could be reported. The overall bird species richness and abundance of herblayer invertebrates in year one was significantly increased on plots with trees compared to control plots. Even on a local scale, plantings have affected the fauna within one year after tree planting: the difference in leaf-litter invertebrate family richness and herblayer invertebrate abundance in year one compared to the baseline survey was significantly positively related to plot size. The test for relative shifts within trophic compartments of invertebrates in relation to plot size and tree diversity level, however, did not show any significant results.

Overall increase in bird species richness across the plantation but non-significant responses of birds at the plot level suggested that, at this early stage of the experiment, overall habitat complexity at the landscape scale is more important than tree identity, tree diversity, tree composition and plot size. This is in line with other studies that found habitat heterogeneity to be a very important factor determining bird diversity and composition (Sekercioglu 2002; Walther 2002; Teuscher et al. 2015). Trees provide habitat for birds for roosting, nesting and foraging (Thiollay 1995) and facilitate movement through the agricultural landscape (Harvey 2000). It is likely that frugivorous birds, that were found to be absent in oil palm plantations (Prabowo et al. 2015), will be attracted again as soon as the planted fruit trees start fruiting. Arriving birds, especially frugivorous and granivorous species, will then function as seed dispersers (Whelan, Wenny \& Marquise 2008), accelerating the recruitment of plants within the plots. Insectivorous birds are also expected to increase in number and diversity due to an expected increase in numbers of herbivorous insects feeding on the 


\section{Chapter 4: discussion}

foliage of the planted trees (Schuldt et al. 2010) that provide prey resources for the birds.

Invertebrates responded not only on a landscape scale but also locally to enrichment plantings. Stopping fertilizer and pesticide application in combination with the creation of new small-scale habitat structures by the planted trees is likely to have caused this positive impact on the herb layer invertebrate abundance and richness in leaf-litter family richness. Both variables were positively related to plot size. This is congruent with findings that large inputs of fertilizer and pesticides have negative effects on biodiversity (Geiger et al. 2010; Decourtye, Henry \& Desneux 2013) and that, hence, a reduction of pesticide and fertilizer application protects functional agrobiodiversity (Tscharntke et al. 2011). The increase in leaf-litter invertebrate family richness could additionally be correlated to an increased litter input by the planted trees, as leaf-litter dwelling macroinvertebrates strongly depend on litter input from the vegetation (Gillison et al. 2003). Not only the quantity of resource availability, but also the increased stoichiometric diversity in the leaves might play an important role in affecting the diversity of leaf-litter invertebrates (Ott et al. 2014). The significant positive relationship between invertebrate family richness/abundance and plot size suggests, however, that landscape effects might be more important than qualitative factors such as tree diversity. Lacking shifts within trophic compartments of invertebrate communities between year one and the baseline indicate that there may be a time-lag in the response of important ecosystem processes to differences in plant diversity, which was also reported from other studies (Cardinale et al., 2012; Eisenhauer et al., 2012; but see Schuldt et al., 2010).

First results of the experiment showed that enrichment plantings can have positive effects on bird and invertebrate communities. However, my data collected on the experimental site represent only a snapshot in the early stages of the experiment. Over time, mechanisms and processes associated to enrichment plantings may change whilst the planted trees are growing and future findings might hence be different.

To gain a deeper understanding of the mechanisms and consequences of tree islands for environmental enrichment in mono-culture production systems, bird and invertebrate communities are of key importance. Both groups represent key bio- 
indicators and thus are a valuable tool for monitoring the impact of habitat changes on the functioning of ecosystems. In the following section, I discuss the importance of birds and invertebrates for ecosystem functioning.

\subsubsection{The importance of birds and invertebrates as bio-indicators}

In many studies, bird communities are used as bio-indicators to monitor the health of an ecosystem. Birds are easy to observe (during daytime), they are taxonomically well identified, sensitive to changes in habitat quality and play an important role in ecosystem functioning by acting as pollinators, predators, seed dispersers, scavengers, and ecosystem engineers (Sekercioğlu 2006; Tscharntke et al. 2008). Tropical studies suggest high importance of insectivorous birds in agricultural systems (Sekercioğlu 2006) because they can significantly reduce plant damage by insect herbivores (Van Bael, Brawn \& Robinson 2003; Van Bael \& Brawn 2005; Van Bael et al. 2008; Koh 2008b; Karp et al. 2013). Furthermore, birds are considered to be highly effective agents in the transportation of seeds (Darwin 1859; Sekercioğlu 2006). Zoochory (the dispersal of plant seeds by animals) is a very important dispersal mode, especially for tropical trees and plants, as in some forests up to $90 \%$ of tropical plant species seeds are dispersed by animals. Birds often outperform mammals in long-distance dispersal (Sekercioğlu 2006). High diversity and abundance of birds can thus increase seed rain and facilitate the recovery of degraded systems (Sekercioğlu 2006; Cole, Holl \& Zahawi 2010). It is therefore suggested, that tree enrichment plantings, which have as such already been identified to increase bird diversity (Clough et al. 2009; Teuscher et al. 2015), are designed to facilitate avian seed dispersal (Lindell, Reid \& Cole 2013). Another important function within ecosystems is pollination. Bird pollination, compared to insect pollination, is less common. Nevertheless, more than 900 bird species pollinate $\sim 500$ of the 13,500 vascular plant genera (Sekercioğlu 2006).

Invertebrates, in general, also represent a group that is essential for the maintenance of ecosystem functioning. They are the "little things, that run the world" (Wilson 1987) because they influence ecosystem functioning far out of proportion to their body mass and can both have direct and indirect effects on other organisms' activity (Coleman \& Hendrix 2000). Invertebrates act as prey resource, pollinators, 
biological control agents, soil ecosystem engineers and regulators, herbivores, and predators of seeds and other insects (Ewers et al. 2015). A loss in diversity and abundance of invertebrates due to forest conversion (Turner \& Foster 2008; Fayle et al. 2010; Barnes et al. 2014b) has been found to negatively affect multitrophic ecosystem functioning (Barnes et al. 2014b). In particular, this can lead to a decrease in litter decomposition, seed predation and removal, and invertebrate predation (Ewers et al. 2015).

Overall, birds and invertebrates exemplify ideal focal taxa to study the effects of restoration on ecosystem functioning. Both groups function as bio-indicators, as they are sensitive to changes in habitat quality which also highlights the need for the conservation of their diversity and abundance.

\subsubsection{Opportunities and constraints of the biodiversity enrichment experiment}

The biodiversity enrichment experiment provides lucrative ground for interdisciplinary studies that can contribute to the development of specific recommendations on how to design economically realizable oil palm plantations that simultaneously harbor high biodiversity and maintain ecosystem functioning. However, interests of ecology and socio-economics can be opposing, making it difficult to satisfy all the expectations incumbent on this experiment. In the following, I discuss some points regarding the opportunities and constraints of this experiment.

In the biodiversity enrichment experiment, tree species identity, diversity, tree compositions and plot size were simultaneously manipulated. This exceeds most restoration and $\mathrm{BEF}$ experiments with trees, where often only one or two factors are manipulated (Hector et al. 2011; Holl et al. 2011; Bruelheide et al. 2014). Addressing multiple factors at the same time, however, allows for a faster identification of the best planting strategy, making it more economically effective than testing all the factors separately in different experiments. Monitoring the growth of trees, oil palm yield, animal and plant diversity and abundance as well as services and disservices of the tree islands on the surrounding oil palms will then elucidate which tree composition and size of islands can most effectively restore biodiversity and ecosystem functions. At the same time, however, the design could just as well turn out to be unsuitable for large- 
scale, long-term field experiments. The random partitions design was initially developed for lab experiments where only one factor was manipulated (species diversity) (Bell et al. 2009). Knowledge about the applicability of the random partitions design in the field is lacking. In the biodiversity enrichment experiment, each partition series is only represented once (one partition per plot size); hence there are no replicates at all. This could cause problems e.g. in case one plot gets destroyed or the trees within one plot are dying because of pest infestation. It would be impossible to distinguish whether experimental factors such as the species composition and plot size or other underlying mechanisms led to the death of the trees.

The set of trees chosen for the experiment includes native fruit and timber species (Parkia speciosa, Fabaceae; Archidendron pauciflorum, Fabaceae; Durio zibethinus, Malvaceae; Dyera polyphylla, Apocynaceae; Peronema canescens, Verbenaceae; Shorea leprosula, Dipterocarpaceae) which are available in local nurseries and are of economic value. The use of native trees is similarly beneficial for humans and native wildlife. The trees deliver economically valuable products to farmers (fruit, timber latex). Furthermore, the two Fabaceae species may enhance nitrogen availability by nitrogen fixation, thereby enhancing soil fertility and reducing the need for fertilizer use. The concept of biodiversity enrichment with native trees in oil palm plantations may be especially attractive for smallholders as they could benefit from increased diversification of their production and, hence, reduce their risk in case of crop failure. With additional trees in their plantation, the smallholders do not solely rely on oil palm output. Native wildlife will additionally benefit more from the use of native trees than from using exotic trees (Southwood et al. 2004). In particular, native trees have the potential to increase forest-dependent species (Douglas et al. 2014). So far, there is no experience on how the chosen tree species perform when planted within oil palm plantations. One year after establishment, differences in growth and survival rates between the tree species were evident (Anne Gérard, unpubl. data). P. canescens and $A$. pauciflorum had very high growth rates whereas $D$. polyphylla had a comparatively low growth rate. Growth performance might also depend upon water availability, which was found to be reduced in oil palm systems due to high transpiration rates by oil palms (Röll et al. 2015), or upon differences in soil texture and nutrients. Beyond that, planted tree species might differ in their susceptibility to pest infestations. Within the 
framework of the Master project by Jennifer Arns, which I have been co-supervising since the end of 2014, herbivory was estimated on the planted trees 17 months after the establishment of the tree islands. First results show that herbivory significantly differs between the tree species (Jennifer Arns, unpubl. data). Obviously, there are many ambiguities about the suitability of the chosen trees for restoration in oil palm systems. However, this experiment will help gather information on the usefulness of these trees for economically realizable restoration measures and will therefore facilitate further experiments in the future.

One problem linked to the management of the experimental plots is that the removal of fertilizer and pesticide application is not equally advantageous for ecology and economics. From an economic point of view, stopping the application of fertilizers does not seem reasonable, as high yields in agricultural systems are usually maintained and achieved through high fertilizer inputs (Matson et al. 1997). Furthermore, a farmer would use pesticides if the planted trees become infested by insects or fungi, in order to avoid death of trees that would lead to reduced income. For ecological research, however, it makes perfect sense to discontinue the application of fertilizer and herbicides in order to study natural succession and the pure benefits (and disadvantages) of tree islands on biodiversity and ecosystem functions within the oil palm system.

Moreover, from an economic perspective, it is not reasonable to cut oil palm trees once they are established and productive. For this experiment, however, oil palms were cut in order to increase light conditions for better growth performance and survival of the planted trees. This causes huge revenue penalties for the farmers, which have to be remedied by other means. In order to minimize economic losses, it seems reasonable to find other ways to introduce trees into oil palm plantations. In this respect it has to be considered that, if other trees are introduced too early or planted together with oil palms when a new plantation is established, trees may overgrow the surrounding oil palms. Consequently, the oil palm yield will decrease due to shading (Corley \& Tinker 2003). Competition between trees and oil palms will probably have an impact on growth and yield of both, trees and oil palms, depending on planting design. 
Generally, the long-term perspective of conservation efforts and short-term perspective of high yields and revenues are conflicting, as they have to be realized on the same piece of land. In order to optimize the revenues from oil palm management, rotation periods usually do not exceed 25 - 30 years. At the end of a rotation period, the management unit is usually clear-cut to plant the next generation of oil palms (Luskin \& Potts 2011). Thus, the key to successful restoration of biodiversity and its conservation may lie in a commitment to a long term oriented management strategy that goes beyond a single rotation period of oil palms. A contribution of biodiversity enrichment to conservation can only be achieved if restored areas are not clear-cut after the end of oil palm rotation. A solution could be to create a patchwork of differently aged plantations, thereby diminishing the negative impacts of disturbances by largescale clear-cuttings at the end of a rotation period (Luskin \& Potts 2011). In situ, biodiversity might not be eliminated then. This concept appears to be highly suitable to be combined with biodiversity enrichment.

The examples suggest that outcomes from this experiment cannot directly be transferred to real-life situations that farmers are confronted with. In fact, the experiment is a tool to gather basic knowledge on restoration in agricultural landscapes by identifying the most effective island size and tree composition in both ecological and economic terms. Based on this information, pragmatic management guidelines can be developed. However, the implementation of the biodiversity enrichment concept requires a few more thoughts, such as at what time tree islands could be established; i.e. should this happen right at the beginning when an oil palm plantation is newly established, or when oil palms have reached the end of their life cycle and could then be replaced by trees? Despite some conflicts of interest, the biodiversity enrichment experiment is a valuable tool to gather in-depth knowledge on the effects of restoration via tree enrichment plantings in oil palm systems, based on which management implications can be developed. 


\subsection{Outlook and further research}

This thesis has illustrated empirically that biodiversity enrichment plantings can have positive impacts on ecological conditions in agricultural production systems, but that there is a trade-off between ecological and economic functions. In order to develop pragmatic management guidelines that are ecologically beneficial and at the same time feasible in socio-economic terms, it is essential to understand the effects of tree plantings on biodiversity and ecosystem functioning, as well as on the socio-economics of oil palm plantations over time. In this thesis, I have only explored mechanisms of enrichment plantings over a short time and covered a fraction of the vast spectrum of studies possible with this experiment. Further research in various fields is needed to uncover the long-term mechanisms associated with enrichment plantings. In the following, I raise some topics that propose avenues for future research.

Conversion from forest to oil palm plantations leads to high losses in carbon stocks and also reduces of carbon sequestration (Kotowska et al. 2015). Further research is needed to understand which combination of tree species has the greatest potential for taking large amounts of carbon dioxide from the atmosphere and storing it in the wood of the trees or transporting it into the soil.

Numerous experiments have shown that microbial community composition contributes significantly to shaping aboveground biodiversity and the functioning of terrestrial ecosystems (Bardgett \& van der Putten 2014). BEF research on microbial diversity is crucial because many of the most critical ecosystem services are underpinned by microbial processes, e.g. nutrient transformations that improve soil and water quality. How changes in plant and animal diversity induced by enrichment plantings alter microbial diversity as well as how this, in turn, affects ecosystem functioning andaboveground biodiversity through bottom-up effects, would therefore be an interesting topic to do research on.

Seed rain is expected to be higher in plots with higher initial tree diversity, as a consequence of both higher bird diversity (higher seed diversity in bird faeces) and longer period of attractiveness due to complementarity in leafing, fruiting, and flowering periods. Mist-netting studies collecting faecal samples of birds could shed 
light on seed rain and the identity of species that make substantial contributions to seed dispersal (Lindell, Reid \& Cole 2013). In this context, other seed dispersing animals, such as bats in particular should be acknowledged as they also function as important seed dispersers in tropical systems (Kunz et al. 2011). In combination with studies on seed rain, studying shifts in plant communities seem reasonable as over time, a shift from plant communities dominated by weedy invasive species to communities with a high proportion of native species is expected. Ultimately, increased proportion of native plants as a consequence of increased seed rain may positively affect arthropodmediated ecosystem services (Isaacs et al. 2009).

Studies on the effects of plant diversity on higher tropic levels, such as insect herbivores as primary consumers, provide further research possibilities. Most findings suggest that herbivory is reduced with increased plant diversity (Jactel \& Brockerhoff 2007); others indicate that increased plant diversity promotes herbivory (Schuldt et al. 2010, 2015). Within the framework of the Master project by Jennifer Arns, herbivory was estimated on the planted trees 17 months after establishment of the tree islands. Results indicate that herbivory is tree species specific. In this context, studies aiming to identify insect herbivores responsible for plant damage, as well as whether herbivore communities differ between plots of various sizes and diversity levels would be interesting extensions. Furthermore, whether herbivory on the planted trees affects herbivory on oil palms and if that has any consequences for oil palm yields could be studied. Most likely, herbivory by arthropods will be higher in the first years (see Schuldt et al., 2015) due to a lag in successful colonization of higher trophic level species. One year after establishment, no shift in the invertebrate community was detected. To complete the picture of responses on various trophic levels, additional investigation whether or not there will be shifts within the functional groups of bird and bat communities is needed. This is important to consider as birds and bats function as pest control agents, thereby affecting herbivory (Sekercioğlu 2006; Kalka, Smith \& Kalko 2008; Maas et al. 2015). Long-term monitoring of plant-insect interactions as well as top-down control by birds and bats is critical to understand consequences and opportunities of biological pest control and when it is most effective. 
To investigate possible benefits of tree islands on the surrounding oil palms, studies on the spillover from native trees into the plantation system and the identity, diversity and functional importance of the added animals need to be conducted (see e.g. Lucey and Hill, 2012; Lucey et al., 2014). For example, invertebrate communities in the canopy or in the trunk of oil palms inside the plot could be compared to the communities in oil palms outside the plot and the spillover effect and the distance to the tree islands could be tested.

To assess the economic impacts of tree islands, it needs to be investigated if the emerging opportunity costs from planting fewer oil palms to create space for enrichment plantings can be compensated for by the output of the planted trees. Compensation could additionally be drawn from ecosystem services such as biological pest control, pollination, enhanced soil retention, litter decomposition and improved water quality (Foster et al. 2011) because these directly benefit the farmers' income (Tscharntke et al. 2011). In this context, the magnitude of an ecological function (e.g. invertebrate consumption) and that of the consequent ecosystem service benefiting humans (e.g. pest control) needs to be measured in order to provide 'exchange rates' between ecological functions and ecosystem services and to estimate the profit gained by enhanced ecosystem services. Based on knowledge of the combined socio-economic and ecological impact of enrichment plantings, payment schemes for ecosystem services (PES) can be designed that lead to higher levels of adoption of enrichment plantings in smallholder oil palm plantations.

The given examples illustrate the vast opportunity of the presented biodiversity enrichment experiment for future investigations on the effects of enrichment plantings on ecology and socio-economics. This highlights that this thesis has substantially contributed to make advances in BEF and restoration research in tropical agricultural landscapes. The biodiversity enrichment experiment is designed to directly address questions about the potential of enrichment plantings to restore biodiversity, their capacity to improve ecosystem functioning, and their ability to deliver increased ecosystem services whilst minimizing economic losses. With the results of the experiment, the effectiveness of the enrichment plantings will be evaluated to find the best planting strategy and to develop clear guidelines that will have direct relevance for 
high-profile policy issues. The concept of enrichment planting may be similarly attractive for large oil palm estate owners and smallholders; especially if newly developed PES-schemes not only focus on non-deforestation policy and high conservation value habitat. Eventually, the knowledge gained from this biodiversity enrichment experiment can be transferred to or considered by restoration projects in other oil palm plantations or even in other agricultural systems such as rubber plantations and rice paddies; land uses that are also very common in the tropics. Ultimately, this interdisciplinary biodiversity enrichment experiment may contribute to increasing and conserving biodiversity in tropical agricultural landscapes without jeopardizing the food security of a growing human population. 



\section{Part IV}

\section{APPENDIX}





\section{References}

Abood, S.A., Lee, J.S.H., Burivalova, Z., Garcia-Ulloa, J. \& Koh, L.P. (2015) Relative contributions of the logging, fiber, oil palm, and mining industries to forest loss in Indonesia. Conservation Letters, 8, 58-67.

Aerts, R. \& Honnay, O. (2011) Forest restoration, biodiversity and ecosystem functioning. BMC Ecology, 11, 1-10.

Allen, K., Corre, M.D., Tjoa, A. \& Veldkamp, E. (2015) Soil Nitrogen-Cycling Responses to Conversion of Lowland Forests to Oil Palm and Rubber Plantations in Sumatra, Indonesia. Plos One, 10, e0133325.

Amoah, F.M., Nuertey, B.N., Baidoo-Addo, K., Oppong, F.K., Osei-Bonsu, K. \& Asamoah, T.E.O. (1995) Underplanting oil palm with cocoa in Ghana. Agroforestry Systems, 30, 289-299.

Anand, M.O., Krishnaswamy, J. \& Das, A. (2008) Proximity to forests drives bird conservation value of coffee plantations: implications for certification. Ecological Applications, 18, 1754-1763.

Atkinson, P.W., Fuller, R.J., Vickery, J.A., Conway, G.J., Tallowin, J.R.B., Smith, R.E.N., Haysom, K.A., Ings, T.C., Asteraki, E.J. \& Brown, V.K. (2005) Influence of agricultural management, sward structure and food resources on grassland field use by birds in lowland England. Journal of Applied Ecology, 42, 932-942.

Azhar, B., Lindenmayer, D.B., Wood, J., Fischer, J., Manning, A., McElhinny, C. \& Zakaria, M. (2011) The conservation value of oil palm plantation estates, smallholdings and logged peat swamp forest for birds. Forest Ecology and Management, 262, 2306-2315.

Azhar, B., Lindenmayer, D.B., Wood, J., Fischer, J., Manning, A., Mcelhinny, C. \& Zakaria, M. (2013) The influence of agricultural system, stand structural complexity and landscape context on foraging birds in oil palm landscapes. Ibis, 155, 297-312.

Van Bael, S.A., Bichier, P., Ochoa, I. \& Greenberg, R. (2007) Bird diversity in cacao farms and forest fragments of western Panama. Biodiversity and Conservation, 16, 2245-2256.

Van Bael, S.A. \& Brawn, J.D. (2005) The direct and indirect effects of insectivory by birds in two contrasting Neotropical forests. Oecologia, 143, 106-116.

Van Bael, S.A., Brawn, J.D. \& Robinson, S.K. (2003) Birds defend trees from 
herbivores in a Neotropical forest canopy. Proceedings of the National Academy of Sciences of the United States of America, 100, 8304-8307.

Van Bael, S.A., Philpott, S.M., Greenberg, R., Bichier, P., Barber, N.A., Mooney, K.A. \& Gruner, D.S. (2008) Birds as predators in tropical agroforestry systems. Ecology, 89, 928-934.

Balvanera, P., Pfisterer, A.B., Buchmann, N., He, J.-S., Nakashizuka, T., Raffaelli, D. \& Schmid, B. (2006) Quantifying the evidence for biodiversity effects on ecosystem functioning and services. Ecology letters, 9, 1146-1156.

Bardgett, R.D. \& van der Putten, W.H. (2014) Belowground biodiversity and ecosystem functioning. Nature, 515, 505-511.

Barnes, A.D., Emberson, R.M., Chapman, H.M., Krell, F.-T. \& Didham, R.K. (2014a) Matrix habitat restoration alters dung beetle species responses across tropical forest edges. Biological Conservation, 170, 28-37.

Barnes, A.D., Jochum, M., Mumme, S., Haneda, N.F., Farajallah, A., Widarto, T.H. \& Brose, U. (2014b) Consequences of tropical land use for multitrophic biodiversity and ecosystem functioning. Nature Communications, 5, 5351.

Barnosky, A.D., Matzke, N., Tomiya, S., Wogan, G.O.U., Swartz, B., Quental, T.B., Marshall, C., McGuire, J.L., Lindsey, E.L., Maguire, K.C., Mersey, B. \& Ferrer, E. a. (2011) Has the Earth's sixth mass extinction already arrived? Nature, 471, $51-57$.

Basiron, Y. (2007) Palm oil production through sustainable plantations. European Journal of Lipid Science and Technology, 109, 289-295.

Baudron, F. \& Giller, K.E. (2014) Agriculture and nature: Trouble and strife? Biological Conservation, 170, 232-245.

Bawa, K.S., Kress, W.J., Nadkarni, N.M., Lele, S., Raven, P.H., Janzen, D.H., Lugo, A.E., Ashton, P.S. \& Lovejoy, T.E. (2004) Tropical Ecosystems into the 21st Century. Science, 306, 227-228.

Beckschäfer, P., Seidel, D., Kleinn, C. \& Xu, J. (2013) On the exposure of hemispherical photographs in forests. iForest - Biogeosciences and Forestry, 6, 228-237.

Belcher, B. \& Schreckenberg, K. (2007) Commercialisation of non-timber forest products: A reality check. Development Policy Review, 25, 355-377.

Bell, T., Lilley, A.K., Hector, A., Schmid, B., King, L. \& Newman, J.A. (2009) A linear model method for biodiversity-ecosystem functioning experiments. The American Naturalist, 174, 836-849. 
Bhagwat, S.A. \& Willis, K.J. (2008) Agroforestry as a solution to the oil-palm debate. Conservation Biology, 22, 1368-1369.

Bhagwat, S.A., Willis, K.J., Birks, H.J.B. \& Whittaker, R.J. (2008) Agroforestry: a refuge for tropical biodiversity? Trends in ecology \& evolution, 23, 261-267.

Brose, U., Martinez, N.D. \& Williams, R.J. (2003) Estimating species richness: Sensitivity to sample coverage and insensitivity to spatial patterns. Ecology, 84, 2364-2377.

Bruelheide, H., Nadrowski, K., Assmann, T., Bauhus, J., Both, S., Buscot, F., Chen, X.Y., Ding, B., Durka, W., Erfmeier, A., Gutknecht, J.L.M., Guo, D., Guo, L.D., Härdtle, W., He, J.S., Klein, A.M., Kühn, P., Liang, Y., Liu, X., Michalski, S., Niklaus, P.A., Pei, K., Scherer-Lorenzen, M., Scholten, T., Schuldt, A., Seidler, G., Trogisch, S., von Oheimb, G., Welk, E., Wirth, C., Wubet, T., Yang, X., Yu, M., Zhang, S., Zhou, H., Fischer, M., Ma, K. \& Schmid, B. (2014) Designing forest biodiversity experiments: General considerations illustrated by a new large experiment in subtropical China. Methods in Ecology and Evolution, 5, 74-89.

Budidarsono, S. (2012) Socio-economic impacts assessment of palm oil production. World Agroforestry Centre - ICRAF. Technical Brief No. 27: oil palm series, 1-3.

Cardinale, B.J., Duffy, J.E., Gonzalez, A., Hooper, D.U., Perrings, C., Venail, P., Narwani, A., Mace, G.M., Tilman, D., Wardle, D.A., Kinzig, A.P., Daily, G.C., Loreau, M., Grace, J.B., Larigauderie, A., Srivastava, D.S. \& Naeem, S. (2012) Biodiversity loss and its impact on humanity. Nature, 486, 59-67.

Cardinale, B.J., Srivastava, D.S., Duffy, J.E., Wright, J.P., Downing, A.L., Sankaran, M. \& Jouseau, C. (2006) Effects of biodiversity on the functioning of trophic groups and ecosystems. Nature, 443, 989-992.

CBD. (1992) Convention on Biological Diversity, www.cbd.int

Chazdon, R.L. (2008a) Beyond deforestation: restoring forests and ecosystem services on degraded lands. Science (New York, N.Y.), 320, 1458-60.

Chazdon, R.L. (2008b) Beyond deforestation: restoring forests and ecosystem services on degraded lands. Science, 320, 1458-1460.

Chia, F.R. (2011) Survival and growth performance of teak under monocrop system and intercropped with oil palm. Sepilok Bulletin, 13 \& 14, 33-42.

Clough, Y., Barkmann, J., Juhrbandt, J., Kessler, M., Wanger, T.C., Anshary, A., Buchori, D., Cicuzza, D., Darras, K., Putra, D.D., Erasmi, S., Pitopang, R., Schmidt, C., Schulze, C.H., Seidel, D., Steffan-Dewenter, I., Stenchly, K., Vidal, S., Weist, M., Wielgoss, A.C. \& Tscharntke, T. (2011) Combining high biodiversity with high yields in tropical agroforests. Proceedings of the National 
Academy of Sciences of the United States of America, 108, 8311-8316.

Clough, Y., Dwi Putra, D., Pitopang, R. \& Tscharntke, T. (2009) Local and landscape factors determine functional bird diversity in Indonesian cacao agroforestry. Biological Conservation, 142, 1032-1041.

Clough, Y., Kruess, A. \& Tscharntke, T. (2006) Local and landscape factors in differently managed arable fields affect the insect herbivore community of a noncrop plant species. Journal of Applied Ecology, 44, 22-28.

Cole, R.J., Holl, K.D. \& Zahawi, R.A. (2010) Seed rain under tree islands planted to restore degraded lands in a tropical agricultural landscape. Ecological Applications, 20, 1255-1269.

Coleman, D. \& Hendrix, P. (eds). (2000) Invertebrates as Webmasters in Ecosystems. CABI International.

Corbin, J.D. \& Holl, K.D. (2012) Applied nucleation as a forest restoration strategy. Forest Ecology and Management, 265, 37-46.

Corley, R.H.V. (2009) How much palm oil do we need? Environmental Science \& Policy, 12, 134-139.

Corley, R.H.V. \& Tinker, P.B. (2003) The Oil Palm, 4th ed. Wiley-Blackwell, Oxford, UK.

Costanza, R., Arge, R., de Groot, R., Farberk, S., Grasso, M., Hannon, B., Limburg, K., Naeem, S., Neill, R.V.O., Paruelo, J., Raskin, R.G. \& Suttonkk, P. (1997) The value of the world' $\mathrm{s}$ ecosystem services and natural capital. Nature, 387, 253260.

Costanza, R., de Groot, R., Sutton, P., van der Ploeg, S., Anderson, S.J., Kubiszewski, I., Farber, S. \& Turner, R.K. (2014) Changes in the global value of ecosystem services. Global Environmental Change, 26, 152-158.

Daily, G.C., Alex, S., Ehrlich, P.R., Goulder, L., Matson, P.A., Mooney, H.A., Postel, R., Schneider, H., Tilman, D. \& Woodwell, G.M. (1997) Ecosystem Services: Benefits Supplied to Human Societies by Natural Ecosystems. Issues in Ecology, 1, 1-18.

Darwin, C. (1859) On the Origin of Species. John Murray.

Decourtye, A., Henry, M. \& Desneux, N. (2013) Overhaul pesticide testing on bees. Nature, 497, 188.

Dhileepan, K. (1991) Insect pests of intercrops and their potential to infest oil palm in an oil-palm-based agroforestry system in India. Tropical Pest Management, 37, $57-58$. 
Digel, C., Curtsdotter, A., Riede, J., Klarner, B. \& Brose, U. (2014) Unravelling the complex structure of forest soil food webs: Higher omnivory and more trophic levels. Oikos, 1157-1172.

Dislich, C., Keyel, A.C., Salecker, J., Kisel, Y., Meyer, K.M., Corre, D., Faust, H., Hess, B., Knohl, A., Kreft, H., Meijide, A., Nurdiansyah, F., Otten, F., Pe'er, G., Steinebach, S., Tarigan, S., Tölle, M. \& Wiegand, K. (2015) Ecosystem Functions of Oil Palm Plantations - a Review. SFB 990 EFForTS, Ecological and Socioeconomic Functions of Tropical Lowland Rainforest Transformation Systems (Sumatra, Indonesien) - (EFForTS discussion paper series 16), University of Göttingen.

Donald, P.F. (2004) Biodiversity Impacts of Some Agricultural Commodity Production Systems. Conservation Biology, 18, 17-37.

Douglas, D.J.T., Nalwanga, D., Katebaka, R., Atkinson, P.W., Pomeroy, D.E., Nkuutu, D. \& Vickery, J.A. (2014) The importance of native trees for forest bird conservation in tropical farmland. Animal Conservation, 17, 256-264.

Edwards, R. (1996) Estimating live spider weight using preserved specimens. Journal of Arachnology, 24, 161-166.

Edwards, F.A., Edwards, D.P., Hamer, K.C. \& Davies, R.G. (2013) Impacts of logging and conversion of rainforest to oil palm on the functional diversity of birds in Sundaland. Ibis, 155, 313-326.

Edwards, F.A., Edwards, D.P., Larsen, T.H., Hsu, W.W., Benedick, S., Chung, A., Vun Khen, C., Wilcove, D.S. \& Hamer, K.C. (2014) Does logging and forest conversion to oil palm agriculture alter functional diversity in a biodiversity hotspot? Animal Conservation, 17, 163-173.

Edwards, D.P., Fisher, B. \& Wilcove, D.S. (2011) Green labelling being misused. Nature, 475, 174.

Edwards, D.P., Hodgson, J.A., Hamer, K.C., Mitchell, S.L., Ahmad, A.H., Cornell, S.J. \& Wilcove, D.S. (2010) Wildlife-friendly oil palm plantations fail to protect biodiversity effectively. Conservation Letters, 3, 236-242.

Edwards, D.P. \& Laurance, S.G. (2012) Green labelling, sustainability and the expansion of tropical agriculture: Critical issues for certification schemes. Biological Conservation, 151, 60-64.

Egbe, N.E. \& Adenikinju, S.A. (1990) Effect of intercropping on potential yield of cacao in south western Nigeria. Café, Cacao, Thé, 34, 281-284.

Ehrlich, P.R. \& Ehrlich, A.H. (1981) Extinction: The Causes and Consequences of the Disappearance of Species. Random House, New York. 
Eisenhauer, N., Reich, P.B. \& Scheu, S. (2012) Increasing plant diversity effects on productivity with time due to delayed soil biota effects on plants. Basic and Applied Ecology, 13, 571-578.

Ekadinata, A. \& Vincent, G. (2011) Rubber Agroforests in a Changing Landscape: Analysis of Land Use/Cover Trajectories in Bungo District, Indonesia. Forests, Trees and Livelihoods, 20, 3-14.

Elmhirst, R. (1999) Space, identity politics and resource control in Indonesia's transmigration programme. Political Geography, 18, 813-835.

Erhabor, J.O. \& Filson, G.C. (1999) Soil Fertility Changes Under an Oil Palm-Based Intercropping System. Journal of Sustainable Agriculture, 14, 45-61.

Erskine, P.D., Lamb, D. \& Bristow, M. (eds). (2005) Reforestation in the Tropics and Subtropics of Australia. RIRDC Publication No 05/087, Rural Industries Research and Development Corporation, Canberra.

Erskine, P.D., Lamb, D. \& Bristow, M. (2006) Tree species diversity and ecosystem function: Can tropical multi-species plantations generate greater productivity? Forest Ecology and Management, 233, 205-210.

Euler, M., Schwarze, S., Siregar, H. \& Qaim, M. (2015) Oil Palm Expansion among Smallholder Farmers in Sumatra, Indonesia. SFB 990 EFForTS, Ecological and Socioeconomic Functions of Tropical Lowland Rainforest Transformation Systems (Sumatra, Indonesien) - (EFForTS discussion paper series 8), University of Göttingen.

Ewers, R.M., Boyle, M.J.W., Gleave, R.A., Plowman, N.S., Benedick, S., Bernard, H., Bishop, T.R., Bakhtiar, E.Y., Chey, V.K., Chung, A.Y.C., Davies, R.G., Edwards, D.P., Eggleton, P., Fayle, T.M., Hardwick, S.R., Homathevi, R., Kitching, R.L., Khoo, M.S., Luke, S.H., March, J.J., Nilus, R., Pfeifer, M., Rao, S. V, Sharp, A.C., Snaddon, J.L., Stork, N.E., Struebig, M.J., Wearn, O.R., Yusah, K.M. \& Turner, E.C. (2015) Logging cuts the functional importance of invertebrates in tropical rainforest. Nature communications, 6, 6836.

Ewers, R.M., Scharlemann, J.P.W., Balmford, A. \& Green, R.E. (2009) Do increases in agricultural yield spare land for nature? Global Change Biology, 15, 1716-1726.

FAO. (2015) FAOSTAT Online Statistical Service, http://faostat3.fao.org/browse/Q/QC/E

FAO \& JRC. (2012) Global forest land-use change 1990-2005 (eds EJ Lindquist, R D’Annunzio, A Gerrand, K MacDicken, F Achard, R Beuchle, A Brink, HD Eva, P Mayaux, J San-Miguel-Ayanz, and H-J Stibig). FAO forestry paper, 169, 1-40.

Fayle, T.M., Turner, E.C., Snaddon, J.L., Chey, V.K., Chung, A.Y.C., Eggleton, P. \& 
Foster, W.A. (2010) Oil palm expansion into rain forest greatly reduces ant biodiversity in canopy, epiphytes and leaf-litter. Basic and Applied Ecology, 11, 337-345.

Fearnside, P.M. (1997) Transmigration in Indonesia: Lessons from Its Environmental and Social Impacts. Environmental Management, 21, 553-570.

Field, C.B., Campbell, J.E. \& Lobell, D.B. (2008) Biomass energy: the scale of the potential resource. Trends in ecology \& evolution, 23, 65-72.

Fischer, J., Batáry, P., Bawa, K.S., Brussaard, L., Chappell, M.J., Clough, Y., Daily, G.C., Dorrough, J., Hartel, T., Jackson, L.E., Klein, A.M., Kremen, C., Kuemmerle, T., Lindenmayer, D.B., Mooney, H.A., Perfecto, I., Philpott, S.M., Tscharntke, T., Vandermeer, J., Wanger, T.C. \& von Wehrden, H. (2011) Conservation: Limits of Land Sparing. Science, 334, 593.

Fischer, J., Stott, J. \& Law, B.S. (2010) The disproportionate value of scattered trees. Biological Conservation, 143, 1564-1567.

Fitzherbert, E.B., Struebig, M.J., Morel, A., Danielsen, F., Brühl, C.A., Donald, P.F. \& Phalan, B. (2008) How will oil palm expansion affect biodiversity? Trends in ecology \& evolution, 23, 538-545.

Foley, J.A., Defries, R., Asner, G.P., Barford, C., Bonan, G., Carpenter, S.R., Chapin, F.S., Coe, M.T., Daily, G.C., Gibbs, H.K., Helkowski, J.H., Holloway, T., Howard, E.A., Kucharik, C.J., Monfreda, C., Patz, J.A., Prentice, I.C., Ramankutty, N. \& Snyder, P.K. (2005) Global consequences of land use. Science, 309, 570-574.

Foster, W.A., Snaddon, J.L., Turner, E.C., Fayle, T.M., Cockerill, T.D., Ellwood, M.D.F., Broad, G.R., Chung, A.Y.C., Eggleton, P., Khen, C.V. \& Yusah, K.M. (2011) Establishing the evidence base for maintaining biodiversity and ecosystem function in the oil palm landscapes of South East Asia. Philosophical transactions of the Royal Society of London. Series B, Biological sciences, 366, 3277-3291.

Gatto, M., Wollni, M. \& Qaim, M. (2015) Oil palm boom and land-use dynamics in Indonesia: The role of policies and socioeconomic factors. Land Use Policy, 46, 292-303.

Geiger, F., Bengtsson, J., Berendse, F., Weisser, W.W., Emmerson, M., Morales, M.B., Ceryngier, P., Liira, J., Tscharntke, T., Winqvist, C., Eggers, S., Bommarco, R., Pärt, T., Bretagnolle, V., Plantegenest, M., Clement, L.W., Dennis, C., Palmer, C., Oñate, J.J., Guerrero, I., Hawro, V., Aavik, T., Thies, C., Flohre, A., Hänke, S., Fischer, C., Goedhart, P.W. \& Inchausti, P. (2010) Persistent negative effects of pesticides on biodiversity and biological control potential on European farmland. 
Basic and Applied Ecology, 11, 97-105.

Ghazoul, J., Koh, L.P. \& Butler, R.A. (2010) A REDD light for wildlife-friendly farming. Conservation Biology, 24, 644-645.

Gibbs, H.K., Ruesch, A.S., Achard, F., Clayton, M.K., Holmgren, P., Ramankutty, N. \& Foley, J.A. (2010) Tropical forests were the primary sources of new agricultural land in the 1980s and 1990s. Proceedings of the National Academy of Sciences, 107, 16732-16737.

Gibson, L., Lee, T.M., Koh, L.P., Brook, B.W., Gardner, T.A., Barlow, J., Peres, C.A., Bradshaw, C.J.A., Laurance, W.F., Lovejoy, T.E. \& Sodhi, N.S. (2011) Primary forests are irreplaceable for sustaining tropical biodiversity. Nature, 478, 378-381.

Gilbert, N. (2012) Palm-oil boom raises conservation concerns. Nature, 487, 14-15.

Gillison, A.N., Jones, D.T., Susilo, F.-X. \& Bignell, D.E. (2003) Vegetation indicates diversity of soil macroinvertebrates: a case study with termites along a land-use intensification gradient in lowland Sumatra. Organisms Diversity \& Evolution, 3, $111-126$.

Gilroy, J.J., Prescott, G.W., Cardenas, J.S., Castañeda, P.G.D.P., Sánchez, A., RojasMurcia, L.E., Medina Uribe, C.A., Haugaasen, T. \& Edwards, D.P. (2015) Minimizing the biodiversity impact of Neotropical oil palm development. Global Change Biology, 21, 1531-1540.

Gordon, C., Manson, R., Sundberg, J. \& Cruz-Angón, A. (2007) Biodiversity, profitability, and vegetation structure in a Mexican coffee agroecosystem. Agriculture, Ecosystems \& Environment, 118, 256-266.

Gouyon, A., Foresta, H. \& Levang, P. (1993) Does 'jungle rubber' deserve its name? An analysis of rubber agroforestry systems in southeast Sumatra. Agroforestry Systems, 22, 181-206.

Gowing, G. \& Recher, H.F. (1984) Length-weight relationships for invertebrates from forests in south-eastern New South Wales. Austral Ecology, 9, 5-8.

Green, R.E., Cornell, S.J., Scharlemann, J.P.W. \& Balmford, A. (2005) Farming and the fate of wild nature. Science, 307, 550-555.

Grimes, A., Loomis, S., Jahnige, P., Bunrham, M., Onthank, K., Alarcon, R., Cuenca, W., Martinez, C., Neill, D., Balick, M., Bennett, B. \& Mendelsohn, R. (1994) Valuing the rain forest: the economic value of nontimber forest products in Ecuador. Ambio, 23, 405-410.

Groom, M.J., Meffe, G.K. \& Carroll, C.R. (2006) Principles of Conservation Biology, 3rd ed. Sinauer Associates, Inc. 
Gruner, D.S. (2003) Regressions of length and width to predict arthropod biomass in the Hawaiian Islands. Pacific Science, 57, 325-336.

Guillaume, T., Damris, M. \& Kuzyakov, Y. (2015) Losses of soil carbon by converting tropical forest to plantations: erosion and decomposition estimated by $\delta{ }^{13} \mathrm{C}$. Global Change Biology, 21, 3548-3560.

Hall, J.S., Ashton, M.S., Garen, E.J. \& Jose, S. (2011) The ecology and ecosystem services of native trees: Implications for reforestation and land restoration in Mesoamerica. Forest Ecology and Management, 261, 1553-1557.

Hansen, M.C., Potapov, P. V, Moore, R., Hancher, M., Turubanova, S.A., Tyukavina, A., Thau, D., Stehman, S. V, Goetz, S.J., Loveland, T.R., Kommareddy, A., Egorov, A., Chini, L., Justice, C.O. \& Townshend, J.R.G. (2013) High-resolution global maps of 21st-century forest cover change. Science, 342, 850-853.

Harvey, C.A. (2000) Windbreaks enhance seed dispersal into agricultural landscapes in MOnteverde, Costa Rica. Ecological Applications, 10, 155-173.

Hassler, E., Corre, M.D., Tjoa, A., Damris, M., Utami, S.R. \& Veldkamp, E. (2015) Soil fertility controls soil-atmosphere carbon dioxide and methane fluxes in a tropical landscape converted from lowland forest to rubber and oil palm plantations. Biogeosciences, 12, 5831-5852.

Hector, A., Philipson, C., Saner, P., Chamagne, J., Dzulkifli, D., O’Brien, M., Snaddon, J.L., Ulok, P., Weilenmann, M., Reynolds, G. \& Godfray, H.C.J. (2011) The Sabah Biodiversity Experiment: a long-term test of the role of tree diversity in restoring tropical forest structure and functioning. Philosophical Transactions of the Royal Society B: Biological Sciences, 366, 3303-3315.

Herrera, J.M. \& García, D. (2009) The role of remnant trees in seed dispersal through the matrix: Being alone is not always so sad. Biological Conservation, 142, 149158 .

Höfer, H. \& Ott, R. (2009) Estimating biomass of Neotropical spiders and other arachnids (Araneae, Opiliones, Pseudoscorpiones, Ricinulei) by mass-length regressions. Journal of Arachnology, 37, 160-169.

Holl, K.D., Zahawi, R.A., Cole, R.J., Ostertag, R. \& Cordell, S. (2011) Planting Seedlings in Tree Islands Versus Plantations as a Large-Scale Tropical Forest Restoration Strategy. Restoration Ecology, 19, 470-479.

Hooper, D.U., Chapin III, F.S. \& Ewel, J.J. (2005) Effects of biodiversity on ecosystem functioning: a consensus of current knowledge. Ecological Monographs, 75, 3-35.

Hulme, M.F., Vickery, J.A., Green, R.E., Phalan, B., Chamberlain, D.E., Pomeroy, D.E., Nalwanga, D., Mushabe, D., Katebaka, R., Bolwig, S. \& Atkinson, P.W. 
(2013) Conserving the birds of Uganda's banana-coffee arc: land sparing and land sharing compared. PloS one, $\mathbf{8}$, e54597.

Immerzeel, D.J., Verweij, P.A., van der Hilst, F. \& Faaij, A.P.C. (2014) Biodiversity impacts of bioenergy crop production: a state-of-the-art review. GCB Bioenergy, 6, 183-209.

Isaacs, R., Tuell, J., Fiedler, A., Gardiner, M. \& Landis, D. (2009) Maximizing arthropod-mediated ecosystem services in agricultural landscapes: the role of native plants. Frontiers in Ecology and the Environment, 7, 196-203.

Isbell, F., Calcagno, V., Hector, A., Connolly, J., Harpole, W.S., Reich, P.B., SchererLorenzen, M., Schmid, B., Tilman, D., van Ruijven, J., Weigelt, A., Wilsey, B.J., Zavaleta, E.S. \& Loreau, M. (2011) High plant diversity is needed to maintain ecosystem services. Nature, 477, 199-202.

IUCN. (2014) Red List of threatened species, www.iucnredlist.org

IUCN. (2015) Red List of threatened species, www.iucnredlist.org

Jactel, H. \& Brockerhoff, E.G. (2007) Tree diversity reduces herbivory by forest insects. Ecology Letters, 10, 835-848.

Johnson, M. \& Strong, A. (2000) Length-weight relationships of Jamaican arthropods. Entomological News, 111, 270-281.

Kalka, M.B., Smith, A.R. \& Kalko, E.K. V. (2008) Bats limit arthropods and herbivory in a tropical forest. Science, $\mathbf{3 2 0}, 71$.

Kanowski, J., Catterall, C.P., Wardell-Johnson, G.W., Proctor, H. \& Reis, T. (2003) Development of forest structure on cleared rainforest land in eastern Australia under different styles of reforestation. Forest Ecology and Management, 183, 265-280.

Karp, D.S., Mendenhall, C.D., Sandí, R.F., Chaumont, N., Ehrlich, P.R., Hadly, E.A. \& Daily, G.C. (2013) Forest bolsters bird abundance, pest control and coffee yield. Ecology letters, 16, 1339-1347.

Kirui, B.Y.K., Huxham, M., Kairo, J. \& Skov, M. (2008) Influence of species richness and environmental context on early survival of replanted mangroves at Gazi bay, Kenya. Hydrobiologia, 603, 171-181.

Koh, L.P. (2008a) Can oil palm plantations be made more hospitable for forest butterflies and birds? Journal of Applied Ecology, 45, 1002-1009.

Koh, L.P. (2008b) Bird defend oil palms from herbivorous insects. Ecological Applications, 18, 821-825. 
Koh, L.P. \& Ghazoul, J. (2010) Spatially explicit scenario analysis for reconciling agricultural expansion, forest protection, and carbon conservation in Indonesia. Proceedings of the National Academy of Sciences of the United States of America, 107, 11140-11144.

Koh, L.P., Levang, P., Ghazoul, J., Bhagwat, S.A. \& Willis, K.J. (2009) Designer landscapes for sustainable biofuels. Trends in ecology \& evolution, 24, 431-438.

Koh, L.P. \& Wilcove, D.S. (2007) Cashing in palm oil for conservation. Nature, 448, 993-994.

Koh, L.P. \& Wilcove, D.S. (2008) Is oil palm agriculture really destroying tropical biodiversity? Conservation Letters, 1, 60-64.

Kotowska, M.M., Leuschner, C., Triadiati, T., Meriem, S. \& Hertel, D. (2015) Quantifying above- and belowground biomass carbon loss with forest conversion in tropical lowlands of Sumatra (Indonesia). Global Change Biology, 1-15.

Kragt, M.E. \& Robertson, M.J. (2014) Quantifying ecosystem services trade-offs from agricultural practices. Ecological Economics, 102, 147-157.

Kunz, T.H., Braun de Torrez, E., Bauer, D., Lobova, T. \& Fleming, T.H. (2011) Ecosystem services provided by bats. Annals of the New York Academy of Sciences, 1223, 1-38.

Lamb, D., Erskine, P.D. \& Parrotta, J. a. (2005) Restoration of degraded tropical forest landscapes. Science (New York, N.Y.), 310, 1628-32.

Lang, A., Krooss, S. \& Stumpf, H. (1997) Mass-length relationships of epigeal arthropod predators in arable land (Araneae, Chilopoda, Coleoptera). Pedobiologia, 41, 327-333.

Laumonier, Y. (1997) The Vegetation and Physiography of Sumatra. Springer Netherlands.

Laumonier, Y., Uryu, Y., Stüwe, M., Budiman, A., Setiabudi, B. \& Hadian, O. (2010) Eco-floristic sectors and deforestation threats in Sumatra: identifying new conservation area network priorities for ecosystem-based land use planning. Biodiversity and Conservation, 19, 1153-1174.

Laurance, W.F., Koh, L.P., Butler, R., Sodhi, N.S., Bradshaw, C.J.A., Neidel, J.D., Consunji, H. \& Mateo Vega, J. (2010) Improving the performance of the Roundtable on Sustainable Palm Oil for nature conservation. Conservation Biology, 24, 377-381.

Laurance, W.F., Sayer, J. \& Cassman, K.G. (2014) Agricultural expansion and its impacts on tropical nature. Trends in ecology \& evolution, 29, 107-116. 
Lawton, H.J. (1994) What do species do in ecosystems. Oikos, 71, 367-374.

Lee, J.S.H., Ghazoul, J., Obidzinski, K. \& Koh, L.P. (2013) Oil palm smallholder yields and incomes constrained by harvesting practices and type of smallholder management in Indonesia. Agronomy for Sustainable Development, 34, 501-513.

Lee, A.K. \& Kasbi, H. (1980) Intercropping cocoa and oil palm. Proceedings of the International Conference on Cocoa and Coconuts. Kuala Lumpur, Malaysia, June 21 24, 1978. pp. 158-171.

Legendre, P. \& De Cáceres, M. (2013) Beta diversity as the variance of community data: Dissimilarity coefficients and partitioning. Ecology Letters, 16, 951-963.

Lin, B.B. (2011) Resilience in Agriculture through Crop Diversification: Adaptive Management for Environmental Change. BioScience, 61, 183-193.

Lindell, C.A., Reid, J.L. \& Cole, R.J. (2013) Planting design effects on avian seed dispersers in a tropical forest restoration experiment. Restoration Ecology, 21, $515-522$.

Lucey, J.M. \& Hill, J.K. (2012) Spillover of Insects from Rain Forest into Adjacent Oil Palm Plantations. Biotropica, 44, 368-377.

Lucey, J.M., Tawatao, N., Senior, M.J.M., Chey, V.K., Benedick, S., Hamer, K.C., Woodcock, P., Newton, R.J., Bottrell, S.H. \& Hill, J.K. (2014) Tropical forest fragments contribute to species richness in adjacent oil palm plantations. Biological Conservation, 169, 268-276.

Luskin, M.S. \& Potts, M.D. (2011) Microclimate and habitat heterogeneity through the oil palm lifecycle. Basic and Applied Ecology, 12, 540-551.

Maas, B., Clough, Y. \& Tscharntke, T. (2013) Bats and birds increase crop yield in tropical agroforestry landscapes. Ecology letters, 16, 1480-1487.

Maas, B., Tscharntke, T., Saleh, S., Dwi Putra, D. \& Clough, Y. (2015) Avian species identity drives predation success in tropical cacao agroforestry. Journal of Applied Ecology, 52, 735-743.

MacKinnon, J., Phillipps, K. \& Andrew, P. (1993) A Field Guide to Birds of Borneo, Sumatra and Bali: The Greater Sunda Islands. Oxford University Press.

Manning, A.D., Fischer, J. \& Lindenmayer, D.B. (2006) Scattered trees are keystone structures - Implications for conservation. Biological Conservation, 132, 311321.

Margono, B.A., Potapov, P. V, Turubanova, S., Stolle, F. \& Hansen, M.C. (2014) Primary forest cover loss in Indonesia over 2000-2012. Nature Climate Change, 4, 730-735. 
Matson, P.A., Parton, W.J., Power, A.G. \& Swift, M.J. (1997) Agricultural Intensification and Ecosystem Properties. Science, 277, 504-509.

McCarthy, J. (2010) Processes of inclusion and adverse incorporation: oil palm and agrarian change in Sumatra, Indonesia. The Journal of peasant studies, 37, 821850.

McCarthy, J.F., Gillespie, P. \& Zen, Z. (2012) Swimming Upstream: Local Indonesian Production Networks in 'Globalized' Palm Oil Production. World Development, 40, 555-569.

McGill, B. (2015) Land use matters. Nature, 520, 38-39.

Mendenhall, C.D., Karp, D.S., Meyer, C.F.J., Hadly, E.A. \& Daily, G.C. (2014) Predicting biodiversity change and averting collapse in agricultural landscapes. Nature, 509, 213-217.

Mercer, R., Gabriel, A., Barendse, J., Marshall, D. \& Chown, S. (2001) Invertebrate body sizes from Marion Island. Antarctic Science, 13, 135-143.

Miccolis, A., Vasconcelos, S., Castellani, D., Carvalho, V., Kato, O. \& Silva, A. (2014) Oil palm and Agroforestry Systems: coupling yields with environmental services, an experiment in the Brazilian Amazon, http://de.slideshare.net/agroforestry/session-66-oil-palm-agroforestry-systemsbrazilian-amazon

Miettinen, J., Shi, C. \& Liew, S.C. (2011) Deforestation rates in insular Southeast Asia between 2000 and 2010. Global Change Biology, 17, 2261-2270.

Millenium Ecosystem Assessment. (2005) Ecosystems and Human Well-Being: Biodiversity Synthesis. World Resources Institute, Washington, DC.

Monastersky, R. (2014) Life - a status report. Nature, 516, 159-161.

Moreira, X., Abdala-Roberts, L., Parra-Tabla, V. \& Mooney, K.A. (2014) Positive Effects of Plant Genotypic and Species Diversity on Anti-Herbivore Defenses in a Tropical Tree Species. PLoS ONE, 9, e105438.

Morley, R. (2009) Tropical Rain Forests. Earth system Vol. 3: History and Natural Variability (eds V. Cilek),, V.N. Livchits), \& V. V Tokarev), Oxford Eolss Publishers, Oxford, UK.

Myers, N., Mittermeier, R.A., Mittermeier, C.G., Fonseca, G.A.B. \& Kent, J. (2000) Biodiversity hotspots for conservation priorities. Nature, 403, 853-858.

Naeem, S., Bunker, D.E., Hector, A., Loreau, M. \& Perrings, C. (2009) Biodiversity, Ecosystem, Functioning, \& Human Wellbeing: An Ecological and Economic Perspective. Oxford University Press. 
Naeem, S., Chair, F.S.C.I., Costanza, R., Ehrlich, P.R., Golley, F.B., Hooper, D.U., Lawton, J.H., O’Neill, R. V., Mooney, H.A., Sala, O.E., Symstad, A.J. \& Tilman, D. (1999) Biodiversity and Ecosystem Functioning: Maintaining Natural Life Support Processes. Bulletin of the Ecological Society of America, 4, 1-12.

Newbold, T., Hudson, L.N., Hill, S.L.L., Contu, S., Lysenko, I., Senior, R.A., Börger, L., Bennett, D.J., Choimes, A. \& Collen, B. (2015) Global effects of land use on local terrestrial biodiversity. Nature, 520, 45-50.

Obidzinski, K., Andriani, R., Komarudin, H. \& Andrianto, A. (2012) Environmental and Social Impacts of Oil Palm Plantations and their Implications for Biofuel Production in Indonesia. Ecology and Society, 17, 25.

Ojea, E. \& Martin-Ortega, J. (2015) Understanding the economic value of water ecosystem services from tropical forests: A systematic review for South and Central America. Journal of Forest Economics, 21, 1-10.

Okpala, A. (1995) Resources, environment and economic development in Nigeria. Journal of developing societies, 11, 151-158.

Ott, D., Digel, C., Klarner, B., Maraun, M., Pollierer, M., Rall, B.C., Scheu, S., Seelig, G. \& Brose, U. (2014) Litter elemental stoichiometry and biomass densities of forest soil invertebrates. Oikos, 123, 1212-1223.

Paddison, L. (2014) Palm oil: the secret in your shopping basket - have your say. The Guardian.

Peh, K.S.-H., Sodhi, N.S., de Jong, J., Sekercioglu, C.H., Yap, C. a.-M. \& Lim, S.L.-H. (2006) Conservation value of degraded habitats for forest birds in southern Peninsular Malaysia. Diversity and Distributions, 12, 572-581.

Perfecto, I. \& Vandermeer, J. (2002) Quality of agroecological matrix in a tropical montane landscape: Ants in coffee plantations in Southern Mexico. Conservation Biology, 16, 174-182.

Perfecto, I., Vandermeer, J., Mas, A. \& Pinto, L.S. (2005) Biodiversity, yield, and shade coffee certification. Ecological Economics, 54, 435-446.

Perfecto, I., Vandermeer, J. \& Philpott, S.M. (2014) Complex Ecological Interactions in the Coffee Agroecosystem. Annual Review of Ecology, Evolution, and Systematics, 45, 37-58.

Perring, M.P., Standish, R.J., Price, J.N., Craig, M.D., Erickson, T.E., Ruthrof, K.X., Whiteley, A.S., Valentine, L.E. \& Hobbs, R.J. (2015) Advances in restoration ecology: rising to the challenges of the coming decades. Ecosphere, $\mathbf{6}, 131$.

Petit, B. \& Montagnini, F. (2006) Growth in pure and mixed plantations of tree species 
used in reforesting rural areas of the humid region of Costa Rica, Central America. Forest Ecology and Management, 233, 338-343.

Phalan, B., Balmford, A., Green, R.E. \& Scharlemann, J.P.W. (2011a) Minimising the harm to biodiversity of producing more food globally. Food Policy, 36, S62-S71.

Phalan, B., Bertzky, M., Butchart, S.H.M., Donald, P.F., Scharlemann, J.P.W., Stattersfield, A.J. \& Balmford, A. (2013) Crop expansion and conservation priorities in tropical countries. PloS one, 8, e51759.

Phalan, B., Fitzherbert, E.B., Rafflegeau, S., Struebig, M.J. \& Verwilghen, A. (2009) Conservation in oil-palm landscapes. Conservation Biology, 23, 244-245.

Phalan, B., Onial, M., Balmford, A. \& Green, R.E. (2011b) Reconciling food production and biodiversity conservation: land sharing and land sparing compared. Science, 333, 1289-1291.

Potvin, C. \& Gotelli, N.J. (2008a) Biodiversity enhances individual performance but does not affect survivorship in tropical trees. Ecology letters, 11, 217-23.

Potvin, C. \& Gotelli, N.J. (2008b) Biodiversity enhances individual performance but does not affect survivorship in tropical trees. Ecology letters, 11, 217-223.

Prabowo, W.E., Darras, K., Clough, Y., Hernandez, M.T., Arlettaz, R. \& Tscharntke, T. (2015) Bird responses to lowland rainforest transformation in Sumatran smallholder landscapes, Indonesia. submitted.

Pywell, R.F., Heard, M.S., Bradbury, R.B., Hinsley, S., Nowakowski, M., Walker, K.J. \& Bullock, J.M. (2012) Wildlife-friendly farming benefits rare birds, bees and plants. Biology letters, 8, 772-775.

Quijas, S., Schmid, B. \& Balvanera, P. (2010) Plant diversity enhances provision of ecosystem services: A new synthesis. Basic and Applied Ecology, 11, 582-593.

R Core Team. (2014) R: A language and environment for statistical computing. R Foundation for Statistical Computing, Vienna, Austria. URL http://www.Rproject.org/.

R Core Team. (2015) R: A language and environment for statistical computing. $\mathrm{R}$ Foundation for Statistical Computing, Vienna, Austria. URL http://www.Rproject.org/.

Raudsepp-Hearne, C., Peterson, G.D., Tengö, M., Bennett, E.M., Holland, T., Benessaiah, K., MacDonald, G.K. \& Pfeifer, L. (2010) Untangling the Environmentalist's Paradox: Why Is Human Well-being Increasing as Ecosystem Services Degrade? BioScience, 60, 576-589.

Rey-Benayas, J.M., Newton, A.C., Diaz, A. \& Bullock, J.M. (2009) Enhancement of 
Biodiversity and Ecosystem Services by Ecological Restoration: A Meta-Analysis. Science, 8, 1121-1124.

Rianto, B., Mochtar, H. \& Sasmito, A. (2012) Palm Oil Plantation. Industry Landscape, Regulatory and Financial Overview. PwC Indonesia, Jakarta.

Rist, L., Feintrenie, L. \& Levang, P. (2010) The livelihood impacts of oil palm: smallholders in Indonesia. Biodiversity and Conservation, 19, 1009-1024.

Rockström, J., Will, S., Noone, K., Persson, Å., Chapin, F.S., Lambin, E.F., Lenton, T.M., Scheffer, M., Folke, C., Schellnhuber, H.J., Nykvist, B., de Wit, C.A., Hughes, T., van der Leeuw, S., Rodhe, H., Sörlin, S., Snyder, P.K., Costanza, R., Svedin, U., Falkenmark, M., Karlberg, L., Corell, R.W., Fabry, V.J., Hansen, J., Walker, B., Liverman, D., Richardson, K., Crutzen, P. \& Foley, J.A. (2009) A safe operating space for humanity. Nature, 461, 472-475.

Röll, A., Niu, F., Meijide, A., Hardanto, A., Hendrayanto, Knohl, A. \& Hölscher, D. (2015) Transpiration in an oil palm landscape: effects of palm age. Biogeosciences, 12, 5619-5633.

Rotenberg, J. \& Stouffer, P. (2007) Ecological role of a tree (Gmelina arborea) plantation in Guatemala: an assessment of an alternative land use for tropical avian conservation. The Auk, 124, 316-330.

RSPO. (2013) Principles and Criteria for the Production of Sustainable Palm Oil, http://www.rspo.org/file/PnC_RSPO_Rev1.pdf

Sala, O.E., Chapin, F.S., Armesto, J.J., Berlow, E., Bloomfield, J., Dirzo, R., HuberSanwald, E., Huenneke, L.F., Jackson, R.B., Kinzig, A., Leemans, R., Lodge, D.M., Mooney, H.A., Oesterheld, M., Poff, N.L., Sykes, M.T., Walker, B.H., Walker, M. \& Wall, D.H. (2000) Global Biodiversity Scenarios for the Year 2100. Science, 287, 1770-1774.

Salako, E., Lal, R. \& Swift, M. (1995) Intercropping oil palm (Elaeis guineensis) with Cocoyam (Xanthosoma saggitifolium) on windrows and non-windrows in southern Nigeria. Journal of Sustainable Agriculture, 6, 47-60.

Salisbury, C.L. \& Potvin, C. (2015) Does Tree Species Composition Affect Productivity in a Tropical Planted Forest? Biotropica, 47, 559-568.

Sample, B.E., Cooper, R.J., Greer, R.D. \& Whitmore, R.C. (1993) Estimation of Insect Biomass by Length and Width. American Midland Naturalist, 129, 234.

Scherer-Lorenzen, M., Bonilla, J.L. \& Potvin, C. (2007) Tree species richness affects litter production and decomposition rates in a tropical biodiversity experiment. Oikos, 116, 2108-2124. 
Scherer-Lorenzen, M., Potvin, C., Koricheva, J., Schmid, B., Hector, A., Bornik, Z., Reynolds, G. \& Schulz, E.D. (2005) The design of experimental tree plantations for functional biodiversity research. Forest Diversity and Function. Temperate and boreal systems. (eds M. Scherer-Lorenzen),, C. Körner), \& E. Schulze), pp. 347-376. Springer, Berlin, Heidelberg.

Schielzeth, H. (2010) Simple means to improve the interpretability of regression coefficients. Methods in Ecology and Evolution, 1, 103-113.

Schroth, G., da Fonseca, G.A.B., Harvey, C.A., Vasconcelos, H.L., Goscon, C. \& Izar, A.-M.N. (eds). (2004) Agroforestry and Biodiversity Conservation in Tropical Landscapes. Island Press, Washington.

Schuldt, A., Baruffol, M., Böhnke, M., Bruelheide, H., Härdtle, W., Lang, A.C., Nadrowski, K., von Oheimb, G., Voigt, W., Zhou, H., Assmann, T. \& Fridley, J. (2010) Tree diversity promotes insect herbivory in subtropical forests of southeast China. The Journal of Ecology, 98, 917-926.

Schuldt, A., Bruelheide, H., Härdtle, W., Assmann, T., Li, Y., Ma, K., von Oheimb, G. \& Zhang, J. (2015) Early positive effects of tree species richness on herbivory in a large-scale forest biodiversity experiment influence tree growth. Journal of Ecology, 103, 563-571.

Sekercioglu, C.H. (2002) Effects of forestry practices on vegetation structure and bird community of Kibale National Park, Uganda. Biological Conservation, 107, 229240.

Sekercioğlu, C.H. (2006) Increasing awareness of avian ecological function. Trends in Ecology \& Evolution, 21, 464-471.

Sekercioğlu, C.H., Daily, G.C. \& Ehrlich, P.R. (2004) Ecosystem consequences of bird declines. Proceedings of the National Academy of Sciences of the United States of America, 101, 18042-18047.

Sekercioglu, C.H., Ehrlich, P.R., Daily, G.C., Aygen, D., Goehring, D. \& Sandi, R.F. (2002) Disappearance of insectivorous birds from tropical forest fragments. Proceedings of the National Academy of Sciences of the United States of America, 99, 263-267.

Sheil, D., Casson, A., Meijaard, E., van Nordwijk, M., Gaskell, J., Sunderland-Groves, J., Wertz, K. \& Kanninen, M. (2009) The Impacts and Opportunities of Oil Palm in Southeast Asia: What Do We Know and What Do We Need to Know? Occasional paper no. 51. Cifor, Bogor, Indonesia.

Sodhi, N.S., Koh, L.P., Brook, B.W. \& Peter, K.L.N. (2004) Southeast Asian biodiversity: an impending disaster. Trends in ecology \& evolution, 19, 654-660. 
Southwood, T.R.E., Wint, G.R.W., Kennedy, C.E.J. \& Greenwood, S.R. (2004) Seasonality, abundance, species richness and specificity of the phytophagous guild of insects on oak (Quercus) canopies. European Journal of Entomology, 101, 4350.

Srivastava, D.S. \& Vellend, M. (2005) Biodiversity-Ecosystem Function Research: Is It Relevant to Conservation? Annual Review of Ecology, Evolution, and Systematics, 36, 267-294.

Staab, M., Blüthgen, N. \& Klein, A.-M. (2015) Tree diversity alters the structure of a tri-trophic network in a biodiversity experiment. Oikos, 124, 827-834.

Steffan-Dewenter, I., Kessler, M., Barkmann, J., Bos, M.M., Buchori, D., Erasmi, S., Faust, H., Gerold, G., Glenk, K., Gradstein, S.R., Guhardja, E., Harteveld, M., Hertel, D., Höhn, P., Kappas, M., Köhler, S., Leuschner, C., Maertens, M., Marggraf, R., Migge-Kleian, S., Mogea, J., Pitopang, R., Schaefer, M., Schwarze, S., Sporn, S.G., Steingrebe, A., Tjitrosoedirdjo, S.S., Tjitrosoemito, S., Twele, A., Weber, R., Woltmann, L., Zeller, M. \& Tscharntke, T. (2007) Tradeoffs between income, biodiversity, and ecosystem functioning during tropical rainforest conversion and agroforestry intensification. Proceedings of the National Academy of Sciences of the United States of America, 104, 4973-4978.

Stein, A., Gerstner, K. \& Kreft, H. (2014) Environmental heterogeneity as a universal driver of species richness across taxa, biomes and spatial scales. Ecology letters, 866-880.

Storkey, J., Brooks, D., Haughton, A., Hawes, C., Smith, B.M. \& Holland, J.M. (2013) Using functional traits to quantify the value of plant communities to invertebrate ecosystem service providers in arable landscapes. Journal of Ecology, 101, 38-46.

Teuscher, M., Vorlaufer, M., Wollni, M., Brose, U., Mulyani, Y. \& Clough, Y. (2015) Trade-offs between bird diversity and abundance, yields and revenue in smallholder oil palm plantations in Sumatra, Indonesia. Biological Conservation, 186, 306-318.

Tews, J., Brose, U., Grimm, V., Tielborger, K., Wichmann, M., Schwager, M. \& Jeltsch, F. (2004) Animal species diversity driven by habitat heterogeneity/diversity: the importance of keystone structures. Journal of Biogeography, 31, 79-92.

The Jakarta Post. (2009) Indonesia allocates 18 million hectares of land for palm oil. The Jakarta Post.

The World Bank. (2011) The World Bank Group Framework and IFC Strategy for Engagement in the Palm Oil Sector. International Finance Corporation. World 
Bank Group, Washington.

Thiollay, J.-M. (1995) The Role of Traditional Agroforests in the Conservation of Rain Forest Bird Diversity in Sumatra. Conservation Biology, 9, 335-353.

Tilman, D., Cassman, K.G., Matson, P.A., Naylor, R. \& Polasky, S. (2002) Agricultural sustainability and intensive production practices. Nature, 418, 671-677.

TreeDivNet. (2015) www.TreeDivNet.ugent

Tscharntke, T., Clough, Y., Bhagwat, S.A., Buchori, D., Faust, H., Hertel, D., Hölscher, D., Juhrbandt, J., Kessler, M., Perfecto, I., Scherber, C., Schroth, G., Veldkamp, E. \& Wanger, T.C. (2011) Multifunctional shade-tree management in tropical agroforestry landscapes - a review. Journal of Applied Ecology, 48, 619629.

Tscharntke, T., Clough, Y., Wanger, T.C., Jackson, L., Motzke, I., Perfecto, I., Vandermeer, J. \& Whitbread, A. (2012a) Global food security, biodiversity conservation and the future of agricultural intensification. Biological Conservation, 151, 53-59.

Tscharntke, T., Sekercioğlu, C.H., Dietsch, T., Sodhi, N.S., Hoehn, P. \& Tylianakis, J.M. (2008) Landscape constraints on functional diversity of birds and insects in tropical agroecosystems. Ecology, 89, 944-951.

Tscharntke, T., Tylianakis, J.M., Rand, T.A., Didham, R.K., Fahrig, L., Batáry, P., Bengtsson, J., Clough, Y., Crist, T.O., Dormann, C.F., Ewers, R.M., Fründ, J., Holt, R.D., Holzschuh, A., Klein, A.M., Kleijn, D., Kremen, C., Landis, D.A., Laurance, W., Lindenmayer, D., Scherber, C., Sodhi, N., Steffan-Dewenter, I., Thies, C., van der Putten, W.H. \& Westphal, C. (2012b) Landscape moderation of biodiversity patterns and processes - eight hypotheses. Biological Reviews, 87, $661-685$.

Turner, E.C. \& Foster, W.A. (2008) The impact of forest conversion to oil palm on arthropod abundance and biomass in Sabah, Malaysia. Journal of Tropical Ecology, 25, 23-30.

Turner, E.C., Snaddon, J.L., Fayle, T.M. \& Foster, W.A. (2008) Oil palm research in context: identifying the need for biodiversity assessment. PloS one, 3, e1572.

UNCTAD. (2015) United Nations Conference On Trade And Development, www.unctad.info/en/Infocomm/AACP-Products/Palm-oil/

Villamor, G.B., Pontius, R.G. \& van Noordwijk, M. (2014) Agroforest's growing role in reducing carbon losses from Jambi (Sumatra), Indonesia. Regional Environmental Change, 14, 825-834. 
Vitousek, P.M. \& Hooper, D.U. (1997) Biologicl diversity and terrestrial ecosystem biogeochemistry. Biodiversity and ecosystem function (eds E.D. Schulze), \& H.A. Mooney), pp. 3-14. Springer Verlag, New York.

Vorlaufer, M. (2015) Designing Incentive Mechanisms for Sustainable Land Management: Empirical Evidence from Indonesia. Dissertation, University of Göttingen.

Waldron, A., Justicia, R., Smith, L. \& Sanchez, M. (2012) Conservation through Chocolate: a win-win for biodiversity and farmers in Ecuador's lowland tropics. Conservation Letters, 5, 213-221.

Walker, B.H. (1992) Biodiversity and Ecological Redundancy. Conservation Biology, 6, 18-23.

Walther, B.A. (2002) Vertical stratification and use of vegetation and light habitats by Neotropical forest birds. Journal of Ornithology, 143, 64-81.

Wardhaugh, C.W. (2013) Estimation of biomass from body length and width for tropical rainforest canopy invertebrates. Australian Journal of Entomology, 52, 291-298.

Whelan, C.J., Wenny, D.G. \& Marquise, R.J. (2008) Ecosystem services provided by birds. Annals of the New York Academy of Sciences, 1134, 25-60.

Whitmore, T. (1998) An Introduction to Tropical Rain Forests. Oxford University Press, Oxford, UK.

Whittaker, R.H. (1960) Vegetation of the Siskiyou Mountains, Oregon and California. Ecological Monographs, 30, 279-338.

Whitten, T. (2000) The Ecology of Sumatra. Periplus Editions.

Wilcove, D.S., Giam, X., Edwards, D.P., Fisher, B. \& Koh, L.P. (2013) Navjot's nightmare revisited: logging, agriculture, and biodiversity in Southeast Asia. Trends in ecology \& evolution, 28, 531-540.

Wilcove, D.S. \& Koh, L.P. (2010) Addressing the threats to biodiversity from oil-palm agriculture. Biodiversity and Conservation, 19, 999-1007.

Wilman, H., Belmaker, J., Simpson, J., de la Rosa, C., Rivadeneira, M.M. \& Jetz, W. (2014) EltonTraits 1.0: Species-level foraging attributes of the world's birds and mammals. Ecology, 95, 2027-2027.

Wilson, E. (1987) The little things that run the world (The Importance and Conservation of Invertebrates). Conservation Biology, 1, 344-346.

World Trade Organization. (2010) World Trade Report 2010. Trade in natural 
resources.

Wright, J., Symstad, A., Bullock, J.M., Engelhardt, K., Jackson, L. \& Bernhardt, E. (2009) Restoring biodiversity and ecosystem function: will an integrated approach improve results? Biodiversity, Ecosystem Funtioning, and Human Well-Being (eds S. Naeem),, D.E. Bunker),, A. Hector),, M. Loreau), \& C. Perrings), pp. 167-177. Oxford University Press, Oxford, UK.

Yarranton, G.A. \& Morrison, R.G. (1974) Spatial Dynamics of a Primary Succession: Nucleation. Journal of Ecology, 62, 417-428.

Zahawi, R.A. \& Augspurger, C.K. (2006) Tropical forest restoration: tree islands as recruitment foci in degraded lands of Honduras. Ecological Applications, 16, 464478 .

Zahawi, R.A., Holl, K.D., Cole, R.J. \& Reid, J.L. (2013) Testing applied nucleation as a strategy to facilitate tropical forest recovery. Journal of Applied Ecology, 50, 88-96.

Zhang, P., He, L., Fan, X., Huo, P., Liu, Y., Zhang, T., Pan, Y. \& Yu, Z. (2015) Ecosystem Service Value Assessment and Contribution Factor Analysis of Land Use Change in Miyun County, China. Sustainability, 7, 7333-7356. 



\title{
Supplementary Information - Chapter 2
}

\author{
Supplementary table
}

Table S 2.1: List of bird species recorded within a $25 \mathrm{~m}$ radius around the centre of oil palm plantations

\begin{tabular}{|c|c|c|c|c|}
\hline species name & family & common name & a habitat & ${ }_{\mathrm{b}} \mathrm{IUCN}$ \\
\hline Aegithina viridissima & Aegithinidae & Green Iora & gene & NT \\
\hline Aegithina tiphia & Aegithinidae & Common Iora & gene & LC \\
\hline Aethopyga siparaja & Nectariniidae & Crimson Sunbird & gene & LC \\
\hline Amaurornis phoenicurus & Rallidae & White-breasted Waterhen & gene & LC \\
\hline Anthreptes malacensis & Nectariniidae & Plain-throated Sunbird & openco & $\mathrm{LC}$ \\
\hline Artamus leucorhynchus & Artamidae & White-breasted Woodswallow & openco & LC \\
\hline Celeus brachyurus & Picidae & Rufous Woodpecker & edgetol & $\mathrm{LC}$ \\
\hline Centropus bengalensis & Cuculidae & Lesser Coucal & openco & LC \\
\hline Centropus sinensis & Cuculidae & Greater Coucal & openco & LC \\
\hline Chalcophaps indica & Columbidae & Emerald Dove & edgetol & LC \\
\hline Chrysocolaptes lucidus & Picidae & Greater Flameback & edgespec & LC \\
\hline Cisticola exilis & Cisticolidae & Golden-headed Cisticola & openco & LC \\
\hline Dicaeum cruentatum & Dicaeidae & Scarlet-backed Flowerpecker & edgetol & LC \\
\hline Dicaeum trigonostigma & Dicaeidae & Orange-bellied Flowerpecker & edgetol & LC \\
\hline Gallus gallus & Phasianidae & Red Junglefowl & openco & LC \\
\hline Halcyon chloris & Alcedinidae & Collared Kingfisher & openco & LC \\
\hline Halcyon smyrnensis & Alcedinidae & White-throated Kingfisher & openco & LC \\
\hline Hirundo rustica & Hirundinidae & Barn Swallow & openco & LC \\
\hline Lonchura leucogastra & Estrildidae & White-bellied Munia & openco & LC \\
\hline Lonchura molucca & Estrildidae & Black-faced Munia & openco & LC \\
\hline Lonchura punctulata & Estrildidae & Nutmeg Mannikin & openco & LC \\
\hline Loriculus galgulus & Psittacidae & Blue-crowned Hanging-parrot & edgetol & LC \\
\hline Megalaima haemacephala & Ramphastidae & Coppersmith Barbet & openco & LC \\
\hline Orthotomus atrogularis & Sylviidae & Dark-necked Tailorbird & edgespe & LC \\
\hline Orthotomus ruficeps & Sylviidae & Ashy Tailorbird & edgespe & LC \\
\hline Orthotomus sericeus & Sylviidae & Rufous-tailed Tailorbird & edgespe & $\mathrm{LC}$ \\
\hline Prinia familiaris & Cisticolidae & Bar-winged Prinia & openco & $\mathrm{LC}$ \\
\hline Prinia flaviventris & Cisticolidae & Yellow-bellied Prinia & openco & $\mathrm{LC}$ \\
\hline Pycnonotus aurigaster & Pycnonotidae & Sooty-headed Bulbul & edgespec & $\mathrm{LC}$ \\
\hline Pycnonotus goiavier & Pycnonotidae & Yellow-vented Bulbul & gene & $\mathrm{LC}$ \\
\hline Pycnonotus plumosus & Pycnonotidae & Olive-winged Bulbul & edgespec & LC \\
\hline Rhipidura javanica & Rhipiduridae & Pied Fantail & forspec & $\mathrm{LC}$ \\
\hline Streptopelia chinensis & Columbidae & Spotted Dove & gene & LC \\
\hline
\end{tabular}

a: Habitat affinities of birds as classified by Rotenberg and Stouffer (2007): forspec $=$ forest specialist, edgetol $=$ edge-tolerant forest species, edgespec $=$ edge specialist, openco $=$ open-semiopen species, gene $=$ Generalist b: IUCN status (IUCN 2014): LC = least concern, NT = near threatened 


\section{Questionnaire for household study: "tree enrichment"}

We are students from Gottingen University-Germany, Universitas Jambi and IPB , Bogor, who are studying the impact of intercropping fruit and timber trees in oil palm plantations on bird biodiversity. Your participation in answering these questions is very much appreciated. Your responses will be COMPLETELY CONFIDENTIAL and will only be used for research purpose. Your responses will be added to those of 120 other households and analyzed together. If you indicate your voluntary consent by participating in this interview, may we begin?

\section{Household Identification}

\begin{tabular}{|c|c|c|}
\hline QID & Question & Answer \\
\hline 1 & Interviewer (Name) & \\
\hline 2 & Respondent (Full name) & \\
\hline 3 & Is the respondent HHhead? (1) Yes ; (2) No & \\
\hline 3.1 & If QID 3=2 HHhead's Full name & \\
\hline 4 & Village (Name) & \\
\hline 5 & RT & \\
\hline 6 & Date of interview (mm/dd/20YY) & $1 / 20$ \\
\hline 7 & Time of interview & From___.___till___.__ \\
\hline 8 & Signature of interviewer & \\
\hline
\end{tabular}

\section{General plot information (oil palm farmer)}

[A plot is defined as a piece of land under one crop, which is not segmented spatially and where the managerial practices are common and palms/trees are of approximately the same age.]

How many oil palm plots do you have? 


\begin{tabular}{|c|c|c|c|c|c|c|}
\hline QID & & Plot 1 & Plot 2 & Plot 3 & Plot 4 & Plot 5 \\
\hline 1 & Area of plot (ha) & & & & & \\
\hline 2 & Number of oil palms in the plot (\#) & & & & & \\
\hline 3 & Year of planting & & & & & \\
\hline 4 & Year of first harvest ever (YYYY) & & & & & \\
\hline 5 & Year of last replanting in the plot (YYYY) & & & & & \\
\hline 6 & $\begin{array}{l}\text { If replanted, year of first harvest after } \\
\text { replanting (YYYY) }\end{array}$ & & & & & \\
\hline
\end{tabular}

Selection criteria for the "specific plot": biggest (ha) one of all the plots and the plot must be already productive

Plot number:

7. Who is currently managing the plot? (1) household; (2) entrusted to company; (3) entrusted to farmer cooperative; (4) others, specify:

8. Is the plot managed by sharecropping? (1) Yes; (2) No

If QID 8>1 or 8=1, change plot.

\section{Specific plot information}

\subsection{Ownership}

The following questions refer to the specific plot. Now we would like to ask you some questions about your biggest plot, the one you mentioned that has ha.

\begin{tabular}{|l|l|l|}
\hline QID & Question & Answer \\
\hline 1 & Ownership of land? (1) leased-in; (2) owned & \\
\hline 2 & $\begin{array}{l}\text { If land leased in: Amount of rent paid in last 12 months } \\
\text { ('000 Rp) }\end{array}$ & \\
\hline
\end{tabular}




\subsection{Oil palms on the specific plot}

\begin{tabular}{|c|c|c|}
\hline QID & Question & Answer \\
\hline 3 & Number of different oil palm varieties & \\
\hline 4 & Name of Variety 1 (number of oil palms per variety1) & \\
\hline 5 & Name of Variety 2 (number of oil palms per variety2) & \\
\hline 6 & Number of oil palms which are not productive in the plot & \\
\hline 7 & Number of oil palms which are affected by diseases or pests & \\
\hline 8 & $\begin{array}{l}\text { What kind of pest or disease do you experience on your oil palm plot? (1) rats (2) } \\
\text { pigs (3) pest insects (4) others, specify } \\
\text { (Multiple answers possible) }\end{array}$ & \\
\hline 9 & Distance between oil palm (___ meters*___ meters) & \\
\hline 10 & Number of oil palm rows & \\
\hline 11 & Number of oil palm trees per row & \\
\hline 12 & Have you ever used fire for clearing the land? (1) Yes; (2) No & \\
\hline 13 & If QID12=1, Year of last clearing using fire (YYYY) & \\
\hline 14 & $\begin{array}{l}\text { In the last } 12 \text { months did you keep the cut-off plants and crop residues on the plot? } \\
\text { (1) Yes; (2) No }\end{array}$ & \\
\hline
\end{tabular}

\subsection{Distance from the plot to other structures}

Distance from the plot to (only if not more than $500 \mathrm{~m}$ away from the plot; if it is within the plot, please write $0 \mathrm{~m}$ )

\begin{tabular}{|l|l|l|}
\hline QID & Distance from the plot to................ & Answer \\
\hline 12.1 & Nearest road (meters) & \\
\hline 12.2 & Nearest secondary forest (meters) & \\
\hline 12.3 & Nearest production forest (meters) & \\
\hline
\end{tabular}




\begin{tabular}{|l|l|l|}
\hline 12.4 & Nearest jungle rubber (meters) & \\
\hline 12.5 & Nearest rubber plantation (meters) & \\
\hline 12.6 & Nearest fallow land/cleared land/revitalization (oil palm) (meters) & \\
\hline 12.7 & Nearest paddy field (meters) & \\
\hline 12.8 & Nearest home/kitchen garden (meters) & \\
\hline 12.9 & Nearest river or lake (meters) & \\
\hline
\end{tabular}

\section{Input use on this specific plot in the last 12 months}

The following questions refer to the specific plot

\begin{tabular}{|c|c|c|c|c|c|c|}
\hline QID & Input & $\begin{array}{l}\text { Number of } \\
\text { times used } \\
\text { in last } 12 \\
\text { months (\#) }\end{array}$ & $\begin{array}{l}\text { Name of } \\
\text { input }\end{array}$ & $\begin{array}{l}\text { Unit of } \\
\text { measure- } \\
\text { ment }\end{array}$ & $\begin{array}{l}\text { Quantity used in } \\
\text { plot in } 12 \\
\text { months(QU/plot } \\
\text { /year) }\end{array}$ & $\begin{array}{l}\text { Average price of } \\
\text { input as used in } \\
\text { last } 12 \text { months } \\
\text { (C000Rp./QU) }\end{array}$ \\
\hline 1 & $\begin{array}{l}\text { Seedlings } \\
\text { (replanting) }\end{array}$ & & & & & \\
\hline 2 & $\begin{array}{l}\text { Manure: plant } \\
\text { waste (from } \\
\text { plants outside } \\
\text { the plot) }\end{array}$ & & & $\mathrm{Kg}$ & & \\
\hline 3 & $\begin{array}{l}\text { Manure: } \\
\text { Animal waste }\end{array}$ & & & $\mathrm{Kg}$ /liters & & \\
\hline 4 & $\begin{array}{l}\text { Soil } \\
\text { amendments } \\
\text { (Lime, gypsum) }\end{array}$ & & & & & \\
\hline 5 & $\begin{array}{l}\text { Chemical } \\
\text { fertilizer }\end{array}$ & & & $\mathrm{Kg} /$ liters & & \\
\hline 6 & & & & $\mathrm{Kg}$ /liters & & \\
\hline 7 & & & & $\mathrm{Kg} /$ liters & & \\
\hline
\end{tabular}




\begin{tabular}{|c|c|c|c|c|c|c|}
\hline QID & Input & $\begin{array}{l}\text { Number of } \\
\text { times used } \\
\text { in last } 12 \\
\text { months (\#) }\end{array}$ & $\begin{array}{l}\text { Name of } \\
\text { input }\end{array}$ & $\begin{array}{l}\text { Unit of } \\
\text { measurement }\end{array}$ & $\begin{array}{l}\text { Quantity used in } \\
\text { plot in } 12 \\
\text { months(QU/plot } \\
\text { /year) }\end{array}$ & $\begin{array}{l}\text { Average price } \\
\text { of input as used } \\
\text { in last } 12 \\
\text { months } \\
\text { (c00Rp./QU) }\end{array}$ \\
\hline 9 & Herbicides & & & liter & & \\
\hline 10 & & & & liter & & \\
\hline 11 & & & & liter & & \\
\hline 12 & & & & liter & & \\
\hline 13 & Pesticides & & & liter & & \\
\hline 14 & & & & liter & & \\
\hline 15 & & & & liter & & \\
\hline 16 & & & & liter & & \\
\hline 17 & Maschinery & & & & & \\
\hline 18 & Transport Inputs & & & & & \\
\hline 19 & $\begin{array}{l}\text { Transport } \\
\text { Outputs }\end{array}$ & & & & & \\
\hline
\end{tabular}

\section{Labor Input in last 12 months (specific plot)}

The following questions refer to the specific plot

\begin{tabular}{|l|l|l|l|l|l|l|}
\hline QID & Activity & $\begin{array}{l}\text { Number of } \\
\text { operations in } \\
\text { last } 12 \\
\text { months }\end{array}$ & $\begin{array}{l}\text { Average } \\
\text { Time taken to } \\
\text { complete one } \\
\text { operation } \\
\text { (Unit) }\end{array}$ & $\begin{array}{l}\text { Number of } \\
\text { hired } \\
\text { laborers per } \\
\text { operation }\end{array}$ & $\begin{array}{l}\text { Total costs for } \\
\text { laborers per } \\
\text { operation } \\
\text { (000 } \\
\text { Rp./operation) }\end{array}$ & $\begin{array}{l}\text { Number of } \\
\text { family } \\
\text { laborers } \\
\text { involved per } \\
\text { operation } \\
\text { (from owner* } \\
\text { and from } \\
\text { hired laborers) }\end{array}$ \\
\hline 1 & Replanting & $\begin{array}{l}\text { Seedlings } \\
\text { transportation }\end{array}$ & & & & \\
\end{tabular}




\begin{tabular}{|l|l|l|l|l|l|l|}
\hline 3 & $\begin{array}{l}\text { Manure } \\
\text { application }\end{array}$ & & & & & \\
\hline 4 & $\begin{array}{l}\text { Fertilizer } \\
\text { application }\end{array}$ & & & & & \\
\hline 5 & $\begin{array}{l}\text { Herbicide } \\
\text { Applicaion }\end{array}$ & & & & & \\
\hline 6 & $\begin{array}{l}\text { Pesticide } \\
\text { application }\end{array}$ & & & & \\
\hline 7 & $\begin{array}{l}\text { Manual } \\
\text { weeding on } \\
\text { ground }\end{array}$ & & & & & \\
\hline 8 & $\begin{array}{l}\text { Manual } \\
\text { weeding on } \\
\text { palm/tree (fill } \\
\text { only if done } \\
\text { separately) }\end{array}$ & & & & & \\
\hline 9 & Harvesting & & & & & \\
\hline 10 & $\begin{array}{l}\text { Transportation } \\
\text { harvest }\end{array}$ & & & & & \\
\hline 11 & Marketing & & & & & \\
\hline
\end{tabular}

\section{Outputs oil palm from the specific plot}

The following questions refer to the specific plot

6.1 Last three sales from this specific plot.

\begin{tabular}{|l|l|l|l|l|}
\hline QID & $\begin{array}{l}\text { Sale ID }(1=\text { most } \\
\text { recent sale })\end{array}$ & Date of sale & $\begin{array}{l}\text { Total quantity sold } \\
(\mathrm{kg})\end{array}$ & $\begin{array}{l}\text { Average price obtained for ouput } \\
\left({ }^{\prime} 000 \mathrm{Rp} / \mathrm{kg}\right)\end{array}$ \\
\hline 1 & 1 & & & \\
\hline 2 & 2 & & & \\
\hline 3 & 3 & & & \\
\hline
\end{tabular}


6.2 Harvest in the last 12 months

\begin{tabular}{|l|l|l|}
\hline QID & $\begin{array}{l}\text { Total harvest in last } 12 \text { months from this specific } \\
\text { plot (ton) }\end{array}$ & Total quantity sold $(\mathrm{kg})$ \\
\hline $1 / 2$ & & \\
\hline
\end{tabular}

\subsection{Change of harvest last 12 months}

Please indicate how the harvest changed throughout the last 12 months. Please distinguish between dry and rainy season.

\begin{tabular}{|l|l|l|l|l|l|}
\hline QID & & $\begin{array}{l}\text { Frequency of } \\
\text { harvest (once in } \\
\text { how many days) on } \\
\text { this specific plot }\end{array}$ & $\begin{array}{l}\text { Quantity of harvest } \\
\text { per month } \\
\text { (kg/month) from } \\
\text { this specific plot } \\
\text { any shocks? } \\
\text { Code A }\end{array}$ & $\begin{array}{l}\text { Average prive } \\
\text { obtained for output in } \\
\text { this season ('000Rp } \\
/ \mathrm{kg})\end{array}$ \\
\hline 1 & $\begin{array}{l}\text { Dry season } \\
\text { April- } \\
\text { October) }\end{array}$ & & & & \\
\hline 2 & $\begin{array}{l}\text { Rain season } \\
\text { (November- } \\
\text { March) }\end{array}$ & & & & \\
\hline
\end{tabular}

\section{Intercropping with fruit and timber trees (perennial crops)}

Questions refer to the specific plot

1Do you have fruit or timber trees on your oil palm plot (surrounded by oil palm trees; and not at the edge of oil palm plantation)? (1) Yes, (2) No (if $n=2$, continue with section 9) 
If yes, please specify in the table below:

\begin{tabular}{|c|c|c|c|c|c|c|c|c|}
\hline \multirow[t]{2}{*}{ QID } & \multirow{2}{*}{$\begin{array}{l}\text { Name of } \\
\text { tree } \\
\text { species }\end{array}$} & \multirow[t]{2}{*}{$\begin{array}{l}\text { Number } \\
\text { of trees }\end{array}$} & \multirow{2}{*}{$\begin{array}{l}\text { Number of } \\
\text { already } \\
\text { productive } \\
\text { trees }\end{array}$} & \multirow{2}{*}{$\begin{array}{l}\text { Are the trees (1) } \\
\text { planted (ever) or } \\
\text { (2) left-overs? }\end{array}$} & \multicolumn{4}{|c|}{$\begin{array}{l}\text { Did you maintain these trees at least in the last } \\
12 \text { months? (1) Yes, (2) No }\end{array}$} \\
\hline & & & & & Weeding & Fertilizer & Herbicides & Pesticides \\
\hline \multicolumn{9}{|l|}{2} \\
\hline \multicolumn{9}{|l|}{3} \\
\hline \multicolumn{9}{|c|}{4} \\
\hline \multicolumn{9}{|c|}{5} \\
\hline \multicolumn{9}{|l|}{6} \\
\hline \multicolumn{9}{|l|}{7} \\
\hline \multicolumn{9}{|l|}{8} \\
\hline \multicolumn{9}{|l|}{9} \\
\hline 10 & & & & & & & & \\
\hline & & & & & & & & \\
\hline
\end{tabular}

7.1 Input use intercropped trees in last 12 months

If the respondent maintained the trees by weeding, fertilizer, herbicide or pesticide application, in the last 12 months please continue with the following table.

Please sum it up for all trees. It just refers to trees in the oil palm plot.

\begin{tabular}{|l|l|l|l|l|l|l|}
\hline QID & Input & $\begin{array}{l}\text { Number } \\
\text { of times } \\
\text { used in } \\
\text { last } 12 \\
\text { months } \\
(\#)\end{array}$ & $\begin{array}{l}\text { Name } \\
\text { of } \\
\text { input }\end{array}$ \\
1 & $\begin{array}{l}\text { Seedlings } \\
\text { (replanting) }\end{array}$ & $\begin{array}{l}\text { Unit of } \\
\text { measurement }\end{array}$ & $\begin{array}{l}\text { Quantity used in plot } \\
\text { in 12 } \\
\text { months(QU/plot/year) }\end{array}$ & $\begin{array}{l}\text { Average price of } \\
\text { input as used in } \\
\text { last 12 months } \\
\text { (C00Rp./QU) }\end{array}$ \\
\hline 2 & $\begin{array}{l}\text { Manure: plant } \\
\text { waste (from } \\
\text { plants outside }\end{array}$ & & $\mathrm{Kg}$ & & & \\
\hline
\end{tabular}


Supplementary Information - Chapter 2

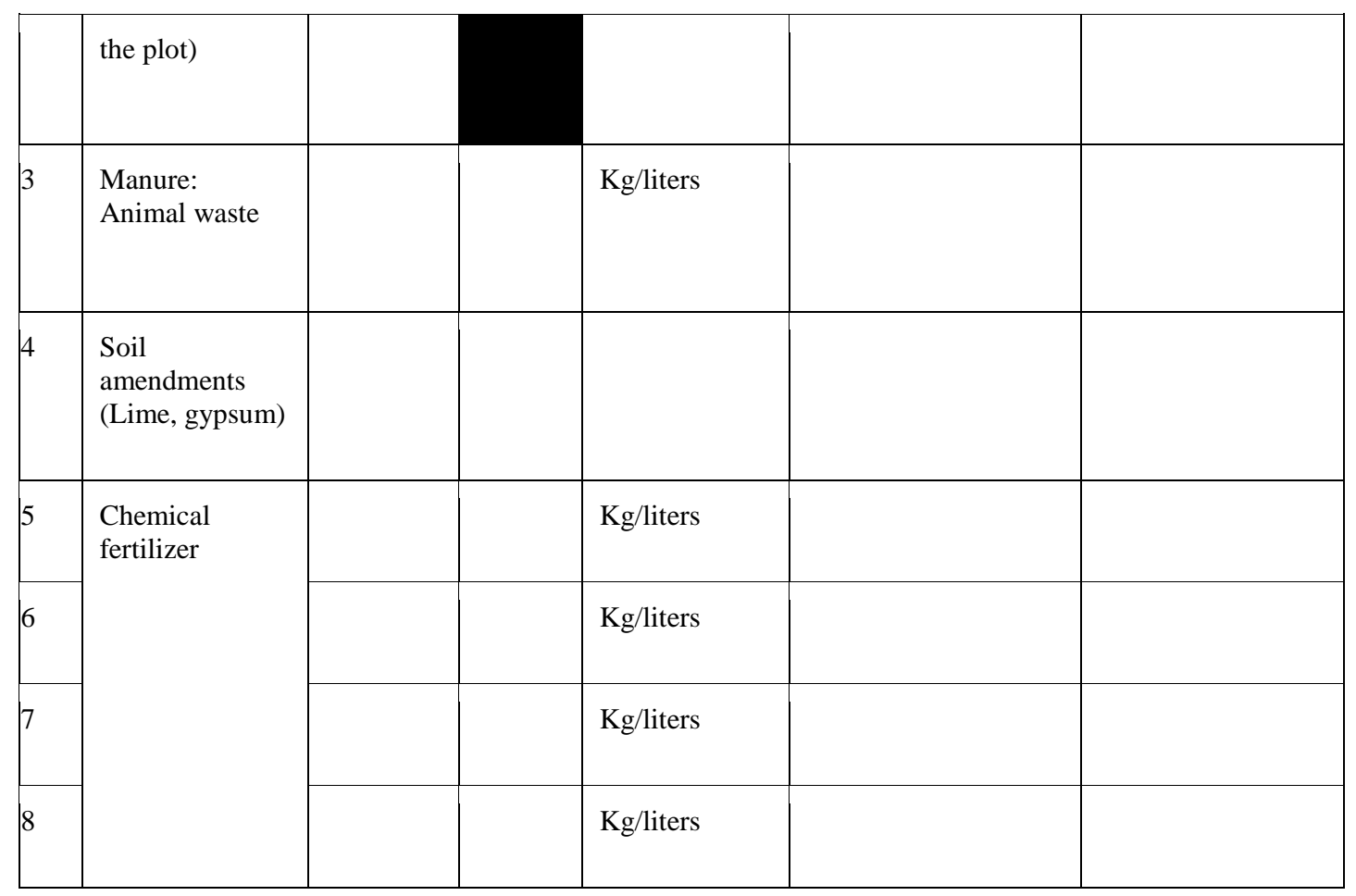

\begin{tabular}{|c|c|c|c|c|c|c|}
\hline QID & Input & $\begin{array}{l}\text { Number } \\
\text { of times } \\
\text { used in } \\
\text { last } 12 \\
\text { months } \\
\text { (\#) }\end{array}$ & $\begin{array}{l}\text { Name } \\
\text { of input }\end{array}$ & $\begin{array}{l}\text { Unit of } \\
\text { measurement }\end{array}$ & $\begin{array}{l}\text { Quantity used in plot in } \\
12 \\
\text { months(QU/plot/year) }\end{array}$ & $\begin{array}{l}\text { Average price of } \\
\text { input as used in } \\
\text { last } 12 \text { months } \\
\text { ( O00Rp./QU) }\end{array}$ \\
\hline 9 & Herbicides & & & liter & & \\
\hline 10 & & & & liter & & \\
\hline 11 & & & & liter & & \\
\hline 12 & & & & liter & & \\
\hline 13 & Pesticides & & & liter & & \\
\hline 14 & & & & liter & & \\
\hline 15 & & & & liter & & \\
\hline 16 & & & & liter & & \\
\hline 17 & Maschinery & & & & & \\
\hline
\end{tabular}




\begin{tabular}{|l|l|l|l|l|l|l|}
\hline 18 & $\begin{array}{l}\text { Transport } \\
\text { Inputs }\end{array}$ & & & & & \\
\hline 19 & $\begin{array}{l}\text { Transport } \\
\text { Outputs }\end{array}$ & & & & & \\
\hline
\end{tabular}

\subsection{Labor Input intercropped trees last 12 months}

If the respondent maintained the trees by weeding, fertilizer, herbicide or pesticide application, in the last 12 months please continue with the following table.

Please sum it up for all trees. It just refers to trees in the oil palm plot.

\begin{tabular}{|c|c|c|c|c|c|c|}
\hline QID & Activity & $\begin{array}{l}\text { Number of } \\
\text { operations } \\
\text { in last } 12 \\
\text { months }\end{array}$ & $\begin{array}{l}\text { Average } \\
\text { Time taken } \\
\text { to complete } \\
\text { one } \\
\text { operation } \\
\text { (Unit) }\end{array}$ & $\begin{array}{l}\text { Number of } \\
\text { hired } \\
\text { laborers per } \\
\text { operation }\end{array}$ & $\begin{array}{l}\text { Total costs for } \\
\text { laborers per } \\
\text { operation } \\
\text { ( } 000 \\
\text { Rp./operation) }\end{array}$ & $\begin{array}{l}\text { Number of } \\
\text { family laborers } \\
\text { involved per } \\
\text { operation (from } \\
\text { owner* and from } \\
\text { hired laborers) }\end{array}$ \\
\hline 1 & Replanting & & & & & \\
\hline 2 & $\begin{array}{l}\text { Seedlings } \\
\text { transportation }\end{array}$ & & & & & \\
\hline 3 & Manure application & & & & & \\
\hline 4 & $\begin{array}{l}\text { Fertilizer } \\
\text { application }\end{array}$ & & & & & \\
\hline 5 & $\begin{array}{l}\text { Herbicide } \\
\text { Applicaion }\end{array}$ & & & & & \\
\hline 6 & $\begin{array}{l}\text { Pesticide } \\
\text { application }\end{array}$ & & & & & \\
\hline 7 & $\begin{array}{l}\text { Manual weeding on } \\
\text { ground }\end{array}$ & & & & & \\
\hline 8 & $\begin{array}{l}\text { Manual weeding on } \\
\text { palm/tree (fill only } \\
\text { if done separately) }\end{array}$ & & & & & \\
\hline 9 & Harvesting & & & & & \\
\hline 10 & $\begin{array}{l}\text { Transportation } \\
\text { harvest }\end{array}$ & & & & & \\
\hline 11 & Marketing & & & & & \\
\hline
\end{tabular}


Supplementary Information - Chapter 2

\section{Tree by-products}

Please do not include rubber here, separate table for rubber.

\begin{tabular}{|c|c|c|c|c|c|c|}
\hline QID & $\begin{array}{l}\text { Name of tree } \\
\text { species }\end{array}$ & $\begin{array}{l}\text { By-product } \\
\text { type (Code } \\
\text { A) }\end{array}$ & $\begin{array}{l}\text { Unit of } \\
\text { measurement } \\
\text { (QU, name) }\end{array}$ & $\begin{array}{l}\text { Production in the } \\
\text { last } 12 \text { months } \\
\text { (QU) }\end{array}$ & $\begin{array}{l}\text { Quantity } \\
\text { (QU) } \\
\text { marketed in } \\
\text { last } 12 \\
\text { months }\end{array}$ & $\begin{array}{l}\text { Average Price } \\
\text { obtained in last } 12 \\
\text { months ('000 } \\
\text { Rp/QU) }\end{array}$ \\
\hline \multicolumn{7}{|l|}{1} \\
\hline \multicolumn{7}{|l|}{2} \\
\hline \multicolumn{7}{|l|}{3} \\
\hline \multicolumn{7}{|l|}{4} \\
\hline \multicolumn{7}{|l|}{5} \\
\hline \multicolumn{7}{|l|}{6} \\
\hline \multicolumn{7}{|l|}{7} \\
\hline & & & & & & \\
\hline & & & & & & \\
\hline
\end{tabular}




\subsection{Labor input (for harvesting/marketing)}

Please sum it up for all trees. It just refers to trees in the oil palm plot. Include rubber here.

\begin{tabular}{|l|l|l|l|l|l|l|}
\hline QID & & $\begin{array}{l}\text { Number of } \\
\text { operations in } \\
\text { last 12 } \\
\text { months }\end{array}$ & $\begin{array}{l}\text { Time } \\
\text { taken to } \\
\text { complete } \\
\text { one } \\
\text { operation }\end{array}$ & $\begin{array}{l}\text { Number of } \\
\text { hired } \\
\text { laborers } \\
\text { per } \\
\text { operation }\end{array}$ & $\begin{array}{l}\text { Total costs for } \\
\text { laborers per } \\
\text { operation in last } \\
12 \text { months (000 } \\
\text { Rp./operation) }\end{array}$ & $\begin{array}{l}\text { Number of } \\
\text { family laborers } \\
\text { involved per } \\
\text { operation (from } \\
\text { owner* and from } \\
\text { hired laborers) }\end{array}$ \\
\hline 1 & Harvesting & & & & & \\
\hline 2 & $\begin{array}{l}\text { Transport } \\
\text { output }\end{array}$ & & & & & \\
\hline 3
\end{tabular}

\subsection{Harvest rubber intercropped in oil palm}

If the oil palm plot is intercropped with rubber, please continue with this table. Otherwise switch to section 8 .

\begin{tabular}{|l|l|l|l|l|}
\hline QID & $\begin{array}{l}\text { Sale ID }(1=\text { most } \\
\text { recent sale })\end{array}$ & Date of sale & Total quantity sold $(\mathrm{kg})$ & $\begin{array}{l}\text { Average price obtained for } \\
\text { output ('000 Rp/kg) }\end{array}$ \\
\hline 1 & 1 & & & \\
\hline 2 & 2 & & & \\
\hline 3 & 3 & & & \\
\hline
\end{tabular}

8.3. Harvest rubber intercropped in oil palm in the last 12 months

\begin{tabular}{|l|l|l|}
\hline QID & $\begin{array}{l}\text { Total harvest in last 12 months from this } \\
\text { specific plot (ton) }\end{array}$ & Total quantity sold (kg) \\
\hline $1 / 2$ & & \\
\hline
\end{tabular}


8.4 Change of harvest rubber intercropped in oil palm

Please indicate how the harvest changed throughout the last 12 months. Please distinguish between dry and rainy season.

\begin{tabular}{|l|l|l|l|l|l|}
\hline QID & & $\begin{array}{l}\text { Frequency of } \\
\text { harvest (once in } \\
\text { how many days)? }\end{array}$ & $\begin{array}{l}\text { Quantity of } \\
\text { harvest per } \\
\text { month } \\
\text { (kg/month) }\end{array}$ & $\begin{array}{l}\text { Were there any } \\
\text { shocks? } \\
\text { Code A }\end{array}$ & $\begin{array}{l}\text { Average price } \\
\text { obtained for output in } \\
\text { this season ('000Rp } \\
/ \mathrm{kg})\end{array}$ \\
\hline 1 & $\begin{array}{l}\text { Dry season } \\
\text { (April- } \\
\text { October) }\end{array}$ & & & & \\
\hline 2 & $\begin{array}{l}\text { Rain season } \\
\text { (November- } \\
\text { March) }\end{array}$ & & & & \\
\hline
\end{tabular}

\section{Arrangement of fruit and timber trees}

Please show the pictures.

Could you please describe to us the arrangement of fruit and timber trees on the specific oil palm plot? Number:

\begin{tabular}{|c|c|c|}
\hline QID & \multirow{4}{*}{$\begin{array}{l}\text { What were the three main reasons for choosing } \\
\text { this arrangement of trees within oil palm } \\
\text { plantation? Code A }\end{array}$} & \\
\hline 1 & & \\
\hline 2 & & \\
\hline 3 & & \\
\hline
\end{tabular}




\section{Cut-off of fruit and timber trees on the specific plot}

\begin{tabular}{|l|l|l|}
\hline QID & & \\
\hline 1 & $\begin{array}{l}\text { Have you ever cut any productive tree in the oil palm plantation } \\
\text { (surrounded by oil palm) in the last 5 years (1) Yes; (2) No }\end{array}$ & \\
\hline 2 & If QID1=1, number of cut productive trees & \\
\hline 3 & If QID1=1, please name the main reason:___ \\
\hline
\end{tabular}

\begin{tabular}{|c|c|c|}
\hline QID & \multirow{4}{*}{$\begin{array}{l}\text { What are the three main reasons for you for } \\
\text { planting the above trees or not removing remnant } \\
\text { trees in the oil palm plot? Code A }\end{array}$} & \\
\hline 4 & & \\
\hline \multicolumn{2}{|l|}{5} & \\
\hline \multicolumn{2}{|l|}{6} & \\
\hline \multicolumn{3}{|c|}{$\begin{array}{l}\text { Code A: (1) to maintain soil fertility; (2) to reduce likelihood for soil erosion; (3) to increase rainfall absorption; } \\
\text { (4) to preserve groundwater;; (6) to fulfill food/housing needs; (7) for other economic activities; (8) pest } \\
\text { management; (9) weed management; (10) to make border with border to neighboring plots ; (11) others, } \\
\text { specify: }\end{array}$} \\
\hline
\end{tabular}

\begin{tabular}{|c|c|c|}
\hline QID & \multirow{4}{*}{$\begin{array}{l}\text { From your perspective, what are the three main } \\
\text { problems associated with planting trees within the } \\
\text { oil palm plantation? ( general question) Code A }\end{array}$} & \\
\hline 7 & & \\
\hline \multicolumn{2}{|l|}{8} & \\
\hline \multicolumn{2}{|l|}{9} & \\
\hline \multicolumn{3}{|c|}{$\begin{array}{l}\text { Code A: (1) no problems (2) competition for water (3) competition for nutrients (4) others, } \\
\text { specify: }\end{array}$} \\
\hline
\end{tabular}




\section{Perception about functions of fruit and timber trees within oil palm plantations}

Now, we would like to know your perception on fruit or timber trees in oil palm plantations. We will read some statements. Please mention whether you (1) strongly disagree; (2) disagree; (3) agree; (4) strongly agree.

\begin{tabular}{|c|c|c|c|c|c|c|}
\hline QID & $\begin{array}{l}\text { Fruit and Timber trees within oil palm } \\
\text { plantations........ }\end{array}$ & $\begin{array}{l}\text { Strongly } \\
\text { Disagree }\end{array}$ & Disagree & Agree & $\begin{array}{l}\text { Strongly } \\
\text { Agree }\end{array}$ & $\begin{array}{l}\text { Don't } \\
\text { know }\end{array}$ \\
\hline 1 & Increase soil fertility & & & & & \\
\hline 2 & Decrease soil erosion & & & & & \\
\hline 3 & Decrease water availability & & & & & \\
\hline 4 & Increase bird diversity & & & & & \\
\hline 5 & $\begin{array}{l}\text { Increase number of individuals per bird } \\
\text { species }\end{array}$ & & & & & \\
\hline 6 & Increase insect diversity & & & & & \\
\hline 7 & $\begin{array}{l}\text { Increase number of individuals per } \\
\text { insect species }\end{array}$ & & & & & \\
\hline 8 & $\begin{array}{l}\text { Decrease likelihood of pest and disease } \\
\text { in oil palm plantations }\end{array}$ & & & & & \\
\hline 9 & Increase the oil palm yield & & & & & \\
\hline 10 & Decrease oil palm yield & & & & & \\
\hline 11 & $\begin{array}{l}\text { Compete with oil palm trees for } \\
\text { nutrients }\end{array}$ & & & & & \\
\hline
\end{tabular}




\section{Cultivation of fruit and timber trees outside oil palm plot}

Now we would like to know, if you cultivate any of the below mentioned fruit and timber trees outside oil palm plantations. If the respondent does not cultivate the following systems, please indicate is by N.A.

Please tick $(\sqrt{ })$ the related blank box which shows the name of the trees and the type of the field where it's cultivated!

\begin{tabular}{|l|l|l|l|l|l|l|}
\hline QID & Type of fields & \multicolumn{4}{l|}{ The name of the trees } \\
\cline { 4 - 7 } & & Jengkol & Durian & Petai & Jelutung & Sungkai \\
\hline 1 & Home garden & & & & & \\
\hline 2 & Rubber Plantation & & & & & \\
\hline 3 & Individual owned production forest & & & & & \\
\hline 4 & Other, specify: & & & & & \\
\hline
\end{tabular}

13. Bird diversity, abundance and distribution in oil palm plantation

The following questions refer to the specific plot.

1.Have you ever observed any birds on your oil palm plot?

(1) Yes, (2) No

If QID1=1, 2. how many different bird species have you observed on the plot? 
3.If you know the names of the birds observed on the plots, please write them down below:

\begin{tabular}{|l|l|}
\hline QID & Name of birds \\
\hline 1 & \\
\hline 2 & \\
\hline 3 & \\
\hline 4 & \\
\hline
\end{tabular}

4. Have you observed birds feeding on the oil palm fruits? (1) Yes, (2) No If QID4=1, 5. and if you know the names of the birds feeding on oil palms, please write down below:

\begin{tabular}{|l|l|}
\hline QID & Name of birds \\
\hline 1 & \\
\hline 2 & \\
\hline 3 & \\
\hline 4 & \\
\hline
\end{tabular}

6. According to your observation, is the number of bird species and/or the number of individuals per bird species in non-oil palm structures (fruit and timber tress, river, lake) larger, the same or smaller than in oil palm plantations? (1)larger, (2) smaller, (3)the same

7. Do you think that birds have a positive, negative, or no effect on the yield of oil palm? (1) Positive effect, (2) Negative effect (3) No effect

8. Please specify why you think that birds have a (see answer QID7) effect:

9. Do you currently own rubber or jungle rubber plantations? (1)Yes, (2) No 
If QID9=1, 10. Have you observed more, less or the same number of birds on the rubber/jungle rubber plot compared to the oil palm plot?

(1) More,

(2) the same (3) less

\section{Birds caught at the specific oil palm plot}

1. Have you caught any birds in the last 12 months?

(1) Yes, (2) No

If QID1=1 please fill out the table.

\begin{tabular}{|l|l|l|l|l|}
\hline QID & \multirow{2}{*}{$\begin{array}{l}\text { Total number of birds caught } \\
\text { in the last 12 months }\end{array}$} & \multicolumn{2}{|l|}{ Number of birds caught per location } \\
\cline { 3 - 5 } & & On specific plot & Within 1 km around plot & Other location \\
\hline 2 & & & & \\
\hline
\end{tabular}

3.Do you know the species name of at least one caught bird? (1) Yes, (2) No

If QID3=1, 4 please fill out table

\begin{tabular}{|l|l|l|l|l|}
\hline QID & Bird species & $\begin{array}{l}\text { Number of caught birds per } \\
\text { bird species (if known) in } \\
\text { last 12 months }\end{array}$ & $\begin{array}{l}\text { Number of sold } \\
\text { birds per bird } \\
\text { species }\end{array}$ & $\begin{array}{l}\text { Average price per } \\
\text { bird species ('000 Rp) }\end{array}$ \\
\hline 1 & & & & \\
\hline 3 & & & & \\
\hline 4 & & & & \\
\hline
\end{tabular}


4. We will read out three categories of bird sizes. Please, name the number of birds caught per category of bird size (not wingspan).

\begin{tabular}{|l|l|l|l|l|}
\hline QID & Bird size & $\begin{array}{l}\text { Number of caught birds per } \\
\text { bird size category (if known) } \\
\text { in last 12 months }\end{array}$ & $\begin{array}{l}\text { Number of sold birds } \\
\text { per bird size category }\end{array}$ & $\begin{array}{l}\text { Average price per } \\
\text { bird per bird size } \\
\text { category ('000 Rp) }\end{array}$ \\
\hline 1 & $<15 \mathrm{~cm}$ & & & \\
\hline 2 & $15 \mathrm{~cm}-25 \mathrm{~cm}$ & & & \\
\hline 3 & $>25 \mathrm{~cm}$ & & & \\
\hline
\end{tabular}

5. Which characteristics/features of birds increase the selling price? Order features according to importance.

\begin{tabular}{|l|l|}
\hline QID & Characteristics \\
\hline 1 & \\
\hline 2 & \\
& \\
\hline 3 & \\
\hline
\end{tabular}

6. Which method do you use to catch the birds?

\begin{tabular}{|l|l|}
\hline QID & Method \\
\hline 1 & \\
\hline 2 & \\
\hline 3 & \\
\hline
\end{tabular}

7. Number of birds that you keep as pet in your household?

\section{Thanks for your participation!}






\section{Supplementary Information - Chapter 3}

\section{Supplementary figures}

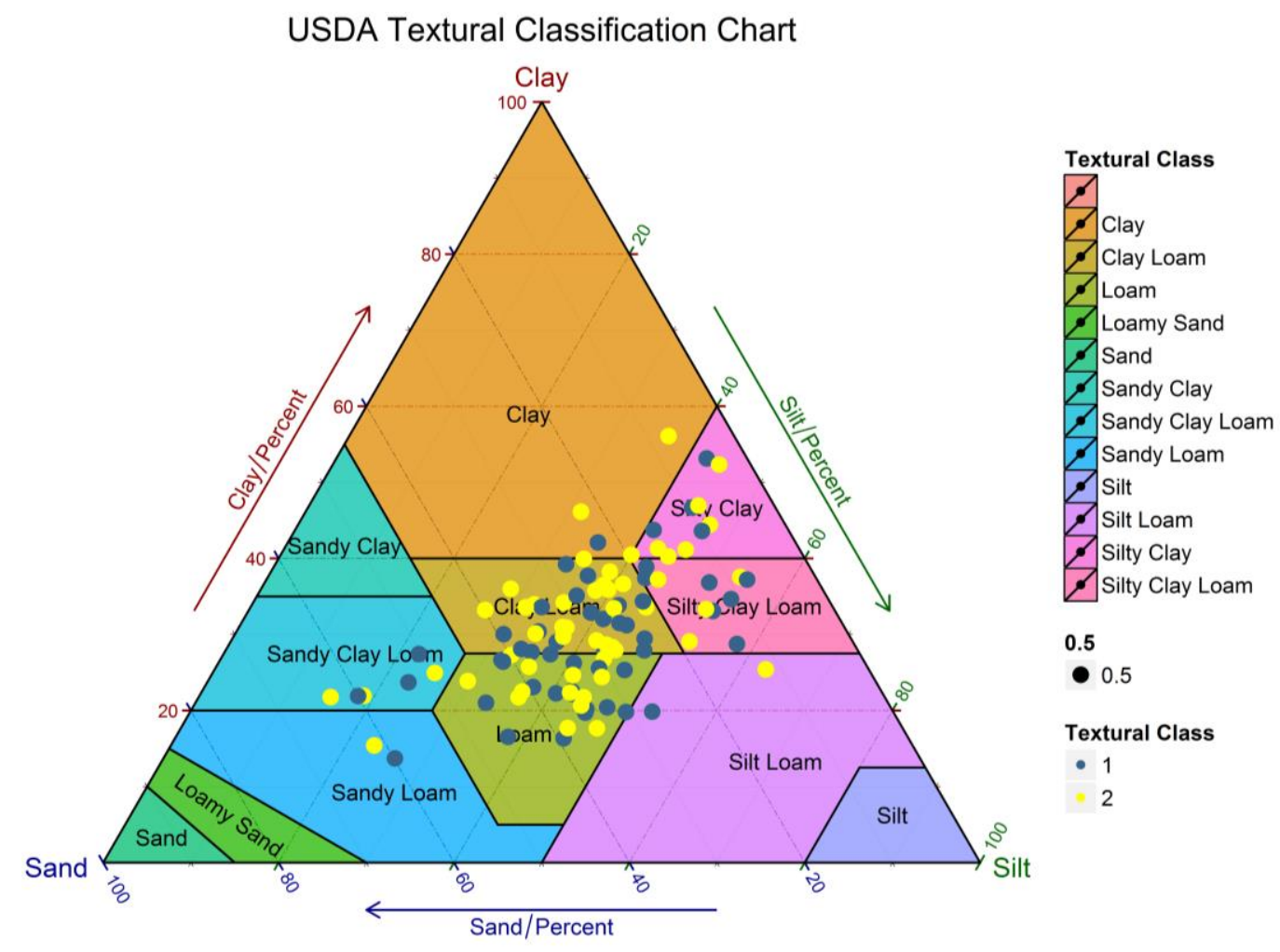

Figure S 3.1: Soil texture of all plots in two depths $(1=0-10 \mathrm{~cm}$ (yellow points), $2=10-30 \mathrm{~cm}$ (grey points)) according to the USDA textural classification chart. We found a high variability among the plots and higher clay content in $10-30 \mathrm{~cm}$ than in $0-10 \mathrm{~cm}$. 

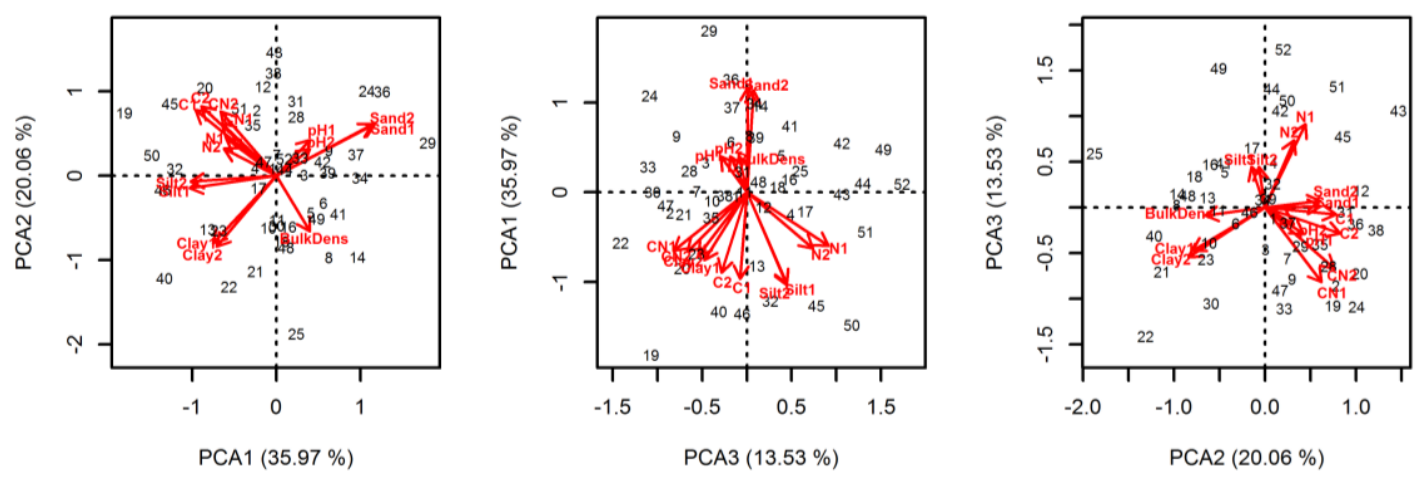

Figure S 3.2: Principal component analysis of the soil data.
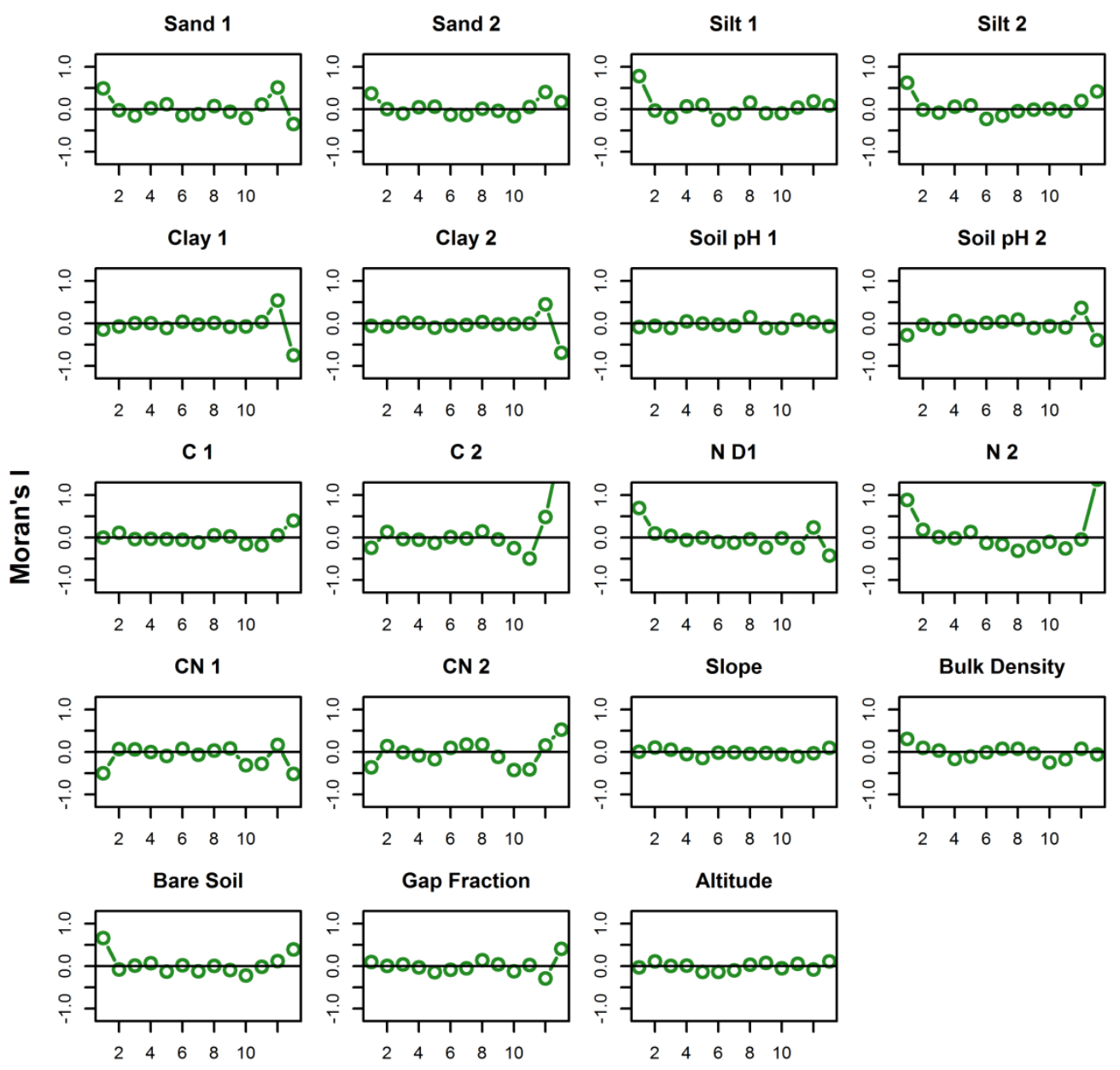

Distance $(1.8 \mathrm{~km})$

Figure S 3.3: Spatial correlogram to check for spatial autocorrelation of the environmental variables. Moran's I is given as a function of distance. Values significant at a nominal (twosided) 5\%-level are represented by filled circles and non-significant values by open circles. 


\section{Supplementary tables}

Table S 3.1: Partitions of the experimental design (columns). Per partition, each species (A-F) is present in each diversity level (block) without replacement. Thus, there are different numbers of plots per diversity level (number in first row; species composition for each plot in the second row).

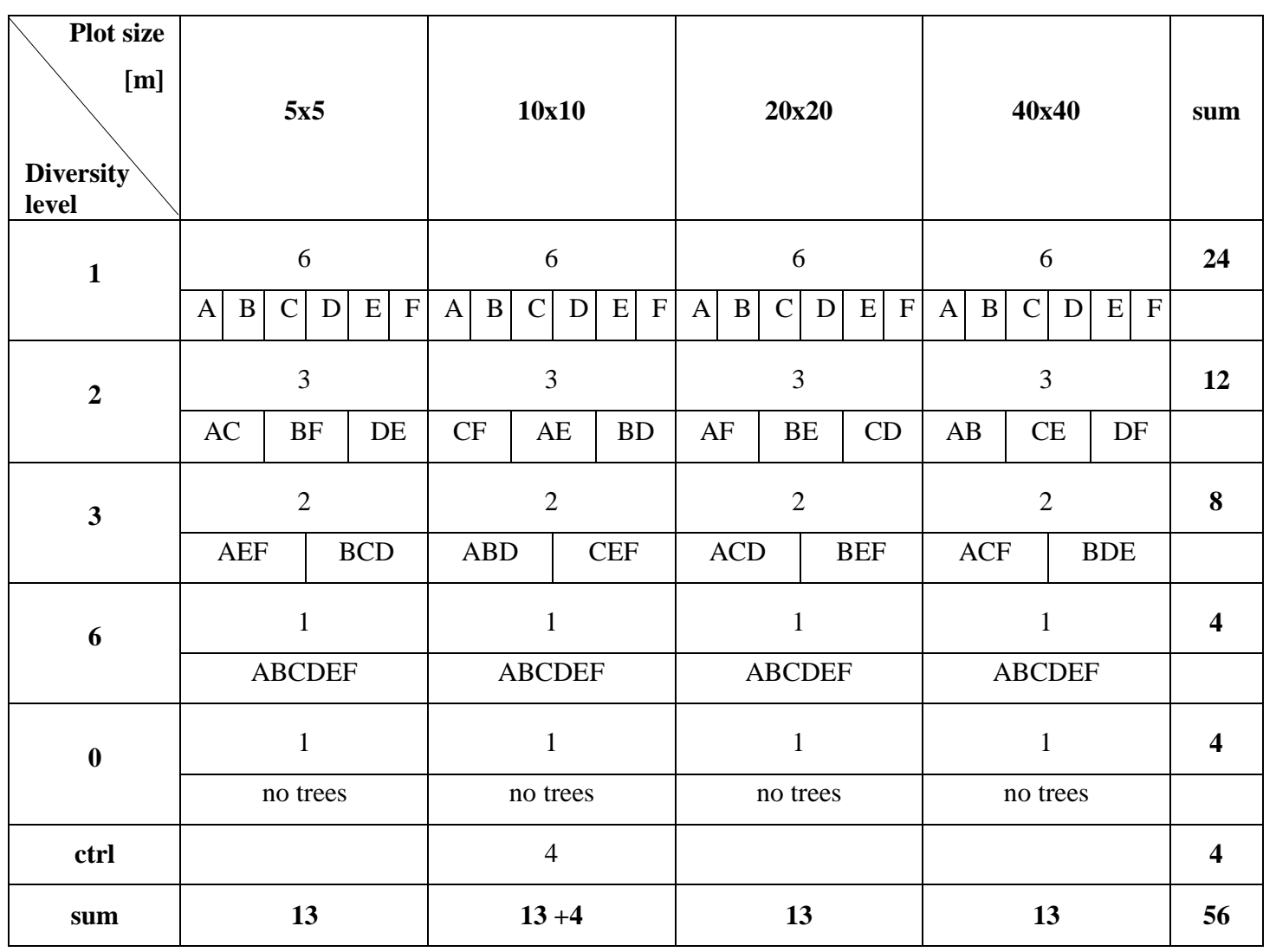

Table S 3.2: Plot infos

\begin{tabular}{lrrrrrr}
\hline Plot ID & Latitude & Longitude & Plot size & $\begin{array}{r}\text { Tree } \\
\text { diversity } \\
\text { level }\end{array}$ & $\begin{array}{r}\text { Number of } \\
\text { fruit tree } \\
\text { species }\end{array}$ & $\begin{array}{r}\text { Number of } \\
\text { timber tree } \\
\text { species }\end{array}$ \\
\hline 1 & -1.941619 & 103.251905 & 1600 & 1 & 1 & 0 \\
2 & -1.941743 & 103.252978 & 400 & 3 & 2 & 1 \\
3 & -1.943296 & 103.251765 & 400 & 2 & 1 & 1 \\
4 & -1.943206 & 103.253171 & 100 & 1 & 0 & 1 \\
5 & -1.944778 & 103.251792 & 1600 & 1 & 1 & 0 \\
6 & -1.944615 & 103.253150 & 25 & 1 & 0 & 1 \\
7 & -1.944689 & 103.255158 & 1600 & 3 & 1 & 2 \\
8 & -1.945868 & 103.249106 & 25 & 1 & 0 & 1 \\
9 & -1.945784 & 103.250588 & 100 & 3 & 2 & 1 \\
10 & -1.945945 & 103.251840 & 400 & 0 & 0 & 0 \\
11 & -1.945896 & 103.253220 & 100 & 1 & 0 & 1 \\
12 & -1.945888 & 103.254342 & 400 & 1 & 1 & 0 \\
13 & -1.945911 & 103.255925 & 100 & 1 & 0 & 1
\end{tabular}


Supplementary Information - Chapter 3

\begin{tabular}{|c|c|c|c|c|c|c|}
\hline 14 & -1.947283 & 103.249167 & 100 & 1 & 1 & 0 \\
\hline 15 & -1.947151 & 103.250424 & 400 & 1 & 1 & 0 \\
\hline 16 & -1.947333 & 103.251907 & 25 & 3 & 2 & 1 \\
\hline 17 & -1.947338 & 103.253148 & 400 & 1 & 0 & 1 \\
\hline 18 & -1.947168 & 103.254498 & 25 & 2 & 0 & 1 \\
\hline 19 & -1.947317 & 103.255865 & 400 & 6 & 3 & 3 \\
\hline 20 & -1.947337 & 103.257347 & 100 & 1 & 1 & 0 \\
\hline 21 & -1.948628 & 103.247800 & 100 & 6 & 3 & 3 \\
\hline 22 & -1.948734 & 103.249137 & 25 & 2 & 1 & 1 \\
\hline 23 & -1.948868 & 103.251317 & 1600 & 6 & 3 & 3 \\
\hline 24 & -1.948381 & 103.254313 & 1600 & 2 & 1 & 1 \\
\hline 25 & -1.948656 & 103.255886 & 25 & 1 & 1 & 0 \\
\hline 26 & -1.948487 & 103.257201 & 1600 & 2 & 0 & 1 \\
\hline 27 & -1.949921 & 103.246436 & 100 & 2 & 1 & 1 \\
\hline 28 & -1.950023 & 103.247777 & 25 & 1 & 1 & 0 \\
\hline 29 & -1.949964 & 103.248967 & 1600 & 3 & 2 & 1 \\
\hline 30 & -1.949809 & 103.252968 & 400 & 1 & 0 & 1 \\
\hline 31 & -1.949966 & 103.254488 & 25 & 1 & 1 & 0 \\
\hline 32 & -1.949976 & 103.255904 & 100 & 2 & 1 & 1 \\
\hline 33 & -1.950016 & 103.257276 & 400 & 3 & 1 & 2 \\
\hline 34 & -1.951426 & 103.245068 & 100 & 2 & 1 & 1 \\
\hline 35 & -1.951823 & 103.246590 & 1600 & 0 & 0 & 0 \\
\hline 36 & -1.951060 & 103.247721 & 400 & 2 & 1 & 1 \\
\hline 37 & -1.951176 & 103.248844 & 100 & 0 & 0 & 0 \\
\hline 38 & -1.951715 & 103.250417 & 400 & 1 & 0 & 1 \\
\hline 39 & -1.951383 & 103.251800 & 25 & 2 & 2 & 0 \\
\hline 40 & -1.951366 & 103.257142 & 25 & 0 & 0 & 0 \\
\hline 41 & -1.952674 & 103.243797 & 100 & 1 & 1 & 0 \\
\hline 42 & -1.952757 & 103.244984 & 25 & 1 & 0 & 1 \\
\hline 43 & -1.949631 & 103.258593 & 1600 & 1 & 1 & 0 \\
\hline 44 & -1.952709 & 103.247815 & 25 & 3 & 1 & 2 \\
\hline 45 & -1.953066 & 103.248695 & 1600 & 1 & 0 & 1 \\
\hline 46 & -1.954422 & 103.242421 & 1600 & 2 & 2 & 0 \\
\hline 47 & -1.953952 & 103.243710 & 400 & 2 & 1 & 1 \\
\hline 48 & -1.954103 & 103.245204 & 100 & 3 & 1 & 2 \\
\hline 49 & -1.953998 & 103.246627 & 1600 & 1 & 0 & 1 \\
\hline 50 & -1.954061 & 103.247820 & 25 & 6 & 3 & 3 \\
\hline 51 & -1.954249 & 103.249144 & 400 & 1 & 1 & 0 \\
\hline 52 & -1.955189 & 103.243481 & 1600 & 1 & 0 & 1 \\
\hline 53 & & & 100 & Control & - & - \\
\hline 54 & & & 100 & Control & - & - \\
\hline 55 & & & 100 & Control & - & - \\
\hline 56 & & & 100 & Control & - & - \\
\hline
\end{tabular}


Table S 3.3: Length-mass regression parameters for calculation of individual body masses from measured body lengths. For damaged individuals where body length could not be measured, body mass was substituted by species median body mass or order median body mass (for species with single individuals). 'Taxon' and 'Group' specify which animals the presented regression has been used for in this study. Regressions were available from the literature that estimate both dry mass (DM) and fresh mass (FM) ('Mass type') for different taxa. Appendix Tab. 4 presents the dry mass-fresh mass conversion, used to convert all estimated body masses to fresh mass. The equations and regression parameters, 'a' and 'b', are presented, as well as the size range the regressions were calculated from ('Min' and 'Max'). All regressions were taken from the literature ('Reference'), with different specific definitions of how body length was measured ('Details of body length measurement') and specificity of the given regression ('Regression specificity'). (Barnes et al. 2014; modified and extended)

\begin{tabular}{|c|c|c|c|c|c|c|c|c|c|}
\hline Taxon & Group & $\begin{array}{l}\text { Mass } \\
\text { type }\end{array}$ & $\begin{array}{l}\text { Equation } \mathrm{M}[\mathrm{mg}], \\
\mathrm{L}[\mathrm{mm}]\end{array}$ & $\mathrm{a}$ & $\mathrm{b}$ & $\begin{array}{l}\text { Min } \\
(\mathrm{mm})\end{array}$ & $\begin{array}{l}\operatorname{Max} \\
(\mathrm{mm})\end{array}$ & Reference & $\begin{array}{r}\text { Regression } \\
\text { specificity }\end{array}$ \\
\hline All insect taxa & & $\mathrm{DM}$ & $\mathrm{M}=\mathrm{a}^{*}(\mathrm{~L})^{\wedge} \mathrm{b}$ & 0.035 & 2.173 & 0.9 & 17.6 & (Gruner 2003) & $\begin{array}{r}\text { Inferred, all } \\
\text { insect taxa }\end{array}$ \\
\hline All insect taxa & & DM & $M=\exp (a+b * \log (L))$ & -3.628 & 2.494 & 2.13 & 54.51 & $\begin{array}{l}\text { (Sample } \text { et al. } \\
\text { 1993) }\end{array}$ & $\begin{array}{r}\text { Inferred, all } \\
\text { insect taxa }\end{array}$ \\
\hline Araneae & Araneae $<2.5 \mathrm{~mm}$ & FM & $M=\exp (a+b * \log (L))$ & -1.958 & 2.746 & 0.56 & 2.5 & $\begin{array}{l}\text { (Höfer \& Ott } \\
\text { 2009) }\end{array}$ & Group specific \\
\hline Araneae & Hunting & FM & $M=\exp (a+b * \log (L))$ & -2.108 & 3.017 & 0.67 & 36 & $\begin{array}{l}\text { (Höfer \& Ott } \\
\text { 2009) }\end{array}$ & Group specific \\
\hline Araneae & Web-building & FM & $\mathrm{M}=\exp (\mathrm{a}+\mathrm{b} * \log (\mathrm{L}))$ & -1.784 & 2.255 & 0.56 & 10.67 & $\begin{array}{l}\text { (Höfer \& Ott } \\
2009 \text { ) }\end{array}$ & Group specific \\
\hline Araneae & Spiders random & FM & $M=\exp (a+b * \log (L))$ & -1.844 & 2.711 & 1.8 & 21.5 & $\begin{array}{l}\text { (Edwards } \\
1996)\end{array}$ & Group specific \\
\hline Araneae & Anapidae & FM & $\mathrm{M}=\exp (\mathrm{a}+\mathrm{b} * \log (\mathrm{L}))$ & -1.784 & 2.255 & 0.56 & 10.67 & $\begin{array}{l}\text { (Höfer \& Ott } \\
\text { 2009) }\end{array}$ & $\begin{array}{r}\text { Inferred, web- } \\
\text { building }\end{array}$ \\
\hline Araneae & Araneidae & FM & $\mathrm{M}=\exp (\mathrm{a}+\mathrm{b} * \log (\mathrm{L}))$ & -1.923 & 2.923 & 2.10 & 21.20 & $\begin{array}{l}\text { (Edwards } \\
1996)\end{array}$ & Group specific \\
\hline Araneae & Clubionidae & FM & $\mathrm{M}=\exp (\mathrm{a}+\mathrm{b} * \log (\mathrm{L}))$ & -2.156 & 2.653 & 2.5 & 9 & $\begin{array}{l}\text { (Edwards } \\
1996)\end{array}$ & Group specific \\
\hline Araneae & Corinnidae & FM & $\mathrm{M}=\exp (\mathrm{a}+\mathrm{b} * \log (\mathrm{L}))$ & -2.108 & 3.017 & 0.67 & 36 & $\begin{array}{l}\text { (Höfer \& Ott } \\
\text { 2009) }\end{array}$ & $\begin{array}{r}\text { Inferred, } \\
\text { hunting spiders }\end{array}$ \\
\hline Araneae & Ctenidae & FM & $M=\exp (a+b * \log (L))$ & -1.758 & 2.894 & 1.3 & 36 & $\begin{array}{l}\text { (Höfer \& Ott } \\
2009 \text { ) }\end{array}$ & Group specific \\
\hline Araneae & Deinopidae & FM & $M=\exp (a+b * \log (L))$ & -1.844 & 2.711 & 1.8 & 21.5 & Edwards 1996 & $\begin{array}{l}\text { Inferred, spiders } \\
\text { random sample }\end{array}$ \\
\hline Araneae & Dysderidae & FM & $\mathrm{M}=\exp (\mathrm{a}+\mathrm{b} * \log (\mathrm{L}))$ & -2.108 & 3.017 & 0.67 & 36 & $\begin{array}{l}\text { (Höfer \& Ott } \\
\text { 2009) }\end{array}$ & $\begin{array}{r}\text { Inferred, } \\
\text { hunting spiders }\end{array}$ \\
\hline Araneae & Gnaphosidae & FM & $\mathrm{M}=\exp (\mathrm{a}+\mathrm{b} * \log (\mathrm{L}))$ & -2.83 & 3.055 & 3 & 13.1 & $\begin{array}{l}\text { (Edwards } \\
1996)\end{array}$ & Group specific \\
\hline Araneae & Linyphiidae & FM & $\mathrm{M}=\exp (\mathrm{a}+\mathrm{b} * \log (\mathrm{L}))$ & -1.892 & 2.754 & 1.5 & 5.5 & $\begin{array}{l}\text { (Edwards } \\
1996)\end{array}$ & Group specific \\
\hline Araneae & Lycosidae & FM & $M=\exp (a+b * \log (L))$ & -2.043 & 2.842 & 2 & 23.5 & $\begin{array}{l}\text { (Edwards } \\
1996)\end{array}$ & Group specific \\
\hline Araneae & Miturgidae & FM & $\mathrm{M}=\exp (\mathrm{a}+\mathrm{b} * \log (\mathrm{L}))$ & -2.83 & 3.055 & 3 & 13.1 & $\begin{array}{l}\text { (Edwards } \\
1996)\end{array}$ & $\begin{array}{r}\text { Inferred, } \\
\text { gnaphosidae }\end{array}$ \\
\hline Araneae & Mysmenidae & FM & $\mathrm{M}=\exp \left(\mathrm{a}+\mathrm{b}^{*} \log (\mathrm{L})\right)$ & -1.784 & 2.255 & 0.56 & 10.67 & $\begin{array}{l}\text { (Höfer \& Ott } \\
2009)\end{array}$ & $\begin{array}{r}\text { Inferred, web- } \\
\text { building }\end{array}$ \\
\hline Araneae & Ochyroceratidae & FM & $\mathrm{M}=\exp (\mathrm{a}+\mathrm{b} * \log (\mathrm{L}))$ & -1.784 & 2.255 & 0.56 & 10.67 & $\begin{array}{l}\text { (Höfer \& Ott } \\
\text { 2009) }\end{array}$ & $\begin{array}{r}\text { Inferred, web- } \\
\text { building }\end{array}$ \\
\hline Araneae & Oonopidae & FM & $\mathrm{M}=\exp (\mathrm{a}+\mathrm{b} * \log (\mathrm{L}))$ & -2.039 & 2.666 & 0.67 & 2.5 & $\begin{array}{l}\text { (Höfer \& Ott } \\
2009)\end{array}$ & Group specific \\
\hline Araneae & Oxyopidae & FM & $M=\exp (a+b * \log (L))$ & -2.108 & 3.017 & 0.67 & 36 & $\begin{array}{l}\text { (Höfer \& Ott } \\
2009)\end{array}$ & $\begin{array}{r}\text { Inferred, } \\
\text { hunting spiders }\end{array}$ \\
\hline Araneae & Philodromidae & FM & $\mathrm{M}=\exp (\mathrm{a}+\mathrm{b} * \log (\mathrm{L}))$ & -1.985 & 2.940 & 2.50 & 8.60 & $\begin{array}{l}\text { (Edwards } \\
1996)\end{array}$ & Group specific \\
\hline Araneae & Pholcidae & FM & $M=\exp (a+b * \log (L))$ & -1.784 & 2.255 & 0.56 & 10.67 & $\begin{array}{l}\text { (Höfer \& Ott } \\
2009 \text { ) }\end{array}$ & $\begin{array}{r}\text { Inferred, web- } \\
\text { building }\end{array}$ \\
\hline Araneau & Pisauridae & FM & $M=\exp (a+b * \log (L))$ & -2.108 & 3.017 & 0.67 & 36 & $\begin{array}{l}\text { (Höfer \& Ott } \\
2009)\end{array}$ & $\begin{array}{r}\text { Inferred, } \\
\text { hunting spiders }\end{array}$ \\
\hline Araneae & Salticidae & FM & $\mathrm{M}=\exp (\mathrm{a}+\mathrm{b} * \log (\mathrm{L}))$ & -2.184 & 2.901 & 4.00 & 13.00 & $\begin{array}{l}\text { (Edwards } \\
1996)\end{array}$ & Group specific \\
\hline
\end{tabular}


Supplementary Information - Chapter 3

\begin{tabular}{|c|c|c|c|c|c|c|c|c|c|}
\hline Araneae & Sparassidae & FM & $\mathrm{M}=\exp (\mathrm{a}+\mathrm{b} * \log (\mathrm{L}))$ & -2.108 & 3.017 & 0.67 & 36 & $\begin{array}{l}\text { (Höfer \& Ott } \\
2009 \text { ) }\end{array}$ & $\begin{array}{r}\text { Inferred, } \\
\text { hunting spiders }\end{array}$ \\
\hline Araneae & Tetrablemmidae & FM & $M=\exp (a+b * \log (L))$ & -2.039 & 2.666 & 0.67 & 2.5 & $\begin{array}{l}\text { (Höfer \& Ott } \\
2009)\end{array}$ & $\begin{array}{r}\text { Inferred, } \\
\text { oonopidae }\end{array}$ \\
\hline Araneae & Tetragnathidae & FM & $M=\exp (a+b * \log (L))$ & -2.615 & 2.574 & 3.50 & 9.00 & $\begin{array}{l}\text { (Edwards } \\
1996)\end{array}$ & Group specific \\
\hline Araneae & Theridiidae & FM & $M=\exp (a+b * \log (L))$ & -1.577 & 2.907 & 1.50 & 7.50 & $\begin{array}{l}\text { (Edwards } \\
1996)\end{array}$ & Group specific \\
\hline Araneae & Theridiosomatidae & FM & $M=\exp (a+b * \log (L))$ & -1.784 & 2.255 & 0.56 & 10.67 & $\begin{array}{l}\text { (Höfer \& Ott } \\
2009 \text { ) }\end{array}$ & $\begin{array}{r}\text { Inferred, web- } \\
\text { building }\end{array}$ \\
\hline Araneae & Thomisidae & FM & $M=\exp (a+b * \log (L))$ & -1.644 & 2.973 & 1.80 & 8.00 & $\begin{array}{l}\text { (Edwards } \\
1996)\end{array}$ & Group specific \\
\hline Araneae & Zodariidae & FM & $M=\exp (a+b * \log (L))$ & -2.108 & 3.017 & 0.67 & 36 & $\begin{array}{l}\text { (Höfer \& Ott } \\
2009 \text { ) }\end{array}$ & $\begin{array}{r}\text { Inferred, } \\
\text { hunting spiders }\end{array}$ \\
\hline Blattodea & Blaberidae & DM & $M=\exp (a+b * \log (L))$ & -3.980 & 2.760 & 2.20 & 14.00 & $\begin{array}{l}\text { (Wardhaugh } \\
\text { 2013) }\end{array}$ & $\begin{array}{l}\text { Inferred, } \\
\text { blattodea }\end{array}$ \\
\hline Blattodea & Blattellidae & DM & $M=\exp (a+b * \log (L))$ & -3.980 & 2.760 & 2.20 & 14.00 & $\begin{array}{l}\text { (Wardhaugh } \\
\text { 2013) }\end{array}$ & $\begin{array}{l}\text { Inferred, } \\
\text { blattodea }\end{array}$ \\
\hline Blattodea & Blattidae & DM & $M=\exp (a+b * \log (L))$ & -3.980 & 2.760 & 2.20 & 14.00 & $\begin{array}{l}\text { (Wardhaugh } \\
\text { 2013) }\end{array}$ & $\begin{array}{l}\text { Inferred, } \\
\text { blattodea }\end{array}$ \\
\hline Coleoptera & Aderidae & DM & $M=\exp (a+b * \log (L))$ & -3.247 & 2.492 & 3.34 & 34.82 & $\begin{array}{l}\text { (Sample } \text { et al. } \\
\text { 1993) }\end{array}$ & $\begin{array}{r}\text { Inferred, } \\
\text { coleoptera }\end{array}$ \\
\hline Coleoptera & Anthicidae & DM & $M=\exp (a+b * \log (L))$ & -3.247 & 2.492 & 3.34 & 34.82 & $\begin{array}{l}\text { (Sample } \text { et al. } \\
\text { 1993) }\end{array}$ & $\begin{array}{r}\text { Inferred, } \\
\text { coleoptera }\end{array}$ \\
\hline Coleoptera & Anthribidae & DM & $M=\exp (a+b * \log (L))$ & -3.247 & 2.492 & 3.34 & 34.82 & $\begin{array}{l}\text { (Sample } \text { et al. } \\
\text { 1993) }\end{array}$ & $\begin{array}{r}\text { Inferred, } \\
\text { coleoptera }\end{array}$ \\
\hline Coleoptera & Carabidae & DM & $M=a * L^{\wedge} b$ & 0.0237 & 2.7054 & 2.88 & 24 & $\begin{array}{l}\text { (Lang, Krooss } \\
\text { \& Stumpf }\end{array}$ & Group specific \\
\hline Coleoptera & Chrysomelidae & DM & $M=\exp (a+b * \log (L))$ & -2.427 & 2.171 & 3.34 & 7.84 & $\begin{array}{l}\text { (Sample et al. } \\
\text { 1993) }\end{array}$ & Group specific \\
\hline Coleoptera & Corylophidae & DM & $M=\exp (a+b * \log (L))$ & -3.247 & 2.492 & 3.34 & 34.82 & $\begin{array}{l}\text { (Sample } \text { et al. } \\
\text { 1993) }\end{array}$ & $\begin{array}{r}\text { Inferred, } \\
\text { coleoptera }\end{array}$ \\
\hline Coleoptera & Colydiidae & DM & $M=\exp (a+b * \log (L))$ & -3.247 & 2.492 & 3.34 & 34.82 & $\begin{array}{l}\text { (Sample } \text { et al. } \\
\text { 1993) }\end{array}$ & $\begin{array}{r}\text { Inferred, } \\
\text { coleoptera }\end{array}$ \\
\hline Coleoptera & Discolomidae & DM & $M=\exp (a+b * \log (L))$ & -3.247 & 2.492 & 3.34 & 34.82 & $\begin{array}{l}\text { (Sample } \text { et al. } \\
\text { 1993) }\end{array}$ & $\begin{array}{r}\text { Inferred, } \\
\text { coleoptera }\end{array}$ \\
\hline Coleoptera & Hydraenidae & DM & $M=\exp (a+b * \log (L))$ & -3.247 & 2.492 & 3.34 & 34.82 & $\begin{array}{l}\text { (Sample } \text { et al. } \\
\text { 1993) }\end{array}$ & $\begin{array}{r}\text { Inferred, } \\
\text { coleoptera }\end{array}$ \\
\hline Coleoptera & Lagrioidinae & DM & $M=\exp (a+b * \log (L))$ & -3.247 & 2.492 & 3.34 & 34.82 & $\begin{array}{l}\text { (Sample } \text { et al. } \\
\text { 1993) }\end{array}$ & $\begin{array}{r}\text { Inferred, } \\
\text { coleoptera }\end{array}$ \\
\hline Coleoptera & Pselaphidae & DM & $M=\exp (a+b * \log (L))$ & -3.247 & 2.492 & 3.34 & 34.82 & $\begin{array}{l}\text { (Sample } \text { et al. } \\
\text { 1993) }\end{array}$ & $\begin{array}{r}\text { Inferred, } \\
\text { coleoptera }\end{array}$ \\
\hline Coleoptera & Scolytidae & DM & $M=\exp (a+b * \log (L))$ & -3.247 & 2.492 & 3.34 & 34.82 & $\begin{array}{l}\text { (Sample } \text { et al. } \\
\text { 1993) }\end{array}$ & $\begin{array}{r}\text { Inferred, } \\
\text { coleoptera }\end{array}$ \\
\hline Coleoptera & Curculionidae & DM & $M=\exp (a+b * \log (L))$ & -3.247 & 2.492 & 3.34 & 34.82 & $\begin{array}{l}\text { (Sample } \text { et al. } \\
\text { 1993) }\end{array}$ & $\begin{array}{r}\text { Inferred, } \\
\text { coleoptera }\end{array}$ \\
\hline Coleoptera & Elateridae & DM & $\mathrm{M}=\mathrm{a} * \mathrm{~L}^{\wedge} \mathrm{b}$ & 0.0138 & 2.595 & 1.65 & 10.3 & (Gruner 2003) & $\begin{array}{r}\text { Inferred, slender } \\
\text { beetles }\end{array}$ \\
\hline Coleoptera & Nitidulidae & DM & $M=\exp (a+b * \log (L))$ & -3.247 & 2.492 & 3.34 & 34.82 & $\begin{array}{l}\text { (Sample } \text { et al. } \\
\text { 1993) }\end{array}$ & $\begin{array}{r}\text { Inferred, } \\
\text { coleoptera }\end{array}$ \\
\hline Coleoptera & Phalacridae & DM & $M=\exp (a+b * \log (L))$ & -3.247 & 2.492 & 3.34 & 34.82 & $\begin{array}{l}\text { (Sample } \text { et al. } \\
\text { 1993) }\end{array}$ & $\begin{array}{r}\text { Inferred, } \\
\text { coleoptera }\end{array}$ \\
\hline Coleoptera & Ptiliidae & DM & $M=\exp (a+b * \log (L))$ & -3.247 & 2.492 & 3.34 & 34.82 & $\begin{array}{l}\text { (Sample } \text { et al. } \\
\text { 1993) }\end{array}$ & $\begin{array}{r}\text { Inferred, } \\
\text { coleoptera }\end{array}$ \\
\hline Coleoptera & Scarabaeidae & DM & $M=\exp (a+b * \log (L))$ & -2.448 & 2.494 & 4.24 & 24.79 & $\begin{array}{l}\text { (Sample } \text { et al. } \\
\text { 1993) }\end{array}$ & Group specific \\
\hline Coleoptera & Scydmaenidae & DM & $M=\exp (a+b * \log (L))$ & -3.247 & 2.492 & 3.34 & 34.82 & $\begin{array}{l}\text { (Sample } \text { et al. } \\
\text { 1993) }\end{array}$ & $\begin{array}{r}\text { Inferred, } \\
\text { coleoptera }\end{array}$ \\
\hline Coleoptera & Silvanidae & DM & $M=a * L^{\wedge} b$ & 0.0138 & 2.595 & 1.65 & 10.3 & (Gruner 2003) & $\begin{array}{r}\text { Inferred, slender } \\
\text { beetles }\end{array}$ \\
\hline Coleoptera & Staphylinidae & DM & $M=a * L^{\wedge} b$ & 0.0134 & 2.26 & 2.2 & 13.6 & $\begin{array}{l}\text { (Lang, Krooss } \\
\text { \& Stumpf } \\
1997 \text { ) }\end{array}$ & Group specific \\
\hline Coleoptera & Tenebrionidae & DM & $M=\exp (a+b * \log (L))$ & -0.043 & 1.2 & 5.65 & 13.39 & $\begin{array}{l}\text { (Sample et al. } \\
\text { 1993) }\end{array}$ & Group specific \\
\hline Dermaptera & Anisolabididae & DM & $M=\exp (a+b * \log (L))$ & -3.628 & 2.494 & 2.13 & 54.51 & $\begin{array}{l}\text { (Sample } \text { et al. } \\
\text { 1993) }\end{array}$ & $\begin{array}{r}\text { Inferred, all } \\
\text { insect taxa }\end{array}$ \\
\hline Dermaptera & Labiduridae & DM & $M=\exp (a+b * \log (L))$ & -3.628 & 2.494 & 2.13 & 54.51 & $\begin{array}{l}\text { (Sample } \text { et al. } \\
\text { 1993) }\end{array}$ & $\begin{array}{r}\text { Inferred, all } \\
\text { insect taxa }\end{array}$ \\
\hline Dermaptera & Labiidae & DM & $M=\exp (a+b * \log (L))$ & -3.628 & 2.494 & 2.13 & 54.51 & $\begin{array}{l}\text { (Sample } \text { et al. } \\
\text { 1993) }\end{array}$ & $\begin{array}{l}\text { Inferred, all } \\
\text { insect taxa }\end{array}$ \\
\hline
\end{tabular}




\begin{tabular}{|c|c|c|c|c|c|c|c|c|c|}
\hline Dermaptera & Spongiphoridae & DM & $M=\exp (a+b * \log (L))$ & -3.628 & 2.494 & 2.13 & 54.51 & $\begin{array}{l}\text { (Sample } \text { et al. } \\
\text { 1993) }\end{array}$ & $\begin{array}{r}\text { Inferred, all } \\
\text { insect taxa }\end{array}$ \\
\hline Dermaptera & Uniden & DM & $M=\exp (a+b * \log (L))$ & -3.628 & 2.494 & 2.13 & 54.51 & $\begin{array}{l}\text { (Sample } \text { et al. } \\
\text { 1993) }\end{array}$ & $\begin{array}{r}\text { Inferred, all } \\
\text { insect taxa }\end{array}$ \\
\hline Diplura & Campodeidae & DM & $\mathrm{M}=\mathrm{a} *(\mathrm{~L})^{\wedge} \mathrm{b}$ & 0.034 & 2.191 & 0.9 & 17.6 & (Gruner 2003) & $\begin{array}{r}\text { Inferred, general } \\
\text { arthropod }\end{array}$ \\
\hline Diplura & Japygidae & DM & $\mathrm{M}=\mathrm{a} *(\mathrm{~L})^{\wedge} \mathrm{b}$ & 0.034 & 2.191 & 0.9 & 17.6 & (Gruner 2003) & $\begin{array}{r}\text { Inferred, general } \\
\text { arthropod }\end{array}$ \\
\hline Diplura & Stratiopmydae & DM & $\mathrm{M}=\mathrm{a} *(\mathrm{~L})^{\wedge} \mathrm{b}$ & 0.034 & 2.191 & 0.9 & 17.6 & (Gruner 2003) & $\begin{array}{r}\text { Inferred, general } \\
\text { arthropod }\end{array}$ \\
\hline Diplura & Uniden & DM & $\mathrm{M}=\mathrm{a} *(\mathrm{~L})^{\wedge} \mathrm{b}$ & 0.034 & 2.191 & 0.9 & 17.6 & (Gruner 2003) & $\begin{array}{r}\text { Inferred, general } \\
\text { arthropod }\end{array}$ \\
\hline Diptera & Adults & DM & $\mathrm{M}=\mathrm{a} *(\mathrm{~L})^{\wedge} \mathrm{b}$ & 0.0153 & 2.573 & 1.75 & 8.6 & (Gruner 2003) & $\begin{array}{r}\text { Original, diptera } \\
\text { adult }\end{array}$ \\
\hline Diptera & Asteiidae & DM & $\mathrm{M}=\mathrm{a} *(\mathrm{~L})^{\wedge} \mathrm{b}$ & 0.0153 & 2.573 & 1.75 & 8.6 & (Gruner 2003) & $\begin{array}{r}\text { Original, diptera } \\
\text { adult }\end{array}$ \\
\hline Diptera & Bibionidae & DM & $\mathrm{M}=\mathrm{a} *(\mathrm{~L})^{\wedge} \mathrm{b}$ & 0.035 & 2.173 & 0.9 & 17.6 & (Gruner 2003) & $\begin{array}{r}\text { Inferred, all } \\
\text { insect taxa }\end{array}$ \\
\hline Diptera & Calliphoridae & DM & $\mathrm{M}=\mathrm{a} *(\mathrm{~L})^{\wedge} \mathrm{b}$ & 0.0153 & 2.573 & 1.75 & 8.6 & (Gruner 2003) & $\begin{array}{r}\text { Original, diptera } \\
\text { adult }\end{array}$ \\
\hline Diptera & Cecidomyiidae & DM & $\mathrm{M}=\mathrm{a} *(\mathrm{~L})^{\wedge} \mathrm{b}$ & 0.035 & 2.173 & 0.9 & 17.6 & (Gruner 2003) & $\begin{array}{r}\text { Inferred, all } \\
\text { insect taxa }\end{array}$ \\
\hline Diptera & Ceratopogonidae & DM & $\mathrm{M}=\mathrm{a} *(\mathrm{~L})^{\wedge} \mathrm{b}$ & 0.0153 & 2.573 & 1.75 & 8.6 & (Gruner 2003) & $\begin{array}{r}\text { Original, diptera } \\
\text { adult }\end{array}$ \\
\hline Diptera & Chironomidae & DM & $\mathrm{M}=\mathrm{a} *(\mathrm{~L})^{\wedge} \mathrm{b}$ & 0.0153 & 2.573 & 1.75 & 8.6 & (Gruner 2003) & $\begin{array}{r}\text { Original, diptera } \\
\text { adult }\end{array}$ \\
\hline Diptera & Chloropidae & DM & $\mathrm{M}=\mathrm{a} *(\mathrm{~L})^{\wedge} \mathrm{b}$ & 0.0153 & 2.573 & 1.75 & 8.6 & (Gruner 2003) & $\begin{array}{r}\text { Original, diptera } \\
\text { adult }\end{array}$ \\
\hline Diptera & Clusiidae & DM & $\mathrm{M}=\mathrm{a} *(\mathrm{~L})^{\wedge} \mathrm{b}$ & 0.0153 & 2.573 & 1.75 & 8.6 & (Gruner 2003) & $\begin{array}{r}\text { Original, diptera } \\
\text { adult }\end{array}$ \\
\hline Diptera & Culicidae & DM & $\mathrm{M}=\mathrm{a} *(\mathrm{~L})^{\wedge} \mathrm{b}$ & 0.0153 & 2.573 & 1.75 & 8.6 & (Gruner 2003) & $\begin{array}{r}\text { Original, diptera } \\
\text { adult }\end{array}$ \\
\hline Diptera & Deuterophlebiidae & DM & $\mathrm{M}=\mathrm{a} *(\mathrm{~L})^{\wedge} \mathrm{b}$ & 0.0153 & 2.573 & 1.75 & 8.6 & (Gruner 2003) & $\begin{array}{r}\text { Original, diptera } \\
\text { adult }\end{array}$ \\
\hline Diptera & Dolichopodidae & DM & $M=a *(L)^{\wedge} b$ & 0.0153 & 2.573 & 1.75 & 8.6 & (Gruner 2003) & $\begin{array}{r}\text { Original, diptera } \\
\text { adult }\end{array}$ \\
\hline Diptera & Drosophilidae & DM & $\mathrm{M}=\mathrm{a} *(\mathrm{~L})^{\wedge} \mathrm{b}$ & 0.0153 & 2.573 & 1.75 & 8.6 & (Gruner 2003) & $\begin{array}{r}\text { Original, diptera } \\
\text { adult }\end{array}$ \\
\hline Diptera & Lauxaniidae & DM & $\mathrm{M}=\mathrm{a} *(\mathrm{~L})^{\wedge} \mathrm{b}$ & 0.0153 & 2.573 & 1.75 & 8.6 & (Gruner 2003) & $\begin{array}{r}\text { Original, diptera } \\
\text { adult }\end{array}$ \\
\hline Diptera & Muscidae & DM & $\mathrm{M}=\mathrm{a} *(\mathrm{~L})^{\wedge} \mathrm{b}$ & 0.0153 & 2.573 & 1.75 & 8.6 & (Gruner 2003) & $\begin{array}{r}\text { Original, diptera } \\
\text { adult }\end{array}$ \\
\hline Diptera & Mycetophylidae & DM & $\mathrm{M}=\mathrm{a} *(\mathrm{~L})^{\wedge} \mathrm{b}$ & 0.0153 & 2.573 & 1.75 & 8.6 & (Gruner 2003) & $\begin{array}{r}\text { Original, diptera } \\
\text { adult }\end{array}$ \\
\hline Diptera & Opomyzidae & DM & $\mathrm{M}=\mathrm{a} *(\mathrm{~L})^{\wedge} \mathrm{b}$ & 0.0153 & 2.573 & 1.75 & 8.6 & (Gruner 2003) & $\begin{array}{r}\text { Original, diptera } \\
\text { adult }\end{array}$ \\
\hline Diptera & Phoridae & DM & $M=a *(L)^{\wedge} b$ & 0.0153 & 2.573 & 1.75 & 8.6 & (Gruner 2003) & $\begin{array}{r}\text { Original, diptera } \\
\text { adult }\end{array}$ \\
\hline Diptera & Piophilidae & DM & $\mathrm{M}=\mathrm{a} *(\mathrm{~L})^{\wedge} \mathrm{b}$ & 0.0153 & 2.573 & 1.75 & 8.6 & (Gruner 2003) & $\begin{array}{r}\text { Original, diptera } \\
\text { adult }\end{array}$ \\
\hline Diptera & Psychodidae & DM & $\mathrm{M}=\mathrm{a} *(\mathrm{~L})^{\wedge} \mathrm{b}$ & 0.0153 & 2.573 & 1.75 & 8.6 & (Gruner 2003) & $\begin{array}{r}\text { Original, diptera } \\
\text { adult }\end{array}$ \\
\hline Diptera & Sciaridae & DM & $\mathrm{M}=\mathrm{a} *(\mathrm{~L})^{\wedge} \mathrm{b}$ & 0.0153 & 2.573 & 1.75 & 8.6 & (Gruner 2003) & $\begin{array}{r}\text { Original, diptera } \\
\text { adult }\end{array}$ \\
\hline Diptera & Simuliidae & DM & $\mathrm{M}=\mathrm{a} *(\mathrm{~L})^{\wedge} \mathrm{b}$ & 0.0153 & 2.573 & 1.75 & 8.6 & (Gruner 2003) & $\begin{array}{r}\text { Original, diptera } \\
\text { adult }\end{array}$ \\
\hline Diptera & Sphaeroceridae & DM & $\mathrm{M}=\mathrm{a} *(\mathrm{~L})^{\wedge} \mathrm{b}$ & 0.0153 & 2.573 & 1.75 & 8.6 & (Gruner 2003) & $\begin{array}{r}\text { Original, diptera } \\
\text { adult }\end{array}$ \\
\hline Diptera & Pipunculidae & DM & $\mathrm{M}=\mathrm{a} *(\mathrm{~L})^{\wedge} \mathrm{b}$ & 0.0153 & 2.573 & 1.75 & 8.6 & (Gruner 2003) & $\begin{array}{r}\text { Original, diptera } \\
\text { adult }\end{array}$ \\
\hline Diptera & Scatopsidae & DM & $\mathrm{M}=\mathrm{a} *(\mathrm{~L})^{\wedge} \mathrm{b}$ & 0.0153 & 2.573 & 1.75 & 8.6 & (Gruner 2003) & $\begin{array}{r}\text { Original, diptera } \\
\text { adult }\end{array}$ \\
\hline Diptera & Tipulidae & DM & $\mathrm{M}=\mathrm{a} *(\mathrm{~L})^{\wedge} \mathrm{b}$ & 0.0153 & 2.573 & 1.75 & 8.6 & (Gruner 2003) & $\begin{array}{r}\text { Original, diptera } \\
\text { adult }\end{array}$ \\
\hline Diptera & Uniden & DM & $\mathrm{M}=\mathrm{a} *(\mathrm{~L})^{\wedge} \mathrm{b}$ & 0.0153 & 2.573 & 1.75 & 8.6 & (Gruner 2003) & $\begin{array}{r}\text { Original, diptera } \\
\text { adult }\end{array}$ \\
\hline Ephemeroptera & Baetidae & DM & $\mathrm{M}=\mathrm{a} *(\mathrm{~L})^{\wedge} \mathrm{b}$ & 0.035 & 2.173 & 0.9 & 17.6 & (Gruner 2003) & $\begin{array}{r}\text { Inferred, all } \\
\text { insect taxa }\end{array}$ \\
\hline Chilopoda & All & DM & $\mathrm{M}=\exp (\mathrm{a}+\mathrm{b} * \log (\mathrm{L}))$ & -4.049 & 2.18 & 4 & 47 & $\begin{array}{l}\text { (Gowing \& } \\
\text { Recher 1984) }\end{array}$ & $\begin{array}{l}\text { Inferred, } \\
\text { chilopoda }\end{array}$ \\
\hline
\end{tabular}


Supplementary Information - Chapter 3

\begin{tabular}{|c|c|c|c|c|c|c|c|c|c|}
\hline Geophilomorpha & Dignathodontidae & DM & $M=\exp (a+b * \log (L))$ & -4.049 & 2.18 & 4 & 47 & $\begin{array}{l}\text { (Gowing \& } \\
\text { Recher 1984) }\end{array}$ & $\begin{array}{r}\text { Inferred, } \\
\text { chilopoda }\end{array}$ \\
\hline Geophilomorpha & Geophilidae & DM & $\mathrm{M}=\exp (\mathrm{a}+\mathrm{b} * \log (\mathrm{L}))$ & -4.049 & 2.18 & 4 & 47 & $\begin{array}{l}\text { (Gowing \& } \\
\text { Recher 1984) }\end{array}$ & $\begin{array}{r}\text { Inferred, } \\
\text { chilopoda }\end{array}$ \\
\hline Geophilomorpha & Mecistocephalidae & DM & $\mathrm{M}=\exp (\mathrm{a}+\mathrm{b} * \log (\mathrm{L}))$ & -4.049 & 2.18 & 4 & 47 & $\begin{array}{l}\text { (Gowing \& } \\
\text { Recher 1984) }\end{array}$ & $\begin{array}{l}\text { Inferred, } \\
\text { chilopoda }\end{array}$ \\
\hline Diplopoda & All & DM & $\mathrm{M}=\exp (\mathrm{a}+\mathrm{b} * \log (\mathrm{L}))$ & -4.591 & 2.543 & 11.0 & 47.0 & $\begin{array}{l}\text { (Gowing \& } \\
\text { Recher 1984) }\end{array}$ & $\begin{array}{r}\text { Inferred, } \\
\text { diplopoda }\end{array}$ \\
\hline Glomerida & Glomeridae & DM & $\mathrm{M}=\exp (\mathrm{a}+\mathrm{b} * \log (\mathrm{L}))$ & -4.591 & 2.543 & 11.0 & 47.0 & $\begin{array}{l}\text { (Gowing \& } \\
\text { Recher 1984) }\end{array}$ & $\begin{array}{r}\text { Inferred, } \\
\text { diplopoda }\end{array}$ \\
\hline Hemiptera & Aleyrodidae & DM & $M=\exp (a+b * \log (L))$ & -2.823 & 2.225 & 2.13 & 13.25 & $\begin{array}{l}\text { (Sample } \text { et al. } \\
1993 \text { ) }\end{array}$ & $\begin{array}{r}\text { Inferred, } \\
\text { homoptera }\end{array}$ \\
\hline Hemiptera & Alydidae & DM & $M=\exp (a+b * \log (L))$ & -4.784 & 3.075 & 3.2 & 40.23 & $\begin{array}{l}\text { (Sample } \text { et al. } \\
1993 \text { ) }\end{array}$ & $\begin{array}{r}\text { Original, } \\
\text { hemiptera }\end{array}$ \\
\hline Hemiptera & Anthocoridae & DM & $M=\exp (a+b * \log (L))$ & -4.784 & 3.075 & 3.2 & 40.23 & $\begin{array}{l}\text { (Sample } \text { et al. } \\
\text { 1993) }\end{array}$ & $\begin{array}{r}\text { Original, } \\
\text { hemiptera }\end{array}$ \\
\hline Hemiptera & Aphididae & DM & $M=\exp (a+b * \log (L))$ & -2.823 & 2.225 & 2.13 & 13.25 & $\begin{array}{l}\text { (Sample } \text { et al. } \\
1993 \text { ) }\end{array}$ & $\begin{array}{r}\text { Inferred, } \\
\text { homoptera }\end{array}$ \\
\hline Hemiptera & Aradidae & DM & $\mathrm{M}=\exp (\mathrm{a}+\mathrm{b} * \log (\mathrm{L}))$ & -4.784 & 3.075 & 3.2 & 40.23 & $\begin{array}{l}\text { (Sample } \text { et al. } \\
\text { 1993) }\end{array}$ & $\begin{array}{r}\text { Original, } \\
\text { hemiptera }\end{array}$ \\
\hline Hemiptera & Ceratocombidae & DM & $\mathrm{M}=\exp (\mathrm{a}+\mathrm{b} * \log (\mathrm{L}))$ & -4.784 & 3.075 & 3.2 & 40.23 & $\begin{array}{l}\text { (Sample } \text { et al. } \\
1993 \text { ) }\end{array}$ & $\begin{array}{r}\text { Original, } \\
\text { hemiptera }\end{array}$ \\
\hline Hemiptera & Cicadellidae & DM & $\mathrm{M}=\exp (\mathrm{a}+\mathrm{b} * \log (\mathrm{L}))$ & -3.735 & 2.561 & 2.13 & 13.25 & $\begin{array}{l}\text { (Sample } \text { et al. } \\
1993 \text { ) }\end{array}$ & Group specific \\
\hline Hemiptera & Cixiidae & DM & $\mathrm{M}=\exp (\mathrm{a}+\mathrm{b} * \log (\mathrm{L}))$ & -4.784 & 3.075 & 3.2 & 40.23 & $\begin{array}{l}\text { (Sample } \text { et al. } \\
\text { 1993) }\end{array}$ & $\begin{array}{r}\text { Inferred, } \\
\text { hemiptera }\end{array}$ \\
\hline Hemiptera & Coreidae & DM & $M=\exp (a+b * \log (L))$ & -4.784 & 3.075 & 3.2 & 40.23 & $\begin{array}{l}\text { (Sample } \text { et al. } \\
\text { 1993) }\end{array}$ & $\begin{array}{r}\text { Inferred, } \\
\text { hemiptera }\end{array}$ \\
\hline Hemiptera & Cydnidae & DM & $M=\exp (a+b * \log (L))$ & -4.784 & 3.075 & 3.2 & 40.23 & $\begin{array}{l}\text { (Sample } \text { et al. } \\
\text { 1993) }\end{array}$ & $\begin{array}{r}\text { Inferred, } \\
\text { hemiptera }\end{array}$ \\
\hline Hemiptera & Delphacidae & DM & $M=\exp (a+b * \log (L))$ & -2.823 & 2.225 & 2.13 & 13.25 & $\begin{array}{l}\text { (Sample } \text { et al. } \\
1993 \text { ) }\end{array}$ & $\begin{array}{r}\text { Inferred, } \\
\text { homoptera }\end{array}$ \\
\hline Hemiptera & Derbidae & DM & $M=\exp (a+b * \log (L))$ & -2.823 & 2.225 & 2.13 & 13.25 & $\begin{array}{l}\text { (Sample } \text { et al. } \\
\text { 1993) }\end{array}$ & $\begin{array}{r}\text { Inferred, } \\
\text { homoptera }\end{array}$ \\
\hline Hemiptera & Dictyopharidae & DM & $M=\exp (a+b * \log (L))$ & -2.823 & 2.225 & 2.13 & 13.25 & $\begin{array}{l}\text { (Sample } \text { et al. } \\
\text { 1993) }\end{array}$ & $\begin{array}{r}\text { Inferred, } \\
\text { homoptera }\end{array}$ \\
\hline Hemiptera & Dipsocoridae & DM & $\mathrm{M}=\exp (\mathrm{a}+\mathrm{b} * \log (\mathrm{L}))$ & -4.784 & 3.075 & 3.2 & 40.23 & $\begin{array}{l}\text { (Sample } \text { et al. } \\
\text { 1993) }\end{array}$ & $\begin{array}{r}\text { Inferred, } \\
\text { hemiptera }\end{array}$ \\
\hline Hemiptera & Eriosomatidae & DM & $\mathrm{M}=\exp (\mathrm{a}+\mathrm{b} * \log (\mathrm{L}))$ & -2.823 & 2.225 & 2.13 & 13.25 & $\begin{array}{l}\text { (Sample } \text { et al. } \\
\text { 1993) }\end{array}$ & $\begin{array}{r}\text { Inferred, } \\
\text { homoptera }\end{array}$ \\
\hline Hemiptera & Flatidae & DM & $\mathrm{M}=\exp (\mathrm{a}+\mathrm{b} * \log (\mathrm{L}))$ & -2.823 & 2.225 & 2.13 & 13.25 & $\begin{array}{l}\text { (Sample } \text { et al. } \\
\text { 1993) }\end{array}$ & $\begin{array}{r}\text { Inferred, } \\
\text { homoptera }\end{array}$ \\
\hline Hemiptera & Geocoridae & DM & $\mathrm{M}=\exp (\mathrm{a}+\mathrm{b} * \log (\mathrm{L}))$ & -4.784 & 3.075 & 3.2 & 40.23 & $\begin{array}{l}\text { (Sample } \text { et al. } \\
\text { 1993) }\end{array}$ & $\begin{array}{r}\text { Inferred, } \\
\text { hemiptera }\end{array}$ \\
\hline Hemiptera & Hydrometridae & DM & $M=\exp (a+b * \log (L))$ & -4.784 & 3.075 & 3.2 & 40.23 & $\begin{array}{l}\text { (Sample } \text { et al. } \\
\text { 1993) }\end{array}$ & $\begin{array}{r}\text { Inferred, } \\
\text { hemiptera }\end{array}$ \\
\hline Hemiptera & Largidae & DM & $\mathrm{M}=\exp (\mathrm{a}+\mathrm{b} * \log (\mathrm{L}))$ & -4.784 & 3.075 & 3.2 & 40.23 & $\begin{array}{l}\text { (Sample } \text { et al. } \\
\text { 1993) }\end{array}$ & $\begin{array}{r}\text { Inferred, } \\
\text { hemiptera }\end{array}$ \\
\hline Hemiptera & Lophopidae & DM & $\mathrm{M}=\exp (\mathrm{a}+\mathrm{b} * \log (\mathrm{L}))$ & -2.823 & 2.225 & 2.13 & 13.25 & $\begin{array}{l}\text { (Sample } \text { et al. } \\
\text { 1993) }\end{array}$ & $\begin{array}{r}\text { Inferred, } \\
\text { homoptera }\end{array}$ \\
\hline Hemiptera & Lygaeidae & DM & $M=\exp (a+b * \log (L))$ & -4.784 & 3.075 & 3.2 & 40.23 & $\begin{array}{l}\text { (Sample } \text { et al. } \\
\text { 1993) }\end{array}$ & $\begin{array}{r}\text { Inferred, } \\
\text { hemiptera }\end{array}$ \\
\hline Hemiptera & Meenoplidae & DM & $\mathrm{M}=\exp (\mathrm{a}+\mathrm{b} * \log (\mathrm{L}))$ & -2.823 & 2.225 & 2.13 & 13.25 & $\begin{array}{l}\text { (Sample } \text { et al. } \\
\text { 1993) }\end{array}$ & $\begin{array}{r}\text { Inferred, } \\
\text { homoptera }\end{array}$ \\
\hline Hemiptera & Miridae & DM & $\mathrm{M}=\exp (\mathrm{a}+\mathrm{b} * \log (\mathrm{L}))$ & -4.784 & 3.075 & 3.2 & 40.23 & $\begin{array}{l}\text { (Sample } \text { et al. } \\
\text { 1993) }\end{array}$ & $\begin{array}{r}\text { Inferred, } \\
\text { hemiptera }\end{array}$ \\
\hline Hemiptera & Nabidae & DM & $\mathrm{M}=\exp (\mathrm{a}+\mathrm{b} * \log (\mathrm{L}))$ & -4.784 & 3.075 & 3.2 & 40.23 & $\begin{array}{l}\text { (Sample } \text { et al. } \\
\text { 1993) }\end{array}$ & $\begin{array}{r}\text { Inferred, } \\
\text { hemiptera }\end{array}$ \\
\hline Hemiptera & Pentatomidae & DM & $M=\exp (a+b * \log (L))$ & -4.197 & 3.053 & 6.35 & 16.73 & $\begin{array}{l}\text { (Sample } \text { et al. } \\
\text { 1993) }\end{array}$ & Group specific \\
\hline Hemiptera & Pseudococcidae & DM & $\mathrm{M}=\exp (\mathrm{a}+\mathrm{b} * \log (\mathrm{L}))$ & -2.823 & 2.225 & 2.13 & 13.25 & $\begin{array}{l}\text { (Sample } \text { et al. } \\
\text { 1993) }\end{array}$ & $\begin{array}{r}\text { Inferred, } \\
\text { homoptera }\end{array}$ \\
\hline Hemiptera & Reduviidae & DM & $M=\exp (a+b * \log (L))$ & -4.784 & 3.075 & 3.2 & 40.23 & $\begin{array}{l}\text { (Sample } \text { et al. } \\
\text { 1993) }\end{array}$ & $\begin{array}{r}\text { Inferred, } \\
\text { hemiptera }\end{array}$ \\
\hline Hemiptera & Ricaniidae & DM & $\mathrm{M}=\exp (\mathrm{a}+\mathrm{b} * \log (\mathrm{L}))$ & -2.823 & 2.225 & 2.13 & 13.25 & $\begin{array}{l}\text { (Sample } \text { et al. } \\
\text { 1993) }\end{array}$ & $\begin{array}{r}\text { Inferred, } \\
\text { homoptera }\end{array}$ \\
\hline Hemiptera & Schizopteridae & DM & $\mathrm{M}=\exp (\mathrm{a}+\mathrm{b} * \log (\mathrm{L}))$ & -4.784 & 3.075 & 3.2 & 40.23 & $\begin{array}{l}\text { (Sample et al. } \\
\text { 1993) }\end{array}$ & $\begin{array}{r}\text { Inferred, } \\
\text { hemiptera }\end{array}$ \\
\hline Hemiptera & Tingidae & DM & $M=\exp (a+b * \log (L))$ & -4.784 & 3.075 & 3.2 & 40.23 & $\begin{array}{l}\text { (Sample } \text { et al. } \\
\text { 1993) }\end{array}$ & $\begin{array}{r}\text { Inferred, } \\
\text { hemiptera }\end{array}$ \\
\hline
\end{tabular}


Supplementary Information - Chapter 3

\begin{tabular}{|c|c|c|c|c|c|c|c|c|c|}
\hline Hemiptera & Tropiduchidae & DM & $M=\exp (a+b * \log (L))$ & -2.823 & 2.225 & 2.13 & 13.25 & $\begin{array}{l}\text { (Sample et al. } \\
\text { 1993) }\end{array}$ & $\begin{array}{r}\text { Inferred, } \\
\text { homoptera }\end{array}$ \\
\hline Hemiptera & Uniden & DM & $M=\exp (a+b * \log (L))$ & -4.784 & 3.075 & 3.2 & 40.23 & $\begin{array}{l}\text { (Sample } \text { et al. } \\
\text { 1993) }\end{array}$ & $\begin{array}{r}\text { Inferred, } \\
\text { hemiptera }\end{array}$ \\
\hline Hymenoptera & Aphelinidae & DM & $M=\exp (a+b * \log (L))$ & -3.336 & 2.104 & 1 & 12 & $\begin{array}{l}\text { (Gowing \& } \\
\text { Recher 1984) }\end{array}$ & $\begin{array}{l}\text { Inferred, hym. } \\
\text { Excl formicidae }\end{array}$ \\
\hline Hymenoptera & Bethylidae & DM & $M=\exp (a+b * \log (L))$ & -3.336 & 2.104 & 1 & 12 & $\begin{array}{l}\text { (Gowing \& } \\
\text { Recher 1984) }\end{array}$ & $\begin{array}{l}\text { Inferred, hym. } \\
\text { Excl formicidae }\end{array}$ \\
\hline Hymenoptera & Braconidae & DM & $M=\exp (a+b * \log (L))$ & -3.336 & 2.104 & 1 & 12 & $\begin{array}{l}\text { (Gowing \& } \\
\text { Recher 1984) }\end{array}$ & $\begin{array}{l}\text { Inferred, hym. } \\
\text { Excl formicidae }\end{array}$ \\
\hline Hymenoptera & Ceraphronidae & DM & $M=\exp (a+b * \log (L))$ & -3.336 & 2.104 & 1 & 12 & $\begin{array}{l}\text { (Gowing \& } \\
\text { Recher 1984) }\end{array}$ & $\begin{array}{l}\text { Inferred, hym. } \\
\text { Excl formicidae }\end{array}$ \\
\hline Hymenoptera & Chalcididae & DM & $M=\exp (a+b * \log (L))$ & -3.336 & 2.104 & 1 & 12 & $\begin{array}{l}\text { (Gowing \& } \\
\text { Recher 1984) }\end{array}$ & $\begin{array}{l}\text { Inferred, hym. } \\
\text { Excl formicidae }\end{array}$ \\
\hline Hymenoptera & Cynipidae & DM & $M=\exp (a+b * \log (L))$ & -3.336 & 2.104 & 1 & 12 & $\begin{array}{l}\text { (Gowing \& } \\
\text { Recher 1984) }\end{array}$ & $\begin{array}{l}\text { Inferred, hym. } \\
\text { Excl formicidae }\end{array}$ \\
\hline Hymenoptera & Diapriidae & DM & $M=\exp (a+b * \log (L))$ & -3.336 & 2.104 & 1 & 12 & $\begin{array}{l}\text { (Gowing \& } \\
\text { Recher 1984) }\end{array}$ & $\begin{array}{l}\text { Inferred, hym. } \\
\text { Excl formicidae }\end{array}$ \\
\hline Hymenoptera & Dryinidae & DM & $M=\exp (a+b * \log (L))$ & -3.336 & 2.104 & 1 & 12 & $\begin{array}{l}\text { (Gowing \& } \\
\text { Recher 1984) }\end{array}$ & $\begin{array}{l}\text { Inferred, hym. } \\
\text { Excl formicidae }\end{array}$ \\
\hline Hymenoptera & Dryniidae & DM & $\mathrm{M}=\exp (\mathrm{a}+\mathrm{b} * \log (\mathrm{L}))$ & -3.336 & 2.104 & 1 & 12 & $\begin{array}{l}\text { (Gowing \& } \\
\text { Recher 1984) }\end{array}$ & $\begin{array}{l}\text { Inferred, hym. } \\
\text { Excl formicidae }\end{array}$ \\
\hline Hymenoptera & Encyrtidae & $\mathrm{DM}$ & $\mathrm{M}=\exp (\mathrm{a}+\mathrm{b} * \log (\mathrm{L}))$ & -3.336 & 2.104 & 1 & 12 & $\begin{array}{l}\text { (Gowing \& } \\
\text { Recher 1984) }\end{array}$ & $\begin{array}{l}\text { Inferred, hym. } \\
\text { Excl formicidae }\end{array}$ \\
\hline Hymenoptera & Eucoilidae & $\mathrm{DM}$ & $M=\exp (a+b * \log (L))$ & -3.336 & 2.104 & 1 & 12 & $\begin{array}{l}\text { (Gowing \& } \\
\text { Recher 1984) }\end{array}$ & $\begin{array}{l}\text { Inferred, hym. } \\
\text { Excl formicidae }\end{array}$ \\
\hline Hymenoptera & Eulophidae & DM & $M=\exp (a+b * \log (L))$ & -3.336 & 2.104 & 1 & 12 & $\begin{array}{l}\text { (Gowing \& } \\
\text { Recher 1984) }\end{array}$ & $\begin{array}{l}\text { Inferred, hym. } \\
\text { Excl formicidae }\end{array}$ \\
\hline Hymenoptera & Figitidae & DM & $M=\exp (a+b * \log (L))$ & -3.336 & 2.104 & 1 & 12 & $\begin{array}{l}\text { (Gowing \& } \\
\text { Recher 1984) }\end{array}$ & $\begin{array}{l}\text { Inferred, hym. } \\
\text { Excl formicidae }\end{array}$ \\
\hline Hymenoptera & Formicidae & DM & $M=\exp (a+b * \log (L))$ & -3.996 & 2.489 & 2 & 18 & $\begin{array}{l}\text { (Gowing \& } \\
\text { Recher 1984) }\end{array}$ & Group specific \\
\hline Hymenoptera & Ichneumonidae & DM & $\mathrm{M}=\exp (\mathrm{a}+\mathrm{b} * \log (\mathrm{L}))$ & -3.336 & 2.104 & 1 & 12 & $\begin{array}{l}\text { (Gowing \& } \\
\text { Recher 1984) }\end{array}$ & $\begin{array}{l}\text { Inferred, hym. } \\
\text { Excl formicidae }\end{array}$ \\
\hline Hymenoptera & Mymaridae & DM & $M=\exp (a+b * \log (L))$ & -3.336 & 2.104 & 1 & 12 & $\begin{array}{l}\text { (Gowing \& } \\
\text { Recher 1984) }\end{array}$ & $\begin{array}{l}\text { Inferred, hym. } \\
\text { Excl formicidae }\end{array}$ \\
\hline Hymenoptera & Mymarommatidae & DM & $\mathrm{M}=\exp (\mathrm{a}+\mathrm{b} * \log (\mathrm{L}))$ & -3.336 & 2.104 & 1 & 12 & $\begin{array}{l}\text { (Gowing \& } \\
\text { Recher 1984) }\end{array}$ & $\begin{array}{l}\text { Inferred, hym. } \\
\text { Excl formicidae }\end{array}$ \\
\hline Hymenoptera & Platygastridae & DM & $M=\exp (a+b * \log (L))$ & -3.336 & 2.104 & 1 & 12 & $\begin{array}{l}\text { (Gowing \& } \\
\text { Recher 1984) }\end{array}$ & $\begin{array}{l}\text { Inferred, hym. } \\
\text { Excl formicidae }\end{array}$ \\
\hline Hymenoptera & Scelionidae & DM & $M=\exp (a+b * \log (L))$ & -3.336 & 2.104 & 1 & 12 & $\begin{array}{l}\text { (Gowing \& } \\
\text { Recher 1984) }\end{array}$ & $\begin{array}{l}\text { Inferred, hym. } \\
\text { Excl formicidae }\end{array}$ \\
\hline Hymenoptera & Sphecidae & DM & $M=\exp (a+b * \log (L))$ & -3.336 & 2.104 & 1 & 12 & $\begin{array}{l}\text { (Gowing \& } \\
\text { Recher 1984) }\end{array}$ & $\begin{array}{l}\text { Inferred, hym. } \\
\text { Excl formicidae }\end{array}$ \\
\hline Hymenoptera & Tiphiidae & DM & $M=\exp (a+b * \log (L))$ & -3.336 & 2.104 & 1 & 12 & $\begin{array}{l}\text { (Gowing \& } \\
\text { Recher 1984) }\end{array}$ & $\begin{array}{l}\text { Inferred, hym. } \\
\text { Excl formicidae }\end{array}$ \\
\hline Hymenoptera & Trichogrammatidae & DM & $M=\exp (a+b * \log (L))$ & -3.336 & 2.104 & 1 & 12 & $\begin{array}{l}\text { (Gowing \& } \\
\text { Recher 1984) }\end{array}$ & $\begin{array}{l}\text { Inferred, hym. } \\
\text { Excl formicidae }\end{array}$ \\
\hline Hymenoptera & Vespidae & DM & $\mathrm{M}=\exp (\mathrm{a}+\mathrm{b} * \log (\mathrm{L}))$ & -3.336 & 2.104 & 1 & 12 & $\begin{array}{l}\text { (Gowing \& } \\
\text { Recher 1984) }\end{array}$ & $\begin{array}{l}\text { Inferred, hym. } \\
\text { Excl formicidae }\end{array}$ \\
\hline Isopoda & All & DM & $M=\exp (a+b * \log (L))$ & -4.81 & 3.44 & 2.7 & 8 & $\begin{array}{l}\text { (Wardhaugh } \\
\text { 2013) }\end{array}$ & $\begin{array}{r}\text { Original, } \\
\text { isopoda }\end{array}$ \\
\hline Isopoda & Oniscidae & DM & $M=\exp (a+b * \log (L))$ & -4.81 & 3.44 & 2.7 & 8 & $\begin{array}{l}\text { (Wardhaugh } \\
\text { 2013) }\end{array}$ & $\begin{array}{r}\text { Original, } \\
\text { isopoda }\end{array}$ \\
\hline Isopoda & Philosciidae & DM & $M=\exp (a+b * \log (L))$ & -4.81 & 3.44 & 2.7 & 8 & $\begin{array}{l}\text { (Wardhaugh } \\
\text { 2013) }\end{array}$ & $\begin{array}{r}\text { Original, } \\
\text { isopoda }\end{array}$ \\
\hline Isopoda & Armadillidae & DM & $M=\exp (a+b * \log (L))$ & -4.81 & 3.44 & 2.7 & 8 & $\begin{array}{l}\text { (Wardhaugh } \\
\text { 2013) }\end{array}$ & $\begin{array}{r}\text { Original, } \\
\text { isopoda }\end{array}$ \\
\hline Isopoda & Termitidae & DM & $\mathrm{M}=\exp (\mathrm{a}+\mathrm{b} * \log (\mathrm{L}))$ & -4.81 & 3.44 & 2.7 & 8 & $\begin{array}{l}\text { (Wardhaugh } \\
\text { 2013) }\end{array}$ & $\begin{array}{r}\text { Original, } \\
\text { isopoda }\end{array}$ \\
\hline Isoptera & Rhinotermitidae & DM & $\mathrm{M}=\mathrm{e}^{\wedge} \mathrm{a} * \mathrm{~L}^{\wedge} \mathrm{b}$ & -5.802 & 3.177 & 3.30 & 5.60 & $\begin{array}{l}\text { (Johnson \& } \\
\text { Strong 2000) }\end{array}$ & $\begin{array}{r}\text { Inferred, } \\
\text { isoptera }\end{array}$ \\
\hline Isoptera & Termitidae & DM & $\mathrm{M}=\mathrm{e}^{\wedge} \mathrm{a} * \mathrm{~L}^{\wedge} \mathrm{b}$ & -5.802 & 3.177 & 3.30 & 5.60 & $\begin{array}{l}\text { (Johnson \& } \\
\text { Strong 2000) }\end{array}$ & $\begin{array}{l}\text { Inferred, } \\
\text { isoptera }\end{array}$ \\
\hline Lepidoptera & Acanthopteroctetidae & DM & $M=\exp (a+b * \log (L))$ & -5.036 & 3.122 & 2.76 & 40.73 & $\begin{array}{l}\text { (Sample } \text { et al. } \\
\text { 1993) }\end{array}$ & $\begin{array}{r}\text { Inferred, } \\
\text { lepidoptera }\end{array}$ \\
\hline Lepidoptera & Acanthopteroctetidae & DM & $M=\exp (a+b * \log (L))$ & -5.036 & 3.122 & 2.76 & 40.73 & $\begin{array}{l}\text { (Sample et al. } \\
\text { 1993) }\end{array}$ & $\begin{array}{r}\text { Inferred, } \\
\text { lepidoptera }\end{array}$ \\
\hline Lepidoptera & Gelechiidae & $\mathrm{DM}$ & $\mathrm{M}=\exp (\mathrm{a}+\mathrm{b} * \log (\mathrm{L}))$ & -5.036 & 3.122 & 2.76 & 40.73 & $\begin{array}{l}\text { (Sample } \text { et al. } \\
\text { 1993) }\end{array}$ & $\begin{array}{r}\text { Inferred, } \\
\text { lepidoptera }\end{array}$ \\
\hline
\end{tabular}


Supplementary Information - Chapter 3

\begin{tabular}{|c|c|c|c|c|c|c|c|c|c|}
\hline Lepidoptera & Geometridae & DM & $M=\exp (a+b * \log (L))$ & -5.036 & 3.122 & 2.76 & 40.73 & $\begin{array}{l}\text { (Sample } \text { et al. } \\
\text { 1993) }\end{array}$ & $\begin{array}{r}\text { Inferred, } \\
\text { lepidoptera }\end{array}$ \\
\hline Lepidoptera & Gracillariidae & DM & $\mathrm{M}=\exp (\mathrm{a}+\mathrm{b} * \log (\mathrm{L}))$ & -5.036 & 3.122 & 2.76 & 40.73 & $\begin{array}{l}\text { (Sample } \text { et al. } \\
\text { 1993) }\end{array}$ & $\begin{array}{r}\text { Inferred, } \\
\text { lepidoptera }\end{array}$ \\
\hline Lepidoptera & Noctuidae & DM & $\mathrm{M}=\exp (\mathrm{a}+\mathrm{b} * \log (\mathrm{L}))$ & -5.036 & 3.122 & 2.76 & 40.73 & $\begin{array}{l}\text { (Sample } \text { et al. } \\
\text { 1993) }\end{array}$ & $\begin{array}{r}\text { Inferred, } \\
\text { lepidoptera }\end{array}$ \\
\hline Lepidoptera & Pyralidae & DM & $\mathrm{M}=\exp (\mathrm{a}+\mathrm{b} * \log (\mathrm{L}))$ & -5.036 & 3.122 & 2.76 & 40.73 & $\begin{array}{l}\text { (Sample } \text { et al. } \\
\text { 1993) }\end{array}$ & $\begin{array}{r}\text { Inferred, } \\
\text { lepidoptera }\end{array}$ \\
\hline Lepidoptera & Thyrididae & DM & $\mathrm{M}=\exp (\mathrm{a}+\mathrm{b} * \log (\mathrm{L}))$ & -5.036 & 3.122 & 2.76 & 40.73 & $\begin{array}{l}\text { (Sample } \text { et al. } \\
1993 \text { ) }\end{array}$ & $\begin{array}{r}\text { Inferred, } \\
\text { lepidoptera }\end{array}$ \\
\hline Lepidoptera & Tineidae & DM & $M=\exp (a+b * \log (L))$ & -5.036 & 3.122 & 2.76 & 40.73 & $\begin{array}{l}\text { (Sample } \text { et al. } \\
\text { 1993) }\end{array}$ & $\begin{array}{r}\text { Inferred, } \\
\text { lepidoptera }\end{array}$ \\
\hline Lepidoptera & Tortricidae & DM & $M=\exp (a+b * \log (L))$ & -5.036 & 3.122 & 2.76 & 40.73 & $\begin{array}{l}\text { (Sample } \text { et al. } \\
\text { 1993) }\end{array}$ & $\begin{array}{r}\text { Inferred, } \\
\text { lepidoptera }\end{array}$ \\
\hline Lepidoptera & Zygaenidae & DM & $M=\exp (a+b * \log (L))$ & -5.036 & 3.122 & 2.76 & 40.73 & $\begin{array}{l}\text { (Sample } \text { et al. } \\
\text { 1993) }\end{array}$ & $\begin{array}{r}\text { Inferred, } \\
\text { lepidoptera }\end{array}$ \\
\hline Lepidoptera & Uniden & DM & $M=\exp (a+b * \log (L))$ & -5.036 & 3.122 & 2.76 & 40.73 & $\begin{array}{l}\text { (Sample } \text { et al. } \\
\text { 1993) }\end{array}$ & $\begin{array}{r}\text { Inferred, } \\
\text { lepidoptera }\end{array}$ \\
\hline Lithobiomorpha & Henicopidae & DM & $\mathrm{M}=\exp (\mathrm{a}+\mathrm{b} * \log (\mathrm{L}))$ & -4.049 & 2.18 & 4 & 47 & $\begin{array}{l}\text { (Gowing \& } \\
\text { Recher 1984) }\end{array}$ & $\begin{array}{r}\text { Inferred, } \\
\text { chilopoda }\end{array}$ \\
\hline Mantodea & Mantidae & DM & $\mathrm{M}=\exp (\mathrm{a}+\mathrm{b} * \log (\mathrm{L}))$ & -6.340 & 3.010 & 6.00 & 66.00 & $\begin{array}{l}\text { (Wardhaugh } \\
\text { 2013) }\end{array}$ & Group specific \\
\hline Neuroptera & Chrysopidae & DM & $\mathrm{M}=\exp (\mathrm{a}+\mathrm{b} * \log (\mathrm{L}))$ & -4.483 & 2.570 & 3.45 & 54.51 & $\begin{array}{l}\text { (Sample } \text { et al. } \\
\text { 1993) }\end{array}$ & $\begin{array}{r}\text { Inferred, } \\
\text { neuroptera }\end{array}$ \\
\hline Opiliones & All & FM & $M=\exp (a+b * \log (L))$ & -0.899 & 2.984 & 0.57 & 6.9 & $\begin{array}{l}\text { (Höfer \& Ott } \\
2009 \text { ) }\end{array}$ & $\begin{array}{l}\text { Inferred, } \\
\text { opiliones }\end{array}$ \\
\hline Orthoptera & Acrididae & DM & $\mathrm{M}=\exp (\mathrm{a}+\mathrm{b} * \log (\mathrm{L}))$ & -3.17 & 2.61 & 2.3 & 33 & $\begin{array}{l}\text { (Wardhaugh } \\
\text { 2013) }\end{array}$ & $\begin{array}{r}\text { Inferred, } \\
\text { orthoptera }\end{array}$ \\
\hline Orthoptera & Gryllidae & DM & $M=\exp (a+b * \log (L))$ & -3.17 & 2.61 & 2.3 & 33 & $\begin{array}{l}\text { (Wardhaugh } \\
\text { 2013) }\end{array}$ & $\begin{array}{r}\text { Inferred, } \\
\text { orthoptera }\end{array}$ \\
\hline Orthoptera & Tetrigidae & DM & $M=\exp (a+b * \log (L))$ & -3.17 & 2.61 & 2.3 & 33 & $\begin{array}{l}\text { (Wardhaugh } \\
\text { 2013) }\end{array}$ & $\begin{array}{r}\text { Inferred, } \\
\text { orthoptera }\end{array}$ \\
\hline Orthoptera & Gryllacrididae & DM & $M=\exp (a+b * \log (L))$ & -3.17 & 2.61 & 2.3 & 33 & $\begin{array}{l}\text { (Wardhaugh } \\
\text { 2013) }\end{array}$ & $\begin{array}{l}\text { Inferred, } \\
\text { orthoptera }\end{array}$ \\
\hline Orthoptera & Tettigoniidae & DM & $M=\exp (a+b * \log (L))$ & -3.17 & 2.61 & 2.3 & 33 & $\begin{array}{l}\text { (Wardhaugh } \\
\text { 2013) }\end{array}$ & $\begin{array}{l}\text { Inferred, } \\
\text { orthoptera }\end{array}$ \\
\hline Orthoptera & Tridactylidae & DM & $\mathrm{M}=\exp (\mathrm{a}+\mathrm{b} * \log (\mathrm{L}))$ & -3.17 & 2.61 & 2.3 & 33 & $\begin{array}{l}\text { (Wardhaugh } \\
\text { 2013) }\end{array}$ & $\begin{array}{l}\text { Inferred, } \\
\text { orthoptera }\end{array}$ \\
\hline Polydesmida & Paradoxosomatidae & DM & $M=\exp (a+b * \log (L))$ & -4.591 & 2.543 & 11.0 & 47.0 & $\begin{array}{l}\text { (Gowing \& } \\
\text { Recher 1984) }\end{array}$ & $\begin{array}{r}\text { Inferred, } \\
\text { diplopoda }\end{array}$ \\
\hline Polydesmida & Platyrhacidae & DM & $\mathrm{M}=\exp (\mathrm{a}+\mathrm{b} * \log (\mathrm{L}))$ & -4.591 & 2.543 & 11.0 & 47.0 & $\begin{array}{l}\text { (Gowing \& } \\
\text { Recher 1984) }\end{array}$ & $\begin{array}{r}\text { Inferred, } \\
\text { diplopoda }\end{array}$ \\
\hline Polydesmida & Cryptodesmidae & DM & $\mathrm{M}=\exp (\mathrm{a}+\mathrm{b} * \log (\mathrm{L}))$ & -4.591 & 2.543 & 11.0 & 47.0 & $\begin{array}{l}\text { (Gowing \& } \\
\text { Recher 1984) }\end{array}$ & $\begin{array}{r}\text { Inferred, } \\
\text { diplopoda }\end{array}$ \\
\hline Polydesmida & Dalodesmidae & DM & $\mathrm{M}=\exp (\mathrm{a}+\mathrm{b} * \log (\mathrm{L}))$ & -4.591 & 2.543 & 11.0 & 47.0 & $\begin{array}{l}\text { (Gowing \& } \\
\text { Recher 1984) }\end{array}$ & $\begin{array}{r}\text { Inferred, } \\
\text { diplopoda }\end{array}$ \\
\hline Polydesmida & Haplodesmidae & DM & $\mathrm{M}=\exp (\mathrm{a}+\mathrm{b} * \log (\mathrm{L}))$ & -4.591 & 2.543 & 11.0 & 47.0 & $\begin{array}{l}\text { (Gowing \& } \\
\text { Recher 1984) }\end{array}$ & $\begin{array}{r}\text { Inferred, } \\
\text { diplopoda }\end{array}$ \\
\hline Polydesmida & Opisotretidae & DM & $\mathrm{M}=\exp (\mathrm{a}+\mathrm{b} * \log (\mathrm{L}))$ & -4.591 & 2.543 & 11.0 & 47.0 & $\begin{array}{l}\text { (Gowing \& } \\
\text { Recher 1984) }\end{array}$ & $\begin{array}{r}\text { Inferred, } \\
\text { diplopoda }\end{array}$ \\
\hline Polydesmida & Pyrgodesmidae & DM & $\mathrm{M}=\exp (\mathrm{a}+\mathrm{b} * \log (\mathrm{L}))$ & -4.591 & 2.543 & 11.0 & 47.0 & $\begin{array}{l}\text { (Gowing \& } \\
\text { Recher 1984) }\end{array}$ & $\begin{array}{r}\text { Inferred, } \\
\text { diplopoda }\end{array}$ \\
\hline Polyxenida & Polyxenidae & DM & $M=\exp (a+b * \log (L))$ & -4.591 & 2.543 & 11.0 & 47.0 & $\begin{array}{l}\text { (Gowing \& } \\
\text { Recher 1984) }\end{array}$ & $\begin{array}{r}\text { Inferred, } \\
\text { diplopoda }\end{array}$ \\
\hline Pseudoscorpionida & All & FM & $M=\exp (a+b * \log (L))$ & -1.892 & 2.515 & 0.86 & 2.10 & $\begin{array}{l}\text { (Höfer \& Ott } \\
2009 \text { ) }\end{array}$ & Group specific \\
\hline Psocoptera & Uniden & DM & $M=a *(L)^{\wedge} b$ & 0.014 & 3.115 & 1.50 & 3.15 & (Gruner 2003) & $\begin{array}{r}\text { Inferred, } \\
\text { psocoptera }\end{array}$ \\
\hline Psocoptera & Psoquillidae & DM & $M=a *(L)^{\wedge} b$ & 0.014 & 3.115 & 1.50 & 3.15 & (Gruner 2003) & $\begin{array}{r}\text { Inferred, } \\
\text { psocoptera }\end{array}$ \\
\hline Psocoptera & Pachytroctidae & DM & $M=a *(L)^{\wedge} b$ & 0.014 & 3.115 & 1.50 & 3.15 & (Gruner 2003) & $\begin{array}{r}\text { Inferred, } \\
\text { psocoptera }\end{array}$ \\
\hline Psocoptera & Mesopsocidae & DM & $M=a *(L)^{\wedge} b$ & 0.014 & 3.115 & 1.50 & 3.15 & (Gruner 2003) & $\begin{array}{r}\text { Inferred, } \\
\text { psocoptera }\end{array}$ \\
\hline Psocoptera & Liposcelidae & DM & $M=a *(L)^{\wedge} b$ & 0.014 & 3.115 & 1.50 & 3.15 & (Gruner 2003) & $\begin{array}{r}\text { Inferred, } \\
\text { psocoptera }\end{array}$ \\
\hline Psocoptera & Ectopsocidae & DM & $M=a *(L)^{\wedge} b$ & 0.014 & 3.115 & 1.50 & 3.15 & (Gruner 2003) & $\begin{array}{r}\text { Inferred, } \\
\text { psocoptera }\end{array}$ \\
\hline Psocoptera & Epipsocidae & DM & $\mathrm{M}=\mathrm{a} *(\mathrm{~L})^{\wedge} \mathrm{b}$ & 0.014 & 3.115 & 1.50 & 3.15 & (Gruner 2003) & $\begin{array}{r}\text { Inferred, } \\
\text { psocoptera }\end{array}$ \\
\hline
\end{tabular}




\begin{tabular}{|c|c|c|c|c|c|c|c|c|c|}
\hline Psocoptera & Elipsocidae & DM & $\mathrm{M}=\mathrm{a} *(\mathrm{~L})^{\wedge} \mathrm{b}$ & 0.014 & 3.115 & 1.50 & 3.15 & (Gruner 2003) & $\begin{array}{r}\text { Inferred, } \\
\text { psocoptera }\end{array}$ \\
\hline Psocoptera & Hemipsocidae & DM & $\mathrm{M}=\mathrm{a} *(\mathrm{~L})^{\wedge} \mathrm{b}$ & 0.014 & 3.115 & 1.50 & 3.15 & (Gruner 2003) & $\begin{array}{r}\text { Inferred, } \\
\text { psocoptera }\end{array}$ \\
\hline Psocoptera & Lepidopsocidae & DM & $\mathrm{M}=\mathrm{a} *(\mathrm{~L})^{\wedge} \mathrm{b}$ & 0.014 & 3.115 & 1.50 & 3.15 & (Gruner 2003) & $\begin{array}{r}\text { Inferred, } \\
\text { psocoptera }\end{array}$ \\
\hline Psocoptera & Psyllipsocidae & DM & $\mathrm{M}=\mathrm{a} *(\mathrm{~L})^{\wedge} \mathrm{b}$ & 0.014 & 3.115 & 1.50 & 3.15 & (Gruner 2003) & $\begin{array}{r}\text { Inferred, } \\
\text { psocoptera }\end{array}$ \\
\hline Schizomida & Protoschizomidae & FM & $\mathrm{M}=\exp (\mathrm{a}+\mathrm{b} * \log (\mathrm{L}))$ & -2.108 & 3.017 & 0.67 & 36 & $\begin{array}{l}\text { (Höfer \& Ott } \\
2009 \text { ) }\end{array}$ & $\begin{array}{l}\text { Inferred, } \\
\text { hunting spiders }\end{array}$ \\
\hline Scolopendromorpha & Cryptopidae & DM & $\mathrm{M}=\exp (\mathrm{a}+\mathrm{b} * \log (\mathrm{L}))$ & -4.049 & 2.18 & 4 & 47 & $\begin{array}{l}\text { (Gowing \& } \\
\text { Recher 1984) }\end{array}$ & $\begin{array}{r}\text { Inferred, } \\
\text { chilopoda }\end{array}$ \\
\hline Symphyla & Scutegerillidae & DM & $\mathrm{M}=\mathrm{a} *(\mathrm{~L})^{\wedge} \mathrm{b}$ & 0.035 & 2.173 & 0.9 & 17.6 & (Gruner 2003) & $\begin{array}{r}\text { Inferred, all } \\
\text { insect taxa }\end{array}$ \\
\hline Thysanoptera & Aeolothripidae & DM & $\mathrm{M}=\mathrm{a} *(\mathrm{~L})^{\wedge} \mathrm{b}$ & 0.035 & 2.173 & 0.9 & 17.6 & (Gruner 2003) & $\begin{array}{l}\text { Inferred, all } \\
\text { insect taxa }\end{array}$ \\
\hline Thysanoptera & Phlaeothripidae & DM & $\mathrm{M}=\mathrm{a} *(\mathrm{~L})^{\wedge} \mathrm{b}$ & 0.035 & 2.173 & 0.9 & 17.6 & (Gruner 2003) & $\begin{array}{l}\text { Inferred, all } \\
\text { insect taxa }\end{array}$ \\
\hline Thysanoptera & Thripidae & DM & $\mathrm{M}=\mathrm{a} *(\mathrm{~L})^{\wedge} \mathrm{b}$ & 0.035 & 2.173 & 0.9 & 17.6 & (Gruner 2003) & $\begin{array}{r}\text { Inferred, all } \\
\text { insect taxa }\end{array}$ \\
\hline Thysanoptera & Merothripidae & DM & $\mathrm{M}=\mathrm{a} *(\mathrm{~L})^{\wedge} \mathrm{b}$ & 0.035 & 2.173 & 0.9 & 17.6 & (Gruner 2003) & $\begin{array}{r}\text { Inferred, all } \\
\text { insect taxa }\end{array}$ \\
\hline Schizomida & Hubbardiidae & FM & $M=\exp (a+b * \log (L))$ & -2.108 & 3.017 & 0.67 & 36 & $\begin{array}{l}\text { (Höfer \& Ott } \\
2009 \text { ) }\end{array}$ & $\begin{array}{l}\text { Inferred, } \\
\text { hunting spiders }\end{array}$ \\
\hline
\end{tabular}

Table S 3.4: Dry-to-FM conversion from the literature for transformation of dry body masses (DM) (from length-DM regression calculations) to fresh mass (FM)

\begin{tabular}{llllll}
\hline Taxon & $\begin{array}{l}\text { Equation FM[mg], } \\
\mathrm{DM}[\mathrm{mg}]\end{array}$ & $\mathrm{a}$ & $\mathrm{b}$ & Reference & $\begin{array}{l}\text { Regression } \\
\text { specificity }\end{array}$ \\
\hline $\begin{array}{l}\text { All groups with dry-mass } \\
\text { length-mass regressions } \\
\text { (see Appendix Tab. 1) }\end{array}$ & $\mathrm{FM}=\exp (\mathrm{a}+\mathrm{b} * \log (\mathrm{DM}))$ & 0.6111 & 1.0213 & $\begin{array}{l}\text { (Mercer } \text { et } \\
\text { al. 2001) }\end{array}$ & Insecta \\
\hline
\end{tabular}


Table S 3.5: Soil data (soil depths: $1=0-10 \mathrm{~cm} ; 2=10-30$ ). (baseline; 52 plots; no controls)

\begin{tabular}{|c|c|c|c|c|c|c|c|c|c|c|c|c|c|c|}
\hline PlotID & Sand1 & Sand2 & Silt1 & Silt2 & Clay1 & Clay2 & $\mathrm{pH} 1$ & pH2 & $\mathrm{C} 1$ & $\mathrm{C} 2$ & N1 & $\mathrm{N} 2$ & CN1 & $\mathrm{CN} 2$ \\
\hline 1 & 0.289 & 283 & 433 & 431 & .278 & 0.286 & & & 0.018 & 0.016 & 0.004 & 0.004 & 0.042 & .044 \\
\hline 2 & 0.332 & 0.292 & 0.406 & 0.417 & 0.262 & 0.292 & 4.610 & 4.420 & 0.023 & 0.019 & 0.003 & 0.004 & 0.066 & 0.044 \\
\hline 3 & .353 & 0.339 & 0.373 & 0.322 & 0.274 & 0.339 & 4.470 & 4.400 & 0.020 & 0.012 & 0.004 & 0.003 & 0.048 & 0.035 \\
\hline 4 & 0.269 & 0.295 & 0.410 & 0.437 & 0.320 & 0.268 & 4.400 & 4.220 & 0.024 & 0.012 & 0.005 & 0.005 & 0.052 & 0.027 \\
\hline 5 & 0.348 & 0.276 & 0.450 & 0.444 & 0.202 & 0.279 & 4.410 & 4.380 & 0.018 & 0.008 & 0.004 & 0.004 & 0.046 & 0.023 \\
\hline 6 & 0.373 & 0.398 & 0.350 & 0.270 & 0.277 & 0.332 & 4.260 & 4.190 & 0.017 & 0.011 & 0.004 & 0.004 & 0.043 & 0.030 \\
\hline 7 & 0.332 & 0.321 & 0.332 & 0.369 & 0.336 & 0.310 & 4.370 & 4.430 & 0.020 & 0.017 & 0.004 & 0.004 & 0.051 & 0.041 \\
\hline 8 & 0.338 & 0.355 & 0.372 & 0.285 & 0.290 & 0.360 & 4.080 & 4.260 & 0.012 & 0.010 & 0.004 & 0.004 & 0.034 & 0.027 \\
\hline 9 & .393 & 0.304 & 0.307 & 0.354 & 0.300 & 0.342 & 5.020 & 4.960 & 0.021 & 0.012 & 0.004 & 0.004 & 0.050 & 0.031 \\
\hline 10 & 276 & 0.260 & 0.332 & 0.383 & 0.392 & 0.358 & 4.210 & 4.130 & 0.019 & 0.014 & 0.004 & 0.004 & 0.047 & 0.036 \\
\hline 11 & 0.243 & 0.224 & 0.419 & 0.410 & 0.338 & 0.366 & 4.6 & 4.380 & 0.017 & 0.012 & 0.004 & 0.004 & 0.043 & 0.028 \\
\hline 12 & & 0.349 & 0.451 & 0.475 & 0.197 & 0.177 & & 4.330 & 0.024 & 0.018 & 0.004 & 0.004 & 0.055 & 0.044 \\
\hline 13 & 0.111 & 0.086 & 0.543 & 0.539 & 0.347 & 0.375 & 4.380 & 4.490 & 0.022 & 0.015 & 0.005 & 0.004 & 0.048 & 0.037 \\
\hline 14 & 0.351 & 0.327 & 0.345 & 0.376 & 0.304 & 0.297 & 4.680 & 4.550 & 0.010 & 0.008 & 0.004 & 0.004 & 0.029 & 0.021 \\
\hline 15 & & 0.213 & 0.478 & 0.451 & 0.279 & 0.336 & & & 0.037 & 0.009 & 0.005 & 0.004 & 0.078 & 0.021 \\
\hline 16 & 0.279 & 0.278 & 0.468 & 0.439 & 0.253 & 0.283 & 4.210 & 4.250 & 0.019 & 0.007 & 0.004 & 0.004 & 0.050 & 0.019 \\
\hline 17 & 247 & 0.250 & 0.441 & 0.415 & 0.312 & 0.334 & 4.490 & 4.560 & 0.026 & 0.012 & 0.006 & 0.004 & 0.045 & 0.027 \\
\hline 18 & & 0.252 & 0.431 & 0.349 & 0.315 & 0.399 & & 10 & 0.016 & 0.011 & 0.004 & 0.004 & 0.037 & 0.027 \\
\hline 19 & & 0.086 & 0.548 & 0.470 & 0.372 & 0.444 & 4.410 & 4.320 & 0.039 & 0.023 & 0.005 & 0.004 & 0.072 & 0.061 \\
\hline 20 & 235 & 0.186 & 0.470 & 0.523 & 0.294 & 0.291 & 4.560 & 4.670 & 0.027 & 0.021 & 0.004 & 0.004 & 0.065 & 0.052 \\
\hline 21 & & 0.161 & 0.425 & 0.426 & 0.389 & 0.413 & & 270 & 0.016 & 0.013 & 0.004 & 0.003 & 0.047 & 0.037 \\
\hline 22 & 0.095 & 0.075 & 0.438 & 0.365 & 0.467 & 0.561 & & 4.430 & 0.018 & 0.014 & 0.003 & 0.004 & 0.054 & 0.036 \\
\hline 23 & 139 & 0.154 & 0.530 & 0.443 & 0.331 & 0.403 & 4.400 & 4.130 & 0.024 & 0.014 & 0.004 & 0.003 & 0.057 & 0.041 \\
\hline 24 & & 0.593 & 0.230 & 0.187 & 0.237 & 0.219 & & 4.380 & 0.021 & 0.014 & 0.003 & 0.004 & 0.062 & 0.037 \\
\hline 25 & & 0.195 & 0.431 & 0.400 & 0.374 & 0.405 & 4.070 & 4.250 & 0.012 & 0.004 & 0.004 & 0.003 & 0.031 & 0.012 \\
\hline 26 & 59 & 0.245 & 0.364 & 0.397 & 0.377 & 0.359 & & 4.2 & 0.023 & 0.014 & 0.004 & 0.003 & 0.062 & 0.042 \\
\hline 27 & & 0.130 & 0.409 & 0.459 & 0.437 & 0.411 & & 560 & 0.026 & 0.019 & 0.004 & 0.004 & 0.060 & 0.047 \\
\hline 28 & & 0.398 & 0.321 & 0.329 & 0.266 & 0.273 & & 4.290 & 0.025 & 0.016 & 0.004 & 0.004 & 0.059 & 0.041 \\
\hline 29 & 500 & 0.632 & 0.181 & 0.151 & 0.219 & 0.218 & & 4.5 & 0.014 & 0.011 & 0.004 & 0.004 & 0.037 & 0.030 \\
\hline 30 & 225 & 0.225 & 0.354 & 0.314 & 0.421 & 0.461 & 4.750 & 4.660 & 0.023 & 0.011 & 0.004 & 0.004 & 0.061 & 0.025 \\
\hline 31 & 393 & 0.382 & 0.443 & 0.441 & 0.163 & 0.177 & 4.620 & 4.500 & 0.024 & 0.017 & 0.004 & 0.004 & 0.055 & 0.042 \\
\hline 32 & 133 & 0.117 & 0.579 & 0.629 & 0.288 & 0.254 & & & 0.027 & 0.017 & 0.004 & 0.004 & 0.061 & 0.044 \\
\hline 33 & .383 & 0.350 & 0.336 & 0.314 & 0.281 & 0.336 & 4.370 & 4.360 & 0.022 & 0.013 & 0.003 & 0.003 & 0.064 & 0.038 \\
\hline 34 & 458 & 0.418 & 0.332 & 0.365 & 0.210 & 0.217 & 4.530 & 4.370 & 0.016 & 0.007 & 0.003 & 0.004 & 0.0 & 0.020 \\
\hline 35 & & 0.317 & 0.424 & 0.374 & 0.222 & 0.309 & & & 0.031 & 0.016 & 0.004 & 0.004 & 0.071 & 0.038 \\
\hline 36 & .599 & 0.614 & 0.264 & 0.232 & 0.137 & 0.154 & 4.310 & 4.280 & 0.018 & 0.014 & 0.004 & 0.004 & 0.047 & 0.039 \\
\hline 37 & .503 & 0.497 & 0.223 & 0.254 & 0.274 & 0.249 & 4.270 & 4.400 & 0.021 & 0.012 & 0.005 & 0.004 & 0.0 & 0.031 \\
\hline 38 & & & & & 0.226 & 0.239 & & & 0.026 & 0.019 & 0.0 & 0.004 & 0.056 & 0.047 \\
\hline 39 & 0.372 & 0.386 & 0.405 & 0.357 & 0.222 & 0.258 & 4.550 & 4.490 & 0.017 & 0.012 & 0.004 & 0.004 & 0.042 & 0.031 \\
\hline 40 & 0.046 & 0.036 & 0.423 & 0.441 & 0.531 & 0.523 & 3.970 & 4.100 & 0.022 & 0.016 & 0.004 & 0.005 & 0.052 & 0.034 \\
\hline 41 & 0.412 & 0.356 & 0.324 & 0.342 & 0.264 & 0.301 & & & 0.017 & 0.009 & 0.005 & 0.003 & 0.033 & 0.026 \\
\hline 42 & 0.394 & 0.410 & 0.375 & 0.365 & 0.231 & 0.225 & 4.460 & 4.470 & 0.017 & 0.013 & 0.005 & 0.005 & 0.033 & 0.027 \\
\hline 43 & 0.456 & 0.352 & 0.379 & 0.442 & 0.165 & 0.207 & 4.780 & 4.430 & 0.028 & 0.017 & 0.006 & 0.005 & 0.048 & 0.034 \\
\hline 44 & 0.307 & 0.341 & 0.438 & 0.413 & 0.256 & 0.246 & & 4.340 & 0.020 & 0.013 & 0.006 & 0.005 & 0.036 & 0.026 \\
\hline 45 & 0.213 & 0.181 & 0.444 & 0.447 & 0.344 & 0.372 & 4.360 & 4.330 & 0.035 & 0.020 & 0.006 & 0.005 & 0.056 & 0.036 \\
\hline 46 & 0.099 & 0.086 & 0.465 & 0.444 & 0.436 & 0.469 & 4.460 & 4.270 & 0.025 & 0.023 & 0.005 & 0.005 & 0.050 & 0.042 \\
\hline 47 & 0.280 & 0.247 & 0.392 & 0.389 & 0.329 & 0.365 & 4.590 & 4.600 & 0.022 & 0.015 & 0.004 & 0.004 & 0.063 & 0.036 \\
\hline 48 & 0.285 & 0.231 & 0.364 & 0.387 & 0.351 & 0.383 & 4.400 & 4.350 & 0.018 & 0.010 & 0.004 & 0.004 & 0.045 & 0.023 \\
\hline 49 & 0.305 & 0.343 & 0.497 & 0.439 & 0.198 & 0.217 & 4.500 & 4.470 & 0.015 & 0.009 & 0.005 & 0.005 & 0.032 & 0.019 \\
\hline 50 & 0.125 & 0.146 & 0.507 & 0.521 & 0.368 & 0.333 & 4.090 & 4.130 & 0.033 & 0.018 & 0.006 & 0.005 & 0.053 & 0.034 \\
\hline 51 & 0.275 & 0.309 & 0.527 & 0.447 & 0.199 & 0.244 & 4.430 & 4.440 & 0.025 & 0.016 & 0.006 & 0.005 & 0.045 & 0.032 \\
\hline 52 & 0.323 & 0.356 & 0.473 & 0.421 & 0.204 & 0.224 & 4.240 & 4.470 & 0.020 & 0.012 & 0.006 & 0.005 & 0.034 & 0.025 \\
\hline
\end{tabular}


Table S 3.6: Abiotic data (baseline; 52 plots; no controls)

\begin{tabular}{|c|c|c|c|c|c|c|c|c|}
\hline PlotID & PC axis 1 & PC axis 2 & PC axis 3 & Slope & $\begin{array}{r}\text { Bare soil } \\
\text { (logit-transf.) }\end{array}$ & $\begin{array}{r}\text { Gap fraction } \\
\text { (logit-transf.) }\end{array}$ & Altitude & Bulk Density \\
\hline 1 & -0.008 & 0.017 & -0.023 & 12.2 & 0.426 & -7.600 & 61.187 & 1.096 \\
\hline 2 & -0.044 & 0.151 & -0.165 & 12.6 & -1.072 & -7.824 & 46.909 & 1.013 \\
\hline 3 & 0.064 & 0.002 & -0.089 & 3.8 & -2.143 & -7.264 & 40.508 & 1.029 \\
\hline 4 & -0.048 & 0.018 & 0.096 & 7.6 & -1.696 & -7.824 & 55.266 & 0.927 \\
\hline 5 & 0.079 & -0.085 & 0.075 & 5.0 & -1.696 & -7.130 & 54.217 & 1.180 \\
\hline 6 & 0.109 & -0.062 & -0.034 & 9.8 & -2.376 & -6.375 & 44.756 & 0.991 \\
\hline 7 & 0.002 & 0.048 & -0.108 & 1.8 & -3.664 & -5.681 & 37.585 & 1.024 \\
\hline 8 & 0.122 & -0.187 & 0.006 & 4.3 & -1.355 & -7.824 & 62.622 & 1.165 \\
\hline 9 & 0.121 & 0.058 & -0.151 & 14.6 & -1.355 & -7.600 & 50.671 & 1.127 \\
\hline 10 & -0.019 & -0.119 & -0.075 & 7.6 & -0.824 & -7.418 & 57.198 & 1.147 \\
\hline 11 & 0.002 & -0.100 & -0.006 & 0.4 & 0.426 & -7.824 & 57.346 & 1.023 \\
\hline 12 & -0.031 & 0.204 & 0.036 & 8.7 & -4.185 & -5.127 & 53.014 & 0.935 \\
\hline 13 & -0.158 & -0.122 & 0.021 & 9.2 & -1.072 & -6.570 & 53.488 & 1.239 \\
\hline 14 & 0.187 & -0.186 & 0.029 & 7.8 & -1.551 & -7.824 & 51.453 & 1.330 \\
\hline 15 & NA & NA & NA & 6.7 & -4.185 & NA & 64.824 & 0.972 \\
\hline 16 & 0.028 & -0.117 & 0.091 & 5.7 & -2.844 & -6.375 & 54.111 & 1.024 \\
\hline 17 & -0.041 & -0.028 & 0.126 & 0.5 & -2.512 & -6.724 & 54.584 & 1.261 \\
\hline 18 & 0.011 & -0.150 & 0.066 & 3.2 & -2.376 & -6.907 & 51.891 & 1.039 \\
\hline 19 & -0.350 & 0.144 & -0.207 & 2.4 & -2.143 & -5.806 & 48.205 & 1.054 \\
\hline 20 & -0.164 & 0.202 & -0.140 & 0.6 & -2.143 & -6.724 & 42.325 & 0.911 \\
\hline 21 & -0.048 & -0.219 & -0.135 & 1.3 & -1.072 & -7.130 & 64.646 & 1.297 \\
\hline 22 & -0.109 & -0.254 & -0.273 & 20.8 & -2.143 & -6.907 & 44.184 & 1.232 \\
\hline 23 & -0.132 & -0.125 & -0.109 & 20.9 & -2.143 & -8.111 & 53.527 & 1.288 \\
\hline 24 & 0.208 & 0.195 & -0.210 & 6.8 & -2.376 & -7.600 & 53.576 & 1.043 \\
\hline 25 & 0.046 & -0.361 & 0.115 & 2.4 & -1.696 & -6.318 & 45.676 & 1.060 \\
\hline 26 & NA & NA & NA & 1.8 & NA & -6.375 & 44.704 & 1.101 \\
\hline 27 & NA & NA & NA & 1.0 & NA & -6.436 & 45.110 & 1.020 \\
\hline 28 & 0.046 & 0.135 & -0.124 & 16.0 & -2.143 & -7.418 & 67.125 & 1.039 \\
\hline 29 & 0.348 & 0.076 & -0.081 & 5.0 & -2.376 & -6.811 & 47.803 & 1.199 \\
\hline 30 & 0.001 & -0.114 & -0.203 & 1.2 & -1.072 & -6.644 & 62.541 & 1.199 \\
\hline 31 & 0.045 & 0.171 & -0.009 & 9.4 & -1.355 & -7.012 & 52.121 & 1.284 \\
\hline 32 & -0.233 & 0.016 & 0.051 & 1.0 & -2.844 & -6.811 & 52.459 & 1.030 \\
\hline 33 & 0.055 & 0.041 & -0.213 & 3.8 & -1.355 & -7.418 & 60.492 & 1.011 \\
\hline 34 & 0.192 & -0.004 & 0.016 & 2.1 & -3.317 & -6.375 & 44.696 & 0.976 \\
\hline 35 & -0.054 & 0.117 & -0.078 & 0.3 & -2.376 & -6.907 & 44.409 & 1.201 \\
\hline 36 & 0.243 & 0.193 & -0.035 & 2.4 & -0.385 & -7.600 & 47.186 & 1.058 \\
\hline 37 & 0.183 & 0.049 & -0.032 & 0.2 & -1.355 & -7.824 & 45.073 & 1.190 \\
\hline 38 & -0.007 & 0.236 & -0.048 & 0.2 & -4.185 & -6.644 & 38.856 & 0.891 \\
\hline 39 & 0.118 & 0.007 & 0.019 & 1.9 & -2.844 & -6.375 & 43.305 & 1.144 \\
\hline 40 & -0.257 & -0.235 & -0.060 & 2.0 & -4.185 & -6.501 & 52.591 & 0.972 \\
\hline 41 & 0.143 & -0.087 & 0.094 & 4.2 & -2.143 & -7.418 & 54.482 & 1.205 \\
\hline 42 & 0.106 & 0.033 & 0.205 & 5.8 & -2.844 & -6.318 & 46.566 & 1.151 \\
\hline 43 & -0.004 & 0.284 & 0.205 & 6.8 & -1.355 & -8.111 & 52.190 & 0.910 \\
\hline 44 & 0.019 & 0.014 & 0.251 & 5.0 & -2.844 & -5.334 & 45.754 & 1.139 \\
\hline 45 & -0.244 & 0.165 & 0.150 & 0.4 & -5.293 & -6.436 & 42.781 & 0.793 \\
\hline 46 & -0.261 & -0.032 & -0.010 & 13.0 & -1.355 & -7.418 & 47.151 & 1.107 \\
\hline 47 & -0.029 & 0.033 & -0.175 & 3.7 & -2.844 & -5.422 & 51.193 & 1.019 \\
\hline 48 & 0.022 & -0.164 & 0.025 & 0.9 & -0.824 & -7.824 & 46.168 & 1.236 \\
\hline 49 & 0.093 & -0.098 & 0.295 & 4.7 & -0.824 & -6.436 & 42.980 & 1.429 \\
\hline 50 & -0.286 & 0.048 & 0.227 & 1.3 & -5.293 & -5.445 & 47.903 & 0.931 \\
\hline 51 & -0.085 & 0.154 & 0.256 & 1.2 & -5.293 & -7.264 & 46.758 & 0.883 \\
\hline 52 & 0.018 & 0.039 & 0.335 & 2.9 & -1.072 & -6.907 & 54.421 & 1.053 \\
\hline
\end{tabular}


Table S 3.7: Summary tables from linear and generalized linear models testing the effects of plot size and tree diversity on the environmental variables. In case of overdispersion, we used the negative binomial distribution for modelling. Asterisks denote significance levels: $* \mathrm{p}<$ $0.05 ; * * \mathrm{p}<0.01 ; * * * \mathrm{p}<0.001 . \mathrm{TD}=$ tree diversity, $\mathrm{PS}=$ plot size, $\mathrm{SR}=$ species richness, $\mathrm{AB}$ $=$ abundance, $\mathrm{FR}=$ family richness, $\mathrm{BM}=$ body mass, $\mathrm{LL}$ inv. = leaf-litter invertebrates, $\mathrm{HL}$ inv. $=$ herb-layer invertebrates.

\begin{tabular}{|c|c|c|c|c|c|c|c|}
\hline Response & Fixed effects & Estimate & Std. Error & t-value & p-value & & R2 \\
\hline \multirow[t]{3}{*}{ PCaxis1 } & TD & -0.0552 & 0.034 & -1.643 & 0.104 & & 0.043 \\
\hline & PS & -0.013 & 0.014 & -0.874 & 0.384 & & \\
\hline & TD: PS & 0.006 & 0.006 & 0.973 & 0.333 & & \\
\hline \multirow[t]{3}{*}{ PCaxis 2} & $\mathrm{TD}$ & 0.038 & 0.032 & 1.184 & 0.239 & & 0.141 \\
\hline & PS & 0.050 & 0.014 & 3.631 & $<0.001$ & $* * *$ & \\
\hline & TD: PS & -0.008 & 0.006 & -1.343 & 0.183 & & \\
\hline \multirow[t]{3}{*}{ PCaxis 3} & $\mathrm{TD}$ & 0.102 & 0.031 & 3.229 & 0.002 & $* *$ & 0.162 \\
\hline & PS & 0.038 & 0.013 & 2.808 & 0.006 & $* *$ & \\
\hline & TD: PS & -0.023 & 0.006 & -4.034 & $<0.001$ & $* * *$ & \\
\hline \multirow[t]{3}{*}{ Slope } & $\mathrm{TD}$ & -3.457 & 1.172 & -2.951 & 0.004 & $* *$ & 0.102 \\
\hline & PS & -1.414 & 0.504 & -2.808 & 0.006 & $* *$ & \\
\hline & TD: PS & 0.738 & 0.212 & 3.475 & $<0.001$ & $* * *$ & \\
\hline \multirow[t]{3}{*}{ Bare soil } & $\mathrm{TD}$ & -0.473 & 0.310 & -1.526 & 0.130 & & 0.008 \\
\hline & PS & -0.047 & 0.133 & -0.352 & 0.726 & & \\
\hline & TD: PS & 0.073 & 0.056 & 1.299 & 0.197 & & \\
\hline \multirow[t]{3}{*}{ Gap fraction } & $\mathrm{TD}$ & 0.495 & 0.174 & 2.851 & 0.005 & $* *$ & 0.084 \\
\hline & PS & 0.062 & 0.075 & 0.834 & 0.406 & & \\
\hline & TD: PS & -0.079 & 0.031 & -2.506 & 0.014 & $*$ & \\
\hline \multirow[t]{3}{*}{ Altitude } & $\mathrm{TD}$ & -0.309 & 1.625 & -0.190 & 0.849 & & -0.025 \\
\hline & PS & -0.468 & 0.698 & -0.671 & 0.504 & & \\
\hline & TD: PS & 0.067 & 0.294 & 0.229 & 0.820 & & \\
\hline \multirow[t]{3}{*}{ Plant SR (nb) } & $\mathrm{TD}$ & -0.156 & 0.065 & -2.408 & 0.016 & $*$ & 0.075 \\
\hline & PS & -0.065 & 0.028 & -2.351 & 0.019 & $*$ & \\
\hline & TD: PS & 0.031 & 0.011 & 2.727 & 0.006 & $* *$ & \\
\hline \multirow[t]{3}{*}{ Plant AB } & $\mathrm{TD}$ & 0.048 & 0.100 & 0.476 & 0.634 & & 0.021 \\
\hline & PS & 0.010 & 0.043 & 0.225 & 0.822 & & \\
\hline & TD: PS & -0.001 & 0.018 & -0.075 & 0.940 & & \\
\hline \multirow[t]{3}{*}{ Bird SR } & $\mathrm{TD}$ & -0.182 & 0.113 & -1.611 & 0.107 & & 0.056 \\
\hline & PS & -0.104 & 0.049 & -2.106 & 0.035 & $*$ & \\
\hline & TD: PS & 0.040 & 0.020 & 1.989 & 0.047 & $*$ & \\
\hline \multirow[t]{3}{*}{ Bird AB } & $\mathrm{TD}$ & -0.130 & 0.336 & 7.891 & 0.368 & & 0.009 \\
\hline & PS & -0.048 & 0.061 & -0.783 & 0.433 & & \\
\hline & TD: PS & 0.024 & 0.026 & 0.946 & 0.344 & & \\
\hline \multirow[t]{3}{*}{ Bird BM } & $\mathrm{TD}$ & -0.226 & 0.225 & -1.006 & 0.317 & & 0.026 \\
\hline & PS & -0.176 & 0.097 & -1.826 & 0.071 & & \\
\hline & TD: PS & 0.061 & 0.041 & 1.492 & 0.139 & & \\
\hline \multirow[t]{3}{*}{ LL inv. FM } & $\mathrm{TD}$ & 0.037 & 0.133 & 0.283 & 0.777 & & 0.048 \\
\hline & PS & -0.072 & 0.059 & -1.226 & 0.220 & & \\
\hline & TD: PS & 0.002 & 0.024 & 0.078 & 0.938 & & \\
\hline \multirow[t]{3}{*}{ LL inv. $A B$} & TD & 0.049 & 0.234 & 1.829 & 0.067 & & 0.037 \\
\hline & PS & 0.195 & 0.101 & 1.937 & 0.053 & & \\
\hline & TD: PS & -0.087 & 0.043 & -2.048 & 0.041 & $*$ & \\
\hline
\end{tabular}


Supplementary Information - Chapter 3

\begin{tabular}{llrrrrr} 
LL inv. BM & TD & 0.377 & 0.343 & 1.097 & 0.275 & 0.089 \\
& PS & -0.150 & 0.148 & -1.020 & 0.311 & \\
HL inv. SR & TD: PS & -0.060 & 0.062 & -0.967 & 0.336 & 0.071 \\
& TD & 0.202 & 0.123 & 1.644 & 0.100 & \\
HL inv. AB & PS & 0.055 & 0.055 & 1.001 & 0.317 & 0.053 \\
& TD: PS & -0.023 & 0.022 & -1.010 & 0.312 & \\
HL inv. BM & TD & 0.243 & 0.136 & 1.791 & 0.073 & 0.001 \\
& PS & 0.089 & 0.059 & 1.512 & 0.131 & \\
& TD: PS & -0.034 & 0.025 & -1.375 & 0.169 & \\
& TD & 0.008 & 0.237 & 0.035 & 0.972 & \\
& PS & -0.011 & 0.102 & -0.112 & 0.911 & \\
\hline
\end{tabular}


Table S 3.8: Biotic data (baseline; 52 plots; no controls). $\mathrm{SR}=$ species richness, $\mathrm{AB}=$ abundance, $\mathrm{BM}=$ biomass, $\mathrm{FR}=$ family richness, $\mathrm{LL} / \mathrm{HL}$ inv. = leaf-litter/herb-layer invertebrates

\begin{tabular}{|c|c|c|c|c|c|c|c|c|c|c|c|}
\hline PlotID & $\begin{array}{r}\text { Plant } \\
\text { SR }\end{array}$ & $\begin{array}{r}\text { Plant } \\
\text { AB }\end{array}$ & $\begin{array}{r}\text { Bird } \\
\text { SR }\end{array}$ & $\begin{array}{r}\text { Bird } \\
\text { AB }\end{array}$ & $\begin{array}{r}\text { Bird } \\
\text { BM } \\
{[\mathrm{g}]}\end{array}$ & $\begin{array}{r}\text { LL inv. } \\
\text { FR }\end{array}$ & $\begin{array}{r}\text { LL inv. } \\
\text { AB }\end{array}$ & $\begin{array}{r}\text { LL inv. } \\
\text { BM } \\
{[\mathrm{mg}]}\end{array}$ & $\begin{array}{r}\text { HL inv. } \\
\text { FR }\end{array}$ & $\begin{array}{r}\text { HL inv. } \\
\mathrm{AB}\end{array}$ & $\begin{array}{r}\text { HL inv. } \\
\text { BM } \\
{[\mathrm{mg}]}\end{array}$ \\
\hline 1 & 14 & 220 & 0 & 0 & 0.00 & 5 & 7 & 3.61 & 4 & 12 & 27.32 \\
\hline 2 & 24 & 482 & 4 & 6 & 233.43 & 7 & 11 & 5.32 & 8 & 33 & 168.57 \\
\hline 3 & 15 & 739 & 3 & 12 & 131.70 & 6 & 8 & 12.45 & 22 & 69 & 137.97 \\
\hline 4 & 21 & 482 & 4 & 15 & 308.93 & 30 & 210 & 141.08 & 15 & 35 & 373.86 \\
\hline 5 & 16 & 996 & 4 & 14 & 150.02 & 3 & 11 & 0.96 & 8 & 18 & 65.77 \\
\hline 6 & 16 & 586 & 5 & 9 & 291.51 & 11 & 24 & 23.77 & 7 & 17 & 479.79 \\
\hline 7 & 16 & 607 & 2 & 10 & 90.48 & 4 & 14 & 7.40 & 25 & 42 & 235.60 \\
\hline 8 & 16 & 675 & 4 & 8 & 372.08 & 7 & 10 & 22.61 & 5 & 15 & 102.00 \\
\hline 9 & 11 & 274 & 8 & 21 & 1115.02 & 6 & 9 & 8.22 & 8 & 16 & 55.82 \\
\hline 10 & 20 & 542 & 5 & 18 & 614.89 & 6 & 25 & 146.13 & 8 & 24 & 45.64 \\
\hline 11 & 12 & 284 & 3 & 4 & 92.55 & 12 & 30 & 7.88 & 7 & 25 & 972.55 \\
\hline 12 & 9 & 573 & 6 & 11 & 312.99 & 13 & 151 & 98.40 & 14 & 40 & 1133.81 \\
\hline 13 & 17 & 203 & 4 & 10 & 335.13 & 6 & 18 & 14.00 & 3 & 5 & 327.33 \\
\hline 14 & 16 & 361 & 4 & 16 & 588.90 & 5 & 9 & 2.57 & 6 & 12 & 116.43 \\
\hline 16 & 21 & 718 & 4 & 14 & 289.06 & 13 & 39 & 37.00 & 22 & 50 & 116.08 \\
\hline 17 & 19 & 603 & 6 & 14 & 810.48 & 12 & 23 & 48.73 & 16 & 48 & 473.72 \\
\hline 18 & 24 & 872 & 7 & 19 & 1115.99 & 8 & 9 & 110.47 & 11 & 47 & 346.00 \\
\hline 19 & 21 & 642 & 9 & 14 & 582.17 & 12 & 38 & 45.80 & 15 & 35 & 258.98 \\
\hline 20 & 21 & 330 & 5 & 7 & 252.04 & 6 & 23 & 11.58 & 19 & 44 & 201.39 \\
\hline 21 & 22 & 595 & 4 & 8 & 353.96 & 14 & 33 & 68.23 & 20 & 49 & 205.17 \\
\hline 22 & 21 & 646 & 3 & 8 & 202.69 & 5 & 6 & 8.21 & 6 & 9 & 74.77 \\
\hline 23 & 20 & 632 & 6 & 18 & 789.38 & 8 & 11 & 5.73 & 18 & 35 & 119.64 \\
\hline 24 & 13 & 525 & 4 & 12 & 360.60 & 8 & 14 & 5.02 & 9 & 20 & 331.77 \\
\hline 25 & 18 & 384 & 1 & 3 & 29.04 & 13 & 37 & 91.60 & 6 & 8 & 21.23 \\
\hline 28 & 19 & 438 & 5 & 15 & 570.60 & 12 & 19 & 45.60 & 19 & 29 & 36.28 \\
\hline 29 & 23 & 507 & 6 & 13 & 565.84 & 10 & 20 & 33.78 & 5 & 10 & 88.11 \\
\hline 30 & 13 & 734 & 4 & 12 & 296.83 & 4 & 4 & 12.84 & 15 & 38 & 165.46 \\
\hline 31 & 14 & 474 & 7 & 10 & 317.63 & 13 & 27 & 31.21 & 4 & 9 & 118.56 \\
\hline 32 & 21 & 492 & 2 & 4 & 56.84 & 12 & 46 & 21.70 & 10 & 31 & 147.92 \\
\hline 33 & 15 & 594 & 5 & 8 & 467.71 & 4 & 9 & 2.15 & 6 & 25 & 102.52 \\
\hline 34 & 13 & 1092 & 7 & 25 & 701.73 & 6 & 29 & 34.44 & 12 & 39 & 805.17 \\
\hline 35 & 20 & 851 & 3 & 4 & 118.86 & 3 & 35 & 35.09 & 14 & 53 & 233.24 \\
\hline 36 & 19 & 414 & 4 & 5 & 223.50 & 6 & 14 & 10.69 & 4 & 13 & 101.92 \\
\hline 37 & 22 & 304 & 11 & 21 & 1244.57 & 6 & 7 & 0.76 & 6 & 13 & 193.15 \\
\hline 38 & 8 & 120 & 7 & 18 & 542.43 & 15 & 42 & 53.03 & 12 & 18 & 268.28 \\
\hline 39 & 11 & 399 & 4 & 14 & 224.08 & 6 & 9 & 25.17 & 11 & 17 & 57.79 \\
\hline 40 & 18 & 340 & 5 & 13 & 342.32 & 8 & 20 & 17.41 & 9 & 22 & 512.67 \\
\hline 41 & 17 & 514 & 2 & 4 & 74.96 & 14 & 83 & 94.65 & 15 & 27 & 39.08 \\
\hline 42 & 16 & 379 & 2 & 3 & 27.46 & 9 & 23 & 11.30 & 23 & 68 & 685.27 \\
\hline 43 & 17 & 268 & 2 & 6 & 50.18 & 3 & 4 & 1.18 & 7 & 13 & 106.69 \\
\hline 44 & 16 & 254 & 6 & 15 & 330.03 & 11 & 112 & 78.22 & 9 & 19 & 289.24 \\
\hline 45 & 15 & 230 & 7 & 32 & 676.98 & 16 & 83 & 149.17 & 27 & 54 & 746.31 \\
\hline 46 & 12 & 223 & 3 & 6 & 128.98 & 26 & 224 & 180.06 & 5 & 36 & 159.10 \\
\hline 47 & 14 & 369 & 1 & 1 & 27.80 & 14 & 25 & 9.33 & 6 & 16 & 610.80 \\
\hline 48 & 26 & 682 & 3 & 6 & 140.92 & 3 & 5 & 2.47 & 5 & 6 & 30.08 \\
\hline 49 & 19 & 455 & 3 & 6 & 261.76 & 3 & 7 & 5.05 & 13 & 23 & 145.71 \\
\hline 50 & 5 & 359 & 3 & 7 & 221.96 & 17 & 69 & 49.84 & 22 & 46 & 302.90 \\
\hline 51 & 6 & 347 & 5 & 15 & 420.08 & 16 & 63 & 90.36 & 19 & 39 & 78.98 \\
\hline 52 & 19 & 548 & 4 & 8 & 156.66 & 1 & 3 & 0.61 & 6 & 13 & 63.74 \\
\hline
\end{tabular}


Table S 3.9: List of plant species (baseline; 52 plots; no controls)

\begin{tabular}{|c|c|c|c|}
\hline Species & Family & $\begin{array}{r}\text { Total } \\
\text { abundance }\end{array}$ & $\begin{array}{r}\text { Dominance (number } \\
\text { of plots present on) }\end{array}$ \\
\hline Adiantum latifolium Lam. & Pteridaceae & 228 & 32 \\
\hline Ageratum conyzoides $(\mathrm{L}.) \mathrm{L}$. & Compositae & 380 & 16 \\
\hline Ageratum spec. & Compositae & 1 & 1 \\
\hline Alternanthera sessilis (L.) R.Br. ex DC. & Amaranthaceae & 57 & 4 \\
\hline Asplenium normale D. Don & Aspleniaceae & 91 & 17 \\
\hline cf. Asplenium spec. & Aspleniaceae & 3 & 2 \\
\hline Asystasia gangetica (L.) T.Anderson & Acanthaceae & 4470 & 49 \\
\hline Bauhinia semibifida Roxb. & Leguminosae & 1 & 1 \\
\hline Blechnum orientale L. & Blechnaceae & 8 & 2 \\
\hline Breynia cernua (Poir.) Müll.Arg. & Phyllanthaceae & 7 & 4 \\
\hline Centotheca lappacea (L.) Desv. & Poaceae & 1390 & 42 \\
\hline Centrosema pubescens Benth. & Leguminosae & 38 & 5 \\
\hline Chromolaena odorata (L.) R.M.King \& H.Rob. & Compositae & 9 & 5 \\
\hline Cleome rutidosperma $\mathrm{DC}$. & Cleomaceae & 5 & 1 \\
\hline Clerodendrum spec. & Lamiaceae & 2 & 2 \\
\hline Clidemia hirta (L.) D. Don & Melastomataceae & 2171 & 50 \\
\hline Commelina diffusa Burm.f. & Commelinaceae & 7 & 1 \\
\hline Coptosapelta flavescens Korth. & Rubiaceae & 2 & 1 \\
\hline Crassocephalum crepidioides (Benth.) S.Moore & Compositae & 3 & 2 \\
\hline Croton argyratus Blume & Euphorbiaceae & 1 & 1 \\
\hline Croton hirtus L'Hér. & Euphorbiaceae & 24 & 5 \\
\hline Cuphea carthagenensis (Jacq.) J.F.Macbr. & Lythraceae & 8 & 2 \\
\hline Cyclosorus heterocarpus (Blume) Ching & Thelypteridaceae & 54 & 7 \\
\hline Cyclosorus megaphyllus Ching & Thelypteridaceae & 1256 & 41 \\
\hline Cyperus diffusus Vahl & Cyperaceae & 156 & 28 \\
\hline Cyrtococcum patens (L.) A.Camus & Poaceae & 1251 & 38 \\
\hline Cyrtococcum spec. (L.) & Poaceae & 17 & 2 \\
\hline Dicranopteris linearis (Burm. f.) Underw. & Gleicheniaceae & 9 & 1 \\
\hline Dioscorea alata $\mathrm{L}$. & Dioscoreaceae & 3 & 2 \\
\hline Elaeis guineensis Jacq. & Arecaceae & 122 & 30 \\
\hline fern spec. 01 & & 1 & 1 \\
\hline cf. Ficus spec. & Moraceae & 1 & 1 \\
\hline Ficus cf. variegata Blume & Moraceae & 19 & 7 \\
\hline grass spec. & Poaceae & 4 & 1 \\
\hline grass spec. 01 & Poaceae & 250 & 5 \\
\hline grass spec. 02 & Poaceae & 2 & 1 \\
\hline herb spec. 01 & & 1 & 1 \\
\hline herb spec. 02 & & 2 & 1 \\
\hline herb spec. 03 & & 2 & 1 \\
\hline herb spec. 04 & & 1 & 1 \\
\hline herb spec. 05 & & 1 & 1 \\
\hline Hyptis capitata Jacq. & Lamiaceae & 6 & 1 \\
\hline Imperata cylindrica $($ L.) Raeusch & Poaceae & 85 & 10 \\
\hline Lantana camara $\mathrm{L}$. & Verbenaceae & 2 & 1 \\
\hline Lindernia crustacea (L.) F.Muell. & Linderniaceae & 8 & 4 \\
\hline Lindernia diffusa (L.) Wettst. & Linderniaceae & 1 & 1 \\
\hline Ludwigia octovalvis (Jacq.) P.H.Raven & Onagraceae & 4 & 2 \\
\hline Lygodium circinatum (Burm. f.) Sw. & Lygodiaceae & 82 & 23 \\
\hline Mallotus peltatus (Geiseler) Müll.Arg. & Euphorbiaceae & 5 & 1 \\
\hline Melastoma malabathricum $\mathrm{L}$. & Melastomataceae & 66 & 23 \\
\hline Merremia spec. & Convolvulaceae & 7 & 2 \\
\hline Merremia umbellata (L.) Hallier f. & Convolvulaceae & 71 & 5 \\
\hline Microlepia speluncae (L.) T. Moore & Dennstaedtiaceae & 76 & 22 \\
\hline
\end{tabular}


Mikania micrantha (L.) Willd.

Mimosa cf. pudica L.

Nephrolepis cf. acutifolia (Desv.) Christ

Oplismenus compositus (L.) P.Beauv.

Ottochloa nodosa (Kunth) Dandy

Ottochloa spec. 1 (Kunth) Dandy

Oxalis barrelieri $\mathrm{L}$.

Panicum cf. laxum $\mathrm{Sw}$.

Paspalum cf. conjugatum P.J.Bergius

Paspalum spec.

Peperomia pellucida (L.) Kunth

Pericampylus glaucus (Lam.) Merr.

Phyllanthus cf. niruri L.

Pronephrium triphyllum (Sw.) Holttum

Pteris cf. armata C. Presl

Pteris ensiformis Burm. f.

Pueraria phaseoloides (Roxb.) Benth.

Salvia occidentalis Sw.

Leguminosae

Nephrolepidaceae

13

Poaceae 38

Poaceae 938

Poaceae 684

Oxalidaceae

Poaceae

1294

Poaceae

Poaceae

Piperaceae

Menispermaceae

Phyllanthaceae

Thelypteridaceae

Pteridaceae

Pteridaceae

Leguminosae

Lamiaceae

Schizostachyum sp.

Poaceae

Scleria levis Retz.

Scleria spec.

seedling spec. 1

Selaginella willdenowii (Desv. ex Poir.) Baker

Cyperaceae

Cyperaceae

Solanum jamaicense Mill.

Spermacoce alata Aubl.

Stenochlaena palustris (Burm. f.) Bedd.

Strombosia javanica Thwaites

Taenitis blechnoides (Willd.) Sw.

Tectaria vasta (Blume) Copel.

Urceola brachysepala Hook.f.

Urceola spec.

woody spec. 01

woody spec. 02

woody spec. 03

woody spec. 04

woody spec. 05

woody spec. 06

woody spec. 07

woody spec. 08

woody spec. 09

woody spec. 10

woody spec. 11

woody spec. 12

woody spec. 12

woody spec. 13

Selaginellaceae

Solanaceae

Rubiaceae

Blechnaceae

Olacaceae

Pteridaceae

Tectariaceae

Apocynaceae

Apocynaceae 
Table S 3.10: List of bird species recorded within a $75 \mathrm{~m}$ radius around the centre of each plot (baseline; 52 plots; no controls)

\begin{tabular}{llrrrr}
\hline Species & Family & $\begin{array}{r}\text { Total } \\
\text { abundance }\end{array}$ & Total biomass [g] & $\begin{array}{r}\text { Dominance } \\
\text { (number of plots } \\
\text { present on) }\end{array}$ \\
\hline Amaurornis phoenicurus & Rallidae & 10 & 1440.00 & 5 & LC \\
Celeus brachyurus & Picidae & 1 & 85.94 & 1 & LC \\
Centropus sinensis & Cuculidae & 1 & 280.70 & 1 & LC \\
Chalcophaps indica & Columbidae & 9 & 1228.86 & 7 & LC \\
Dicaeum trigonostigma & Dicaeidae & 16 & 113.60 & 13 & LC \\
Eurystomus orientalis & Coraciidae & 2 & 286.04 & 2 & LC \\
Geopelia striata & Columbidae & 8 & 452.80 & 6 & LC \\
Halcyon smyrnensis & Alcedinidae & 33 & 2924.80 & 22 & LC \\
Megalaima & Ramphastidae & 2 & 88.98 & 2 & LC \\
Merops viridis & Meropidae & 3 & 34.80 & 1 & LC \\
Orthotomus ruficeps & Sylviidae & 61 & 429.30 & 27 & LC \\
Orthotomus sericeus & Sylviidae & 21 & 216.00 & 48 & LC \\
Prinia familiaris & Cisticolidae & 241 & 1810.16 & 14 & LC \\
Pycnonotus aurigaster & Pycnonotidae & 31 & 1019.59 & 38 & LC \\
Pycnonotus goiavier & Pycnonotidae & 191 & 4698.20 & 7 & LC \\
Pycnonotus plumosus & Pycnonotidae & 14 & 453.05 & 2 & LC \\
Rhipidura javanica & Rhipiduridae & 2 & 25.00 & 1 & LC \\
Spilornis cheela & Accipitridae & 1 & 597.74 & 6 & LC \\
Stigmatopelia chinensis & Columbidae & 8 & 1272.00 & 359 & LC \\
Todiramphus chloris & Alcedinidae & 14 & 396.00 & LC \\
Treron vernans & Columbidae & 3 & & 3 &
\end{tabular}

IUCN status: $\mathrm{LC}=$ least concern

Table S 3.11: List of families of leaf-litter invertebrates recorded on the plots (baseline; 52 plots; no controls)

\begin{tabular}{llrrr}
\hline Family & Order & $\begin{array}{r}\text { Total abundance } \\
\text { (of individuals } \\
\text { in this family) }\end{array}$ & $\begin{array}{r}\text { Total biomass } \\
{[\mathrm{mg}]}\end{array}$ & $\begin{array}{r}\text { Dominance } \\
\text { (number of plots } \\
\text { present on) }\end{array}$ \\
\hline Aphididae & Hemiptera & 1 & 0.06 & 1 \\
Araneidae & Araneae & 3 & 7.66 & 3 \\
Armadillidae & Isopoda & 3 & 29.15 & 1 \\
Blaberidae & Blattodea & 10 & 19.14 & 7 \\
Blattellidae & Blattodea & 7 & 18.11 & 5 \\
Blattidae & Blattodea & 8 & 7.08 & 7 \\
Campodeidae & Diplura & 1 & 0.34 & 1 \\
Carabidae & Coleoptera & 7 & 9.22 & 5 \\
Chrysomelidae & Coleoptera & 2 & 13.02 & 2 \\
Cicadellidae & Hemiptera & 1 & 1.24 & 1 \\
Colydiidae & Coleoptera & 2 & 0.33 & 2 \\
Corinnidae & Araneae & 17 & 79.22 & 14 \\
Cryptodesmidae & Polydesmida & 1 & 0.70 & 2 \\
Cryptopidae & Scolopendromorpha & 4 & 13.23 & 2 \\
Ctenidae & Araneae & 2 & 15.84 & 2 \\
Cydnidae & Hemiptera & 8 & 3.42 & 1 \\
Dalodesmidae & Polydesmida & 3 & 6.40 & 2 \\
Delphacidae & Hemiptera & 2 & 0.47 &
\end{tabular}




\begin{tabular}{|c|c|c|c|c|}
\hline Dignathodontidae & Geophilomorpha & 1 & 0.25 & 1 \\
\hline Dipsocoridae & Hemiptera & 22 & 2.66 & 10 \\
\hline Drosophilidae & Diplura & 1 & 0.50 & 1 \\
\hline Dryinidae & Hymenoptera & 1 & 0.40 & 1 \\
\hline Elateridae & Coleoptera & 2 & 0.08 & 2 \\
\hline Epipsocidae & Psocoptera & 2 & 0.08 & 1 \\
\hline Formicidae & Hymenoptera & 1291 & 562.23 & 50 \\
\hline Geophilidae & Geophilomorpha & 16 & 207.48 & 10 \\
\hline Glomeridae & Glomerida & 4 & 11.06 & 3 \\
\hline Gnaphosidae & Araneae & 36 & 16.40 & 24 \\
\hline Gryllidae & Orthoptera & 6 & 25.86 & 6 \\
\hline Henicopidae & Lithobiomorpha & 16 & 18.57 & 6 \\
\hline Hubbardiidae & Schizomida & 1 & 9.90 & 1 \\
\hline Hydraenidae & Coleoptera & 2 & 0.26 & 1 \\
\hline Japygidae & Diplura & 9 & 13.70 & 5 \\
\hline Labiduridae & Dermaptera & 1 & 4.35 & 1 \\
\hline Labiidae & Dermaptera & 7 & 26.39 & 7 \\
\hline Largidae & Hemiptera & 6 & 2.39 & 4 \\
\hline Linyphiidae & Araneae & 28 & 9.91 & 18 \\
\hline Liposcelidae & Psocoptera & 1 & 0.24 & 1 \\
\hline Lycosidae & Araneae & 44 & 126.11 & 23 \\
\hline Lygaeidae & Hemiptera & 6 & 1.32 & 4 \\
\hline Mantidae & Mantodea & 3 & 0.71 & 3 \\
\hline Mesopsocidae & Psocoptera & 1 & 0.05 & 1 \\
\hline Miridae & Hemiptera & 2 & 0.35 & 2 \\
\hline Myrmeleontidae & Neuroptera & 1 & 2.00 & 1 \\
\hline Mysmenidae & Araneae & 30 & 2.91 & 16 \\
\hline Neobisiidae & Pseudoscorpion & 1 & 0.29 & 1 \\
\hline Nitidulidae & Coleoptera & 2 & 1.69 & 2 \\
\hline Olpiidae & Pseudoscorpion & 1 & 0.35 & 1 \\
\hline Oniscidae & Isopoda & 1 & 0.18 & 1 \\
\hline Oonopidae & Araneae & 34 & 12.79 & 15 \\
\hline Opisotretidae & Polydesmida & 6 & 4.81 & 4 \\
\hline Oxyopidae & Araneae & 7 & 36.46 & 7 \\
\hline Pachytroctidae & Psocoptera & 1 & 0.07 & 1 \\
\hline Paradoxosomatidae & Polydesmida & 1 & 0.54 & 1 \\
\hline Phalacridae & Coleoptera & 36 & 8.67 & 3 \\
\hline Phalangodidae & Opiliones & 4 & 7.15 & 2 \\
\hline Philosciidae & Isopoda & 44 & 115.33 & 17 \\
\hline Phlaeothripidae & Thysanoptera & 7 & 1.39 & 6 \\
\hline Pholcidae & Araneae & 1 & 0.21 & 1 \\
\hline Platyrhacidae & Polydesmida & 1 & 22.35 & 1 \\
\hline Polyxenidae & Polyxenida & 5 & 0.59 & 5 \\
\hline Protoschizomidae & Schizomida & 1 & 0.84 & 1 \\
\hline Pseudococcidae & Hemiptera & 1 & 0.39 & 1 \\
\hline Psoquillidae & Psocoptera & 3 & 0.96 & 3 \\
\hline Ptiliidae & Coleoptera & 1 & 0.03 & 1 \\
\hline Pyrgodesmidae & Polydesmida & 70 & 62.15 & 20 \\
\hline Reduviidae & Hemiptera & 8 & 227.19 & 6 \\
\hline Rhinotermitidae & Isoptera & 3 & 1.11 & 2 \\
\hline Salticidae & Araneae & 24 & 59.81 & 18 \\
\hline Schizopteridae & Hemiptera & 6 & 0.18 & 5 \\
\hline Scolytinae & Coleoptera & 3 & 0.74 & 3 \\
\hline Scutigerellidae & Symphyla & 4 & 1.49 & 4 \\
\hline Scydmaenidae & Coleoptera & 3 & 0.08 & 1 \\
\hline Sironidae & Opiliones & 1 & 14.35 & 1 \\
\hline Spongiphoridae & Dermaptera & 22 & 84.49 & 2 \\
\hline Staphylinidae & Coleoptera & 113 & 24.53 & 20 \\
\hline
\end{tabular}




\begin{tabular}{llrrr} 
Stratiomydae & Diplura & 1 & 4.54 & 1 \\
Tenebrionidae & Coleoptera & 13 & 56.57 & 9 \\
Termitidae & Isoptera & 10 & 8.93 & 1 \\
Tetrablemmidae & Araneae & 10 & 1.50 & 6 \\
Tetrigidae & Orthoptera & 4 & 14.90 & 4 \\
Tettigoniidae & Orthoptera & 1 & 3.11 & 1 \\
Theridiidae & Araneae & 45 & 43.31 & 23 \\
Theridiosomatidae & Araneae & 19 & 4.36 & 13 \\
Thomisidae & Araneae & 13 & 39.57 & 10 \\
Tingidae & Hemiptera & 3 & 0.30 & 2 \\
Tridactylidae & Orthoptera & 1 & 2.54 & 1 \\
\hline
\end{tabular}

Table S 3.12: List of families of herb-layer invertebrates recorded on the plots (baseline; 52 plots; no controls)

\begin{tabular}{|c|c|c|c|c|}
\hline Family & Order & $\begin{array}{r}\text { Total abundance } \\
\text { (of individuals in } \\
\text { this family) }\end{array}$ & $\begin{array}{r}\text { Total biomass } \\
{[\mathrm{mg}]}\end{array}$ & $\begin{array}{r}\text { Dominance } \\
\text { (number of plots } \\
\text { present on) }\end{array}$ \\
\hline Acanthopteroctetidae & Lepidoptera & 1 & 6.09 & 1 \\
\hline Acrididae & Orthoptera & 58 & 6282.27 & 24 \\
\hline Aderidae & Coleoptera & 4 & 2.30 & 4 \\
\hline Anthocoridae & Hemiptera & 10 & 1.57 & 2 \\
\hline Anthribidae & Coleoptera & 2 & 0.58 & 1 \\
\hline Aphelinidae & Hymenoptera & 1 & 0.06 & 1 \\
\hline Aphididae & Hemiptera & 14 & 0.81 & 5 \\
\hline Aradidae & Hemiptera & 1 & 1.46 & 1 \\
\hline Araneidae & Araneae & 12 & 70.62 & 9 \\
\hline Asteiidae & Diptera & 22 & 3.30 & 9 \\
\hline Baetidae & Ephemeroptera & 3 & 4.52 & 3 \\
\hline Bibionidae & Diptera & 1 & 11.80 & 1 \\
\hline Blaberidae & Blattodea & 1 & 0.77 & 1 \\
\hline Blattellidae & Blattodea & 15 & 178.96 & 15 \\
\hline Blattidae & Blattodea & 1 & 5.42 & 1 \\
\hline Braconidae & Hymenoptera & 8 & 2.94 & 8 \\
\hline Calliphoridae & Diptera & 2 & 1.19 & 1 \\
\hline Carabidae & Coleoptera & 1 & 4.04 & 1 \\
\hline Cecidomyiidae & Diptera & 9 & 0.27 & 6 \\
\hline Ceraphronidae & Hymenoptera & 5 & 0.10 & 4 \\
\hline Ceratopogonidae & Diptera & 11 & 2.01 & 8 \\
\hline Chironomidae & Diptera & 2 & 0.44 & 1 \\
\hline Chloropidae & Diptera & 8 & 0.75 & 6 \\
\hline Chrysomelidae & Coleoptera & 4 & 30.50 & 4 \\
\hline Cicadellidae & Hemiptera & 96 & 123.60 & 26 \\
\hline Clusiidae & Diptera & 1 & 0.55 & 1 \\
\hline Coreidae & Hemiptera & 1 & 41.75 & 1 \\
\hline Culicidae & Diptera & 26 & 21.68 & 20 \\
\hline Curculionidae & Coleoptera & 1 & 0.50 & 1 \\
\hline Delphacidae & Hemiptera & 53 & 71.70 & 21 \\
\hline Derbidae & Hemiptera & 3 & 5.25 & 3 \\
\hline Diapriidae & Hymenoptera & 3 & 0.46 & 3 \\
\hline Dolichopodidae & Diptera & 1 & 1.27 & 1 \\
\hline
\end{tabular}




\begin{tabular}{|c|c|c|c|c|}
\hline Drosophilidae & Diptera & 1 & 0.69 & 1 \\
\hline Encyrtidae & Hymenoptera & 1 & 0.04 & 1 \\
\hline Eulophidae & Hymenoptera & 12 & 1.86 & 9 \\
\hline Figitidae & Hymenoptera & 1 & 0.06 & 1 \\
\hline Flatidae & Hemiptera & 4 & 3.72 & 3 \\
\hline Formicidae & Hymenoptera & 91 & 68.48 & 34 \\
\hline Geocoridae & Hemiptera & 2 & 1.53 & 2 \\
\hline Geometridae & Lepidoptera & 6 & 5.79 & 5 \\
\hline Gryllidae & Orthoptera & 499 & 3064.30 & 51 \\
\hline Henicopidae & Lithobiomorpha & 1 & 0.21 & 1 \\
\hline Ichneumonidae & Hymenoptera & 16 & 5.72 & 12 \\
\hline Lauxaniiidae & Diptera & 5 & 2.72 & 4 \\
\hline Linyphiidae & Araneae & 2 & 3.95 & 2 \\
\hline Lophopidae & Hemiptera & 1 & 0.68 & 1 \\
\hline Lycosidae & Araneae & 46 & 461.74 & 26 \\
\hline Mantidae & Mantodea & 8 & 298.35 & 7 \\
\hline Meenoplidae & Hemiptera & 2 & 2.18 & 2 \\
\hline Miridae & Hemiptera & 30 & 5.29 & 18 \\
\hline Muscidae & Diptera & 3 & 0.61 & 3 \\
\hline Mycetophilidae & Diptera & 1 & 0.80 & 1 \\
\hline Mymaridae & Hymenoptera & 2 & 0.06 & 2 \\
\hline Mysmenidae & Araneae & 1 & 0.08 & 1 \\
\hline Nabidae & Hemiptera & 2 & 1.06 & 2 \\
\hline Noctuidae & Lepidoptera & 2 & 1.25 & 2 \\
\hline Opomyzidae & Diptera & 3 & 0.61 & 3 \\
\hline Oxyopidae & Araneae & 79 & 829.09 & 30 \\
\hline Phalacridae & Coleoptera & 1 & 0.30 & 1 \\
\hline Phlaeothripidae & Thysanoptera & 6 & 0.55 & 3 \\
\hline Phoridae & Diptera & 2 & 0.10 & 2 \\
\hline Piophilidae & Diptera & 3 & 0.21 & 3 \\
\hline Pipunculidae & Diptera & 2 & 2.92 & 1 \\
\hline Pisauridae & Araneae & 1 & 91.93 & 1 \\
\hline Platygastridae & Hymenoptera & 2 & 0.05 & 2 \\
\hline Pseudococcidae & Hemiptera & 1 & 0.02 & 1 \\
\hline Psychodidae & Diptera & 4 & 0.13 & 4 \\
\hline Pyralidae & Lepidoptera & 1 & 8.15 & 1 \\
\hline Pyrgodesmidae & Polydesmida & 5 & 9.02 & 4 \\
\hline Reduviidae & Hemiptera & 5 & 34.31 & 5 \\
\hline Salticidae & Araneae & 23 & 92.96 & 15 \\
\hline Scatopsidae & Diptera & 1 & 0.06 & 1 \\
\hline Scelionidae & Hymenoptera & 25 & 3.62 & 12 \\
\hline Sciaridae & Diptera & 19 & 0.98 & 10 \\
\hline Sphaeroceridae & Diptera & 5 & 0.76 & 4 \\
\hline Staphylinidae & Coleoptera & 4 & 3.11 & 4 \\
\hline Tetrigidae & Orthoptera & 36 & 1010.79 & 22 \\
\hline Tettigoniidae & Orthoptera & 19 & 703.32 & 11 \\
\hline Theridiidae & Araneae & 28 & 91.57 & 21 \\
\hline Theridiosomatidae & Araneae & 8 & 1.14 & 7 \\
\hline Thomisidae & Araneae & 22 & 76.50 & 14 \\
\hline Thyrididae & Lepidoptera & 4 & 21.64 & 4 \\
\hline Tineidae & Lepidoptera & 8 & 5.17 & 6 \\
\hline Tingidae & Hemiptera & 1 & 0.06 & 1 \\
\hline Tiphiidae & Hymenoptera & 2 & 4.76 & 1 \\
\hline Tipulidae & Diptera & 23 & 25.59 & 14 \\
\hline Tortricidae & Lepidoptera & 1 & 0.32 & 1 \\
\hline Trichodectidae & Phthiraptera & 1 & 0.01 & 1 \\
\hline Trichogrammatidae & Hymenoptera & 1 & 0.00 & 1 \\
\hline Tridactylidae & Orthoptera & 2 & 13.35 & 2 \\
\hline
\end{tabular}




\begin{tabular}{llrrr} 
Tropiduchidae & Hemiptera & 10 & 44.55 & 6 \\
Vespidae & Hymenoptera & 3 & 20.14 & 2 \\
Zygaenidae & Lepidoptera & 1 & 8.82 & 1 \\
\hline
\end{tabular}

Table S 3.13: Biotic data (first year; 56 plots). $\mathrm{SR}=$ species richness, $\mathrm{AB}=$ abundance, $\mathrm{BM}=$ biomass, FR = family richness, LL/HL inv. = leaf-litter/herb-layer invertebrates

\begin{tabular}{|c|c|c|c|c|c|c|c|c|c|}
\hline PlotID & $\begin{array}{r}\text { Bird } \\
\text { SR }\end{array}$ & $\begin{array}{r}\text { Bird } \\
\mathrm{AB}\end{array}$ & $\begin{array}{r}\text { Bird } \\
\text { BM }\end{array}$ & $\begin{array}{r}\text { LL inv. } \\
\text { FR }\end{array}$ & $\begin{array}{r}\text { LL inv. } \\
A B\end{array}$ & $\begin{array}{r}\text { LL inv. } \\
\text { BM }\end{array}$ & $\begin{array}{r}\text { HL inv. } \\
\text { FR }\end{array}$ & $\begin{array}{r}\text { HL inv. } \\
A B\end{array}$ & $\begin{array}{r}\text { HL inv. } \\
\text { BM }\end{array}$ \\
\hline 1 & 4 & 10 & 243.42 & 10 & 42 & 42.95 & 5 & 6 & 64.52 \\
\hline 2 & 6 & 13 & 765.44 & 9 & 20 & 288.91 & 11 & 24 & 161.83 \\
\hline 3 & 6 & 11 & 513.33 & 7 & 31 & 9.86 & 14 & 42 & 438.59 \\
\hline 4 & 5 & 13 & 739.86 & 15 & 88 & 224.38 & 26 & 120 & 282.16 \\
\hline 5 & 5 & 13 & 514.29 & 5 & 35 & 21.33 & 10 & 21 & 199.73 \\
\hline 6 & 7 & 16 & 579.26 & 7 & 14 & 19.93 & 22 & 58 & 532.47 \\
\hline 7 & 6 & 10 & 299.32 & 11 & 15 & 16.42 & 22 & 45 & 428.10 \\
\hline 8 & 8 & 19 & 2132.6 & 3 & 11 & 6.96 & 6 & 6 & 2.14 \\
\hline 9 & 7 & 17 & 1313.05 & 7 & 10 & 46.52 & 22 & 53 & 692.00 \\
\hline 10 & 6 & 14 & 887.65 & 4 & 10 & 14.69 & 12 & 37 & 178.17 \\
\hline 11 & 7 & 11 & 641.1 & 6 & 30 & 18.36 & 24 & 57 & 735.88 \\
\hline 12 & 5 & 8 & 178.96 & 12 & 43 & 19.45 & 30 & 86 & 320.63 \\
\hline 13 & 7 & 10 & 753.19 & 10 & 74 & 11.79 & 16 & 57 & 490.74 \\
\hline 14 & 4 & 13 & 699.06 & 4 & 10 & 4.45 & 10 & 19 & 79.50 \\
\hline 15 & 6 & 13 & 1692.13 & 16 & 49 & 47.05 & 17 & 32 & 1086.18 \\
\hline 16 & 6 & 10 & 234.05 & 4 & 14 & 29.50 & 14 & 28 & 206.38 \\
\hline 17 & 5 & 7 & 352.63 & 7 & 16 & 4.66 & 12 & 20 & 513.22 \\
\hline 18 & 3 & 15 & 459.39 & 5 & 6 & 9.14 & 12 & 22 & 103.47 \\
\hline 19 & 6 & 11 & 1723.4 & 3 & 38 & 33.80 & 15 & 31 & 14.18 \\
\hline 20 & 6 & 10 & 430.03 & 5 & 11 & 28.16 & 21 & 49 & 766.57 \\
\hline 21 & 5 & 11 & 653.14 & 8 & 26 & 37.92 & 21 & 77 & 1268.84 \\
\hline 22 & 5 & 11 & 444.66 & 3 & 15 & 42.93 & 5 & 13 & 6.64 \\
\hline 23 & 5 & 11 & 506.14 & 16 & 33 & 13.55 & 25 & 91 & 669.98 \\
\hline 24 & 5 & 9 & 298.2 & 6 & 97 & 123.11 & 20 & 65 & 707.65 \\
\hline 25 & 6 & 15 & 1251.86 & 2 & 7 & 42.22 & 12 & 31 & 489.17 \\
\hline 26 & 4 & 9 & 213.43 & 15 & 68 & 55.71 & 16 & 53 & 1965.31 \\
\hline 27 & 7 & 10 & 967.46 & 10 & 115 & 269.54 & 21 & 56 & 409.00 \\
\hline 28 & 3 & 9 & 304.58 & 7 & 217 & 253.83 & 4 & 8 & 89.81 \\
\hline 29 & 7 & 13 & 720.56 & 14 & 26 & 17.11 & 24 & 52 & 394.15 \\
\hline 30 & 5 & 10 & 115.4 & 3 & 3 & 0.72 & 12 & 16 & 22.44 \\
\hline 31 & 2 & 6 & 76.2 & 4 & 9 & 6.35 & 12 & 17 & 1393.20 \\
\hline 32 & 4 & 9 & 176.61 & 7 & 13 & 12.55 & 17 & 42 & 1087.27 \\
\hline 33 & 4 & 8 & 716.7 & 4 & 9 & 18.57 & 20 & 81 & 384.49 \\
\hline 34 & 3 & 6 & 221.24 & 17 & 27 & 58.33 & 15 & 28 & 507.55 \\
\hline 35 & 2 & 4 & 73.37 & 12 & 44 & 26.66 & 11 & 49 & 588.41 \\
\hline 36 & 4 & 6 & 117.91 & 5 & 52 & 48.07 & 21 & 37 & 480.15 \\
\hline 37 & 8 & 15 & 754.06 & 3 & 226 & 265.06 & 16 & 79 & 502.26 \\
\hline 38 & 4 & 12 & 234.39 & 13 & 62 & 21.62 & 24 & 69 & 307.77 \\
\hline 39 & 7 & 17 & 1000.52 & 9 & 35 & 58.51 & 10 & 22 & 532.30 \\
\hline 40 & 3 & 7 & 123.12 & 7 & 11 & 10.16 & 9 & 19 & 43.07 \\
\hline 41 & 2 & 5 & 120.88 & 5 & 16 & 7.13 & 12 & 49 & 1159.40 \\
\hline 42 & 4 & 6 & 276.35 & 3 & 10 & 3.89 & 17 & 39 & 228.19 \\
\hline 43 & 6 & 10 & 305.3 & 9 & 16 & 25.02 & 24 & 97 & 975.05 \\
\hline
\end{tabular}


Supplementary Information - Chapter 3

\begin{tabular}{rrrrrrrrrr}
44 & 5 & 9 & 615.08 & 5 & 33 & 45.23 & 17 & 26 & 105.81 \\
45 & 6 & 16 & 1154.07 & 11 & 31 & 176.93 & 18 & 43 & 248.05 \\
46 & 3 & 4 & 222.7 & 10 & 11 & 21.36 & 14 & 44 & 1007.57 \\
47 & 3 & 4 & 93.55 & 14 & 115 & 31.61 & 15 & 67 & 1444.66 \\
48 & 5 & 8 & 373.52 & 2 & 8 & 4.64 & 11 & 32 & 186.84 \\
49 & 1 & 3 & 169.8 & 4 & 10 & 11.36 & 17 & 69 & 631.61 \\
50 & 2 & 5 & 197.72 & 22 & 104 & 40.46 & 12 & 40 & 569.62 \\
51 & 5 & 10 & 644.46 & 10 & 15 & 11.73 & 24 & 77 & 141.15 \\
52 & 6 & 9 & 519.56 & 6 & 31 & 12.68 & 16 & 48 & 987.91 \\
53 & 3 & 10 & 264.12 & 14 & 44 & 190.47 & 9 & 12 & 228.82 \\
54 & 3 & 8 & 376.63 & 6 & 12 & 45.79 & 16 & 25 & 424.78 \\
55 & 2 & 11 & 131.8 & 8 & 43 & 29.74 & 14 & 21 & 42.52 \\
56 & 4 & 10 & 812.85 & 16 & 77 & 40.40 & 15 & 26 & 106.60 \\
\hline
\end{tabular}

Table S 3.14: List of bird species recorded within a $75 \mathrm{~m}$ radius around the centre of each plot one year after establishment (first year; 56 plots)

\begin{tabular}{|c|c|c|c|c|c|}
\hline Species & Family & $\begin{array}{r}\text { Total } \\
\text { abundance }\end{array}$ & Total biomass [g] & $\begin{array}{r}\text { Dominance } \\
\text { (number of plots } \\
\text { present on) }\end{array}$ & IUCN status \\
\hline Centropus sinensis & Cuculidae & 1 & 280.70 & 1 & $\overline{\mathrm{LC}}$ \\
\hline Chalcophaps indica & Columbidae & 10 & 955.78 & 7 & LC \\
\hline Coturnix chinesis & Phasanianidae & 1 & 40.41 & 1 & LC \\
\hline Dicaeum trigonostigma & Dicaeidae & 20 & 127.80 & 16 & LC \\
\hline Geopelia striata & Columbidae & 41 & 1811.20 & 18 & LC \\
\hline Halcyon smyrnensis & Alcedinidae & 19 & 1736.60 & 13 & LC \\
\hline Lanius schach & Laniidae & 2 & 103.02 & 2 & LC \\
\hline Lonchura punctulata & Estrildidae & 7 & 40.80 & 3 & LC \\
\hline Orthotomus atrogularis & Sylviidae & 1 & 7.68 & 1 & LC \\
\hline Orthotomus ruficeps & Sylviidae & 45 & 210.60 & 20 & LC \\
\hline Orthotomus sericeus & Sylviidae & 1 & 10.80 & 1 & LC \\
\hline Prinia familiaris & Cisticolidae & 252 & 1539.12 & 50 & LC \\
\hline Pycnonotus aurigaster & Pycnonotidae & 6 & 221.65 & 3 & LC \\
\hline Pycnonotus goiavier & Pycnonotidae & 198 & 4281.20 & 45 & LC \\
\hline Pycnonotus plumosus & Pycnonotidae & 6 & 174.25 & 4 & LC \\
\hline Rhipidura javanica & Rhipiduridae & 5 & 62.50 & 4 & LC \\
\hline Spilornis cheela & Accipitridae & 8 & 4781.92 & 6 & LC \\
\hline Spizaetus cirrhatus & Accipitridae & 1 & 1475.12 & 1 & LC \\
\hline Stigmatopelia chinensis & Columbidae & 64 & 8904.00 & 28 & LC \\
\hline Todiramphus chloris & Alcedinidae & 61 & 3634.95 & 32 & LC \\
\hline
\end{tabular}

Table S 3.15: List of families of leaf-litter invertebrates recorded on the plots one year after establishment (first year; 56 plots)

\begin{tabular}{llrrr}
\hline Family & Order & $\begin{array}{r}\text { Total abundance } \\
\text { (of individuals in } \\
\text { this family) }\end{array}$ & $\begin{array}{r}\text { Total biomass } \\
{[\mathrm{mg}]}\end{array}$ & $\begin{array}{r}\text { Dominance } \\
\text { (number of plots } \\
\text { present on) }\end{array}$ \\
\hline Acrididae & Orthoptera & 2 & 233.96 & 1 \\
Aderidae & Coleoptera & 10 & 2.10 & 5 \\
Aeolothripidae & Thysanoptera & 2 & 0.27 & 2
\end{tabular}




\begin{tabular}{|c|c|c|c|}
\hline Anisolabididae & Dermaptera & 3 & 76.89 \\
\hline Aphididae & Hemiptera & 4 & 0.60 \\
\hline Araneidae & Araneae & 7 & 25.20 \\
\hline Blaberidae & Blattodea & 9 & 3.59 \\
\hline Blattellidae & Blattodea & 12 & 15.18 \\
\hline Blattidae & Blattodea & 2 & 0.66 \\
\hline Carabidae & Coleoptera & 19 & 6.86 \\
\hline Ceratocombidae & Hemiptera & 1 & 0.01 \\
\hline Chrysomelidae & Coleoptera & 15 & 1.98 \\
\hline Cicadellidae & Hemiptera & 4 & 1.41 \\
\hline Corinnidae & Araneae & 15 & 64.10 \\
\hline Corylophidae & Coleoptera & 6 & 1.23 \\
\hline Cryptodesmidae & Polydesmida & 2 & 2.10 \\
\hline Ctenidae & Araneae & 4 & 16.92 \\
\hline Curculionidae & Coleoptera & 1 & 1.62 \\
\hline Cydnidae & Hemiptera & 11 & 3.33 \\
\hline Dignathodontidae & Geophilomorpha & 1 & 0.25 \\
\hline Dipsocoridae & Hemiptera & 14 & 1.40 \\
\hline Discolomidae & Coleoptera & 1 & 0.39 \\
\hline Dryinidae & Hymenoptera & 1 & 0.30 \\
\hline Ectopsocidae & Psocoptera & 12 & 0.49 \\
\hline Elateridae & Coleoptera & 3 & 0.25 \\
\hline Formicidae & Hymenoptera & 1551 & 1163.63 \\
\hline Gelechiidae & Lepidoptera & 1 & 0.58 \\
\hline Geophilidae & Geophilomorpha & 1 & 12.15 \\
\hline Gnaphosidae & Araneae & 4 & 3.25 \\
\hline Gracillariidae & Lepidoptera & 3 & 0.97 \\
\hline Gryllidae & Orthoptera & 16 & 27.30 \\
\hline Haplodesmidae & Polydesmida & 6 & 1.65 \\
\hline Hemipsocidae & Psocoptera & 3 & 0.09 \\
\hline Heteroceridae & Coleoptera & 1 & 4.89 \\
\hline Japygidae & Diplura & 10 & 10.84 \\
\hline Lagrioidinae & Coleoptera & 1 & 0.26 \\
\hline Linyphiidae & Araneae & 64 & 20.29 \\
\hline Liposcelidae & Psocoptera & 3 & 0.05 \\
\hline Lycosidae & Araneae & 58 & 225.67 \\
\hline Mecistocephalidae & Geophilomorpha & 3 & 39.98 \\
\hline Nabidae & Hemiptera & 15 & 27.77 \\
\hline Neobisiidae & Pseudoscorpion & 1 & 0.24 \\
\hline Nitidulidae & Coleoptera & 4 & 0.55 \\
\hline Oonopidae & Araneae & 13 & 4.11 \\
\hline Oxyopidae & Araneae & 11 & 23.57 \\
\hline Pachytroctidae & Psocoptera & 3 & 0.14 \\
\hline Pentatomidae & Hemiptera & 5 & 543.95 \\
\hline Phalacridae & Coleoptera & 18 & 1.38 \\
\hline Philosciidae & Isopoda & 10 & 20.44 \\
\hline Phlaeothripidae & Thysanoptera & 9 & 2.45 \\
\hline Polyxenidae & Polyxenida & 12 & 4.52 \\
\hline Pselaphidae & Coleoptera & 7 & 1.48 \\
\hline Ptiliidae & Coleoptera & 1 & 0.03 \\
\hline Pyralidae & Lepidoptera & 1 & 1.82 \\
\hline Pyrgodesmidae & Polydesmida & 65 & 63.11 \\
\hline Reduviidae & Hemiptera & 2 & 63.06 \\
\hline Salticidae & Araneae & 22 & 85.07 \\
\hline Scarabaeidae & Coleoptera & 1 & 8.66 \\
\hline Scelionidae & Hymenoptera & 2 & 0.10 \\
\hline Schizopteridae & Hemiptera & 7 & 0.16 \\
\hline Scolytinae & Coleoptera & 1 & 0.11 \\
\hline
\end{tabular}




\begin{tabular}{llrrr} 
Scutigerellidae & Symphyla & 11 & 4.73 & 8 \\
Scydmaenidae & Coleoptera & 4 & 0.69 & 3 \\
Silvanidae & Coleoptera & 10 & 1.64 & 8 \\
Sparassidae & Araneae & 3 & 1.56 & 3 \\
Staphylinidae & Coleoptera & 34 & 7.27 & 17 \\
Termitidae & Isopoda & 1 & 1.48 & 1 \\
Tetrablemmidae & Araneae & 2 & 0.51 & 2 \\
Tetragnathidae & Araneae & 8 & 21.82 & 6 \\
Tetrigidae & Orthoptera & 3 & 37.38 & 2 \\
Theridiidae & Araneae & 39 & 31.61 & 23 \\
Theridiosomatidae & Araneae & 1 & 0.17 & 1 \\
Thomisidae & Araneae & 12 & 22.65 & 8 \\
Zodariidae & Araneae & 5 & 19.51 & 5 \\
\hline
\end{tabular}

Table S 3.16: List of families of herb-layer invertebrates recorded on the plots one year after establishment (first year; 56 plots)

\begin{tabular}{|c|c|c|c|c|}
\hline Family & Order & $\begin{array}{r}\text { Total abundance } \\
\text { (of individuals in } \\
\text { this family) }\end{array}$ & $\begin{array}{r}\text { Total biomass } \\
{[\mathrm{mg}]}\end{array}$ & $\begin{array}{r}\text { Dominance } \\
\text { (number of plots } \\
\text { present on) }\end{array}$ \\
\hline Acrididae & Orthoptera & 100 & 10985.43 & 38 \\
\hline Aderidae & Coleoptera & 4 & 3.45 & 4 \\
\hline Aeolothripidae & Thysanoptera & 7 & 0.25 & 7 \\
\hline Aleyrodidae & Hemiptera & 23 & 1.80 & 14 \\
\hline Alydidae & Hemiptera & 2 & 56.01 & 1 \\
\hline Anapidae & Araneae & 3 & 4.51 & 3 \\
\hline Anthicidae & Coleoptera & 1 & 1.10 & 1 \\
\hline Aphelinidae & Hymenoptera & 2 & 0.14 & 1 \\
\hline Aphididae & Hemiptera & 38 & 3.32 & 21 \\
\hline Aradidae & Hemiptera & 1 & 0.44 & 1 \\
\hline Araneidae & Araneae & 2 & 4.00 & 2 \\
\hline Asteiidae & Diptera & 5 & 0.55 & 3 \\
\hline Baetidae & Ephemeroptera & 1 & 1.86 & 1 \\
\hline Bethylidae & Hymenoptera & 3 & 1.86 & 3 \\
\hline Blaberidae & Blattodea & 9 & 32.00 & 8 \\
\hline Blattellidae & Blattodea & 7 & 8.19 & 5 \\
\hline Blattidae & Blattodea & 8 & 177.08 & 8 \\
\hline Braconidae & Hymenoptera & 32 & 15.95 & 17 \\
\hline Carabidae & Coleoptera & 2 & 4.17 & 2 \\
\hline Cecidomyiidae & Diptera & 72 & 3.53 & 34 \\
\hline Ceraphronidae & Hymenoptera & 27 & 0.72 & 17 \\
\hline Ceratopogonidae & Diptera & 11 & 0.62 & 6 \\
\hline Chalcididae & Hymenoptera & 3 & 1.17 & 3 \\
\hline Chironomidae & Diptera & 1 & 0.06 & 1 \\
\hline Chloropidae & Diptera & 2 & 0.29 & 2 \\
\hline Chrysomelidae & Coleoptera & 3 & 4.45 & 3 \\
\hline Chrysopidae & Neuroptera & 1 & 6.05 & 1 \\
\hline Cicadellidae & Hemiptera & 146 & 196.70 & 40 \\
\hline Cixiidae & Hemiptera & 14 & 3.91 & 10 \\
\hline Clubionidae & Araneae & 1 & 7.74 & 1 \\
\hline Corinnidae & Araneae & 7 & 7.45 & 7 \\
\hline Ctenidae & Araneae & 1 & 10.97 & 1 \\
\hline
\end{tabular}




\begin{tabular}{|c|c|c|c|}
\hline Culicidae & Diptera & 5 & 1.21 \\
\hline Cynipidae & Hymenoptera & 2 & 0.25 \\
\hline Deinopidae & Araneae & 1 & 22.25 \\
\hline Delphacidae & Hemiptera & 23 & 12.66 \\
\hline Deuterophlebiidae & Diptera & 1 & 0.01 \\
\hline Dictyopharidae & Hemiptera & 2 & 20.33 \\
\hline Dolichopodidae & Diptera & 6 & 0.55 \\
\hline Dysderidae & Araneae & 1 & 5.79 \\
\hline Ectopsocidae & Psocoptera & 1 & 0.02 \\
\hline Elipsocidae & Psocoptera & 2 & 0.08 \\
\hline Encyrtidae & Hymenoptera & 18 & 0.53 \\
\hline Eriosomatidae & Hemiptera & 3 & 0.21 \\
\hline Eucoilidae & Hymenoptera & 2 & 0.08 \\
\hline Eulophidae & Hymenoptera & 22 & 2.75 \\
\hline Formicidae & Hymenoptera & 255 & 213.86 \\
\hline Gelechiidae & Lepidoptera & 3 & 2.06 \\
\hline Gnaphosidae & Araneae & 2 & 5.18 \\
\hline Gracillariidae & Lepidoptera & 12 & 3.57 \\
\hline Gryllacrididae & Orthoptera & 4 & 325.74 \\
\hline Gryllidae & Orthoptera & 764 & 7354.87 \\
\hline Hydrometridae & Hemiptera & 2 & 17.94 \\
\hline Ichneumonidae & Hymenoptera & 1 & 2.02 \\
\hline Lepidopsocidae & Psocoptera & 3 & 0.69 \\
\hline Linyphiidae & Araneae & 17 & 30.45 \\
\hline Liposcelidae & Psocoptera & 6 & 0.02 \\
\hline Lycosidae & Araneae & 85 & 1273.62 \\
\hline Mantidae & Mantodea & 14 & 527.72 \\
\hline Merothripidae & Thysanoptera & 2 & 0.14 \\
\hline Miridae & Hemiptera & 50 & 11.17 \\
\hline Miturgidae & Araneae & 1 & 2.26 \\
\hline Muscidae & Diptera & 3 & 1.31 \\
\hline Mycetophilidae & Diptera & 1 & 0.14 \\
\hline Mymaridae & Hymenoptera & 59 & 1.26 \\
\hline Mymarommatidae & Hymenoptera & 3 & 0.04 \\
\hline Nabidae & Hemiptera & 27 & 88.67 \\
\hline Noctuidae & Lepidoptera & 4 & 4.19 \\
\hline Ochyroceratidae & Araneae & 1 & 0.90 \\
\hline Oxyopidae & Araneae & 91 & 574.37 \\
\hline Pachytroctidae & Psocoptera & 4 & 0.15 \\
\hline Pentatomidae & Hemiptera & 1 & 117.74 \\
\hline Phalacridae & Coleoptera & 2 & 0.60 \\
\hline Phasmatidae & Phasmatodea & 1 & 1220.85 \\
\hline Philodromidae & Araneae & 1 & 30.76 \\
\hline Phlaeothripidae & Thysanoptera & 11 & 1.39 \\
\hline Pholcidae & Araneae & 1 & 2.31 \\
\hline Platygastridae & Hymenoptera & 1 & 0.03 \\
\hline Polyxenidae & Polyxenida & 2 & 0.64 \\
\hline Psychodidae & Diptera & 1 & 0.03 \\
\hline Psyllipsocidae & Psocoptera & 2 & 1.91 \\
\hline Pyralidae & Lepidoptera & 1 & 1.50 \\
\hline Reduviidae & Hemiptera & 5 & 606.11 \\
\hline Ricaniidae & Hemiptera & 1 & 0.26 \\
\hline Salticidae & Araneae & 36 & 140.86 \\
\hline Scelionidae & Hymenoptera & 89 & 10.69 \\
\hline Schizopteridae & Hemiptera & 6 & 0.52 \\
\hline Sciaridae & Diptera & 3 & 0.04 \\
\hline Simuliidae & Diptera & 4 & 0.18 \\
\hline Sparassidae & Araneae & 4 & 22.34 \\
\hline
\end{tabular}




\begin{tabular}{llrrr} 
Sphecidae & Hymenoptera & 1 & 13.89 & 1 \\
Staphylinidae & Coleoptera & 3 & 1.67 & 3 \\
Termitidae & Isoptera & 1 & 2.67 & 1 \\
Tetragnathidae & Araneae & 1 & 1.46 & 1 \\
Tetrigidae & Orthoptera & 37 & 978.99 & 23 \\
Tettigoniidae & Orthoptera & 20 & 2320.63 & 16 \\
Theridiidae & Araneae & 8 & 3.24 & 7 \\
Theridiosomatidae & Araneae & 75 & 24.19 & 34 \\
Thomisidae & Araneae & 8 & 22.93 & 6 \\
Thripidae & Thysanoptera & 22 & 1.28 & 13 \\
Tingidae & Hemiptera & 3 & 0.20 & 3 \\
Tipulidae & Diptera & 5 & 2.75 & 5 \\
Trichogrammatidae & Hymenoptera & 15 & 0.18 & 13 \\
Tridactylidae & Orthoptera & 6 & 39.30 & 5 \\
Tropiduchidae & Hemiptera & 2 & 2.23 & 2 \\
\hline
\end{tabular}

Table S 3.17: Species/family numbers, beta diversity and Simpson index for plants, birds and leaf litter invertebrates in forest, oil palm and the experimental site.

\begin{tabular}{llrrr}
\hline & & Forest & Oil palm & Experiment \\
\hline Plants & species richness (total) & & 78 & 53 \\
& mean species richness $( \pm \mathrm{SD})$ & & $32.25 \pm 13.05$ & $25.25 \pm 6.9$ \\
Birds & species richness (total) & 30 & 9 & 6 \\
& Mean species richness $( \pm \mathrm{SD})$ & $11 \pm 4.08$ & $4.5 \pm 1.29$ & $2.25 \pm 1.5$ \\
& mean Simpson index & $0.87 \pm 0.05$ & $0.58 \pm 0.07$ & $0.34 \pm 0.4$ \\
Leaf-litter & family richness (total) & 47 & 25 & 16 \\
& mean family richness & $19.5 \pm 7.94$ & $7.5 \pm 8.35$ & $5.5 \pm 2.38$ \\
& mean Simpson index $( \pm \mathrm{SD})$ & $0.65 \pm 0.06$ & $0.47 \pm 0.26$ & $0.52 \pm 0.23$ \\
\hline
\end{tabular}





\section{Danksagung / Acknowledgements}

Diese Dissertation wäre ohne die Unterstützung vieler Menschen nie möglich gewesen und ich möchte mich an dieser Stelle bei allen Bedanken, die in der Zeit für mich da waren und mich auf meiner turbulenten Reise durch die Promotion begleitet haben.

Mein erster Dank geht an meinen Doktorvater Ulrich Brose, der es mir ermöglicht hat, in einem herausfordernden Projekt zu promovieren. Ich danke ihm für seine Unterstützung und Förderung während der gesamten Zeit, seine wegweisenden Gespräche, seine Geduld und Menschlichkeit sowie sein Verständnis.

Ein großer Dank geht an meinen Zweitbetreuer Yann Clough, der mich ebenfalls seit Beginn meiner Promotion an mit vollstem Einsatz betreut und unterstützt hat. Ich danke ihm für seine unerschütterliche Geduld in der Beantwortung jeglicher (Statistik-) Fragen, seine motivierenden Worte und die vielen Diskussionen.

Ebenfalls vielen Dank an Holger Kreft, meinen Drittbetreuer und Adoptiv-Professor (danke für den Zweit-Arbeitsplatz in deiner AG!), für seine Unterstützung, Betreuung und sein Engagement rund um das B11-Projekt.

Einen großen Dank an alle Chaoten aus meiner tollen Arbeitsgruppe: Malte, Andrew, Leno, Chicki-Chuck, Li, Miri, Herr Ott, Mummi, Flo, Ka, Amrei! Leno, danke für die großartige Unterstützung in Indo und dafür, dass wir gemeinsam die Schlangen und Geister in Bukit Sari besiegt haben. Außerdem werde ich wohl nie die Mimi-mit-Caipivom-Bahnhof-Abholen Aktionen vergessen. Das war der Hammer (Die Mettbrötchen danach auch)! Malte and Andrew thanks for being great "colleagues" and friends :D. I will never forget the times in the office, when Malte wouldn't stop vibrating and when there was no silence in the chicken house. Also thanks for getting me into climbing! Amrei sei gedankt für die weisen Worte, die mich über die gesamte Zeit meiner Promotion begleitet haben: „Den Doktor kriegst du auf jeden Fall - du darfst nur nicht aufhören“. Ohne Rita wäre wohl im Laden nichts gelaufen, daher gilt mein Dank auch ihr, dafür, dass sie sich so sehr für uns Doktoranden/innen eingesetzt hat. Danke, dass ihr immer an mich geglaubt habt, danke für die vielen Diskussionen, danke, dass wir so viel miteinander gelacht und Blödsinn geredet haben! Thanks for everyone who took 
their time to read through the Intro and discussion of my thesis - very much appreciated.

Ein großer Dank geht an Miri Vorlaufer, mit der ich zusammen das erste interdisziplinäre Projekt im SFB gerockt habe. Vielen Dank für die super Zusammenarbeit und die zahlreichen Mettfrühstücke.

Ein sehr großer Dank geht an Anne, die mich als B11 Buddy, Leidensgenossin im heißen und zugenebelten Jambi, Ploteinmessspezialistin und Ansprechpartnerin bei Kompassstörungen, Dr Gigi, todesmutige Schlangenbeschwörerin u.v.m. in den letzten 2.5 Jahren in unserem Projekt begleitet hat. Ich werde wohl nie vergessen, wie wir zusammen das Experiment in Humusindo auf die Beine gestellt haben! Wir waren ein klasse Team! Danke für die coole Zusammenarbeit, in Indo wie in Deutschland (paperaction), mit Getreidekaffee, Boxplötzen und lustigen Skypegeschichten sowie für die wundervolle Unterstützung in den letzten Wochen.

Weiterhin danke ich allen Kolleginnen und Kollegen aus dem SFB 990 für die gute Zusammenarbeit im Projekt und für die Momente, die den Aufenthalt in Jambi wesentlich schöner machten. Danke auch an die Koordinationsteams des SFB in Deutschland und in Indo, die uns durch den bürokratischen Dschungel geschleust und uns in vielen Dingen unterstützt haben.

Ich danke allen Assistentinnen und Assistenten für ihre tatkräftige Mithilfe im Feld und im Lab - ohne sie wäre das Projekt nicht möglich gewesen.

Ein spezieller Dank geht an alle meine großartigen Freunde, die mich während der gesamten Zeit so sehr unterstützt, mit mir gelacht, mir zugehört haben und immer mit Rat und Tat zur Seite standen. Danke, dass ihr für mich da wart, auch wenn es mal nicht so rund lief. Ich bin froh, dass ich euch alle habe!

Zuletzt möchte ich meiner Familie danken, die immer an’s ,guud Kind“ geglaubt hat. Mama und Papa, danke, dass ihr mir meine Ausbildung ermöglicht und mich immer unterstützt habt, um überhaupt so weit kommen zu können. 



\section{Eidesstattliche Erklärung}

Hiermit erkläre ich an Eides statt, dass ich die vorliegende Arbeit selbständig angefertigt, keine unerlaubten Hilfsmittel verwendet und bisher noch keinen Promotionsversuch unternommen habe.

Miriam Teuscher

Göttingen, 27.11.2015 